Elvys Isaias Mercado Curi

\title{
METODOLOGIA DE PROJETO DE ALOCAÇÃO DE ABSORVEDORES DINÂMICOS PARA A REDUÇÃO DE RUÍDO EMITIDO POR TRANSFORMADORES DE POTÊNCIA
}

\author{
Tese apresentado à Escola Politécnica \\ da Universidade de São Paulo para \\ obtenção do Título de Doutor em Enge- \\ nharia.
}


Elvys Isaias Mercado Curi

\title{
METODOLOGIA DE PROJETO DE ALOCAÇÃO DE ABSORVEDORES DINÂMICOS PARA A REDUÇÃO DE RUÍDO EMITIDO POR TRANSFORMADORES DE POTÊNCIA
}

\author{
Tese apresentado à Escola Politécnica \\ da Universidade de São Paulo para \\ obtenção do Título de Doutor em Enge- \\ nharia.
}

Área de concentração:

Controle e Automação

Orientador:

Prof. Dr. Raul Gonzalez Lima

Co-orientador:

Prof. Dr. Edilson Hiroshi Tamai 
Este exemplar foi revisado e alterado em relação à versão original, sob responsabilidade única do autor e com anuência de seu orientador

São Paulo, 28 de Janeiro de 2008

Assinatura do autor

Assinatura do orientador

Ficha Catalográfica

Mercado Curi, Elvys Isaias

METODOLOGIA DE PROJETO DE ALOCAÇÃO DE ABSORVEDORES DINÂMICOS PARA A REDUÇÃO DE RUÍDO EMITIDO POR TRANSFORMADORES DE POTÊNCIA. São Paulo, 2008. $124 \mathrm{p}$.

Tese (Doutorado) - Escola Politécnica da Universidade de São Paulo. Departamento de Engenharia Mecânica.

1. Acústica. 2. Ruído Urbano. 3. Transformadores e Reatores. 4. Vibração de som. I. Universidade de São Paulo. Escola Politécnica. Departamento de Engenharia Mecânica. II. Título. 
A meus pais Isaías e Eleuteria que me ensinarem valorizar o conhecimento. 


\section{Agradecimentos}

Aos Professores da Escola Politécnica: Raul Gonzalez, Edilson Tamai e Sylvio Bistafa e aos engenheiros de Eletropaulo Fabio Fujimoto e Carlos Belardo pelo apoio e confiança nesta pesquisa, à empresa Eletropaulo pela subvenção, ao Eng. Eduardo Martins da empresa $01 \mathrm{~dB}$ pelo fornecimento dos sinais coletados no transformador.

Aos professores da Escola Politécnica: Linilson R. Padovese, Demétrio C. Zachariadis e Amilton Sinatora pelo ensino e apoio que me deram como pósgraduando.

Aos colegas com quem comparto a sala, que ajudaram com seus conhecimentos e opiniões, Engs. Flávio Soares, Juan Carlos Cutipa, Luis Chavez e Lizbeth Paredes.

A meus colegas da Escola Politécnica de LADIN: Carlos Valdez S., Nelson Venegas, Claudia Sarmiento, Wilson Carlos da Silva Junior, Rui Rodrigues Almeida, Rodrigo Fujimoto, Silmara Vicente, Luis Fernando Rocha e Márcia Marú.

Aos amigos da empresa de energia elétrica Furnas Marcio Magalhães e Eduardo Capes; a meu colega Bruno Sanches Masiero que pesquisou o tema control ativo de ruído de transformadores pela ajuda e opiniões.

Agradeço a compreensão e apoio que tive de minha família: esposa Nely Barrios, filhas Irene e Verônica, irmã, Jannet Mercado, seu esposo Juan Carlos Soto, e irmã Mirella Mercado.

Agradeço o apoio da escola de minhas filhas, o externato "João de Barro" ao diretor Carlos Piton, à professora Telma e à auxiliar da escola Maria José que cuidaram e educaram a minhas filhas, dispensando do pagamento de mensalidade no tempo que estive sem bolsa.

Por último agradeço a meus amigos da Igreja Evangélica Cristo Internacional, Alexandro e Rossana, Otto e Gabriela, Darcio e Diana, Luis e Solange 


\section{Resumo}

O ruído acústico produzido pelos transformadores elétricos de potência, instalados em áreas urbanas, gera problemas ambientais e desconforto na população vizinha. Neste trabalho propõe-se desenvolver uma metodologia de projeto para reduzir o ruído dos transformadores com o objetivo de atingir níveis de ruído que a legislação ambiental exige. Um transformador elétrico de potência contém um núcleo, no qual encontram-se as bobinas, dentro de um tanque, ao ativar-se o núcleo e a bobina produz ruido e vibração em todos os componentes do transformador. Para diminuir a vibração e o ruído propõe-se o uso de Absorvedores Dinâmicos (AD) fixados nas paredes do tanque, e amortecedores automotivos ligados à base do tanque. Com os amortecedores procura-se atenuar os deslocamentos da base do tanque impostos pelo núcleo. Este procedimento, isoladamente, diminui a vibração da base do tanque e das paredes do tanque. Adicionalmente, utilizando absorvedores dinâmicos de vibração, projetados e alocados de acordo com resultados de simulações numéricas, é possível reduzir a amplitude de vibração das paredes do tanque. A redução de amplitude de vibração das paredes do tanque leva necessariamente a uma redução do ruído acústico pois o ruído acústico decorre do acoplamento da vibração das paredes com o ar vizinho. Dados de deslocamento das paredes em condições operacionais, Operational Deflection Shape (ODS), foram utilizados para determinar regiões de maior vibração e regiões para alocação dos absorvedores dinâmicos. Os modelos de elementos finitos do tanque, dos absorvedores dinâmicos e o carregamento operacional permitem estimar a redução de ruído e o número e a posição dos absorvedores dinâmicos.

Palavras Chave: Acústica, ruído Urbano, transformadores e reatores, vibração. 


\section{Abstract}

The acoustic noise produced by electric power transformers, installed in urban areas, generates environmental problems and discomfort for the citizens of the neighborhood. The present work proposes a design methodology of devices to reduce the acoustic noise to levels legally accepted. An electric power transformer has a core, where the coils are assembled, inside a tank to active the core and coils make sound and vibration in all transformer component. To reduce vibration and noise it is evaluate the use of Dynamic Absorbers (DA), attached to the walls of the tank, and automotive dampers, attached to the base of the tank. The shock absorbers are intended to attenuate the displacements of the base of the tank imposed by the core of the transformer. This procedure, alone, reduces the vibration amplitude of the base and of the walls of the tank. Additionally, using vibration dynamic absorbers, designed and allocated according to numerical simulations, it is possible to reduce the amplitude of vibration on the walls of the tank. The reduction of the vibration amplitude necessarily leads to a reduction of the acoustic noise, since the acoustic noise is generated through the coupling of the structural vibration and the air in the near field. Operational displacement data, from an Operational Deflection Shape (ODS) analysis, were used to determine regions of vibration higher and regions to location of dinamic absorver. Finite elements models of the tank and of the dynamic absorvers and the operational loading allow the estimation of noise reduction and of the number and position of the dynamic absorvers.

Keywords: Acoustic, urban noise, power transformer and reactor, , vibration. 


\title{
Sumário
}

\section{Lista de Figuras}

\author{
Lista de Tabelas
}

\section{Convenções e Lista de Símbolos}

1 INTRODUÇÃO 1

1.1 Alternativas para a redução do ruído de transformadores . . . . . 2

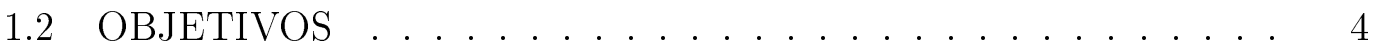

2 REVISÃO DA LITERATURA 5

2.1 Notas históricas sobre o transformador . . . . . . . . . . . 5

2.2 Ruído e Vibração em Transformadores Elétricos . . . . . . . . . . 7

2.2.1 Controle Ativo de Ruído (ANC - Active Noise Control) . . 8

2.2.2 Controle Ativo Estrutural-Acústico . . . . . . . . . . . . . 9

2.2.3 Controle Passivo Estrutural-Acústico . . . . . . . . . . . . 10

2.3 Ruído de Transformadores . . . . . . . . . . . . . . . . . . . . 11

2.3.1 Ruído produzido por transformadores . . . . . . . . . . . . 11

2.3.2 Forças de magnetostricção . . . . . . . . . . . . . . . . . 12

2.3.3 Forças magnéticas das bobinas . . . . . . . . . . . . . . 15

2.3.4 Forças no núcleo de um transformador . . . . . . . . . . 16

2.3.5 Harmônicos . . . . . . . . . . . . . . . . . . . . . 17

2.4 Medição do Som . . . . . . . . . . . . . . . . . . . 17

2.4.1 Medição do som de um transformador . . . . . . . . . . 19

2.4.2 Campo acústico de um transformador . . . . . . . . . 22 
2.5 Som e Vibração . . . . . . . . . . . . . . . . . . . . . .

3 METODOLOGIA DA INVESTIGAÇÃO

3.0.1 Medição do som do transformador . . . . . . . . . . . . . 32

3.0.2 Medida da vibração do transformador . . . . . . . . . . . . 32

3.0.3 Avaliação do ruído produzido pelo tanque usando os sinais de aceleração . . . . . . . . . . . . . . . 33

3.0.4 Determinação das regiões de maior ruído irradiado . . . . 33

3.0.5 Determinação das características fundamentais de um absorvedor dinâmico . . . . . . . . . . . . . 34

3.0.6 Ensaios experimentais do absorvedor dinâmico . . . . . . . 34

3.0.7 Simulação da vibração do Tanque usando o MEF . . . . . 34

3.0.8 Ensaio experimental de absorvedores e amortecedores em condições operacionais . . . . . . . . . . . . . . . 34

$\begin{array}{lll}4 & \text { RESULTADOS } & 37\end{array}$

4.1 Medição do ruído irradiado pelo transformador . . . . . . . . . . . 37

4.1.1 Localização de regiões que mais emitem ruído . . . . . . . 39

4.2 Medidas da vibração do transformador . . . . . . . . . . . . . 40

4.2.1 Avaliação dos resultados da vibração . . . . . . . . . . . . 42

4.2.2 Localização das regiões de maior vibração . . . . . . . . . 43

4.2.3 Análise da face de frente para a rua . . . . . . . . . 45

4.2.4 Análise da face oposta à rua . . . . . . . . . . . 50

4.2.5 Análise da face oposta ao edifício . . . . . . . . . 55

4.2.6 Análise da face frente ao edifício . . . . . . . . . . . 59

4.2.7 Análise da base do transformador . . . . . . . . . . 65

4.2.8 Avaliação dos níveis de velocidade na superfície do tanque 69

4.3 Projeto da montagem de amortecedores viscosos . . . . . . . . . . 71

4.4 Projeto do Absorvedor Dinâmico . . . . . . . . . . . . 73

4.4.1 Equação do movimento do Absorvedor Dinâmico . . . . 73 
4.4.2 Características fundamentais do absorvedor dinâmico . . . 74

4.4.3 Simulação numérica do primeiro absorvedor dinâmico . . 79

4.4.4 Cálculo das dimensões do primeiro absorvedor dinâmico . 80

4.5 Ensaios Experimentais do Primeiro Absorvedor Dinâmico . . . . . 82

4.5.1 Avaliação do desempenho do absorvedor dinâmico na redução da vibração . . . . . . . . . . . . . . . . . . . 83

4.5.2 Avaliação do desempenho do absorvedor dinâmico na atenuação do ruído . . . . . . . . . . . . . . . . . . . . 85

4.6 Projeto do Segundo Absorvedor Dinâmico . . . . . . . . . . . . . 89

4.7 Simulação da Vibração do Tanque Usando o MEF . . . . . . . . . 90

4.8 Verificação Experimental no Transformador . . . . . . . . . . . . 95

4.8.1 Avaliação dos resultados de vibração . . . . . . . . . . . . 111

6 Anexo A

6.1 Holografia Acústica - Resultados . . . . . . . . . . . . . . . . . . 119 


\section{Lista de Figuras}

1.1 Foto de um transformador da subestação Bela Aliança em estudo 1

2.1 Esquema de controle ativo de ruído acústico . . . . . . . . . . . . 8

2.2 Modelo do tanque do transformador com os quadros e os parafusos - extraído de Ming (2000) . . . . . . . . . . . . . . . . . 10

2.3 Aceleração na superfície do núcleo: a) de um transformador Monofásico b) de um transformador Trifásico - extraído de Weiser

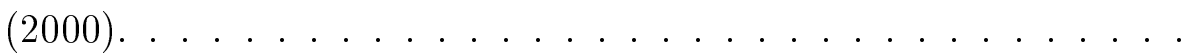

2.4 Desenho de juntas sobrepostas do núcleo do transformador: a) Com um degrau b) Com 4 degraus - extraído de Weiser (2000). . 14

2.5 Deformações das lâminas do núcleo: a) Foto b) Comportamento do fluxo e a relação com a geometria das lâminas - extraído de Weiser (2000) . . . . . . . . . . . . . . . . . . . . 14

2.6 Forcas que atuam no núcleo produzido por duas bobinas simétricas - extraído de Karsai K. Kerenyi e Kiss (1987) . . . . . . . . . . . 15

2.7 Posições típicas dos microfones para medição de ruído de transformadores sem sistema de resfriamento (Normas Técnicas ABNT NBR 7277) . . . . . . . . . . . . . . .

2.8 Posições típicas dos microfones para medição de ruído de transformadores com sistema de resfriamento montado no tanque ou separado na distância menor de $3 m$ da superfície de irradiação (Normas Técnicas ABNT - NBR 7277) . . . . . . . . . .

2.9 Posições típicas dos microfones para medição de ruído de transformadores com sistema de resfriamento montado no tanque ou separado por distância igual ou superior a $3 m$ da superfície de irradiação (Normas Técnicas ABNT - NBR 7277) . . . . . . . . .

2.10 Simulação do campo acústico de um transformador no plano vertical - extraído de Rausch M. Kaltenbacher e Lerch (2002) . . . . 
2.11 Simulação do campo acústico de um transformador no plano horizontal - extraído de Rausch M. Kaltenbacher e Lerch (2001) . . .

2.12 Diagrama de blocos do método de Holografia Acústica em Campo Próximo NAH que processa sinais de pressão sonora - extraido de Williams (2004). . . . . . . . . . . . . . .

2.13 Diagrama de blocos do método ODS que processa sinais de aceleração para avaliar o deslocamento da superfície do tanque - o diagrama é construído seguindo o exemplo da figura $2.12 \ldots . .28$

3.1 Diagrama de blocos da metodologia da investigação . . . . . . . 36

4.1 Espectro de níveis de pressão do ruído emitido pelo transformador. 37

4.2 Níveis de pressão sonora de 5 dias de medição, e os valores médios 38

4.3 Resultados da medição holográfica em uma face do transformador a) imagem mostrando as intensidades de som b) foto indicando-se a região testada . . . . . . . . . . . . . . . . . . . 39

4.4 Correlação cruzada de todos os espectros de freqüência coletadas do tanque do transformador . . . . . . . . . . . . . . . . 40

4.5 Modelo geométrico do transformador para análise de ODS. . . . . 41

4.6 Modelo geométrico do transformador para análise ODS de deslocamentos do tanque e dos radiadores . . . . . . . . . . . . . 42

4.7 Deslocamento da superfície do tanque detectado pelo método de

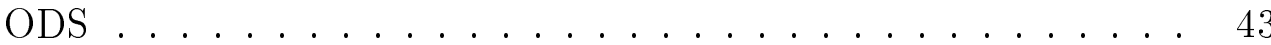

4.8 Desenho da face frente à rua e pontos onde foram coletados os sinais. 46

4.9 Densidade Espectral de Potência da velocidade dos sinais coletados na face frente à rua. . . . . . . . . . . . . . . . . . . . . 46

4.10 Níveis de velocidade da vibração da face frente à rua. . . . . . . . 47

4.11 Níveis de velocidade e dimensões geométricas da face frente à rua. 48

4.12 Deslocamento da face frente à rua para dois instantes com defasagem de 180 graus. . . . . . . . . . . . . . . . . . . . . . . . . . 48

4.13 Gráfico de cores do deslocamento máximo na face frente à rua. . . 49

4.14 Gráfico de cores do deslocamento máximo da face frente à rua em outro instante . . . . . . . . . . . . . . . . . . 
4.15 Desenho da face frente à rua, indicando o posicionamento dos absorvedores dinâmicos. . . . . . . . . . . . . . . . . 50

4.16 Desenho da face oposta à rua. . . . . . . . . . . . . . . . . . 51

4.17 Densidade Espectral de Potência da velocidade dos sinais coletados na face oposta à rua. . . . . . . . . . . . . . . . . . . . . 51

4.18 Níveis de velocidade função da posição na face oposta à rua . . . 52

4.19 Gráfico de cores dos níveis de velocidade na face oposta à rua . 52

4.20 Gráfico de cores do deslocamento da face oposta à rua em dois instantes defasados de 180 graus. . . . . . . . . . . . . . . 53

4.21 Gráfico de cores do deslocamento máximo da face oposta à rua. 53

4.22 Gráfico de cores do deslocamento máximo da face oposta à rua em outro instante . . . . . . . . . . . . . . . . 54

4.23 Desenho da face oposta à rua, indicando o posicionamento dos absorvedores dinâmicos . . . . . . . . . . . . . . 54

4.24 Desenho da face oposta ao edifício. . . . . . . . . . . . . . . . 55

4.25 Densidade Espectral de Potência da velocidade dos sinais coletados na face oposta ao edifício . . . . . . . . . . . . . 56

4.26 Níveis de velocidade da vibração da face oposta ao edifício. . . . . 56

4.27 Níveis de velocidade sobrepostos com as medidas geométricas da face oposta ao edifício. . . . . . . . . . . . . . . . . . . . 57

4.28 Gráfico de cores do deslocamento da face oposta ao edifício em dois instantes defasados de 180 graus. . . . . . . . . . . . . . 57

4.29 Gráfico de cores do deslocamento máximo da face atrás dos edifícios. 58

4.30 Gráfico de cores do deslocamento máximo da face atrás dos edifícios com defasagem de 180 graus. . . . . . . . . . . . . . . . 58

4.31 Posicionamento dos absorvedores dinâmicos na face oposta ao edifício. . . . . . . . . . . . . . . . . . . . 59

4.32 Desenho de uma seção da face frente aos edifícios. . . . . . . . . . 60

4.33 Densidade Espectral de Potência da velocidade dos sinais coletados na face frente aos edifícios. . . . . . . . . . . . . . . . . 60

4.34 Níveis de velocidade da vibração da face frente aos edifícios. . . . 61 
4.35 Níveis de velocidade sobrepostos com o desenho da face frente ao edifício. ..................... 61

4.36 Gráfico de cores do deslocamento da face frente ao edifício em dois instantes defasados de 180 graus . . . . . . . . . . . . . . . 62

4.37 Gráfico de cores do deslocamento máximo da face frente ao edifício em um instante. . . . . . . . . . . . . . . . . . 63

4.38 Gráfico de cores do deslocamento máximo da face frente ao edifício em outro instante . . . . . . . . . . . . . . .

4.39 Posicionamento dos absorvedores dinâmicos na face frente ao edifício: a) usando o resultados dos níveis de velocidade, b) usando uma foto que ilustra os espaços livres. . . . . . . . . . . . . . . . 64

4.40 Desenho da superfície base do tanque, indicando a posição dos acelerômetros na intersecção das linhas tracejadas. . . . . . . . . . 65

4.41 Densidade Espectral de Potência da velocidade da base do tanque. 66

4.42 Níveis de velocidade da vibração da base do tanque . . . . . . . . 67

4.43 Níveis de velocidade em 2 dimensões sobreposto ao diagrama da base do tanque . . . . . . . . . . . . . . 67

4.44 Gráfico de cores do deslocamento da base para dois instantes defasados em 180 graus. . . . . . . . . . . . . . . . . . . . . 68

4.45 Gráfico de cores do deslocamento máximo da base em um instante de maior deslocamento. . . . . . . . . . . . . . . . 68

4.46 Gráfico de cores do deslocamento máximo da base em outro instante. 69

4.47 Comparação dos resultados de holografia acústica com os obtidos pelo método de nível de velocidade da superfície na face frente aos edifícios. . . . . . . . . . . . . . . . . 70

4.48 Desenho do amortecedor montado entre a base e a fundação de concreto. . . . . . . . . . . . . . . 72

4.49 Distribuição dos amortecedores na base do tanque. . . . . . . . . 72

4.50 Diagrama de um sistema duas massas e duas molas amortecido . . 73

4.51 Simulação por EF da força em um ponto da face do tanque . . . . 75

4.52 Sinal do deslocamento do ponto central da parede do tanque: a) No domínio do tempo, b) No domínio da freqüência . . . . . . 76 
4.53 Curva que mostra o comportamento do absorvedor dinâmico com e sem amortecimento, extraído de Hartog (1972) . . . . . . . . 76

4.54 Amplitude em função da massa do absorvedor dinâmico e do coeficiente de amortecimento. . . . . . . . . . . . . . 77

4.55 Comparação do deslocamento da carcaça e do absorvedor dinâmico. 78

4.56 Comparação do deslocamento da parede do tanque e do absorvedor dinâmico. . . . . . . . . . . . . . . . . . . . . 79

4.57 Simulação do funcionamento do AD1 no ponto médio do tanque . 79

4.58 Desenho do AD1: a) Esquema com as proporções b) Diagrama de corpo livre da mola. . . . . . . . . . . . . . . . . . . . . 80

4.59 Esquema do funcionamento da mola . . . . . . . . . . . . . . . . . 82

4.60 Desenho do AD1 montado no ponto central de uma face oposta ao edifício. . . . . . . . . . . . . . . . . 82

4.61 Fotos do primeiro protótipo do absorvedor dinâmico: a) mostrando suas partes b) fixado no transformador. . . . . . . . . . . . . . 83

4.62 Comparação da potência de vibração sem e com AD1 de 18,5 kg, $20 \mathrm{~kg}$ e $21 \mathrm{~kg}$ de massa: a) no ponto 2 , b) no ponto 1, c) no ponto

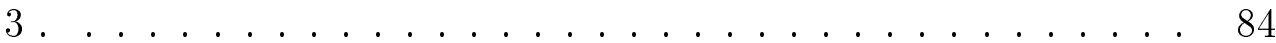

4.63 Comparação da potência: a) Potência em pontos b) Porcentagem da redução da potência.

4.64 Comparação do sinal de aceleração, com e sem absorvedor dinâmico nos pontos 1,2 e $3 \ldots \ldots$. . . . . . . 8

4.65 Comparação do $L_{v}$ por faixa de terça de oitava para os pontos 2 , 1 e 3 (vermelho, massa de $0,0 \mathrm{~kg}$, verde, massa de $18,5 \mathrm{~kg}$, preto, massa de $20 \mathrm{~kg}$ e azul, massa de $21 \mathrm{~kg})$. . . . . . . . . . . . 88

4.66 Comparação da diminuição do PSD da velocidade para o caso sem AD (vermelho) e com absorvedor dinâmico (preto) . . . . . . . . . 89

4.67 Esquema do AD2 montado indicando seus componentes. . . . . . 90

4.68 Modelo geométrico do tanque do transformador em EF. . . . . . . 91

4.69 Malha de elementos finitos do tanque do transformador com doze absorvedores dinâmicos de $5 \mathrm{~kg}$ cada um. . . . . . . . . . . . . 93 
4.70 Desenho da distribuição dos transformadores da subestação Bela aliança . . . . . . . . . . . . . . . . . . 96

4.71 Desenho do tanque mostrando os pontos de medição de som . . 97

4.72 Localização dos pontos onde foram coletados os sinais de vibração a) face frente ao edifício, b) face oposta à rua, c) face oposta ao edifício d) face frente à rua . . . . . . . . . . . . . . . . . . . . . 98

4.73 Foto do amortecedor montado na base do tanque . . . . . . . . . 98

4.74 Posicionamento dos amortecedores na base do tanque. O quadrado de aresta verde representa a posição do suporte superior, e o retângulo de aresta verde representa o amortecedor . . . . . . . . . 99

4.75 Localização dos absorvedores dinâmicos a) face frente ao edifício, b) face oposta à rua, c) face oposta ao edifício d) face frente à rua. 100

4.76 Foto dos absorvedores dinâmicos montados na face frente ao edifício100

4.77 Superfície curva que mostra valores das medições no caso normal a) medição do $L p$ na freqüência de $120 \mathrm{~Hz}$, b) medição do $L p$ global sonora . . . . . . . . . . . . . . . . . . 103

4.78 Comparação entre os valores da medição normal (malha de linhas) e os valores da medição só com amortecedor (superfície colorida) a) comparação em $120 \mathrm{~Hz}$, b) comparação no nível global de pressão sonora ......................... 104

4.79 Comparação entre os valores da medição normal (malha de linhas) e e os valores da medição com amortecedor e ADs (superfície colorida) a) comparação em $120 \mathrm{~Hz}$, b) comparação no nível global de pressão sonora . . . . . . . . . . . . . . . . . . . . . . . . 104

4.80 Comparação entre os valores da medição normal (malha de linhas) e os valores da medição com ADs (superfície colorida) a) comparação em $120 \mathrm{~Hz}$, b) comparação no nível global de pressão sonora 105

4.81 Comparação entre os valores da medição normal (malha de linhas) e os valores da medição só com amortecedor (superfície colorida) considerando uma correção $(-3,5 d B)$ devido ao horário, comparação na freqüência de $120 \mathrm{~Hz}$. . . . . . . . . . . . . . . . 106 
4.82 Comparação entre os valores da medição normal (malha de linhas) e os valores da medição com amortecedor e absorvedores dinâmicos (superfície colorida) considerando uma correção $(-3,5 d B)$ devido ao horário, comparação na freqüência de $120 \mathrm{~Hz}$. . . . . . . . . . 106

4.83 Comparação entre os valores da medição normal (malha de linhas) e os valores da medição só com absorvedores dinâmicos (superfície colorida) considerando uma correção $(-3,5 d B)$ devido ao horário, comparação na freqüência de $120 \mathrm{~Hz}$. . . . . . . . . . . . . . . 107

4.84 Sinais do $L p$ na freqüência de $120 \mathrm{~Hz}$ na condição normal em duas dimensões projetado diante da face frente ao edifício, incluindo os radiadores em proporção a suas dimensões . . . . . . . . . . . . . 108

4.85 Comparação dos sinais do $L p$, na freqüência de $120 \mathrm{~Hz}$, na condição normal e com amortecedor em duas dimensões projetado na face frente ao edifício, incluindo os radiadores e absorvedores dinâmicos (retângulo pequeno preto) em escala . . . . . . . . . 109

4.86 Comparação dos sinais do $L p$, na frequência de $120 \mathrm{~Hz}$, na condição normal e com amortecedor e absorvedor dinâmico, em duas dimensões, projetado na face frente ao edifício, incluindo os radiadores e absorvedor dinâmico (retângulo pequeno preto) em escala

4.87 Comparação dos sinais do Lp a $120 \mathrm{~Hz}$ normal e com absorvedor dinâmico em duas dimensões projetado diante a face frente aos prédios incluindo os radiadores e absorvedor dinâmico (retângulo pequeno preto) em escala . . . . . . . . . . . . . . . . . . . 111

4.88 Localização dos suportes dos amortecedores e pontos de medição (desenho em escala) . . . . . . . . . . . . . . . . . . 112

4.89 Localização dos pontos de medição e dos absorvedores dinâmicos (desenho em escala) (a) face frente ao edifício, b) face oposta à rua, c) face oposta ao edifício d) face frente à rua e) base . . . . . 112

4.90 Sinais de aceleração no domínio da freqüência, na faixa de 0 até $900 \mathrm{~Hz}$ : a) face frente ao edifício b) face oposta à rua c) face oposta ao edifício d) face frente á rua e) base do transformador. . . . . . 113

4.91 Sinais de aceleração no domínio da freqüência, na faixa de 100 até $275 \mathrm{~Hz}$ : a) face frente ao edifício b) face oposta á rua. 
4.92 Sinais de aceleração no domínio da freqüência,na faixa de 100 até 275 Hz: c) face oposta ao edifício d) face frente á rua . . . . . . 115

6.1 Intensidade acústica face frente ao predio, detalhe lado esquerdo do comutador . . . . . . . . . . . . . . . . . . . . . . . 119

6.3 Intensidade acústica face frente ao predio, detalhe no comutador. . 119

6.2 Intensidade acústica face frente ao predio, detalhe lado dereito do comutador. . . . . . . . . . . . . . . . . . . . 120

6.4 Intensidade acústica face frente ao predio, detalhe abaixo do comutador. . . . . . . . . . . . . . . . . . . 120

6.5 Intensidade acústica face frente ao predio, detalhe acima do comutador. . . . . . . . . . . . . . . . . . . . 121

6.6 Intensidade acústica face frente ao predio, sinais em proceso. . . . 121 


\section{Lista de Tabelas}

1.1 Alguns métodos usados para diminuir ruído. . . . . . . . . . . 2

4.1 Faixa da terça de oitava . . . . . . . . . . . . . . . . 44

4.2 Níveis de velocidade do tanque . . . . . . . . . . . . . . . 71

4.3 Valores do PSD de velocidade de cada faixa de oitava para os pontos 2,1 e 4 e o nível de velocidade total $L_{v t} \ldots \ldots$. . . . . . 87

4.4 Diminuição de nível de velocidade segundo a massa do absorvedor dinâmico . . . . . . . . . . . . . . . . . . 88

4.5 Lista dos componentes do segundo absorvedor dinâmico . . . . . . 90

4.6 Somatório da potência dos sinais de cada face, excitação apenas na base do transformador . . . . . . . . . . . . . . . . . . 92

4.7 Somatório da potência dos sinais de cada face, sem uso de absorvedores dinâmicos . . . . . . . . . . . . . . . . . . . . . . . 92

4.8 A potência média de deslocamento de cada face, com 12 absorvedores dinâmicos . . . . . . . . . . . . . . . . . . . . . . . . . . . 94

4.9 Redução do nível de potência segundo as simulações . . . . . . . . 94

4.10 Medidas da pressão sonora na freqüência de $120 \mathrm{~Hz}(\mathrm{em} d B)$. . . 101

4.11 Avaliação da redução de som por ponto e total em $120 \mathrm{~Hz}$. . . . 102

4.12 Valores do nível de pressão global do som $($ em $d B)$. . . . . . . . 102

4.13 Valores calculados da atenuação . . . . . . . . . . . . . . . . . 116 


\begin{tabular}{|c|c|c|}
\hline símbolo & descrição & página \\
\hline$h$ & Freqüência específica h. & 17 \\
\hline$L p$ & Nível de pressão & 18 \\
\hline$P_{\text {eficaz }}$ & Pressão eficaz & 18 \\
\hline$P_{r e f}$ & Pressão de referência $=2 \times 10^{-} 5 \mathrm{~N} / \mathrm{m}^{2}$ & 18 \\
\hline$P_{i}$ & Pressão instantánea medida em um intervalo de tempo & 18 \\
\hline$A_{p}$ & Amplitude máxima da pressão & 18 \\
\hline$N$ & Número total de medições de pressão & 18 \\
\hline Lpt & Nível de pressão global $H z$ & 18 \\
\hline$L p_{i}$ & $\begin{array}{l}\text { Nível de pressão de uma faixa de oitava ou terça de } \\
\text { oitava }\end{array}$ & 18 \\
\hline$L_{I}$ & Nível de intensidade do som. & 18 \\
\hline$I$ & Intensidade de som. & 18 \\
\hline$I_{\text {ref }}$ & Intensidade de referência $I_{r e f}=10^{-12} \mathrm{~N} / \mathrm{m} . \mathrm{s}$ & 18 \\
\hline$L_{W}$ & Nível de potência & 19 \\
\hline$W$ & Potência & 19 \\
\hline$W_{\text {ref }}$ & Potência de referência & 19 \\
\hline$S$ & Superfície & 19 \\
\hline$\rho$ & Peso específico do ar (densidade) & 19 \\
\hline$c$ & Velocidade do som & 19 \\
\hline$\rho$. & Peso específico do ar (densidade) & 19 \\
\hline$\vec{I}_{i}(\mathbf{r}, t)$ & Intensidade no ponto $\mathrm{r}$ no instante $\mathrm{t}$ (vetor) & 19 \\
\hline$P(\mathbf{r}, t)$ & Pressão em r no instante t & 19 \\
\hline$\vec{v}(\mathbf{r}, t)$ & Velocidade no ponto $\mathrm{r}$ no instante $\mathrm{t}$ (vetor) & 19 \\
\hline$v(i)$ & Velocidade da superfície (vetor) & 26 \\
\hline$a(j)$ & Aceleração da superfície (vetor) & 26 \\
\hline$\Delta t$ & Intervalo de tempo & 26 \\
\hline$d(i)$ & Deslocamento da superfície (vetor) & 27 \\
\hline$\Delta t$ & Intervalo de tempo & 26 \\
\hline$d(i)$ & Deslocamento da superfície (vetor) & 27 \\
\hline$W$ & Potência do som. & 28 \\
\hline$v_{m}$ & Velocidade média da aceleração. & 28 \\
\hline$S$ & Área da face em teste (superfície) & 28 \\
\hline$\rho$ & Densidade do ar. & 28 \\
\hline$C_{s}$ & Velocidade do ar. & 28 \\
\hline$\sigma$ & Relação de radiação (medida da eficiência da radiação). & 28 \\
\hline
\end{tabular}




\begin{tabular}{|c|c|c|}
\hline símbolo & descrição & página \\
\hline$L_{v}$ & Nível de velocidade & 29 \\
\hline$v_{\text {ref }}$ & Velocidade de referência $v_{r e f}=10^{-9} \mathrm{~m} / \mathrm{s}$ & 29 \\
\hline$L_{a}$ & Nível de aceleração & 29 \\
\hline$a_{m}$ & Aceleração média & 29 \\
\hline$a_{r e f}$ & Aceleração de referência $a_{r e f}=10^{-6} \mathrm{~m} / \mathrm{s}^{2}$ & 29 \\
\hline$L_{d}$ & Nível de deslocamento & 29 \\
\hline$d_{m}$ & Deslocamento médio & 29 \\
\hline$d_{r e f}$ & Deslocamento de referência $d_{r e f}=10^{1} \mathrm{~m}$ & 29 \\
\hline$x$ & Deslocamento de um sistema massa-mola & 29 \\
\hline$A$ & Amplitude máxima de um sistema massa-mola & 29 \\
\hline$e$ & Neperiano & 29 \\
\hline$j$ & Número complexo $-1^{1 / 2}$ & 29 \\
\hline$\dot{x}$ & Velocidade do sistema massa-mola & 29 \\
\hline$\ddot{x}$ & Aceleração do sistema massa-mola & 30 \\
\hline$v_{m 2}$ & Velocidade média no ponto 2 & 30 \\
\hline$v_{m 1}$ & Velocidade média no ponto 1 & 30 \\
\hline$A_{m 2}$ & Amplitude média no ponto 2 & 30 \\
\hline$A_{m 1}$ & Amplitude média no ponto 1 & 30 \\
\hline$A_{i 2}$ & $\begin{array}{l}\text { Amplitude instantánea em um intervalo de tempo no } \\
\text { ponto } 2\end{array}$ & 30 \\
\hline$A_{i 1}$ & $\begin{array}{l}\text { Amplitude instantánea em um intervalo de tempo no } \\
\text { ponto } 1\end{array}$ & 30 \\
\hline$\ddot{x}_{1}$ & Aceleração da parede do tanque. & 73 \\
\hline$\dot{x}_{1}$ & Velocidade da parede do tanque. & 73 \\
\hline$x_{1}$ & Deslocamento da parede do tanque. & 73 \\
\hline$M$ & Massa efetiva em um ponto da parede do tanque. & 73 \\
\hline$c_{e}$ & Coeficiente de amortecimento da parede do tanque. & 73 \\
\hline$k_{e}$ & Coeficiente de rigidez da parede do tanque. & 73 \\
\hline$\dot{x}_{2}$ & Velocidade do absorvedor dinâmico. & 73 \\
\hline$x_{2}$ & Deslocamento do absorvedor dinâmico. & 73 \\
\hline$c_{a}$ & Coeficiente de amortecimento do absorvedor dinâmico. & 73 \\
\hline$k$ & Coeficiente de rigidez do absorvedor dinâmico. & 73 \\
\hline$f(t)$ & Força instantânea. & 73 \\
\hline$\ddot{x}_{2}$ & Aceleração do absorvedor dinâmico. & 73 \\
\hline$m$ & Massa do absorvedor dinâmico. & 73 \\
\hline
\end{tabular}




\begin{tabular}{|c|c|c|}
\hline símbolo & descrição & página \\
\hline$F_{i}$ & Força aplicada na parede do tanque. & 75 \\
\hline$X_{i}$ & Amplitude do deslocamento na parede do tanque. & 75 \\
\hline$\omega_{n}$ & Velocidade angular da freqüência natural. & 75 \\
\hline$f_{n}$ & Freqüência natural. & 75 \\
\hline$f_{a}$ & Freqüência seleccionada de um absorvedor dinâmico. & 77 \\
\hline$\xi$ & Fator de amortecimento. & 77 \\
\hline$\delta_{a}$ & Deflexão da barra no ponto $a$, produzida por uma força. & 81 \\
\hline$F_{\text {in }}$ & Força inercial do bloco da massa. & 81 \\
\hline$L_{a}$ & Comprimento da barra desde o ponto $b$ até o ponto $a$. & 81 \\
\hline$E$ & Modulo de Young. & 81 \\
\hline$I_{n}$ & Momento de inércia da barra. & 81 \\
\hline$k_{a}$ & Coeficiente de rigidez do ponto $a$ & 81 \\
\hline$\delta_{a M}$ & $\begin{array}{l}\text { Deflexão da barra no ponto a produzido por um mo- } \\
\text { mento. }\end{array}$ & 81 \\
\hline$M_{a}$ & Momento fletor no ponto $a$ & 81 \\
\hline$k_{a M}$ & $\begin{array}{l}\text { Coeficiente de rigidez do ponto a devido à aplicação de } \\
\text { momento. }\end{array}$ & 81 \\
\hline$b_{a}$ & Comprimento da barra de $a$ até $b$. & 81 \\
\hline$h_{a}$ & Espessura da barra $a b$ & 81 \\
\hline$\delta_{t}$ & Deflexão total da barra curva de $a$ até $d$. & 81 \\
\hline$\delta_{b}$ & Deflexão da barra no ponto b & 81 \\
\hline$\delta_{c}$ & Deflexão da barra no ponto c & 81 \\
\hline$\delta_{d}$ & Deflexão da barra no ponto d & 81 \\
\hline$L$ & Altura total do AD. & 81 \\
\hline$R$ & Raio de curvatura da placa do AD. & 81 \\
\hline$P_{s}$ & Média da aceleração & 83 \\
\hline$\ddot{x}_{i}$ & Aceleração instantânea de um intervalo de tempo & 83 \\
\hline$\ddot{\ddot{x}}$ & Média do sinal de aceleração & 83 \\
\hline$n$ & Número total de sinais & 83 \\
\hline$L_{v t}$ & Nível de velocidade global de um ponto. & 86 \\
\hline$L_{v 31,5}$ & $\begin{array}{l}\text { Nível de velocidade na faixa de terça de oitava de } 0 \text { até } \\
44 H z \text {. }\end{array}$ & 86 \\
\hline$L_{v 63}$ & $\begin{array}{l}\text { Nível de velocidade na faixa de terça de oitava de } 44 \text { até } \\
88 \mathrm{~Hz} \text {. }\end{array}$ & 86 \\
\hline
\end{tabular}




\begin{tabular}{lll}
\hline símbolo & descrição & página \\
\hline$L_{v 125}$ & $\begin{array}{l}\text { Nível de velocidade na faixa de terça de oitava de } 88 \text { até } \\
\text { 177 } H z .\end{array}$ & 86 \\
$L_{v 250}$ & Nível de velocidade na faixa de terça de oitava de 177 & 86 \\
& até $355 H z$. & \\
$L_{v 500}$ & Nível de velocidade na faixa de terça de oitava de 355 & 86 \\
& até $710 H z$. & \\
$L_{v 1000}$ & Nível de velocidade na faixa de terça de oitava de 710 & 86 \\
& até $1420 H z$. & \\
$d_{m}$ & Deslocamento médio de toda a superfie da face do tan- & 91 \\
& que. & 91 \\
$x_{i}$ & Deslocamento da superfície em um intervalo de tempo. & 91 \\
$N_{p}$ & Número de pontos de uma face. & 91 \\
$n$ & Número de sinais de amplitude. & 91 \\
$P_{s}$ & Potencia eficaz da vibração irradiada na superfície. & 92 \\
$\delta_{p}$ & Massa específica da chapa de aço $7860 \mathrm{~kg} / \mathrm{m}^{3}$ & 92 \\
$e_{p}$ & Espessura da chapa da parede do tanque & 92 \\
$S_{p}$ & Superfície de uma face do tanque & 92 \\
$f_{p}$ & Freqüência de exitação (120 $H z$ ) & 92 \\
\hline & &
\end{tabular}




\section{INTRODUÇÃO}

A expansão urbana aproximou as moradias às subestações de transformadores de potência e de distribuição de energia elétrica, causando desconforto na população devido à poluição sonora produzida principalmente pelos transformadores. A demanda de energia elétrica vem aumentando por diversos motivos, mas sem que esse problema ambiental seja resolvido, torna-se mais difícil a aprovação de projetos de ampliação ou de construção de novas subestações transformadoras de distribuição de energia elétrica. A figura 1.1 mostra um exemplo da proximidade entre edifícios residenciais e os transformadores elétricos na subestação Bela Aliança da AES Eletropaulo.

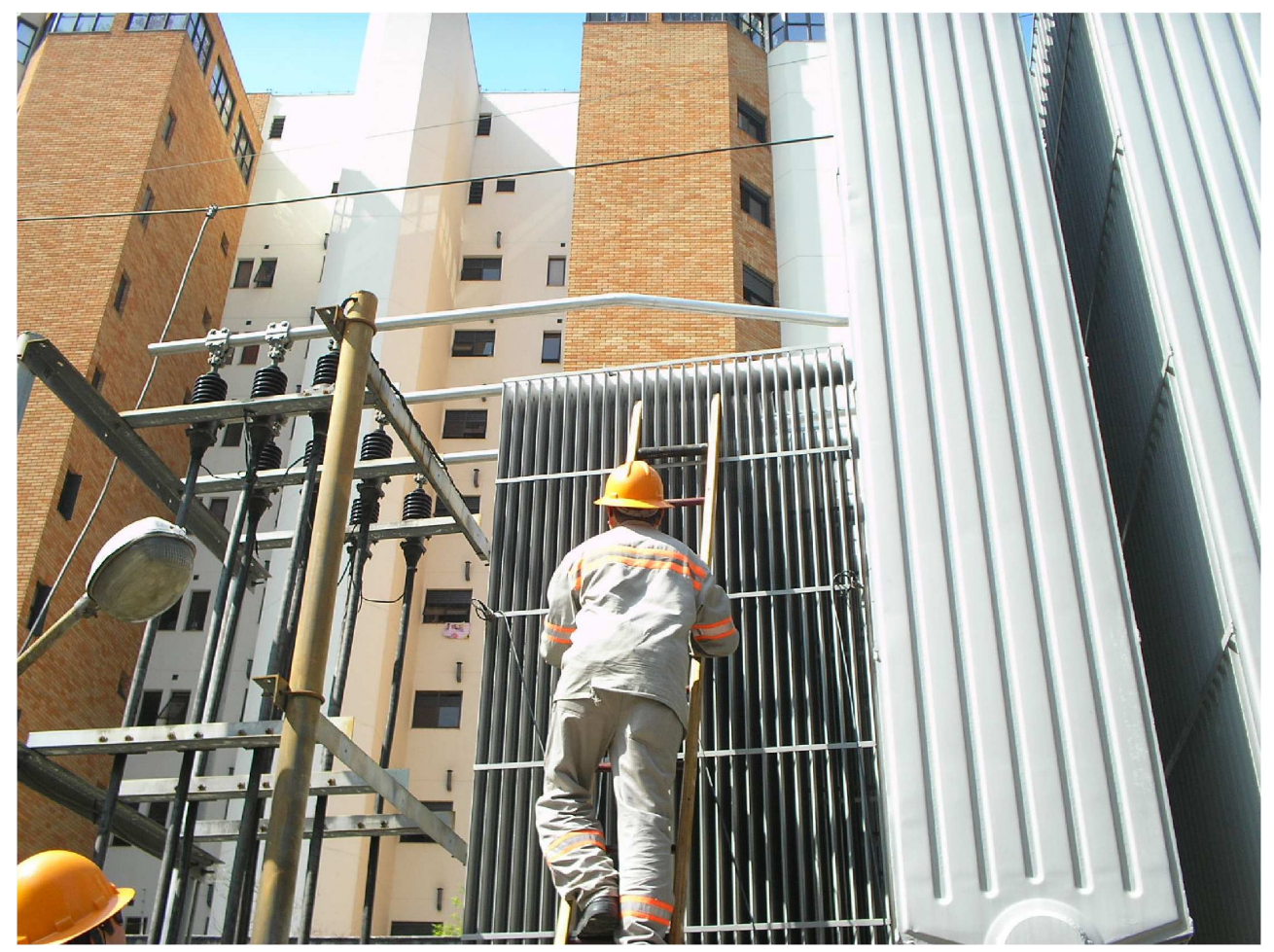

Figura 1.1: Foto de um transformador da subestação Bela Aliança em estudo

Atualmente existem muitas subestações de energia elétrica em operação que não podem aumentar sua produção por estar limitadas pelo incremento do som. 


\subsection{Alternativas para a redução do ruído de trans- formadores}

Em um estudo das alternativas que se tem para a redução do ruído de transformadores, Jasinski R. Calomeno e Fillippin (2005) expõe que existem basicamente quatro formas para reduzir os níveis de vibração e ruído de um transformador:

- Reduzir o nível de vibração na fonte (modificar o núcleo, isolar o tanque das vibrações do núcleo; isolar as vibrações dos trocadores de calor, etc).

- Reduzir o nível de ruído na direção das edificações (colocar barreiras acústicas exteriormente).

- Fazer modificações estruturais no tanque para evitar o fenômeno de ressonância.

- Introduzir absorvedores dinâmicos (dispositivos mecânicos que controlam ou reduzem os níveis de vibração, introduzindo forças de reação e dissipando energia).

Estes métodos são passivos e os dois primeiros métodos são considerados tradicionais. A aplicação destes consegue diminuir até $15 \mathrm{~dB}$ de intensidade de ruído e ainda assim pode não ser possível respeitar as normas existentes.

As modificações estruturais do tanque são complexas, a alteração da estrutura muda a densidade modal, gerando-se o risco de aumentar o ruído por ressonância. Os transformadores que já estão em operação nas subestações não podem ser modificados internamente, pela complexidade e elevado custo, requerendo o desenvolvimento de alternativas tecnológicas para a redução do ruído acústico.

A diminuição do ruído de um transformador de potência é caro, na tabela 1.1 mostra-se a relação de métodos usados pelas empresas fabricantes de transformadores elétricos de potência, os intervalos de decibéis que se consegue diminuir e o incremento de custo que teria respeito a um transformador comum ${ }^{1}$.

Tabela 1.1: Alguns métodos usados para diminuir ruído.

\begin{tabular}{|l|c|c|}
\hline Método usado & Redução (dB) & Incremento de custo (\%) \\
\hline Alterações nas juntas do núcleo & $5-10$ & $10-20$ \\
\hline Isolamento do tanque & $5-15$ & $20-30$ \\
\hline Transf. com amortecedores & $10-20$ & $30-60$ \\
\hline
\end{tabular}

\footnotetext{
${ }^{1}$ Informação fornecida por funcionários de FURNAS -Ibiuma e AES Eletropaulo
} 
Independentemente dos métodos empregados pelos fabricantes, a instalação de absorvedores dinâmicos, nos transformadores de potência que estão em operação, contribuem para a redução do ruído. Segundo os resultado de Jasinski R. Calomeno e Fillippin (2005) e Ming (2000) com o controle da vibração, dos transformadores elétricos de médio porte, consegue-se a redução de ruído acima de $15 d B$. Nesta pesquisa o abordagem é a redução do ruído de um transformador de potência de 30/40 KVA. Estima-se que o custo total para implementar a tecnologia para instalar os absorvedores dinâmicos e amortecedores, estaria em torno de $5 \%$ do custo de um transformador comum, sendo o custo de um absorvedor dinâmico entre 400 a 800 reais e o custo de um amortecedor viscoso é ainda menor.

Em muitas subestações elétricas de Brasil, existem transformadores comuns ou modificados de menor emissão de ruído, instalados próximos às moradias, muitas das subestações estariam próximas ao limite de tolerância de ruído. Se as normas ambientais diminui-se os limites permitidos de decibéis de ruído, as empresas eléctricas teriam que reduzir a emissão de ruído.

A respeito dos métodos de controle ativos, existem duas abordagens principais, Controle Ativo de Ruído (Active Noise Control - ANC) e Controle Ativo Estrutural-Acústico (Active Structural-Acoustic Control - ASAC). Na primeira abordagem, ANC, verifica-se que o tamanho e a complexidade da forma de transformadores elétricos em subestações de distribuição de energia, quase sempre instalados ao ar livre, tornam o campo acústico bastante complexo, dificultando sobremaneira seu controle, exigindo um número considerável de atuadores e sensores, bem como de algoritmos de controle sofisticados. Considerando a segunda abordagem, ASAC, foram encontradas na literatura propostas de uso de atuadores piezoelétricos, eletromagnéticos e absorvedores dinâmicos ajustáveis.

No presente trabalho, o uso dos atuadores piezoelétricos e dos atuadores eletromagnéticos foi descartado pelo alto custo, e, embora os absorvedores dinâmicos aumentem a massa da estrutura, o que torna a solução menos adequada para o problema de ruídos em meios de transporte (interior da cabine de aviões, por exemplo), para transformadores elétricos em subestações este incremento de massa não traz maiores inconvenientes. 


\subsection{OBJETIVOS}

O objetivo deste trabalho é contribuir no desenvolvimento de uma metodologia de projeto de dispositivos, incluindo sua localização, para a redução de ruído acústico gerado por transformadores elétricos de potência. Os dispositivos que serão abordados são os absorvedores dinâmicos de vibração e amortecedores viscosos. Instalando os dispositivos, procura-se reduzir a amplitude dos deslocamentos estruturais e, como conseqüência, reduzir o ruído acústico. 


\section{REVISÃO DA LITERATURA}

Neste capítulo apresentam-se um resumo histórico da invenção do transformador e uma análise de diversos resultados de pesquisa sobre o controle de ruído. Alguns temas esclarecem o contexto do presente trabalho, outros temas influenciam diretamente a metodologia empregada.

\subsection{Notas históricas sobre o transformador}

Em 1831 o inglês Michael Faraday descobriu o fenômeno de indução eletromagnética, ao realizar uma experiência em um aparelho constituído por um anel de ferro (núcleo) com duas bobinas enroladas uma acima da outra. Ele percebeu que ao subministrar uma tensão em uma bobina, induzia-se tensão elétrica na outra bobina, fenômeno ao qual denominou indução eletromagnética. Depois percebeu que é possível induzir corrente elétrica de muitas maneiras, tais como: variando a intensidade da corrente; deslocando um ímã próximo do circuito experimental; ou deslocando o referido circuito nas proximidades de outra corrente. Das observações concluiu que a voltagem induzida é proporcional à variação do fluxo magnético, e expõe em seu livro Experimental Researches in Electricity. Tempos depois o funcionamento do transformador estaria fundamentado pela lei de Faraday de indução magnética.

Sobre a invenção do transformador há três versões diferentes. A respeito da primeira versão, Kostenko e Piotrosvsky (1950) atesta que em 1878 o cientista Russo P. N. Yablochkov construiu a primeira planta elétrica comercial para alimentação das lâmpadas elétricas inventadas por ele que chamou de Vela Yablochkov. A central de energia foi criada em cooperação com as oficinas Works de França tendo um gerador síncrono e um transformador de circuito magnético aberto. Estas foram patenteadas em 1876 e 1877 tendo a evidência da iluminação na exposição mundial de Paris testemunhada pela instituição que formou a Companhia Elétrica de Iluminação Francesa.

Na segunda versão, de acordo com Karsai K. Kerenyi e Kiss (1987), o primeiro 
transformador foi construído em setembro de 1884 na oficina de GANZ em Budapeste e foi conduzido por M. Déry, O. Blathy e K. Zipernovsky. A capacidade deste transformador foi de $1400 \mathrm{kVA}$. Os inventores de GANZ foram os primeiros a usar o termo transformador patenteando-o na monarquia Austro-Húngara, também na Bélgica, Itália, Reino Unido e USA. Este transformador era de uma fase.

Outra versão é de Filho et al. (1999): "Extremamente interessante é a história do transformador. Seu desenvolvimento só foi possível graças ao trabalho científico do americano Joseph Henry em 1832. Contudo, o produto comercial foi desenvolvido pelo francês Lucien Gaulard com o suporte financeiro do empresário inglês John Gibbs em 1882. Percebendo o potencial da nova invenção, o empresário e engenheiro americano George Westinghouse comprou os direitos da patente nos EUA em 1885 e construiu um império industrial, hoje chamado de Westinghouse."

A respeito Braun (1992) diz que depois de ter patenteado uma versão de transformador (em 1882), o francês Lucien H. Gaular e o inglês, John D. Gibbs, inventaram um sistema de iluminação usando corrente alternada e lâmpadas incandescentes, do tipo que inventou Edison, a qual foi mostrada na Itália. Entre os visitantes da exposição estiveram os húngaros: Déry, Blathy e Zipernovsky. Eles aperfeiçoaram o projeto de transformador. E em 1885, na Exposição Nacional Húngara em Budapeste apresentaram o protótipo do sistema de iluminação que se usa até hoje. O empresário norte-americano George Westinghouse contratou William Stanley (jovem engenheiro elétrico). Em 1885 Stanley tinha projetado vários tipos de transformadores superiores aos húngaros. Stanley construiu com ajuda de outros pesquisadores, transformadores com finas lâminas de ferro, os quais diminuíam as perdas de energia. Em 1886 começou a funcionar a planta de energia elétrica, a construção foi dirigida por Stanley e realizada em Great Barrington, Massachussetts. Esta planta operou com corrente alternada (CA), com um gerador de $500 \mathrm{~V}$ e alimentou um conjunto de lâmpadas na distância de $2 \mathrm{~km}$ utilizando transformadores que reduziram a tensão elétrica a $100 \mathrm{~V}$. Desta maneira Westinghouse iniciou a manufatura e venda de equipamentos para distribuir eletricidade de CA.

O primeiro transformador de três fases foi construído pelo engenheiro russo M.O. Doli-Dobrovolsky em 1890 no AEG na Alemanha. No mesmo ano crio-se o primeiro transformador de $30 \mathrm{kVA}$ isolado e resfriado a óleo, este foi construído na Suíça por Brow, diretor da Oerlikon. 


\subsection{Ruído e Vibração em Transformadores Elétri- $\cos$}

Os transformadores elétricos produzem ruído acústico como os demais equipamentos eletromagnéticos, e as principais causas são, segundo Rausch M. Kaltenbacher e Lerch (2002), a tensão magnetostrictiva nas lâminas do núcleo (o ruído neste caso é independente da carga); o movimento causado pelas forças eletromagnéticas resultantes da interação entre o campo magnético de um enrolamento com as correntes elétricas nos demais enrolamentos (este ruído depende da carga do transformador) e os sistemas de refrigeração (bombeamento de óleo, ventiladores, etc.).

O ruído concentra-se principalmente no dobro da freqüência da linha, especificamente nas freqüências de 120, 240, 360 e $480 \mathrm{~Hz}$, embora haja outros harmônicos. A essas freqüências adicionam-se outras devido ao sistema de refrigeração. Nas freqüências maiores, em geral, o ruído é menor e mais facilmente atenuado por métodos passivos. Como o ruído do transformador é basicamente tonal (ocorre em poucas freqüências específicas), ocorrendo 24 horas por dia, ele tende a ser mais irritante que, por exemplo, o ruído do tráfego de veículos, cujo espectro de freqüência é mais distribuído, e que diminui de noite. Por este motivo, em geral, a legislação é mais rigorosa para os ruídos tonais do que para os ruídos de banda larga.

O ruído que se produz em um transformador envolve três conceitos: o de campo magnético, o campo de deslocamentos mecânicos em um sólido, e o campo acústico em um fluido. Ming (1999) estudou as vibrações do tanque do transformador, também concluindo que as freqüências mais importantes são os múltiplos do dobro da freqüência de excitação, no caso, $50 \mathrm{~Hz}$, e que as amplitudes de vibração diminuem nas freqüências mais elevadas, sendo significativas até 800 $H z$. Além disso o artigo concluiu que a radiação de som na tampa e na base do transformador é relativamente pequena em comparação com as que provém das paredes do tanque. Em outros estudos, Garcia B. Burgos e Alonso (2006) propõem modelos matemáticos para calcular a vibração de tanques de transformadores considerando ainda as condições de operação, a geometria e a temperatura. O modelo é usado para detectar possíveis deformações nas bobinas, que podem estar ocorrendo se a vibração medida no transformador for bem superior à vibração predita pelo modelo matemático. Também nesse modelo verifica-se que as vibrações mais significativas ocorrem no dobro da freqüência da linha. 


\subsubsection{Controle Ativo de Ruído (ANC - Active Noise Con- trol)}

O som é uma onda longitudinal com velocidade de propagação no ar de $340 \mathrm{~m} / \mathrm{s}$ (este valor na verdade depende bastante das condições do meio). Considerando a faixa de freqüências em que o som é audível para os seres humanos, entre 20 $\mathrm{Hz}$ e $20 \mathrm{kHz}$, o comprimento de onda está compreendido entre $17 \mathrm{~m}$ e $17 \mathrm{~mm}$, respectivamente. Para a freqüência de $120 \mathrm{~Hz}$, que é a mais importante em transformadores, o comprimento de onda é cerca de $2,8 \mathrm{~m}$, tornando ineficientes os métodos passivos de atenuação do ruído, já que as barreiras precisariam ter dimensões e massa muito grandes. Porém, uma das características das ondas de som (pelo menos nas amplitudes normais) é a linearidade, ou seja, o efeito em um ponto no espaço de duas ondas sonoras distintas é a superposição dos efeitos destas ondas. Assim, pode-se imaginar um som criado artificialmente, em oposição de fase (180 graus, mais especificamente) em relação ao ruído. As duas ondas irão se cancelar por interferência destrutiva. Na literatura sobre o assunto, este som 180 graus fora de fase é chamado de anti-som. Paul Leug, em 1934, patenteou na Alemanha um sistema para reduzir o ruído em dutos usando justamente este princípio (ver figura 2.1), de acordo com Elliott e Nelson (1990). Neste sistema um microfone capta o som que se quer atenuar, e o envia a um dispositivo eletrônico, o sistema de controle. O papel deste sistema de controle é calcular, em função da dinâmica do duto, qual será o som quando ele chegar na posição do alto-falante, e inverter sua fase, e, de acordo com a dinâmica do altofalante, determinar qual a tensão que deve ser aplicada para que ele reproduza este som com fase invertida.

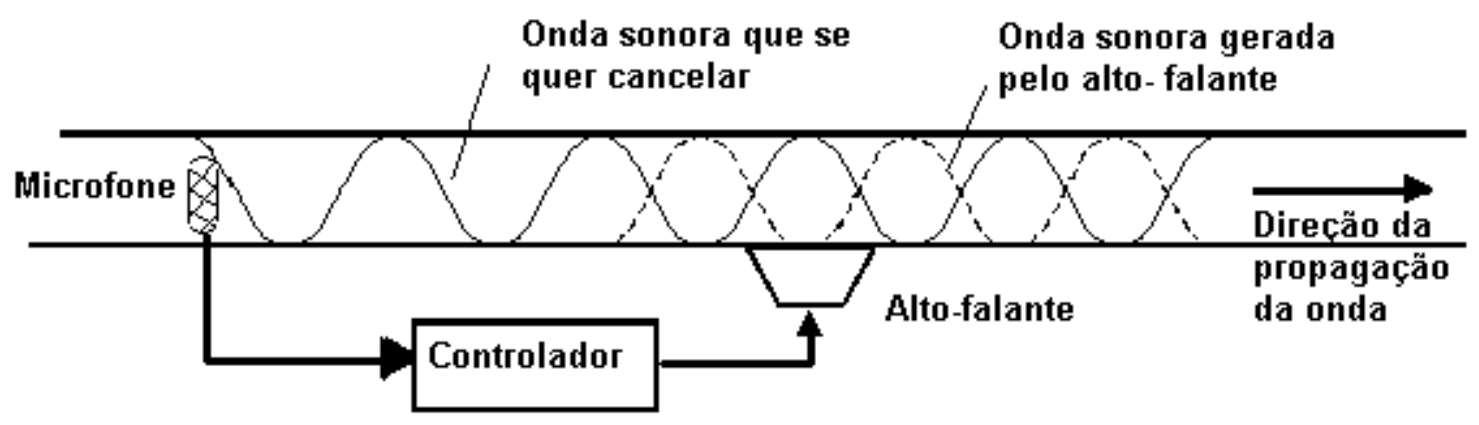

Figura 2.1: Esquema de controle ativo de ruído acústico

Embora o princípio seja simples, os problemas de engenharia envolvidos tornam a aplicação prática muito complexa. O esquema mostrado na figura 2.1 é a implementação de um sistema feedforward. Entretanto, na prática, a onda gerada pelo alto-falante se propaga para trás, e afeta o microfone, introduzindo 
uma realimentação (feedback) prejudicial ao funcionamento do sistema.

Abbott (1993) discute as limitações práticas do controle ativo devido aos efeitos acústicos. Usando modelos simples e idealizados, Abbott determinou quais seriam os limites de desempenho de tais sistemas. Ele considerou a posição da fonte secundária de ruído (a fonte que deverá gerar o anti-som que atenuará o ruído indesejado), e a posição dos microfones de erro (os pontos de calibração mencionados em seu artigo). Suas conclusões indicam que a fonte secundária deve estar o mais próximo possível da fonte primária de ruído, a uma distância menor do que $1 / 10$ do comprimento da onda sonora (para $120 \mathrm{~Hz}$ o comprimento de onda é cerca de 2,8 m). Caso isto não seja possível, cada fonte secundária pode gerar uma zona de silêncio com um diâmetro equivalente a $1 / 10$ do comprimento de onda, ou seja, para uma freqüência de $480 \mathrm{~Hz}$, isto significa uma região de silêncio de apenas $7 \mathrm{~cm}$ de diâmetro para cada fonte secundária. Assim, a aplicação prática de controle ativo de ruído fica limitada a freqüências baixas, e mesmo assim, podendo exigir um grande número de atuadores (alto-falantes) e sensores (microfones).

Elliott e Nelson (1990), Denenberg (1992), Fuller e Flotow (1995) apresentam uma boa revisão do assunto, principalmente da parte histórica e dos princípios básicos. Elliott e Nelson (1993), e Kuo e Morgan (1999) apresentam uma boa revisão dos principais algoritmos e estratégias de controle.

\subsubsection{Controle Ativo Estrutural-Acústico}

Nesta abordagem, também conhecida por Active Structural-Acoustic Control, são usados atuadores para controlar diretamente a vibração da estrutura que está gerando o ruído acústico Olkin J. A. Heck e Naghshineh (1996); Mason P. Berry e Nicolas (1997); Vipperman e Clark (1999). É importante observar que o controle da vibração da estrutura não está diretamente ligado ao controle do ruído acústico, especialmente nas regiões distantes da fonte primária, sendo interessante controlar apenas a vibração dos modos que irradiam o som de forma mais eficiente, e pode ser necessário usar microfones de erro distantes da fonte primária.

Uma técnica adaptativa-passiva que pode ser usada dentro do escopo desta abordagem é o uso de absorvedores dinâmicos auto-ajustáveis. Absorvedores dinâmicos são elementos muito conhecidos e usados para atenuar a vibração de uma estrutura em uma freqüência específica. São basicamente sistemas oscilatórios (massa-mola) fixos na estrutura cuja vibração se quer controlar, e que absorvem sua energia cinética. Para aplicação prática na redução de ruído é necessário 
que a freqüência em que tais dispositivos absorvem a vibração seja auto-ajustável. Obviamente os absorvedores devem ter menor acoplamento com o meio fluido externo (ar), ou produzirão ruído acústico da mesma forma que a estrutura original. Esta é a abordagem escolhida para estudo no presente trabalho.

\subsubsection{Controle Passivo Estrutural-Acústico}

Entre os métodos passivos é interessante mencionar a abordagem proposta por Ming (2000). Nesta abordagem, vínculos físicos adicionais são aplicados à superfície que irradia o som, alterando a forma da vibração, e diminuindo a efetiva transmissão para o ar. A técnica é aplicada em transformadores elétricos, e consiste basicamente de estruturas rígidas (quadros retangulares que envolvem o transformador sem tocá-lo). Parafusos rosqueados nestes quadros são usados para limitar o movimento da superfície do transformador, sendo que entre a superfície e as pontas dos parafusos é colocado um elastômero para garantir um bom contato e não danificar a superfície (ver figura 2.2). O número e a posição destes parafusos precisam ser adequadamente determinados. Verificou-se que para tanques preenchidos com óleo é necessário um número maior de pontos de restrição de movimento para obter a mesma redução de ruído que se obtém em tanques que contém apenas ar.

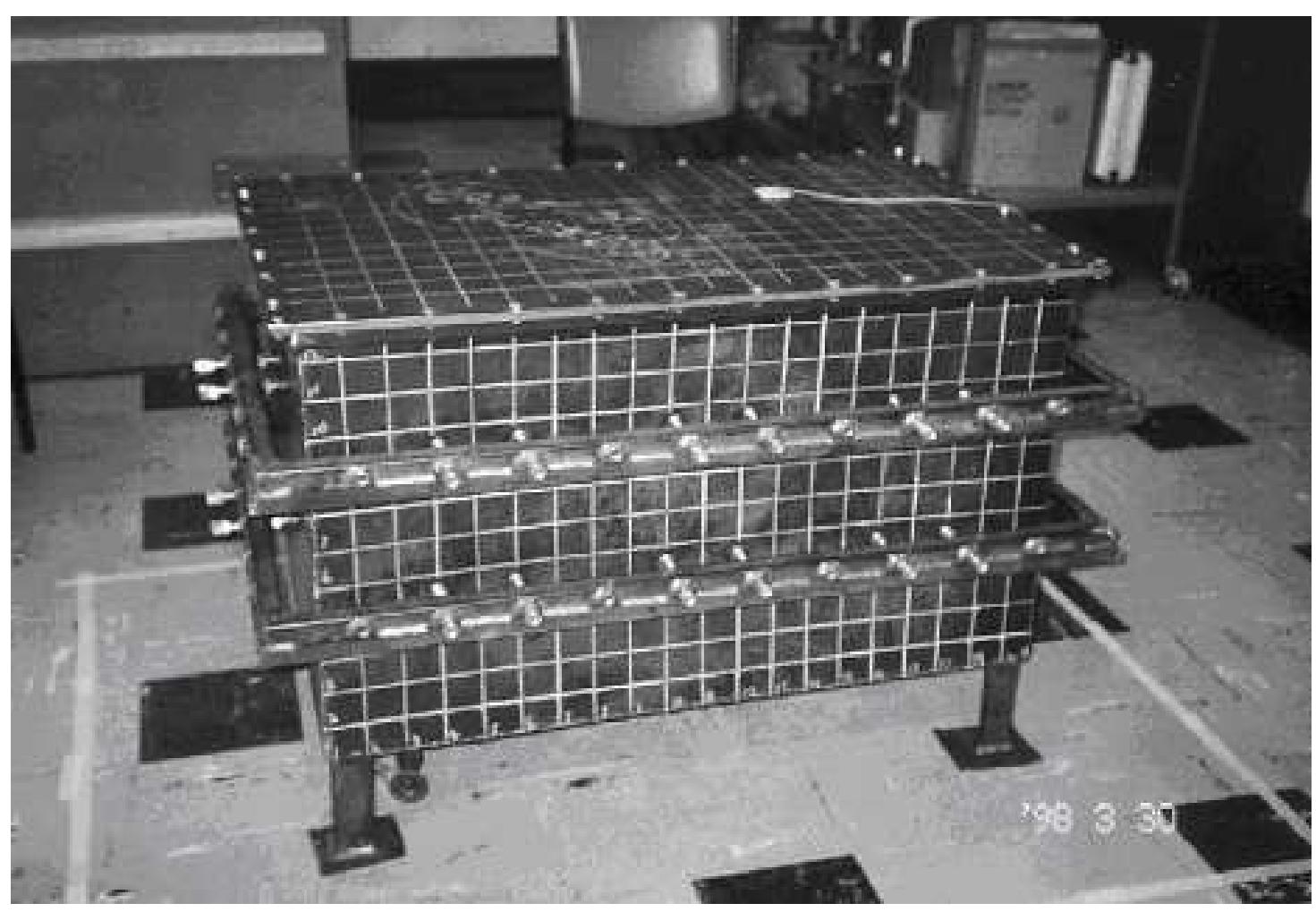

Figura 2.2: Modelo do tanque do transformador com os quadros e os parafusos - extraído de Ming (2000) 
Sobre o uso de absorvedores dinâmicos (AD) para a atenuação de ruído acústico, diversos trabalhos apontam que é uma solução de baixo custo Fuller et al. (1997), que são adequados para reduzir a vibração apenas em uma banda estreita de freqüências Bies e Hansen (1996), sendo necessário o uso de vários ADs distribuídos adequadamente para atenuar a vibração de uma faixa de freqüência mais ampla Grisson e Belegundu A. D.; Koopmann (2005).

O projeto de sintonização dos absorvedores dinâmicos é abordado por Nagaya e Li (1997), onde um novo método de projeto e sintonização de AD é proposto, visto que os métodos convencionais podem resultar em excitação dos modos de vibração mais elevados (maior freqüência), que exercem fortes efeitos no ruído acústico. Em Liu e Lee (2006), um novo método chamado de "intensidade estrutural"é proposto para tratar o problema de localização das principais fontes de ruído de uma estrutura, indicando possíveis pontos onde alterações estruturais sejam necessárias, ou pontos onde se pode colocar atuadores para reduzir o ruído acústico.

\subsection{Ruído de Transformadores}

Nesta seção há uma descrição das forças que ativam a vibração e o ruído no tanque de um transformador e, no final, mostram-se sinais de níveis de pressão de som, coletados em 8 transformadores conversores de 500 MVA.

\subsubsection{Ruído produzido por transformadores}

O informe do comitê de transformadores da IEEE Society (2000), argumenta que, as principais fontes de som de um transformador são:

1. o núcleo, que por efeito da magnetostricção produz forças inter-laminares;

2. o som associado à carga, causado pelas forças magnéticas nas bobinas;

3. forças devidas ao shunt magnético, perdas do fluxo magnético;

4. o sistema de resfriamento (ventiladores e bombas).

O transformador serve para modificar a tensão da corrente elétrica. Pelo núcleo do transformador circula o fluxo magnético gerado pela corrente alternada, o fluxo gera forças de magnetostricção e a corrente gera forças nas bobinas, ambas produzem vibrações e ruído. 


\subsubsection{Forças de magnetostricção}

Ao circular a corrente elétrica pelas bobinas o ferro do núcleo se magnetiza, ao mesmo tempo, produzem-se pequenas modificações nas dimensões das lâminas do núcleo, este fenômeno é chamado de magnetostriç̧ão. As mudanças são independentes da direção do fluxo e acontecem no dobro da freqüência da linha elétrica. Segundo Kelley (1990), os sistemas de potência que usam corrente alternada tem tensão elétrica senoidal que produz uma variação senoidal do fluxo magnético $B$. Estes fluxo magnético introduz deformações induzidas pela magnetostricção. Estas estão em função do fluxo magnético ao quadrado, causando deformações no dobro da freqüência do sinal de tensão elétrica, conforme eq. 2.1 e eq. 2.2.

$$
\begin{gathered}
B(t)=B \cdot \operatorname{sen}(\omega \cdot t) \\
\frac{d e_{l}}{e_{l}} \equiv B^{2}=B_{0}^{2} \operatorname{sen}^{2}(\omega \cdot t)=\frac{1}{2} B_{0}^{2}(1-\cos (2 \omega \cdot t)
\end{gathered}
$$

Autores como Weiser V. Pfützner e Anger (2000) realizaram trabalhos experimentais com transformadores de potência. Seus resultados mostraram o comportamento da aceleração na superfície de um núcleo monofásico, conforme figura 2.3-a, e na superfície de um transformador trifásico, conforme figura 2.3-b. Nelas observam-se as amplitudes da aceleração na superfície do núcleo, o efeito das juntas do núcleo. As juntas podem ser simples, onde as lâminas do núcleo começam e acabam paralelamente, ou as juntas podem ser melhoradas apresentando múltiplos degraus, as lâminas do núcleo começam e acabam em vários grupos de degraus. 

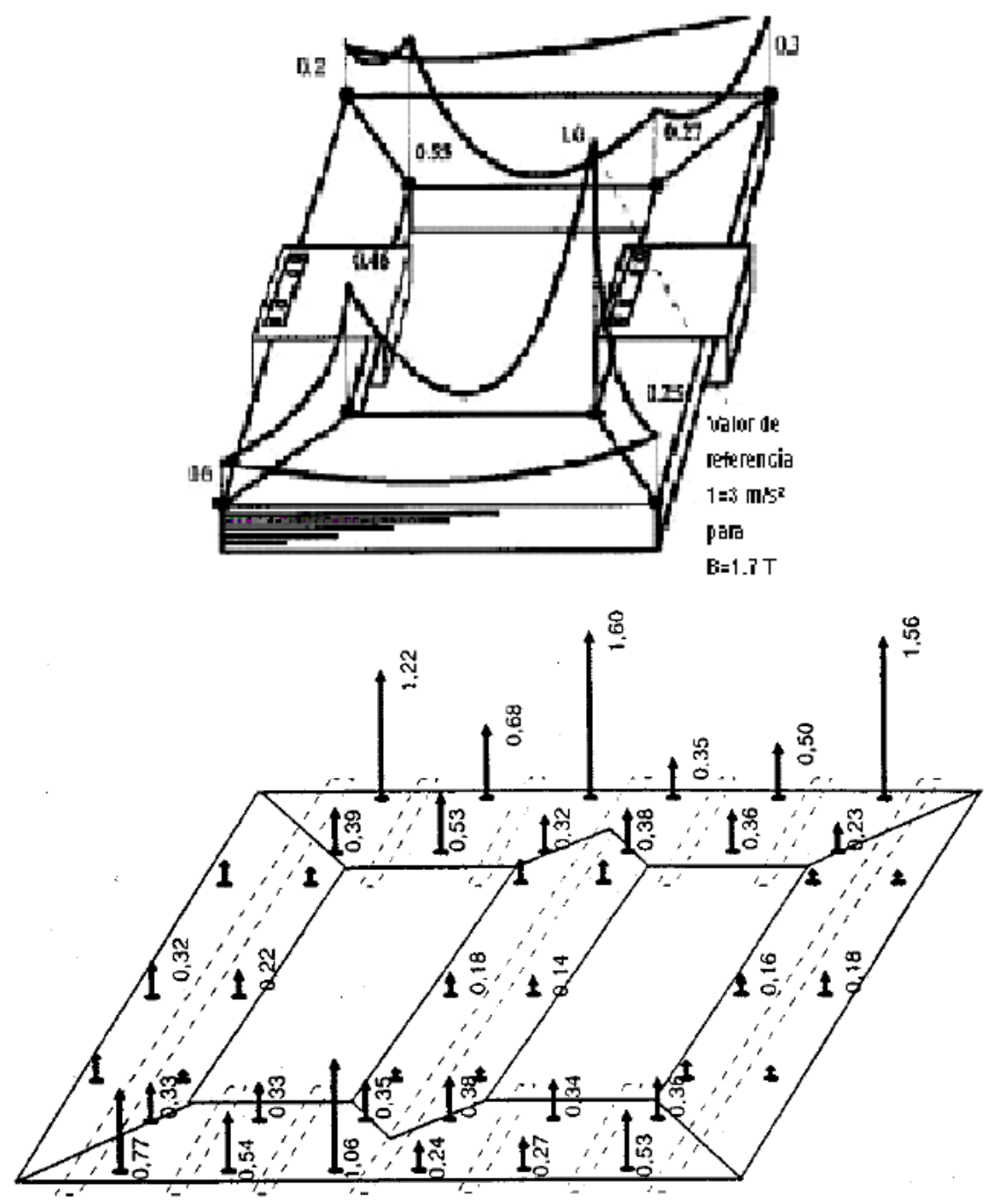

Figura 2.3: Aceleração na superfície do núcleo: a) de um transformador Monofásico b) de um transformador Trifásico - extraído de Weiser (2000).

Na figura 2.3-a, relativa ao núcleo de um transformador monofásico, observase que as acelerações são maiores nas juntas de lâminas do núcleo, sendo a aceleração máxima de $3 \mathrm{~m} / \mathrm{s}^{2}$. A figura 2.3-b pertence ao núcleo de um transformador trifásico de 40 MVA que tem uma junta múltipla ou Multistep Lap Assembling $M S L$ de 6 degraus. A aceleração máxima detectada no núcleo trifásico foi de 1,6 $\mathrm{m} / \mathrm{s}^{2}$, pois o sistema de juntas de múltiplos degraus reduzem as deformações que se produzem nos extremos das lâminas provocadas pelo efeito magnetostrictivo. A figura 2.4 mostra exemplos de juntas de 1 degrau e de 4 degraus. 


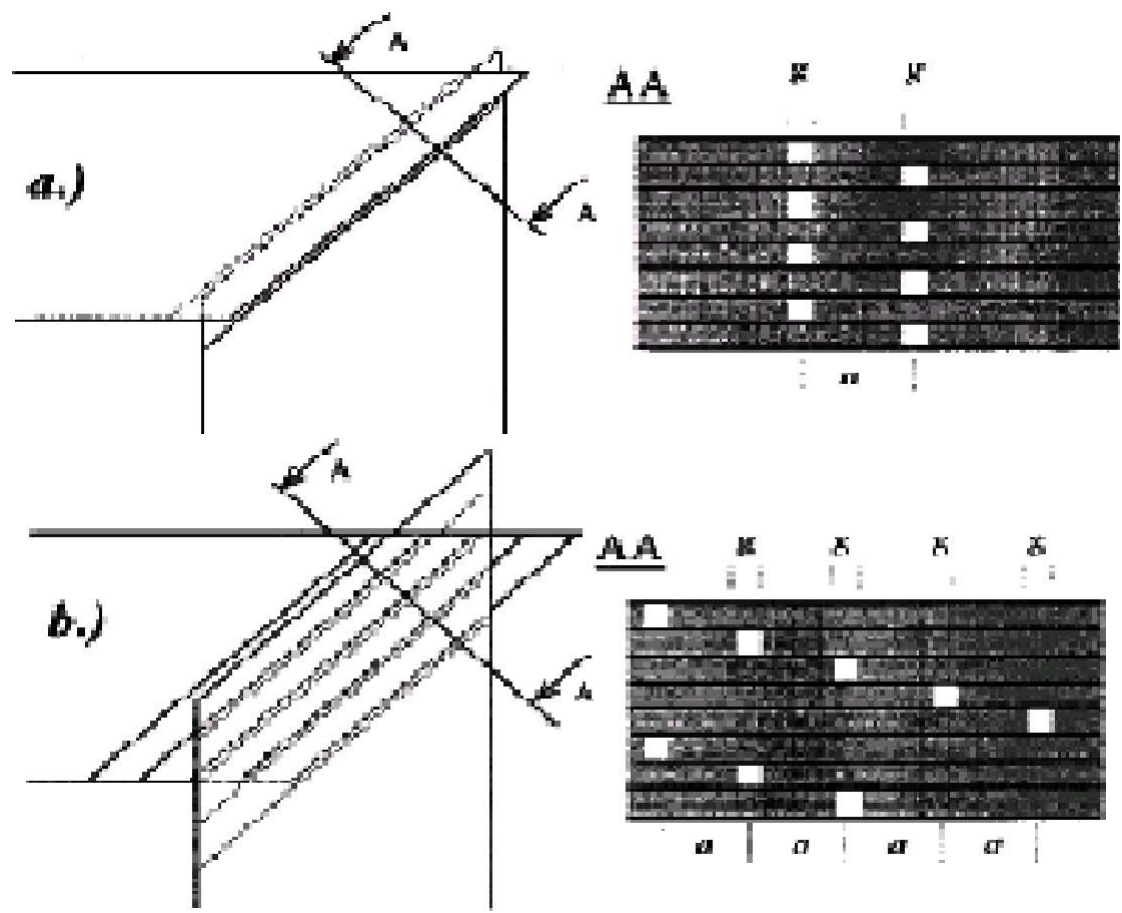

Figura 2.4: Desenho de juntas sobrepostas do núcleo do transformador: a) Com um degrau b) Com 4 degraus - extraído de Weiser (2000).

As deformações produzidas nas lâminas do núcleo, pela magnetostricção, são mostradas na figura 2.5-a, e a atuação do fluxo nas lâminas é ilustrada na figura 2.5-b. Weiser relaciona o comportamento do fluxo magnético, com as dimensões das lâminas e os espaços entre lâminas nas juntas, e argumenta que com as juntas de múltiplos degraus é possível reduzir o ruido em até $10 \mathrm{~dB}$. Os núcleos dos transformadores com juntas de múltiplos degraus são conhecidos por gerar menos ruído e seus custos são $15 \%$ maiores que os convencionais.
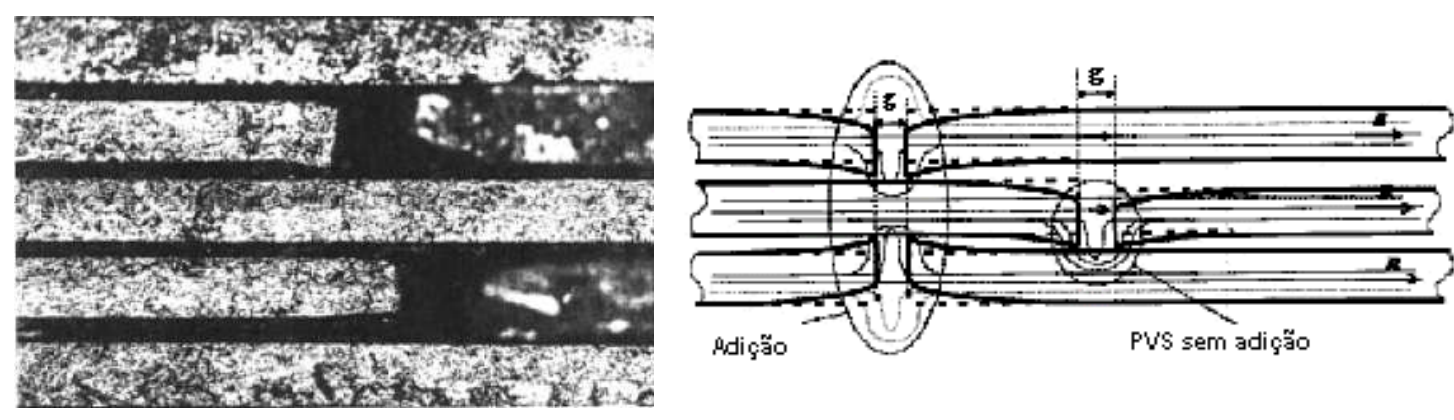

Figura 2.5: Deformações das lâminas do núcleo: a) Foto b) Comportamento do fluxo e a relação com a geometria das lâminas - extraído de Weiser (2000). 


\subsubsection{Forças magnéticas das bobinas}

Sobre as forças das bobinas Karsai K. Kerenyi e Kiss (1987) ${ }^{1}$ sustentam que as forças eletrodinâmicas são acionadas pela circulação da corrente $i$ e pela densidade do campo de fluxo magnético $B$ tendo em conta o comprimento do condutor $d l$. A força elementar na bobina $d \vec{F}_{b}$ calcula-se com a seguinte equação:

$$
d \vec{F}_{b}=i \overrightarrow{d l} \wedge \vec{B}
$$

Estas forças oscilam no dobro da freqüência da tensão elétrica. A distribuição de forças das bobinas está representada na figura 2.6, onde $F a$ denota forças axiais, $F r^{\prime}$ denota forças radiais no sentido vertical e $F r^{\prime \prime}$ denota forças radiais no sentido horizontal.
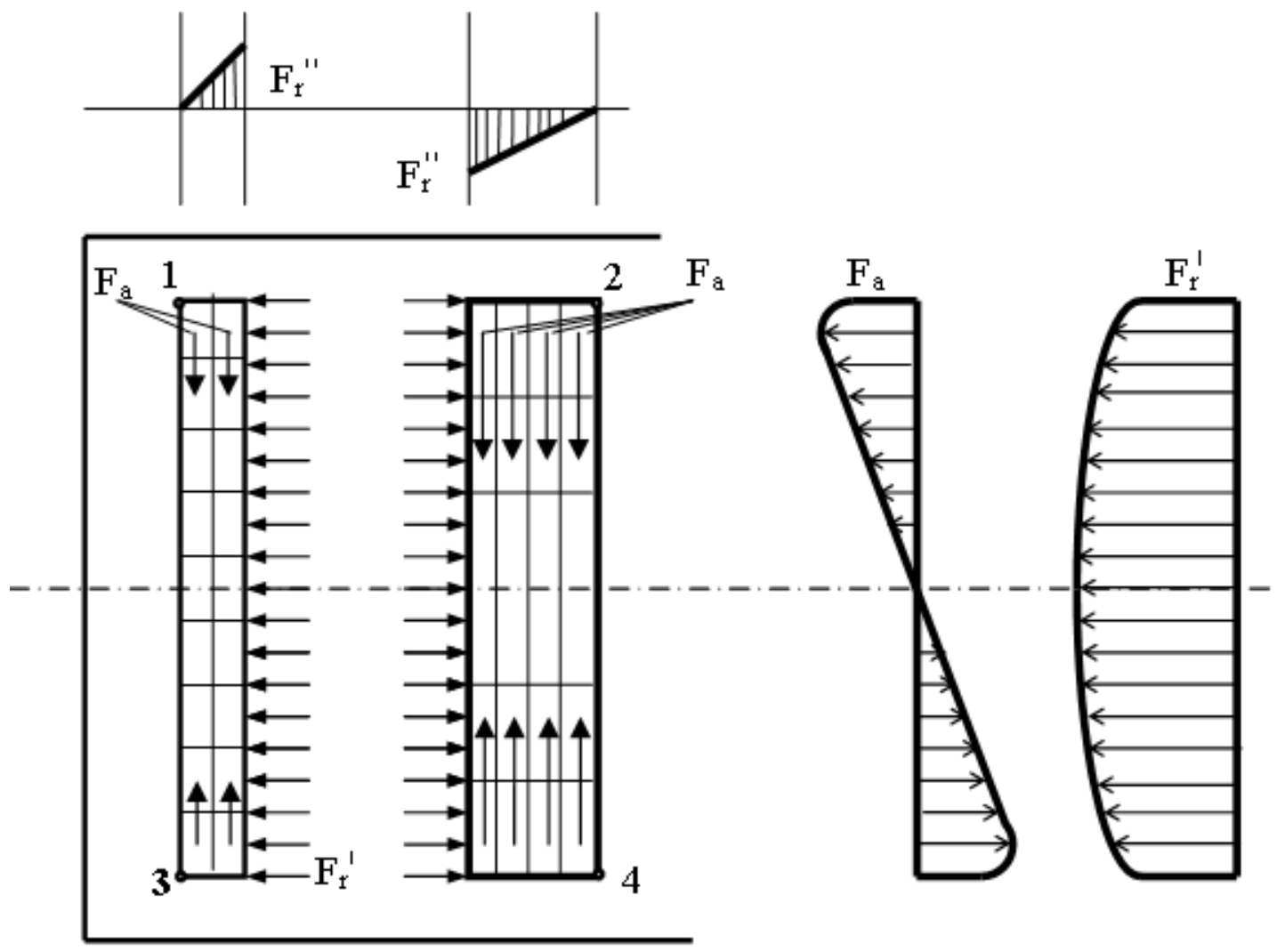

Figura 2.6: Forcas que atuam no núcleo produzido por duas bobinas simétricas - extraído de Karsai K. Kerenyi e Kiss (1987)

Em um transformador de duas bobinas, a corrente circula em ambas com direções opostas. Nelas se produzem as forças radiais $F_{r}$, que tendem a comprimir a bobina em uma direção horizontal, e forças axiais $F_{a}$, que tendem a comprimir a bobina na direção vertical. 


\subsubsection{Forças no núcleo de um transformador}

As forças que aparecem no núcleo de um transformador provém da magnetização das bobinas e da magnetostricção. A este respeito, Garcia B. Burgos e Alonso (2006) fundamentam que as forças na bobina são proporcionais ao quadrado da corrente, eq. 2.4, e as forças de magnetostricção são proporcionais ao quadrado da tensão, eq. 2.5.

$$
\begin{aligned}
& F_{b} \propto i^{2} \\
& F_{n} \propto u^{2}
\end{aligned}
$$

As vibrações do núcleo e das bobinas interagem e transmitem-se ao tanque através do óleo e dos suportes do transformador. Garcia B. Burgos e Alonso (2006) assumem que a vibração do tanque em uma determinada direção é o resultado da adição das vibrações das bobinas e do núcleo naquela direção. O modelo que propõe é no domínio do tempo e da freqüência:

$$
\begin{aligned}
& \ddot{x}_{\text {tanque }}=t_{1} \cdot \ddot{x}_{\text {bobina }}+t_{2} \cdot \ddot{x}_{\text {nucleo }} \\
& \ddot{X}_{\text {tanq }, 120}=t_{1} \cdot i_{120 \mathrm{~Hz}}^{2}+t_{2} \cdot u_{120 \mathrm{~Hz}}^{2}
\end{aligned}
$$

onde $t_{1}$ é um coeficiente de proporcionalidade entre corrente e forca na bobina e $t_{2}$ é um coeficiente de proporcionalidade entre tensão e forca de magnetostricção.

As conclusões de Garcia B. Burgos e Alonso (2006) depois de coletar os sinais do transformador sem carga, que mede a aceleração causada pela magnetostricção, e com carga, que adiciona as acelerações das bobinas, nas superfícies do núcleo e no tanque do transformador, são:

- a amplitude da aceleração na freqüência fundamental é maior quando há com carga, por efeito das vibrações produzidas pelas bobinas;

- os sinais obtidos na parte inferior do núcleo são semelhantes aos obtidos no fundo do tanque; ambas medidas correlacionam-se com a amplitude da aceleração na freqüência fundamental $(120 \mathrm{~Hz})$, seus valores estão em função da corrente ao quadrado. A correlação para o núcleo foi de 0,86 e para o tanque foi de 0,96 ;

- o funcionamento da bomba de óleo modifica os parâmetros para usar os 
modelos propostos.

\subsubsection{Harmônicos}

Segundo Karsai K. Kerenyi e Kiss (1987) ${ }^{2}$ a relação do fluxo magnético instantâneo com a tensão é:

$$
u(t)=2 \frac{\pi}{\sqrt{2}} f_{i} N S_{1} B(t)
$$

onde $f_{i}$ é a freqüência da rede elétrica de entrada, $N$ é o número de espiras, $S_{1}$ é a área da seção que o fluxo magnético atravessa e $B(t)$ é o fluxo magnético instantâneo.

A medição do fluxo magnético é difícil, mas a medição da intensidade de corrente e a queda de tensão é simples. Com a eq. 2.5 relaciona-se a tensão com a força do núcleo. A tensão instantânea ao quadrado resulta

$$
u(t)^{2}=u_{f}^{2} \sin (\omega t)^{2}=u_{f}^{2} \frac{(1-\cos (2 \omega t)}{2} .
$$

A velocidade angular $\omega$ é função da freqüência de acordo com

$$
\omega=2 \pi f
$$

então a aceleração do núcleo decorrente de várias freqüências, considerando a defasagem da queda de tensão, resulta

$$
\ddot{X}_{\text {nucleo }}=2 \sum_{h} u_{h}\left(\cos \left(2 \pi f t+\phi_{u_{h}, i_{h}}\right)\right)
$$

onde $h$ é uma freqüência qualquer, $\phi_{u_{h} . i_{h}}$ é o ângulo de fase da intensidade de corrente em relação á tensão e $i_{h}$ é a amplitude da corrente com freqüência $h$.

\subsection{Medição do Som}

A medição da pressão do som geralmente é mostrada no domínio da freqüência de três diferentes maneiras: nível de pressão $d B$ (re.Pref) que é a pressão física em uma freqüência; nível de pressão auditiva $d B A$ ou grandeza psicoacústica chamada de nivel de audibilidade caracterizada com a curva de Fletcher e Munson Bistafa (2006) e nível de pressão global $d B t$ que é a soma de todas 
as pressões em uma banda de freqüência.

$\mathrm{Na}$ medição do som, a amplitude maior é a mais importante de todos os valores, pois o efeito físico prevalece na audição, ficando os outros valores como som secundário ou de fundo.

O Nível de pressão sonora $L p$ é definida pela razão:

$$
L p=10 \log _{10}\left(\frac{P_{\text {eficaz }}^{2}}{P_{\text {ref }}^{2}}\right) .
$$

onde a pressão de referência é normalmente tomada como a de limiar de audibilidade que é $P_{\text {ref }}=2 \times 10^{-} 5 \mathrm{~N} / \mathrm{m}^{2}$ (Sistema Internacional - SI). A unidade do $L p$ é $d B($ re.Pref $)$,

O valor da pressão eficaz é:

$$
p_{\text {eficaz }}=\frac{\sum_{i=1}^{n} P_{i}^{2}}{N}=0,707 A_{p}
$$

O $d B A$ pode ser calculado por faixas parciais de freqüência (oitava ou terça de oitava), considerando os valores de $d B$ (re. $P_{r e f}$ ) e diminuindo uma quantidade constante por intervalo de faixa de freqüência. Alguns aparelhos de medição realizam estes cálculos e mostram os valores em $d B A$

O Nível de pressão global de uma banda larga $L p t$ é definida assim:

$$
L p t=10 \log _{10}\left(\sum_{i=1}^{n} 10\left(\frac{L p_{i}}{10}\right)\right)
$$

Outros parâmetros do som são o nível de intensidade sonora e o nível de potência sonora. O nível de intensidade é dado pela eq. 2.15. O nível de potência é dados pela eq. 2.16 .

$$
L_{I}=10 \cdot \log _{10}\left(\frac{I}{I_{r e f}}\right)
$$




$$
L_{W}=10 \log _{10}\left(\frac{W}{W_{r e f}}\right)
$$

onde o valor da intensidade de referência é $I_{r e f}=10^{-12} \mathrm{~N} / \mathrm{m} . \mathrm{s}$ (SI) e a unidade é $d B\left(\right.$ re. $\left.I_{r e f}\right)$. A potência de referência é $W_{\text {ref }}=10^{-2} N / m . s$ (SI) e a unidade é $d B\left(\right.$ re. $\left.W_{\text {ref }}\right)$

A intensidade sonora $I$ é definida pela eq. 2.17 ou pela eq. 2.18.

$$
\begin{gathered}
I=\frac{W}{S} . \\
I=\frac{P_{\text {eficaz }}^{2} .}{\rho . c} .
\end{gathered}
$$

A relação entre nível de pressão e nível de intensidade resulta

$$
L_{I}=L p+10 \log _{10}\left(\frac{P_{r e f}^{2}}{I_{\text {ref }} \rho \cdot c}\right) .
$$

A intensidade, de um ponto, é definida vetorialmente conforme a eq. 2.20.

$$
\vec{I}_{i}(\mathbf{r}, t)=P(\mathbf{r}, t) \vec{v}(\mathbf{r}, t)
$$

\subsubsection{Medição do som de um transformador}

A Associação Brasileira de Normas Técnicas ABNT propõe o método de ensaio para transformadores na norma NBR 7277 "Transformadores e Reatores - Determinação do Nível de Ruído", vigente desde novembro de 1988. As medições do nível de pressão acústica divide-se em dois casos, transformadores sem resfriamento e transformadores com sistema de resfriamento. O sistema com resfriamento gera ainda mais dois casos, os que têm seu sistema de resfriamento a uma distância inferior a $3 \mathrm{~m}$ da superfície principal do tanque principal e os transformadores com sistema de resfriamento com distância igual ou maior a $3 \mathrm{~m}$. Para a medição do som dos transformadores sem sistema de resfriamento, deve-se criar uma linha 
de contorno que deve estar afastada $0,3 \mathrm{~m}$ da superfície de irradiação, como é ilustrado na figura 2.7 .
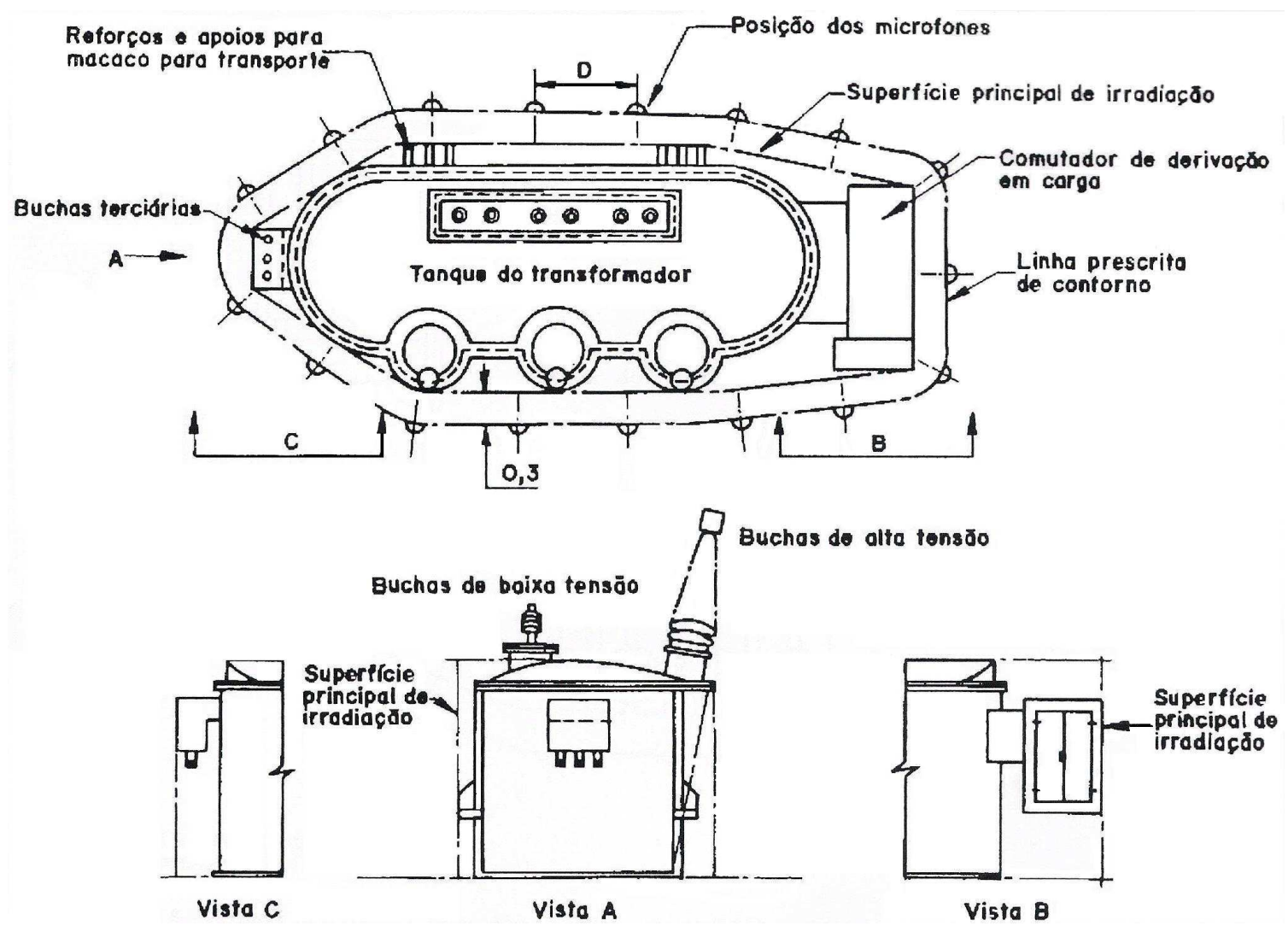

Figura 2.7: Posições típicas dos microfones para medição de ruído de transformadores sem sistema de resfriamento (Normas Técnicas ABNT - NBR 7277)

No caso de ter o sistema de resfriamento há uma distância inferior a $3 \mathrm{~m}$, a linha de contorno é definida como indica a figura 2.8. Neste caso é recomendável medir o nível de ruído com o sistema de resfriamento desligado e depois ligado. Para tanques menores que 2,5 $\mathrm{m}$ de altura, a linha de contorno deve estar em um plano horizontal situado na altura média do tanque, para alturas maiores a 2,5 m, usam-se duas linhas de contornos que devem estar em planos horizontais situados a um terço e dois terços de altura do tanque. Na figura 2.8 a distância de $x$ é $0,3 m$ ou $2 m$ e a distância $D$ não deve exceder a $1 m$. 


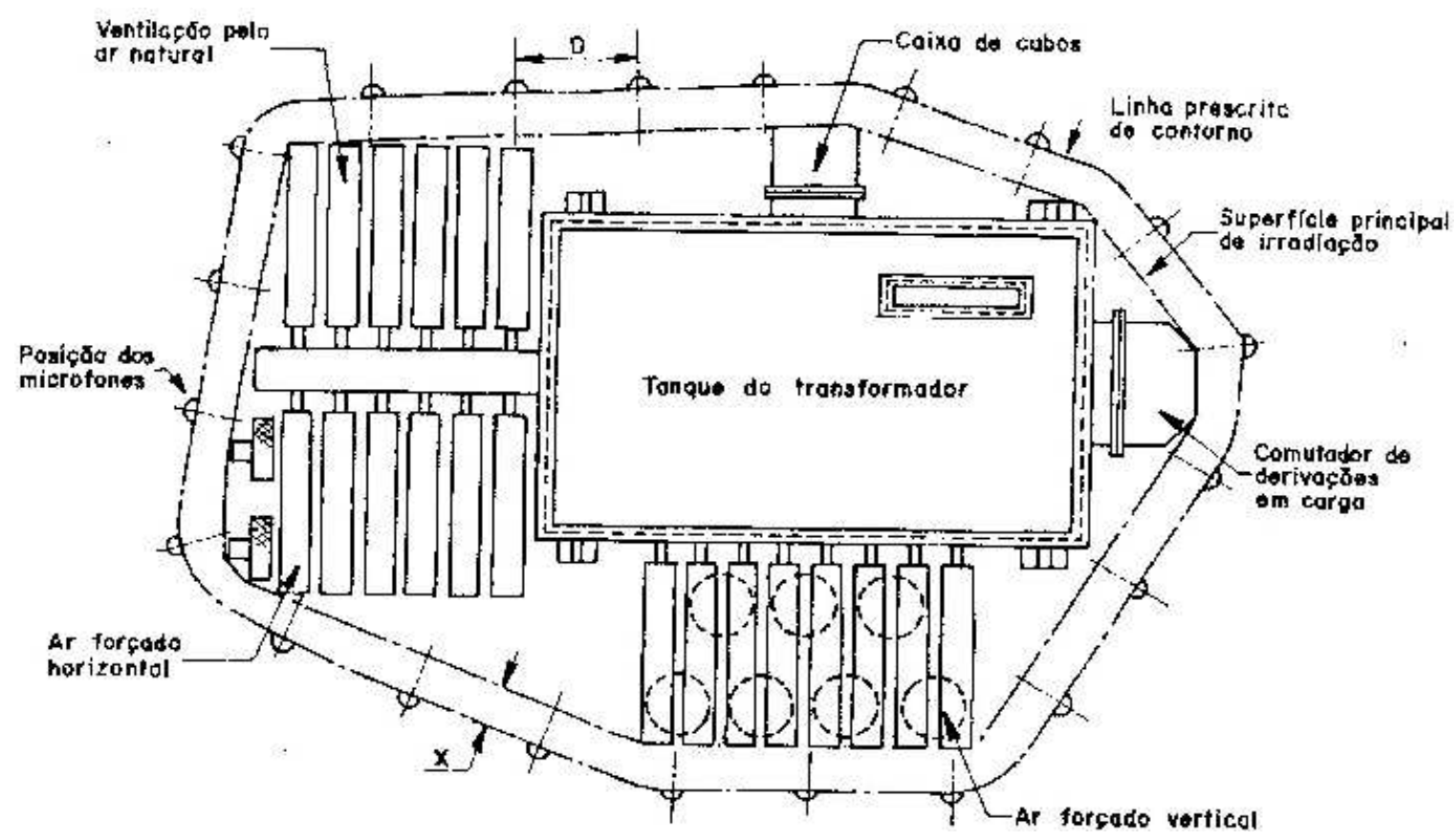

Figura 2.8: Posições típicas dos microfones para medição de ruído de transformadores com sistema de resfriamento montado no tanque ou separado na distância menor de $3 m$ da superfície de irradiação (Normas Técnicas ABNT - NBR 7277)

Caso o sistema de resfriamento estiver há uma distância de $3 \mathrm{~m}$ ou maior da superfície de irradiação do tanque, a linha de contorno deve estar afastada $2 m$ da superfície principal de irradiação. Para estruturas do equipamento de resfriamento com altura inferior a $4 \mathrm{~m}$, a linha de contorno deve estar em um plano horizontal situado na altura média do tanque, para alturas iguais ou superiores que $4 \mathrm{~m}$, usam-se duas linhas de contornos que devem estar em planos horizontais situados a um terço e dois terços de altura do tanque. As posições das medições, em número mínimo de dez, devem estar dispostas em intervalos iguais, não superior a $1 \mathrm{~m}$, como se ilustra na figura 2.9. Também a dimensão $D$ não deve exceder $1 \mathrm{~m}$. 


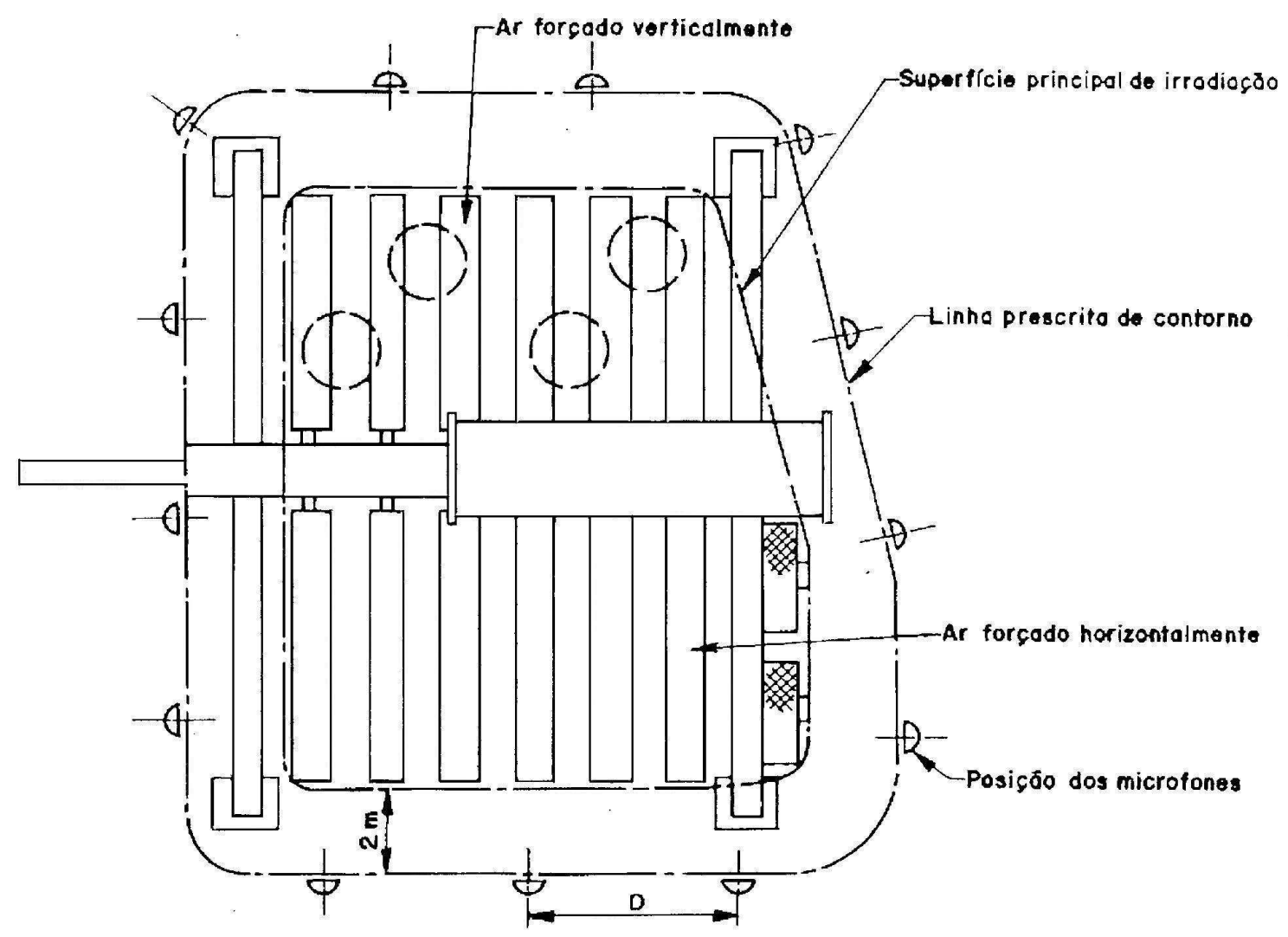

Figura 2.9: Posições típicas dos microfones para medição de ruído de transformadores com sistema de resfriamento montado no tanque ou separado por distância igual ou superior a $3 m$ da superfície de irradiação (Normas Técnicas ABNT - NBR 7277)

\subsubsection{Campo acústico de um transformador}

Exemplos de campo acústico de um transformador é fornecido por Rausch M. Kaltenbacher e Lerch (2001) e Rausch M. Kaltenbacher e Lerch (2002), que estima o campo acústico em duas planos usando o Método de Elementos Finitos do tanque de um transformador. Seus resultados são expostos na figura 2.10 para um plano vertical e na figura 2.11 para um plano horizontal.

Da Fig. 2.10 e da Fig.2.11 observa-se que quanto maior é a distância do tanque, menor a intensidade do ruído, também observa-se que na região superior ao tanque (tampa) a intensidade do ruído é muito maior que nas laterais do tanque (paredes do tanque), esta informação parece contradizer o mencionado por Ming (1999) e Usry et al. (1980) que argumentam que nos cálculos do campo acústico de um transformador desprezam-se, em geral, a radiação de som da tampa e da base do tanque por serem relativamente pequenas, comparadas com a radiação de ruído das paredes do tanque de um transformador. 


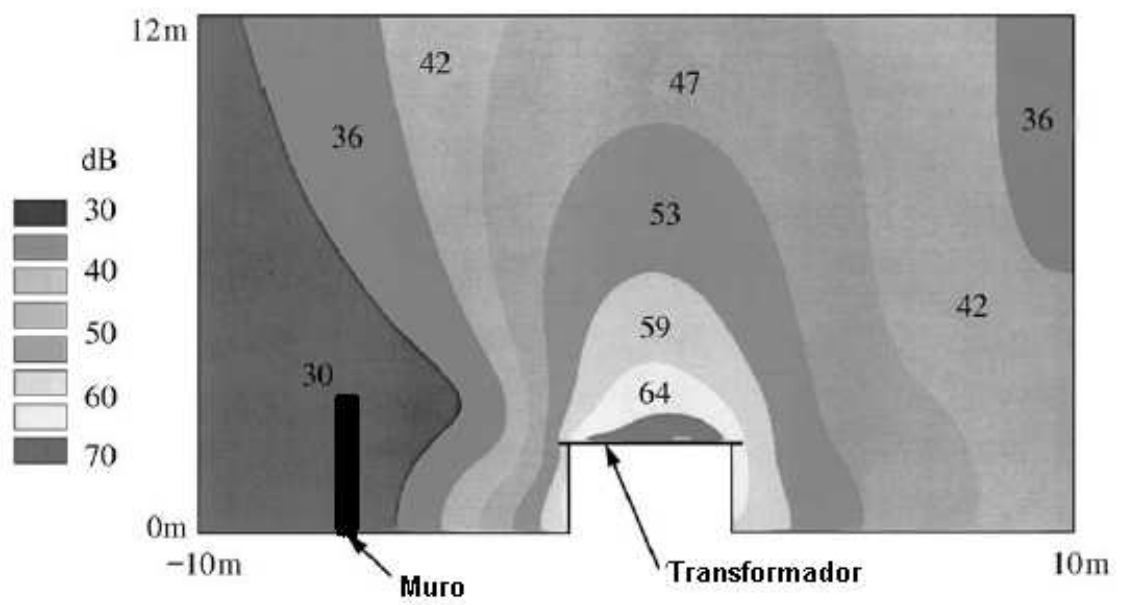

Figura 2.10: Simulação do campo acústico de um transformador no plano vertical - extraído de Rausch M. Kaltenbacher e Lerch (2002)

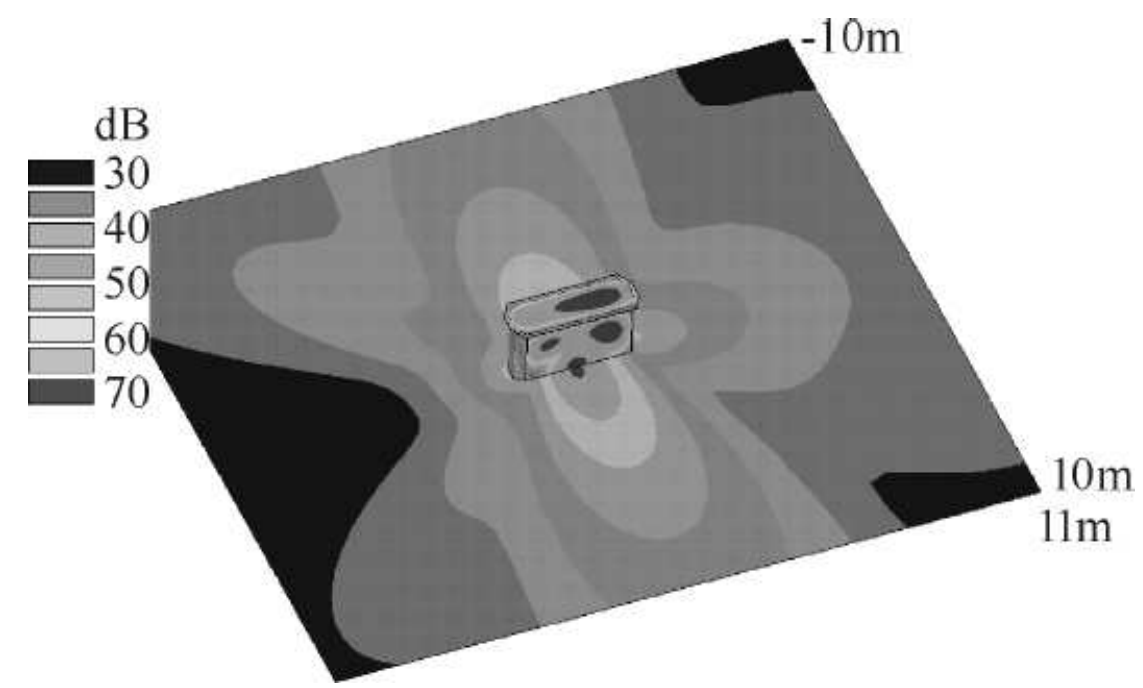

Figura 2.11: Simulação do campo acústico de um transformador no plano horizontal - extraído de Rausch M. Kaltenbacher e Lerch (2001)

O campo acústico dos transformadores de potência classifica-se em: campo acústico próximo e campo acústico distante. Os campos acústicos geralmente são construídos medindo-se os níveis de pressão ou a intensidade acústica.

Gorden (1979) explica que o método de níveis de pressão usa um microfone só para medir a pressão sonora ou valor Nema. O método de níveis de pressão têm duas técnicas: o de Ponto por Ponto que mede em pontos fixos a pressão sonora, a medição é feita em um grade de pontos localizados em um plano imaginário próximo ao transformador. Outra técnica, scan, consiste na medição realizada com o microfone deslocando-se lentamente entre um ponto a outro, colocando-se o valor médio das medições nos pontos do plano imaginário. 
O método de Intensidade Acústica usa dois microfones de pressão, separados em curta distância, a distância é menor que o comprimento da onda acústica de interesse. Calcula-se o gradiente da pressão acústica por aproximações de diferenças finitas e a velocidade da partícula corresponde ao ponto médio entre dois microfones. Champoux Y. Gosselin e Nicolas (1988) conjuntamente com Kendig e Wright (1991) descrevem que, usando apropriados modelos matemáticos, construiu-se o campo acústico próximo e distante. A técnica que utiliza a intensidade sonora é mais confiável na descrição do campo distante que as outras técnicas.

A medição do campo acústico pode ser realizada pelo método de Holografia Acústica de Campo-Próximo, Near Acústic Holography NAH, proposto por Williams e Maynard (1980). Este método consiste no registro da pressão sonora em uma superfície bi-dimensional, usando vários microfones simultaneamente uns próximos aos outros. Com estes dados pode-se calcular o campo de pressão tridimensional, o campo de velocidade das partículas, o campo de intensidade do vetor acústico, a velocidade da superfície e a fonte de radiação do som; sustenta Maynard J. D. Williams e Lee (1985). A medição é feita com vários microfones móveis e um microfone que coleta sinais em um ponto fixo, chamado de sinal de referência. Os sinais de pressão são tratados por métodos computacionais no domínio da freqüência com a Transformada Rápida de Fourier - FFT, considerando a fase. Depois de tratados os sinais recuperam-se com a Transformada Inversa de Fourier - IFFT, obtendo-se finalmente o sinal no tempo nas freqüências selecionadas; tendo cada sinal recuperada em uma freqüência só, em termos de: pressão, velocidade e o nível de energia por regiões.

O Método de holografia em campo próximo é eficiente para medições de som em superfícies planas, mas é limitada em superfícies não planas. Atualmente está em desenvolvimento outro método para medir qualquer forma de superfície como o GENAH (generalized nearfield acoustical holography) associado ao BEM (boundary element method). A medição pelo método de campo acústico próximo foi proposto por J. D. Maynard, E. G. Williams em 1980, demorou 20 anos para ser usado na indústria, sendo na atualidade a medição mais confiável.

A figura 2.12 mostra um diagrama de blocos da holografia acústica em campo próximo NAH, projetado por Williams (2004), onde esta exposta a seqüência do processamento de dados que conduzem à construção da imagem do campo acústico, o cálculo da intensidade sonora, pressão, velocidade e fonte de som. 


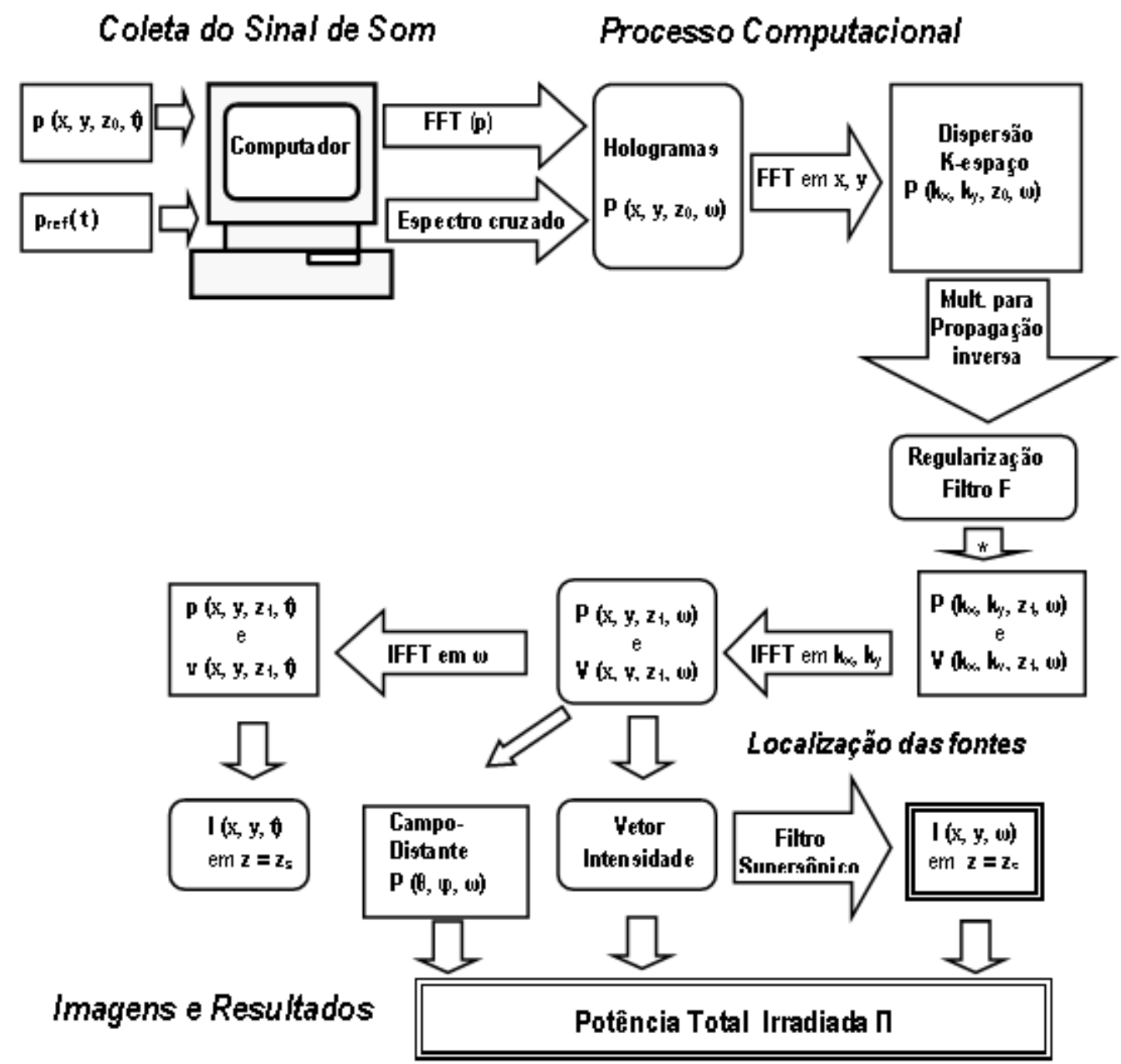

Figura 2.12: Diagrama de blocos do método de Holografia Acústica em Campo Próximo NAH que processa sinais de pressão sonora - extraido de Williams (2004).

O cálculo da velocidade e intensidade na forma vetorial é importante para a construção dos campos acústicos próximos e distante, assim como para a detecção das regiões de maior emissão de som. Com os modelos matemáticos compreendidos desde a eq. 2.12 até a eq. 2.20 calculam-se os valores parciais e totais.

Para a construção do campo acústico próximo ou distante calcula-se a pressão, velocidade e intensidade em um ponto do espaço, para avaliar o comportamento do som em outros pontos considera-se o aumento ou queda das amplitudes no espaço livre, experimentalmente conhecidos, deste modo consegue-se calcular os valores em outras distâncias. Com os valores calculados pode-se criar figuras em três dimensões ou duas dimensões com tonalidades que indiquem a intensidade da energia por regiões. 


\subsection{Som e Vibração}

O som e a vibração que se irradia das parede do tanque consiste em uma série de componentes tonais, no dobro da freqüência de linha elétrica e suas freqüências harmônicas. Podem-se desprezar as outras freqüências porque elas contém baixa intensidade, Ming (1999).

A relação entre ruído acústico e vibração das paredes do tanque pode ser estimada a partir do sinal de aceleração da superfície. Usry et al. (1980) argumenta que usando-se um modelo matemático é possível estimar o campo acústico distante.

Uma vantagem de calcular a radiação do som com as medidas de vibração decorre da não inclusão de fontes de som externas, obtendo-se o som que é irradiado pelas paredes do tanque do transformador. A redução do som irradiado pela estrutura passa pela diminuição da vibração estrutural.

Através da Análise Modal determinam-se os modos de vibrar da superfície do tanque que se sintonizam com as freqüências excitadas pelo transformador em operação, Jasinski R. Calomeno e Fillippin (2005). A Análise Modal é realizada com o transformador desligado, procurando-se os modos de vibrar da superfície do tanque.

O método de análise dinâmico com o transformador em operação é chamado de Operational Deflection Shape ODS. Este método mostra visualmente o padrão de movimento periódico de uma estrutura vibrando em uma freqüência específica resultante de uma condição de operação estacionária, Dossing (1988).

Os deslocamentos da superfície da estrutura $d$ do transformador podem ser calculados, por integração, a partir dos sinais de aceleração $a$. O sinal de velocidade $v$ é calculado pela eq. 2.21. O sinal de deslocamento $d$ é calculado pela eq. 2.22. Através da FFT obtém-se o deslocamento no domínio da freqüência. Para separar o deslocamento em uma freqüência específica, anulam-se as freqüências fora de uma faixa estreita que contém a freqüência de interesse, posteriormente recupera-se o sinal no domínio do tempo com a IFFT do sinal, obtendo-se o deslocamento da superfície na freqüência selecionada. Com os sinais de deslocamento no espaço pode-se descrever o deslocamento de uma superfície através de uma animação.

A integração do sinal de aceleração discreto é realizado por

$$
v(i)=\sum_{j=1}^{i} a(j)(j-1) \Delta t
$$


onde $\Delta t$ é o intervalo de amostragem do sinal de aceleração $a$.

A integração do sinal de velocidade discreto é realizado por

$$
d(i)=\sum_{j=1}^{i} v(j)(j-1) \Delta t
$$

onde $\Delta t$ é o intervalo de amostragem do sinal de velocidade $v$.

Entre o método de Holografia Acústica e o Método de ODS existem algumas semelhanças: ambos coletam dados sem perder a informação de fase em relação ao sinal de referência, ambos processam o sinal para obter informação em outros parâmetros, ambos isolam as respostas em uma faixa estreita de freqüência e recuperam o sinal no tempo de todos os pontos medidos, ambos mostram seus resultado através de imagens dinâmicas. O sinal processado se incorpora em um modelo geométrico do equipamento, no caso de ODS pode-se usar o método de elementos finitos. Ao sintonizar o modelo geométrico com os sinais pode-se observar o comportamento do equipamento ativado na freqüência selecionada.

Usando o método de Holografia Acústica e de ODS pode-se avaliar o comportamento do som ou a vibração em um equipamento. Ao considerar o espaço físico do equipamento e a intensidade ou amplitude dos parâmetros em função do tempo, consegue-se diagnosticar as regiões com maiores deslocamentos ou som. No caso de holografia acústica detectam-se as fontes de som no caso de ODS detectam-se as deformações da superfície. Pelo observado nesta pesquisa, nem sempre as regiões de maior emissão de energia de vibração coincidem com as fontes de som, algumas vezes a emissão de uma região é atenuada com as de outras regiões, devido à superposição de efeitos.

O diagrama de blocos do processamento pelo método de ODS é mostrado na figura 2.13, o diagrama tem alguma semelhança ao diagrama de blocos da figura 2.12 . 
Coleta do sinal de vibração

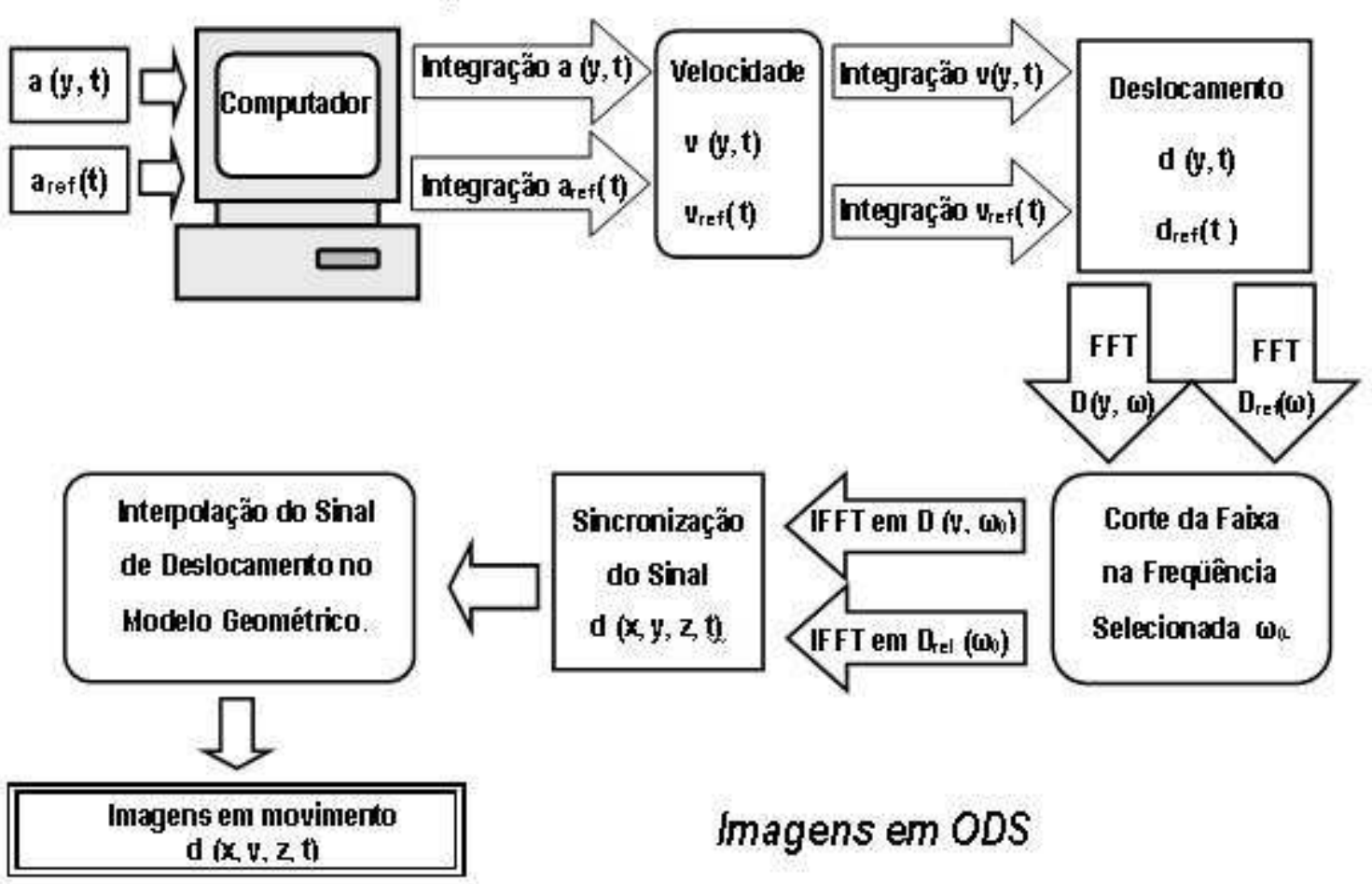

Processo computacional
Figura 2.13: Diagrama de blocos do método ODS que processa sinais de aceleração para avaliar o deslocamento da superfície do tanque - o diagrama é construído seguindo o exemplo da figura 2.12

Para calcular o ruído transmitido ao ar, usando as medições de vibração, Bies e Hansen $(1996)^{3}$ refere-se a um artigo de Takatsubo (1983) e explica que a potência sonora, irradiada pela superfície de uma máquina, pode ser calculada avaliando a energia da superfície usando a velocidade média ao quadrado.

A potência irradiada em uma superfície é:

$$
W=v_{m}^{2} S \rho c \sigma
$$

onde $S$ é o área da superfície, $v_{m}^{2}$ é a velocidade média ao quadrado e $\sigma$ é a medida da eficiência da radiação que é um número menor ou igual 1.

Para o cálculo da velocidade média ao quadrado $v_{m}^{2}$ usa-se:

$$
v_{m}^{2}=\frac{1}{n} \sum_{i=1}^{n} v_{i}^{2}
$$


Para avaliar o som pode-se usar o nível de velocidade $L_{v}$ definido como:

$$
L_{v}=10 \log _{10}\left(\frac{v_{m}^{2}}{v_{r e f}^{2}}\right)
$$

onde o valor da velocidade de referência é $v_{r e f}=10^{-9} \mathrm{~m} / \mathrm{s}(\mathrm{SI})$ e a unidade de $L_{v}$ é $d B\left(\right.$ re. $\left.v_{r e f}\right)$.

Quando uma placa plana vibra, força o ar a movimentar-se (depois de vencer a inércia desta). $\mathrm{O}$ ar impulsionado se desloca quase com a mesma velocidade da superfície da placa, transferindo energia cinética da placa ao ar. A avaliação do som produzido pela vibração da superfície da placa consiste em calcular a energia que é transmitida da placa ao ar.

Outros parâmetros usados na avaliação do som e a vibração é o nível de aceleração e o nível de deslocamento. O nível de aceleração é definido pela eq. 2.26.

$$
L_{a}=10 \log _{10}\left(\frac{a_{m}^{2}}{a_{r e f}^{2}}\right)
$$

onde o valor da aceleração de referência é $a_{r e f}=10^{-6} \mathrm{~m} / \mathrm{s}^{2}$ (SI) e a unidade de $L_{a}$ é $d B\left(\right.$ re. $\left.a_{r e f}\right)$. O nível de deslocamento é definido pela eq. 2.27.

$$
L_{d}=10 \log _{10}\left(\frac{d_{m}^{2}}{d_{r e f}^{2}}\right)
$$

onde o deslocamento de referência é $d_{r e f}=10^{1} \mathrm{~m}(\mathrm{SI})$ e a unidade de $L_{d}$ é $d B$ $\left(\right.$ re.d $\left.d_{r e f}\right)$.

Por outro lado, sabe-se que o deslocamento para o sistema massa mola é

$$
x=A e^{2 \pi f j}
$$

Ao derivar a eq. 2.28 temos a velocidade

$$
\dot{x}=2 \pi f A e^{2 \pi f j} j
$$

Derivando a velocidade temos a aceleração 


$$
\ddot{x}=-(2 \pi f)^{2} A e^{2 \pi f j}
$$

A relação entre aceleração, velocidade e deslocamento é

$$
\frac{\ddot{x_{2}}}{\ddot{x_{1}}}=\frac{\dot{x_{2}}}{\dot{x_{1}}}=\frac{x_{2}}{x_{1}}=\frac{A_{2}}{A_{1}}
$$

A relação entre aceleração, velocidade e deslocamento exposta na eq. 2.32 permite um cálculo de comparação de duas condições: a inicial e a final. Para avaliar a atenuação da vibração será usada esta relação. As proporções de aceleração, velocidade e deslocamento são iguais à razão das amplitudes do deslocamento em uma mesma freqüência. Esta relação é importante na avaliação das simulações, já que o método de elementos finitos calcula o deslocamento em freqüência específica de cada ponto do tanque(ODS), em duas condições, sem dispositivo para diminuir a vibração e com dispositivos instalados para diminuir a vibração.

Para calcular os níveis de velocidade relativo a uma condição inicial podem ser usadas as equações 2.24, 2.24 e 2.32, obtendo-se as variáveis em função da amplitude do deslocamento:

$$
\frac{v_{m 2}^{2}}{v_{m 1}^{2}}=\frac{\sum A_{m 2}^{2}}{\sum A_{m 1}^{2}}
$$

Então as modificações do nível de velocidade de som de uma condição a outra que se encontra próximo à superfície de uma placa vibrando pode ser calculado pela eq. 2.33 .

$$
L_{v}=10 \log _{10}\left(\frac{\sum A_{i 2}^{2}}{\sum A_{i 1}^{2}}\right)
$$




\section{METODOLOGIA DA INVESTIGAÇÃO}

Neste capítulo descrevem-se de forma sintética as etapas planejadas para a execução desta investigação. Detalhes de cada etapa são reportados no ítem 4, "Resultados". A metodologia deste trabalho tem as seguintes etapas:

- medir o ruído do transformador observando as freqüências em que se manifesta o som, utilizando inclusive holografia acústica;

- medir a aceleração na superfície do transformador procurando as regiões de maior vibração, utilizando inclusive a técnica ODS;

- estimar a intensidade sonora a partir dos sinais de aceleração e comparar com a intensidade sonora medida;

- determinar as características fundamentais de um absorvedor dinâmico para redução de ruído;

- projetar um absorvedor dinâmico através do método dos Elemento Finitos e simular seu desempenho;

- projetar dispositivos suporte para amortecedores viscosos que podem ser utilizados para reduzir a amplitude de vibrarão;

- construir absorvedores dinâmicos e dispositivos de fixação de amortecedores;

- medir o som e a vibração antes de montar os absorvedores dinâmicos e amortecedores;

- montar e testar, com o transformador em operação, realizando medições nas mesmas condições de operação que sem os dispositivos;

- avaliar os resultados obtidos com o uso dos dispositivos; 
- simular, com base nos dados de ODS, dados do transformador, dados dos absorvedores dinâmicos e dados dos amortecedores, a resposta do tanque em diversas configurações dos absorvedores dinâmicos;

- elaborar uma proposta de metodologia de projeto de dispositivos e sua alocação para redução de ruído irradiado por transformadores de potência.

\subsubsection{Medição do som do transformador}

A avaliação do som é realizada com medições do Nível de Pressão seguindo os métodos de ensaio da norma de ABNT - NBR 7277. Da observação dos tamanhos dos picos na freqüência determinam-se as freqüências mais importantes do ruído irradiado. Determinadas as freqüências de irradiação do ruído, analisa-se uma possível correspondência com a vibração nas superfícies do transformador.

\subsubsection{Medida da vibração do transformador}

Alguns cuidados são necessários durante a coleta de dados. A medição com carga e sem carga tem faixas de freqüências distintas. A este respeito Garcia B. Burgos e Alonso (2006) manifesta que a vibração produzida por um transformador sem carga elétrica é a vibração provocada pela magnetostricção que é caracterizada por freqüências harmônicas múltiplas de $120 \mathrm{~Hz}$. Quando há carga, adiciona-se a vibração da magnetização das bobinas, caracterizada pela freqüência de $120 \mathrm{~Hz}$. Na base do tanque a amplitude em $120 \mathrm{~Hz}$ é proporcional á carga ou à corrente ao quadrado.

Os sinais de vibração na superfície do tanque de um transformador de 30 $40 \mathrm{kV}$ serão coletados usando 8 acelerômetros, simultaneamente. A freqüência de amostragem será de $12,8 \mathrm{kHz}$. Serão coletados sinais de 138 pontos no tanque, 19 nos suportes do tanque (carrinhos) e 175 nos demais componentes do transformador, totalizando 332 pontos coletados.

Para interpretar o comportamento das ondas de deslocamento na superfície da estrutura, será desenvolvido um modelo geométrico do transformador. A técnica de ODS permite montar uma animação que representa os deslocamentos de alguns pontos em função do tempo e determinar as regiões de maiores e menores deslocamentos. 


\subsubsection{Avaliação do ruído produzido pelo tanque usando os sinais de aceleração}

Para a alocação dos Absorvedores Dinâmicos no tanque do transformador, é necessário conhecer as regiões de maior emissão de ruído e as regiões de maior deslocamento. Dados de ODS devem ser processados para determinar estas regiões.

Para avaliar os níveis de pressão por faixa e global do som, o sinal será dividido em faixas de terças de oitava e será calculada a média de PSD da velocidade. Neste caso, o resultado gera o nível de energia em velocidade por faixas.

Outra análise consiste em associar vetores de deslocamento a uma malha que representa uma face do tanque. Para visualizar o deslocamento de uma face desenvolve-se um gráfico de deslocamento para cada instante de um ciclo de $120 \mathrm{~Hz}$, gerando uma animação do deslocamento. Um gráfico colorido de deslocamentos máximos deve ser elaborado para identificar as regiões de máximo deslocamento.

\subsubsection{Determinação das regiões de maior ruído irradiado}

Nesta etapa procuram-se as regiões de maior amplitude de vibração e as regiões de maior ruído irradiado, pois são regiões onde pode ser eficiente alocar absorvedores dinâmicos. É de fundamental importância caracterizar as freqüências de maior intensidade, uma vez que os absorvedores dinâmicos tem eficácia numa faixa estreita de freqüência.

Para avaliar as zonas que emitem maior ruído e possíveis fontes adicionais de ruído serão realizadas medições de holografia acústica, que indica a intensidade de ruído em pequenas regiões. A freqüência de amostragem dos sinais será de 25,6 $k H z$, tendo uma faixa útil de $3,4 k H z$, serão utilizados 12 microfones, colocados em 445 posições em cada face. A coleta de dados será feita a $0.01 \mathrm{~m}$ de distância da superfície do tanque, a separação entre microfones será de $0.02 \mathrm{~m}$, tendo sempre um microfone fixo em um extremo do tanque, este microfone proverá referência de fase para todos os outros sinais. 


\subsubsection{Determinação das características fundamentais de um absorvedor dinâmico}

Para diminuir a vibração e o ruído propõe-se instalar absorvedores dinâmicos, que, sintonizados numa freqüência de excitação do transformador, absorvam parte da energia de vibração de forma que se acopla fracamente com o ar. Numa primeira análise deve-se utilizar um modelo bastante simples com dois graus de liberdade, duas massas e duas molas para determinar características fundamentais do absorvedor dinâmico. A massa que representa uma região de uma parede do tanque será determinada aproximadamente através de um modelo de elementos finitos do tanque.

Posteriormente, o absorvedor dinâmico deve ser testado, por simulação numérica, em um modelo de elementos finitos que represente uma parede do tanque e um carregamento senoidal.

\subsubsection{Ensaios experimentais do absorvedor dinâmico}

Um protótipo físico de um absorvedor dinâmico deverá ser fixado ao centro de uma face do tanque e a aceleração desta região deverá ser coletada antes e depois da colocação do absorvedor para que seja avaliada a capacidade de redução da amplitude de deslocamento. Este ensaio deve verificar se a massa e a freqüência natural do absorvedor dinâmico estão adequadas.

\subsubsection{Simulação da vibração do Tanque usando o MEF}

Com o objetivo de determinar a quantidade e a localização dos absorvedores dinâmicos deve ser desenvolvido um modelo do tanque usando o Método dos Elementos Finitos (MEF). O carregamento deste modelo será baseado nas medidas de aceleração obtidas no ensaio de ODS.

Com estas simulações podem-se avaliar os ADs, modificando o peso, a posição dos absorvedores no tanque e a quantidade necessária para reduzir o ruído a níveis em conformidade com a legislação.

\subsubsection{Ensaio experimental de absorvedores e amortecedo- res em condições operacionais}

Uma verificação experimental da solução proposta deve ser realizada no transformador localizado na subestação de Bela Aliança, no transformador mais próximo 
dos edifícios. Devem ser realizadas medições de pressão sonora e de aceleração:

1. antes da implementação dos dispositivos;

2. após a instalação dos amortecedores;

3. após a instalação dos absorvedores dinâmicos;

4. considerando apenas os absorvedores dinâmicos.

Se os resultados obtidos experimentalmente e as simulações resulatarem próximos pode-se propor uma metodologia de projeto. Caso os resultados divergirem das simulações, faz-se necessário melhorar modelos e condições de contorno.

Resume-se a metodologia de investigação implementada neste trabalho com a figura 3.1 onde se mostra a seqüência da pesquisa em um diagrama de blocos. 


\section{Diagrama da Metodologia da Investigação}

\section{Diagnostico}

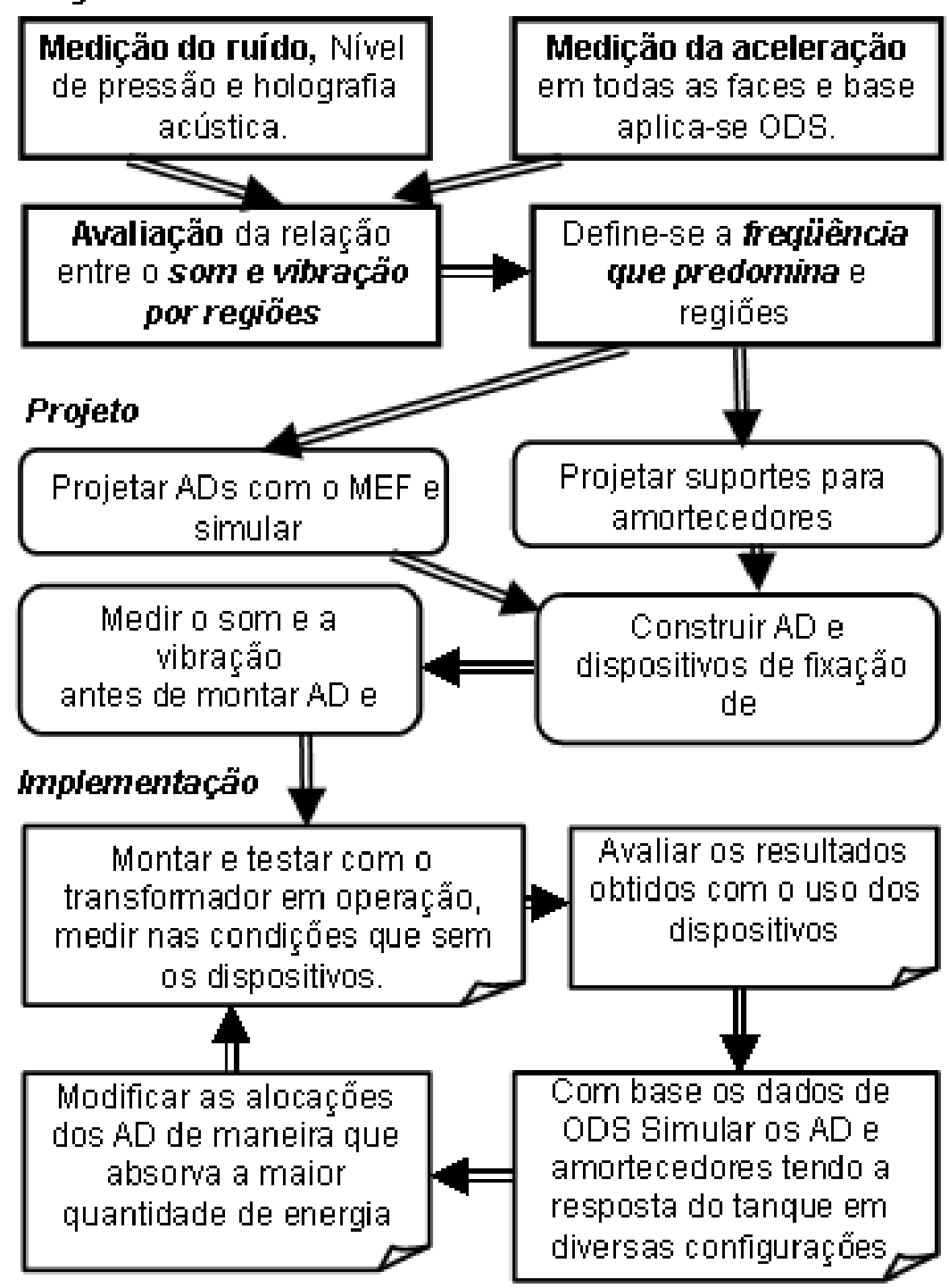

Figura 3.1: Diagrama de blocos da metodologia da investigação 


\section{RESULTADOS}

\subsection{Medição do ruído irradiado pelo transforma- dor}

A avaliação do ruído é realizada em níveis de pressão seguindo os métodos de ensaio da norma de ABNT - NBR 7277. As medições de níveis de pressão do ruído de um transformador de potência, instalado no AES de Bela aliança, foram realizadas pela empresa $01 \mathrm{~dB}$. Os sinais foram coletados na face oposta ao comutador do transformador e é mostrado na figura 4.1. Os resultados mostram que o maior nível de pressão está na freqüência $120 \mathrm{~Hz}$, e suas harmônicas de 240 $\mathrm{Hz}, 360 \mathrm{~Hz}, 480 \mathrm{~Hz}$ e $600 \mathrm{~Hz}$ tem menor amplitude. As medidas de nível de pressão foram realizadas a $0.3 \mathrm{~m}$ do transformador e em diversos outros pontos.

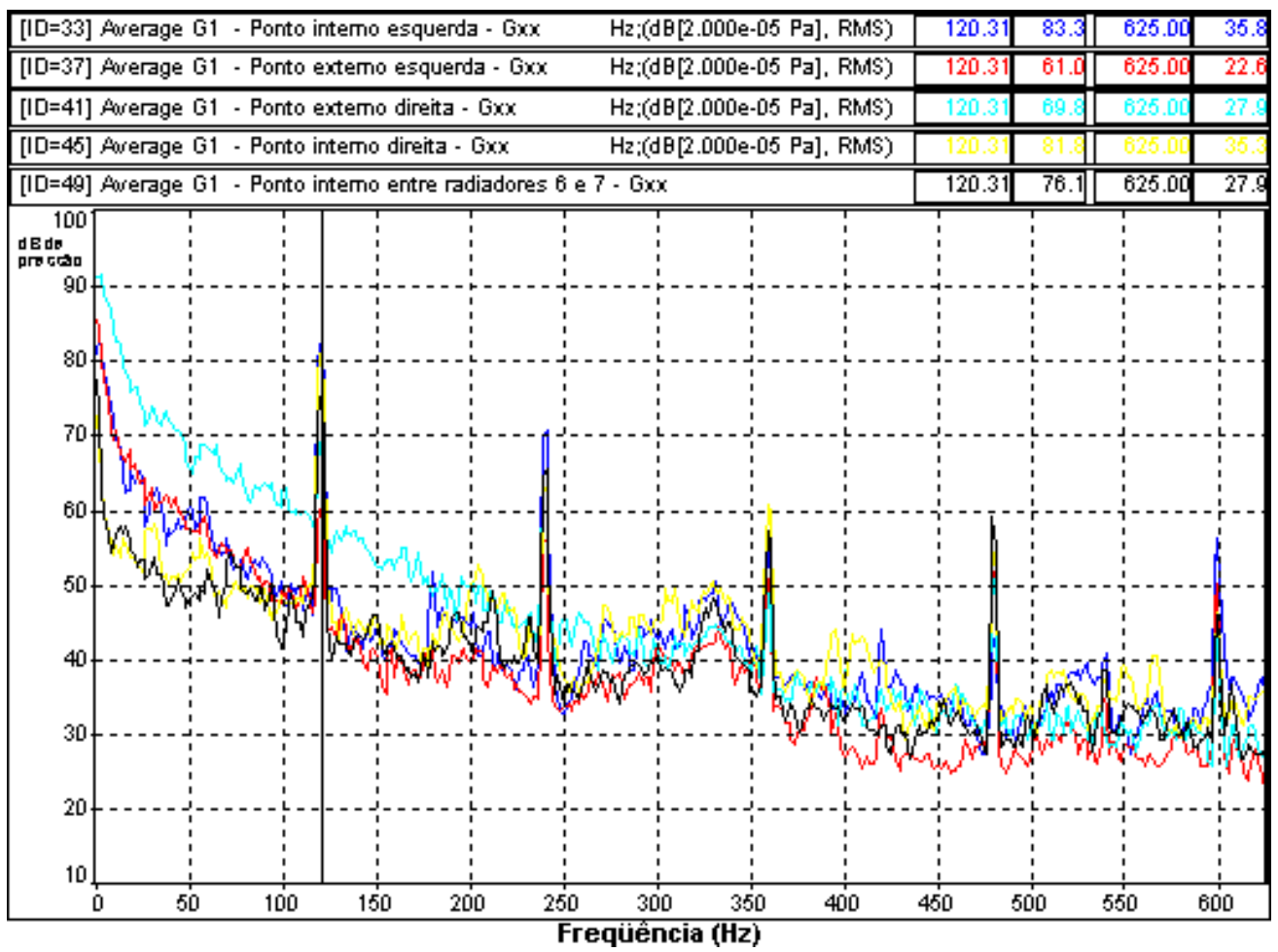

Figura 4.1: Espectro de níveis de pressão do ruído emitido pelo transformador. 
Os transformadores que estão em operação não operam com carga elétrica constante, a carga é modificada segundo a demanda. O ruído é afetado pela carga elétrica e pelo ruído externo, mas na freqüência de $120 \mathrm{~Hz}$ o ruído corresponde essencialmente ao irradiado pelo transformador.

O monitoramento do ruído de um transformador de 500 MVA de uma Empresa Elétrica é mostrado na figura 4.2. Nela observa-se que o pico da amplitude em $120 \mathrm{~Hz}$ do nível de pressão sonora assume diferentes valores conforme o horário. As medidas foram registradas cada 3 horas a partir da zero hora, de segunda a sexta, com data de 13 a 17 de Novembro. O dia 15 de novembro foi feriado, e os registros mostram diferenças relevantes. Nos dias úteis a demanda muda segundo o horário, por isso, as amplitudes são diferentes, sendo menor pela manha e maior pela tarde e mantendo-se a tendência do comportamento entre um dia e outro. Dos dados da figura pode-se observar que é possível o uso da média como fonte de informação considerando o intervalo de erro segundo o horário. Por exemplo, às 24:00 horas a faixa de erro é $2 d B$ e às 18:00 horas o intervalo de erro é de 4,5 $d B$.

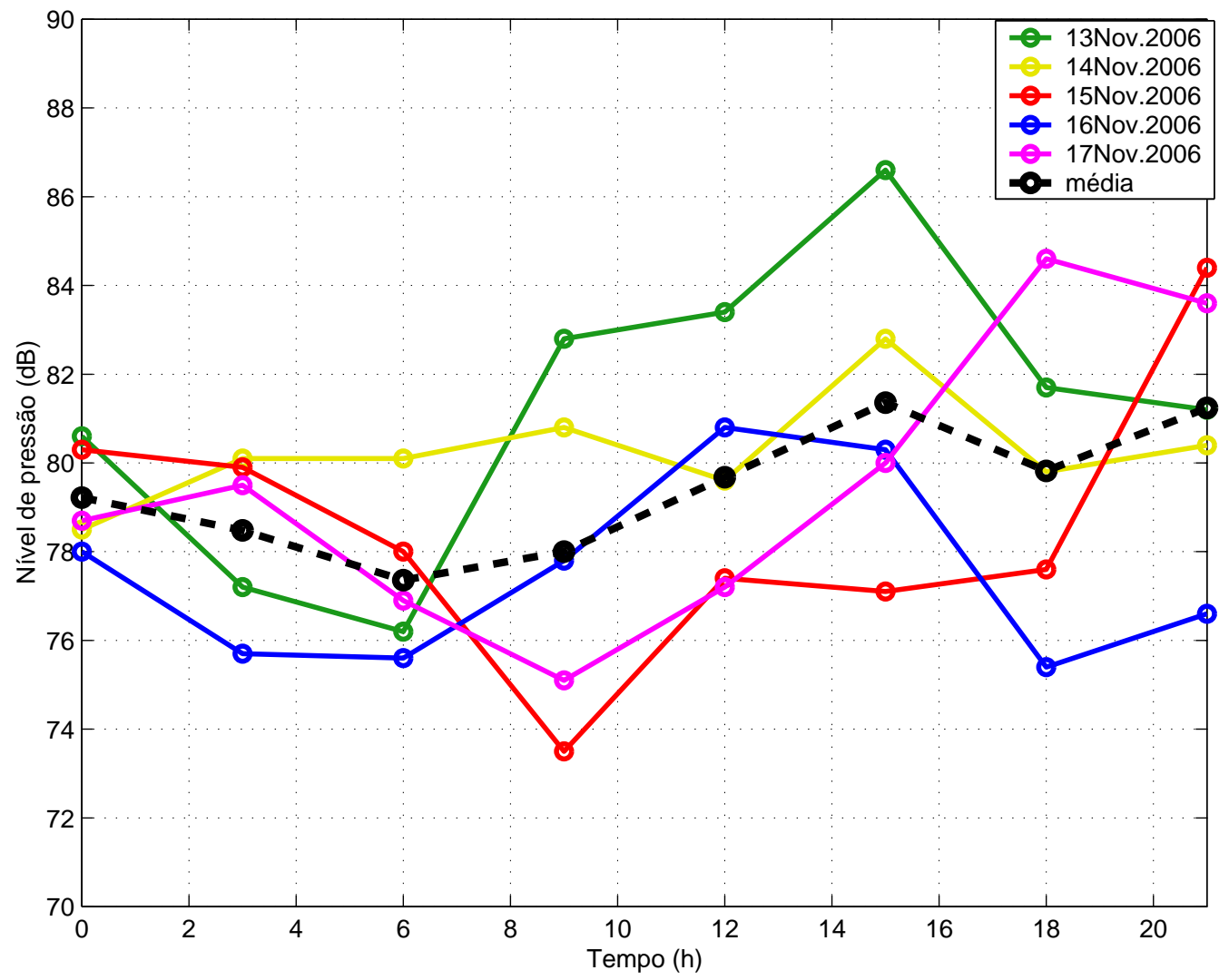

Figura 4.2: Níveis de pressão sonora de 5 dias de medição, e os valores médios 


\subsubsection{Localização de regiões que mais emitem ruído}

Para avaliar as regiões que emitem maior ruído realizaram-se as medições de holografia acústica, que indicam a intensidade de ruído em pequenas regiões. A freqüência de amostragem dos sinais foi de 25,6 kSps, tendo uma faixa útil de 3,4 kHz . Usaram-se 12 microfones e 445 posições de medição em cada face. A coleta foi feita a $0.01 \mathrm{~m}$ de distância da superfície do tanque, a separação entre microfones foi de $0.02 \mathrm{~m}$. Permaneceu um microfone fixo em um extremo do tanque. A face de medição do som foi a face do comutador, por estar frente aos edifícios e não ter obstáculos diante dele que reflete as ondas de som (ao espaço livre). A figura 4.3 mostra um dos resultados da análise de holografia acústica. Trata-se das medições feitas em torno do comutador. No lado direito da figura está uma foto do transformador. O retângulo em vermelho indica a região analisada. No anexo A encontram-se os demais resultados da holografia acústica.

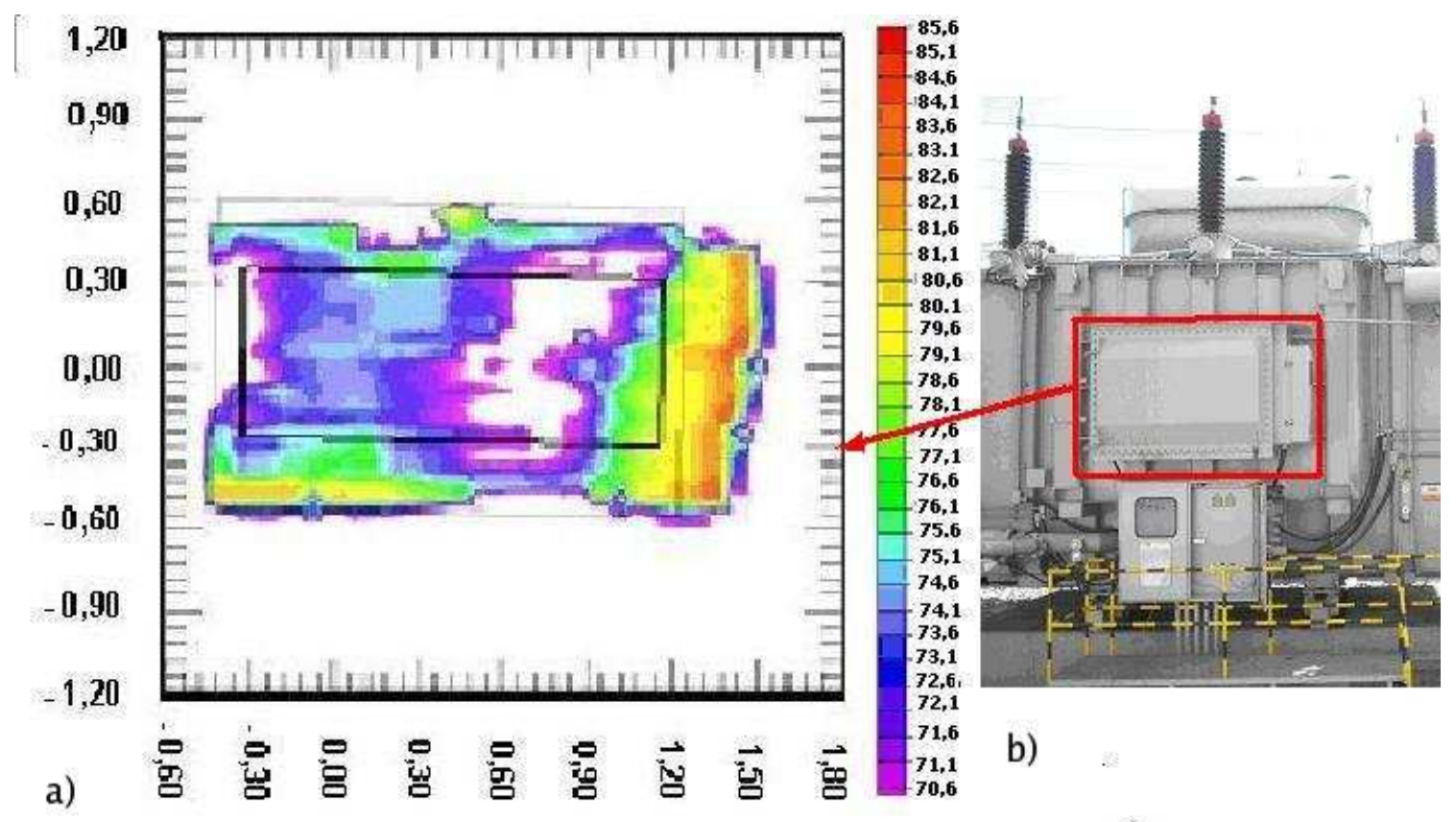

Figura 4.3: Resultados da medição holográfica em uma face do transformador

a) imagem mostrando as intensidades de som b) foto indicando-se a região testada

Os resultados da análise de holografia acústica indicam que a zona de maior emissão está em algumas regiões das paredes do tanque, as maiores atingem próximos a $86 \mathrm{~dB}$ (re. $\left.I_{\text {ref }}\right)$ na freqüência de $120 \mathrm{~Hz}$, como pode ser observado na figura 4.3-a na região vermelha, que está localizada no lado direito da caixa 
do comutador.

\subsection{Medidas da vibração do transformador}

Para avaliar a intensidade da vibração em um transformador de 30 - 40 KVA foram coletados sinais de aceleração na superfície do tanque. Coletaram-se 110 sinais de aceleração nas paredes do tanque, 28 na base e 19 nos suportes móveis (carrinhos) além de 175 nos demais componentes do transformador, totalizando 332 pontos de medição. A freqüência de amostragem foi de 12,8 ksps, usando-se 8 acelerômetros, simultaneamente. A figura 4.4 mostra os resultados da medição da vibração. Observa-se que a principal freqüência é de $120 \mathrm{~Hz}$. Os sinais de correlação cruzada com o sinal de referência tem um pico de 10 até 100 vezes maior que os outros picos.

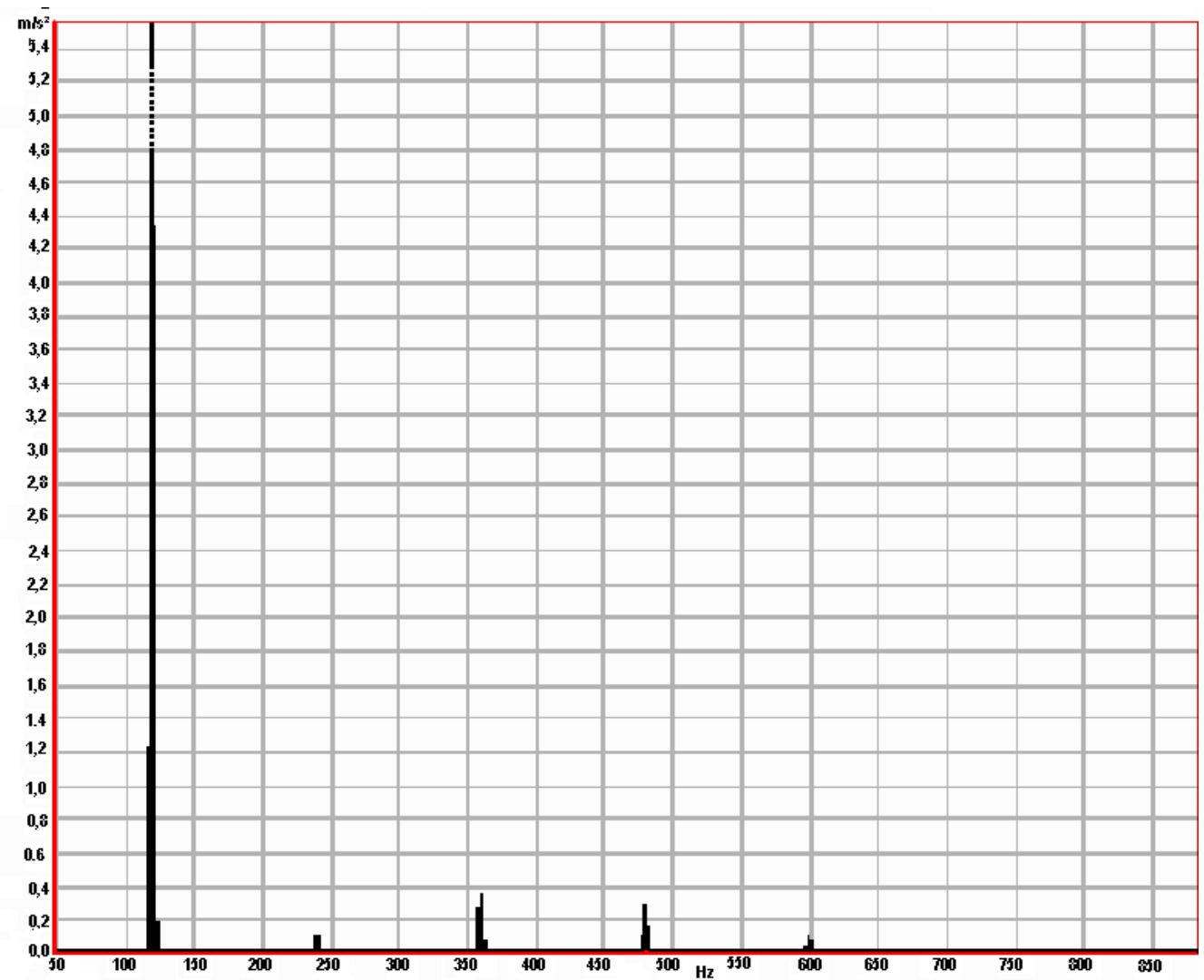

Figura 4.4: Correlação cruzada de todos os espectros de freqüência coletadas do tanque do transformador

Com o objetivo de interpretar o comportamento das ondas de deslocamento, que atravessam a superfície da estrutura, criou-se um modelo geométrico do transformador, posteriormente analisou-se o deslocamento dos pontos em função do tempo. A figura 4.5 mostra o modelo geométrico do tanque em três vistas e um 
desenho em perspectiva. Observam-se os painéis de resfriamento ao redor do tanque. A técnica ODS analisa os deslocamentos dos pontos em função do tempo e compara o deslocamento de um ponto em relação aos outros pontos, informando a posição de cada ponto, deste modo caracteriza-se as ondas que atravessam a superfície e as regiões de maiores e menores deslocamentos.

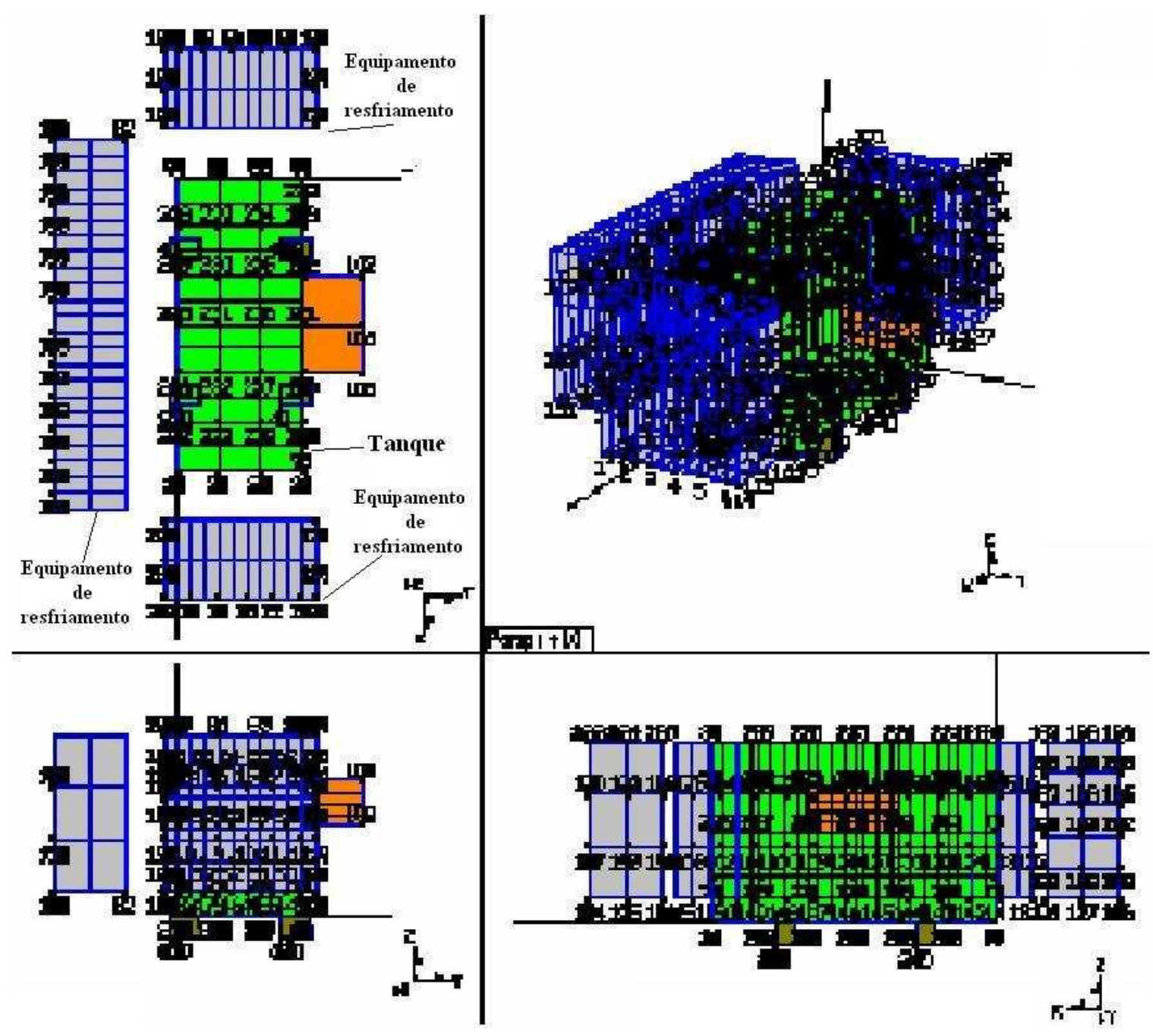

Figura 4.5: Modelo geométrico do transformador para análise de ODS.

Determinada a freqüência principal da vibração (120 Hz segundo a fig. 4.4), os sinais de aceleração são processados para obter deslocamento em cada ponto, em freqüências selecionadas. A empresa $01 \mathrm{~dB}$ usa um software que processa os sinais e desenvolve modelos geométricos onde são incorporados os sinais de deslocamento nos respectivos pontos. Os resultados de ODS geralmente são mostrados em animações. Um instante do deslocamento é mostrado na figura 4.6, nela observa-se o deslocamento de algumas regiões. 


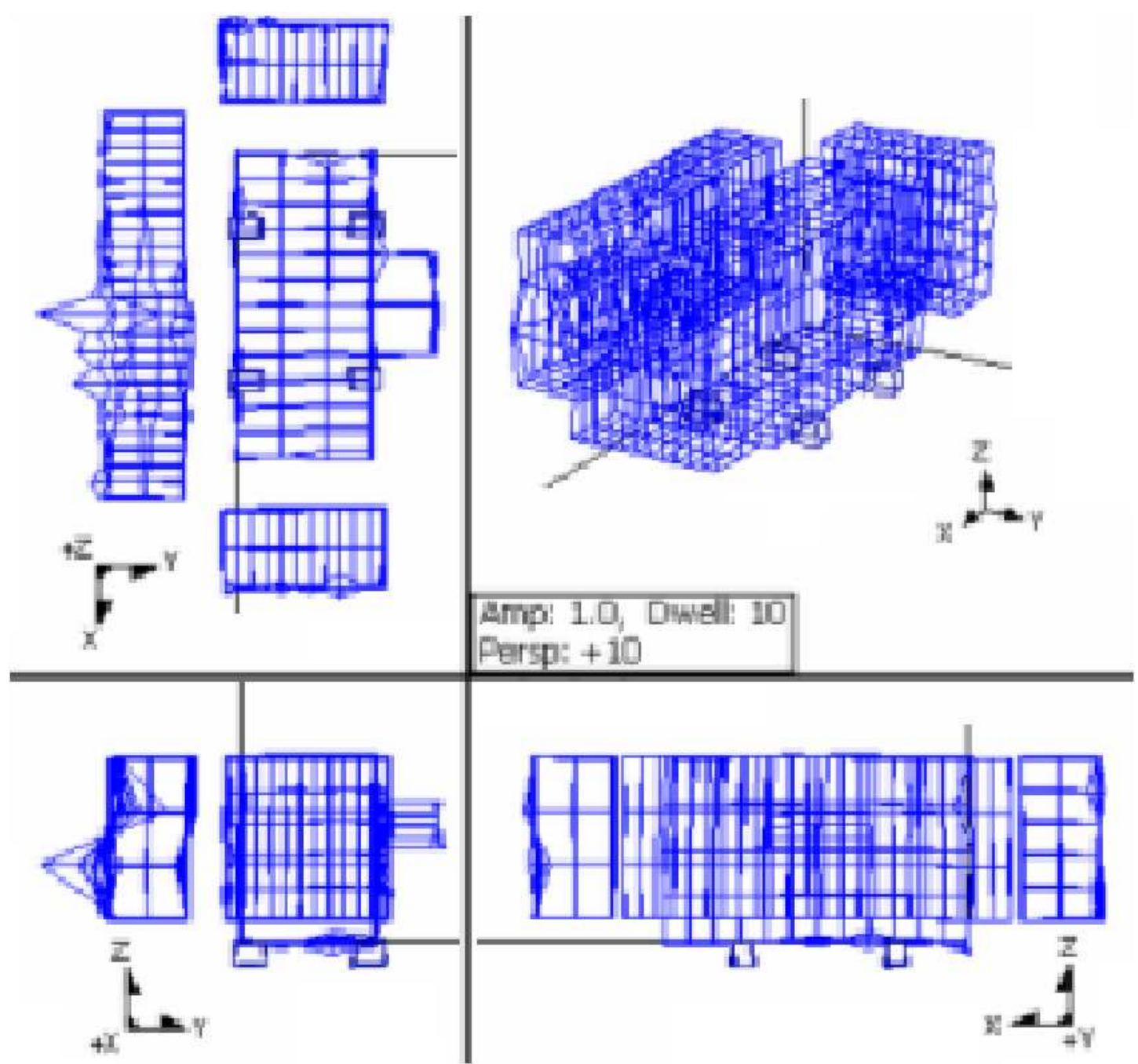

Figura 4.6: Modelo geométrico do transformador para análise ODS de deslocamentos do tanque e dos radiadores

\subsubsection{Avaliação dos resultados da vibração}

De acordo com os resultados, o maior deslocamento foi detectado nos radiadores, que estão composto por placas com espessuras de $2 \mathrm{~mm}$. Entretanto, esta não é a região de maior emissão de ruído pois apresentou $60 \mathrm{~dB}$ (I.p ref) em $120 \mathrm{~Hz}$. A superfície do painel do radiador não acopla com o ar como acontece com as superfícies do tanque. As paredes do tanque têm placas com espessura de 10 $m m$ que se deslocam menos, mas o nível de pressão do ruído em algumas regiões esteve próximo a $90 \mathrm{~dB}\left(\right.$ re. $\left.I_{\text {ref }}\right)$ em $120 \mathrm{~Hz}$. Isto sugere que as paredes do transformador são mais eficientes para produzir ruído em $120 \mathrm{~Hz}$.

Os deslocamentos produzidos no tanque, gerados na freqüência de $120 \mathrm{~Hz}$, são mostrados na figura 4.7. Nela está o modelo geométrico do tanque indicando-se os pontos de medida. Nos pontos de medida foram coletados os sinais de acele- 
ração. A imagem animada dos deslocamentos da superfície do transformador foi desenvolvida com um software de ODS da empresa $01 \mathrm{~dB}$. Nas faces observaramse pontos com movimento em fase ou em contra-fase em relação ao movimento da base do transformador, também foram observadas regiões da superfície onde o deslocamento é pequeno, localizando possíveis nós da onda que se forma na superfície. O movimento sugere que as ondas das paredes do tanque são formados pelo deslocamento da base que transmite as vibrações do núcleo. Estas observações serão utilizadas na etapa da simulação numérica do tanque.

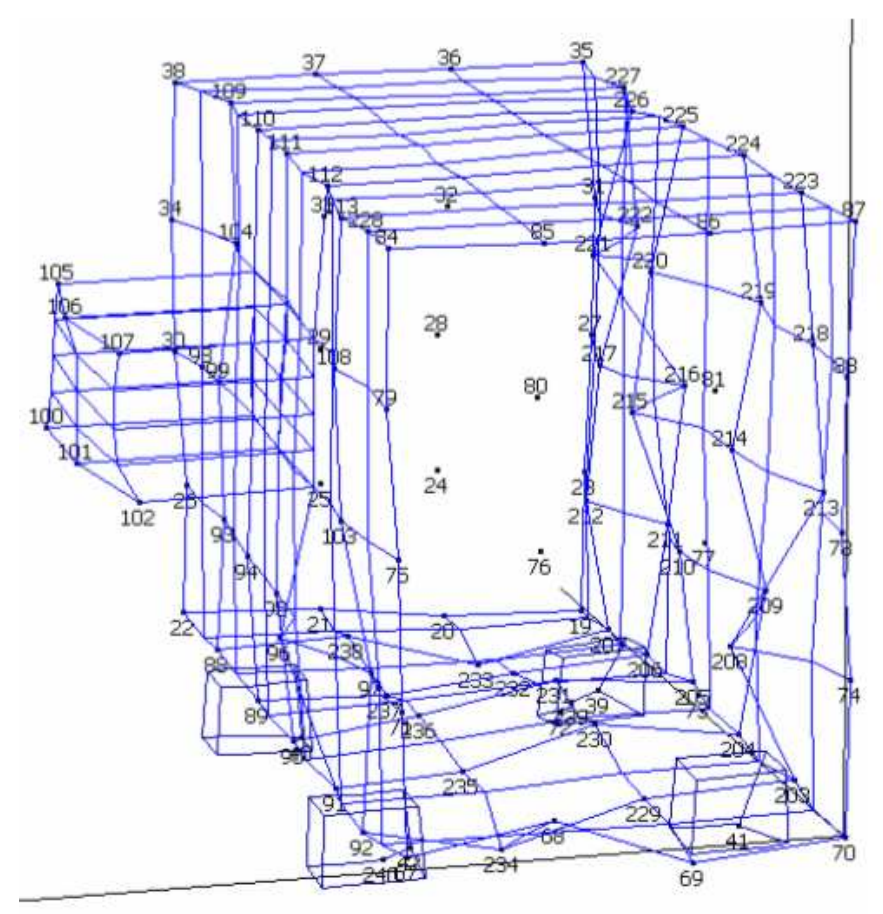

Figura 4.7: Deslocamento da superfície do tanque detectado pelo método de ODS

\subsubsection{Localização das regiões de maior vibração}

Para determinar a localização dos absorvedores dinâmicos no tanque é necessário conhecer as regiões de maior emissão de ruído e as regiões de maior deslocamento. Os sinais de aceleração fornecidos pela empresa $01 \mathrm{~dB}$ foram tratados para determinar as regiões de maior deslocamentos.

A apresentação dos sinais é por face do tanque do transformador. Os nomes adotados para cada face são: a face frente à rua é a face que encontra-se mais próxima à rua, a face oposta é a face paralela à face frente à rua, a face frente aos edifícios é a face onde esta instalado o comutador, a face atrás dos edifícios é a face paralela à face frente aos edifícios e a base é a placa base que forma o fundo 
do tanque.

Para avaliar os níveis de energia de vibração, o sinal é dividido em bandas de terça de oitava e calcula-se a média de PSD da velocidade, obtendo-se o nível de energia de vibração por faixas. As faixas usadas de terça de oitava são mostradas na tabela 4.1 .

Tabela 4.1: Faixa da terça de oitava

\begin{tabular}{|l|l|l|l|l|l|l|l|l|l|l|}
\hline Faixa & 1 & 2 & 3 & 4 & 5 & 6 & 7 & 8 & 9 & 10 \\
\hline Inicial & 0 & 14,2 & 22,5 & 28,3 & 35,6 & 40,1 & 44,8 & 56,3 & 70,9 & 89,2 \\
\hline Final & 14,1 & 22,4 & 28,2 & 35,5 & 40,0 & 44,7 & 56,2 & 70,8 & 89,1 & 112,0 \\
\hline \hline Faixa & 11 & 12 & 13 & 14 & 15 & 16 & 17 & 18 & 19 & 20 \\
\hline Inicial & 112,1 & 141,1 & 178,1 & 224,1 & 282,1 & 355,1 & 447,1 & 562,1 & 708,1 & 891,1 \\
\hline Final & 141,0 & 178,0 & 224,0 & 282,0 & 355,0 & 447,0 & 562,0 & 708,0 & 891,0 & 1120,0 \\
\hline
\end{tabular}

A análise de holografia acústica, realizada pela empresa $01 \mathrm{~dB}$, foi da face frente aos edifícios. Não foi possível realizar medições de som das paredes e da base do tanque, por não ser superfícies livres. No caso das paredes o equipamento de resfriamento encontra-se a $0,55 \mathrm{~m}$ ao frente do tanque e na base, o chão está a 0,475 $\mathrm{m}$; em ambos casos as ondas de som irradiadas pelas superfície do tanque, são refletidas por os corpos próximos a eles. A medição do som e vibração da tampa do tanque é proibido para evitar riscos e acidentes, as normas de segurança impedem o acesso nela com o transformador ligado.

A avaliação das fontes de som, onde não seja possível medir pelo método de holografia acústica, depende das manifestações da vibração na superfície do tanque. As imagens de ODS realizado pela empresa $01 \mathrm{~dB}$ mostraram as deformações do tanque. Esta informação não se relaciona diretamente com o som. Para definir a alocação dos absorvedores dinâmicos faz-se necessário conhecer os pontos de maior deslocamento.

Como foi explicado no ítem 2.5 "Som e Vibração" o deslocamento da superfície do tanque força o ar a movimentar-se. Isto relaciona a velocidade da superfície do tanque com a velocidade do ar. Para avaliar a energia de vibração que se converte em som, usam-se as equações $2.23,2.24$ e 2.25 .

Os sinais de aceleração foram integrados usando-se a eq. 2.21 e obteve-se a velocidade. Para processar o sinal de velocidade ao quadrado pode usar-se o método processamento de sinal de Welch que trata um sinal multiplicado por ele mesmo. A vantagem de usar o método de Welch jaz na filtragem do sinal que ocorre ao dividir o sinal original em vários segmentos, calculando-se a média 
do sinal original. O sinal ao quadrado da velocidade é chamado de densidade espectral de potência (PSD) da velocidade.

Com a eq 2.25 e a eq. 2.32 avaliam-se o nível de velocidade de vibração e sua relação com o som em um ponto. A localização das regiões com maiores deslocamentos será realizada nas faces e na base do tanque.

Como já foi observado na freqüência de $120 \mathrm{~Hz}$ estão os maiores picos. A análise de ODS é realizada nesta freqüência. Filtra-se o sinal de aceleração e integra-se vetorialmente com a eq. 2.21. O resultado é a velocidade e com uma segunda integração, conforme a eq. 2.21, obtém-se o deslocamento. Seleciona-se uma faixa estreita a ser usada, neste caso em $120 \mathrm{~Hz}$, impondo-se o valor zero nas demais freqüências. Com a inversa da Transformada de Fourier obtém-se o sinal no tempo e filtrado em torno de $120 \mathrm{~Hz}$.

Os sinais foram coletados por oito acelerômetros de cada vez, um dos acelerômetros foi fixado em uma posição e mantido sempre no mesmo ponto, este sinal é chamado de sinal de referência. Para ter uma relação entre fase e amplitude de todos os sinais, consideram-se todos os demais sinais, a partir de um instante em que o sinal de referência está com deslocamento zero e um pouco depois, inicia um deslocamento positivo.

\subsubsection{Análise da face de frente para a rua}

Frequentemente o análise da vibração é realizado usando os espectros de freqüência dos sinais, desconsiderando-se os sinais no tempo, este trabalho considera ambas, mas também os incorpora ao espaço físico onde foram coletados. A figura 4.8 mostra o desenho da face frente à rua e os pontos onde foram coletados os sinais. Estes pontos são definidos pelas intersecções das linhas tracejadas.

Na figura 4.9 mostra-se a PSD da velocidade. As cores indicam a altura em relação ao ponto de referência (LH). Ao observar nota-se que os espectros com maiores intensidade estão na freqüência de $120 \mathrm{~Hz}$. A maior amplitude de todas é um sinal de cor preta, que se encontra no segundo grupo de cores, a 2 metros da base e a 1 metro da aresta esquerda. Também mostra a intensidade do segundo harmônico, quase com a mesma intensidade, raias vermelhas, que são os segundos em ordem de intensidade. A intensidade da PSD da velocidade dos pontos próximos das arestas são pequenos, mostrando pouca vibração. 


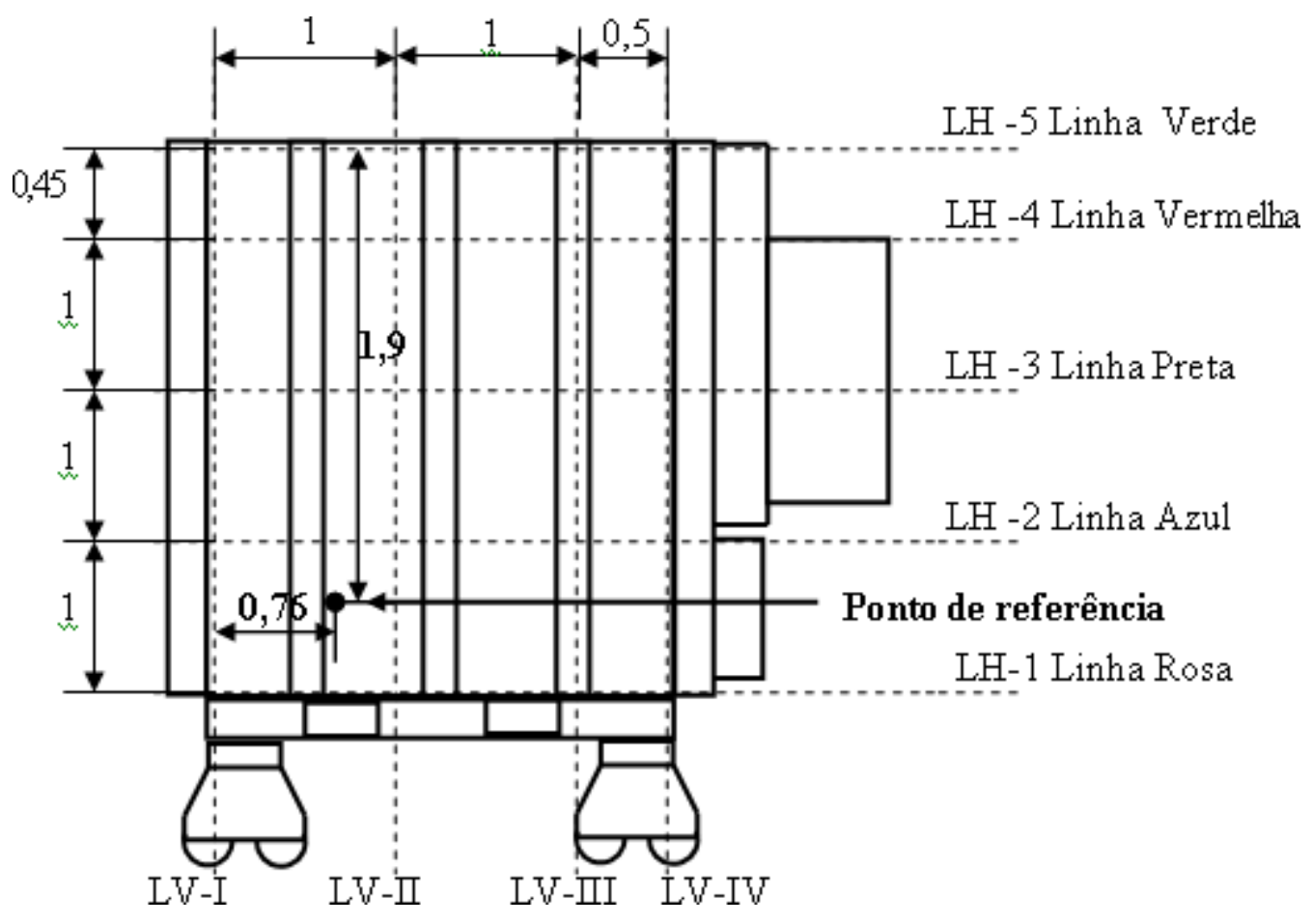

Figura 4.8: Desenho da face frente à rua e pontos onde foram coletados os sinais.

PSD da velocidade da face frente à rua

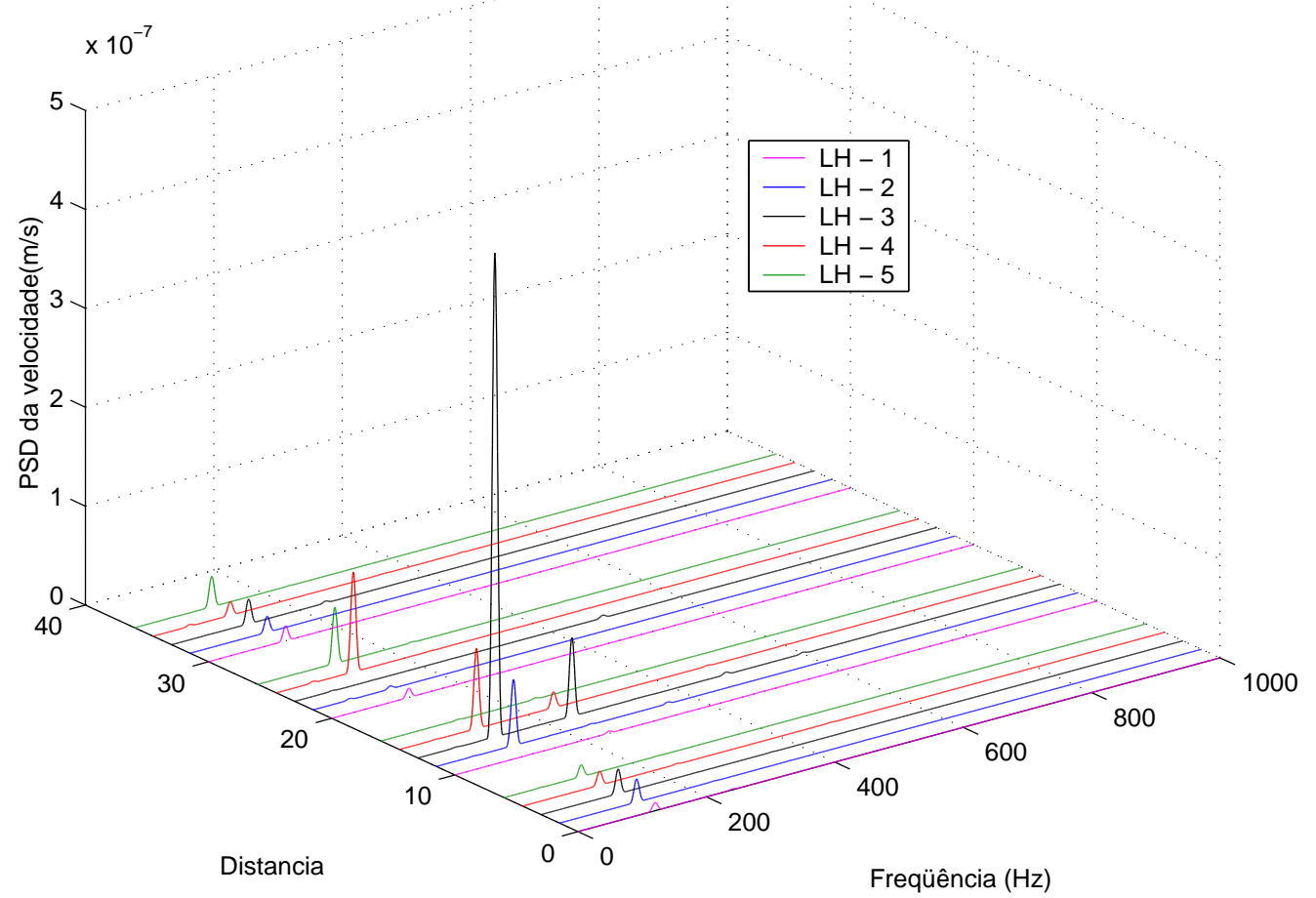

Figura 4.9: Densidade Espectral de Potência da velocidade dos sinais coletados na face frente à rua. 
Os sinais de PSD não fornecem suficiente informação para definir a alocação dos absorvedores dinâmicos. Os níveis de velocidade da vibração da face frente á rua - $L v\left(r e, v_{r e f}\right)$ - de cada ponto foram calculados usando os sinais de PSD da velocidade e as equações 2.24 e 2.25. Os níveis de velocidade segundo a posição foram calculados usando uma interpolação polinomial cúbica, os resultados encontra-se na figura 4.10, onde é apresentada a curva espacial de níveis de velocidade da vibração. A face está no plano xy e os níveis de velocidade da vibração estão representados no eixo z. Na parte inferior da figura encontra-se um desenho feito com linhas azuis, estas têm a forma e as proporções da parede do tanque.

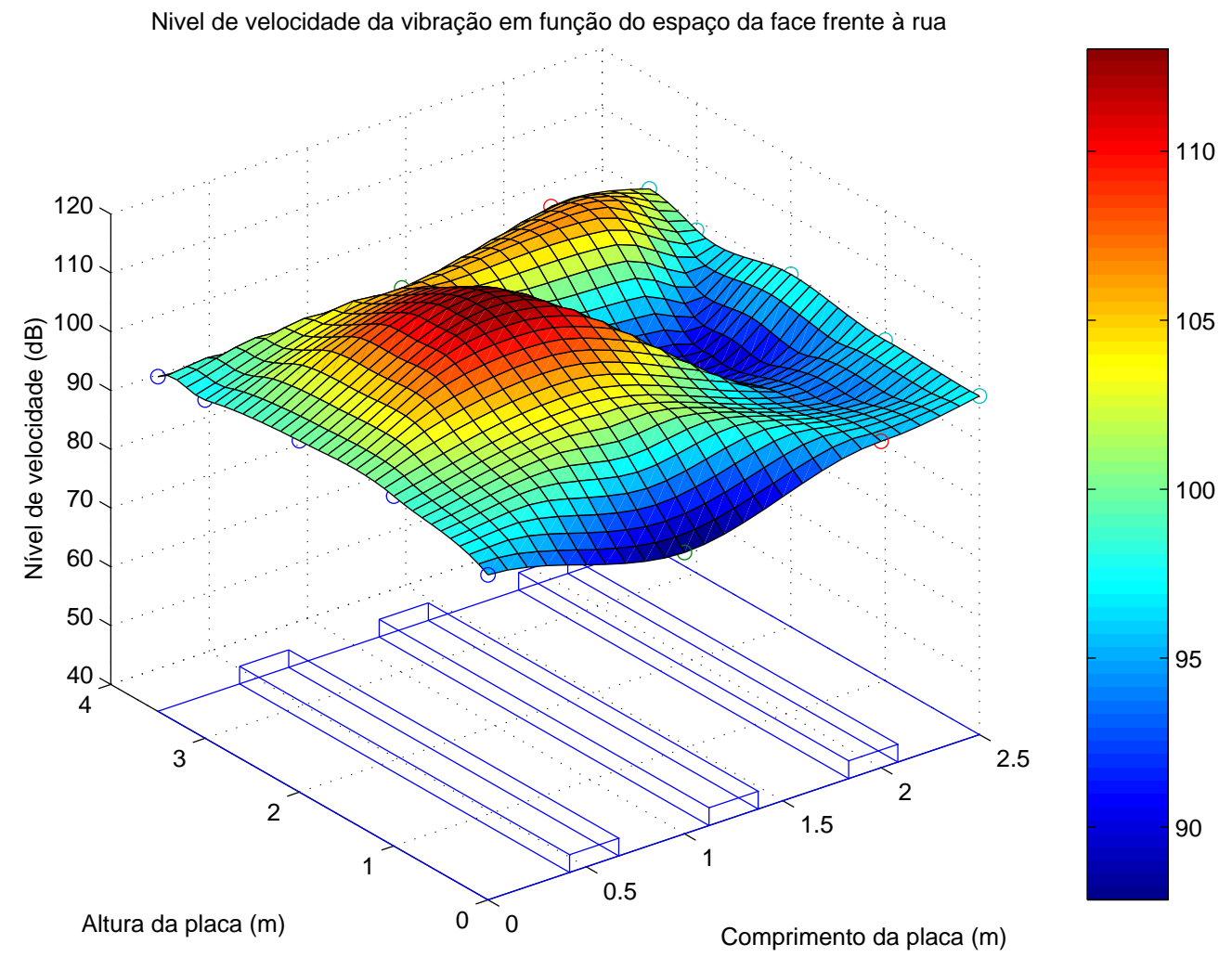

Figura 4.10: Níveis de velocidade da vibração da face frente à rua.

A figura 4.11 apresenta a projeção da figura 4.10 no plano da face, mostrando os níveis de velocidade, $L v\left(r e, v_{r e f}\right)$, representando sua intensidade por cores, e a forma geométrica da face. A partir desta figura pode-se propor a localização dos absorvedores dinâmicos, já que as informações geométricas e os níveis de velocidade sonora estão juntas, diferenciando-se as regiões com maior intensidade de velocidade com o cor vermelha.

Os vetores de deslocamento são colocados em uma malha que representa uma face e um script de Matlab gera os gráficos. Para cada instante é gerada uma figura, reconstituindo-se o movimento de um ciclo. 


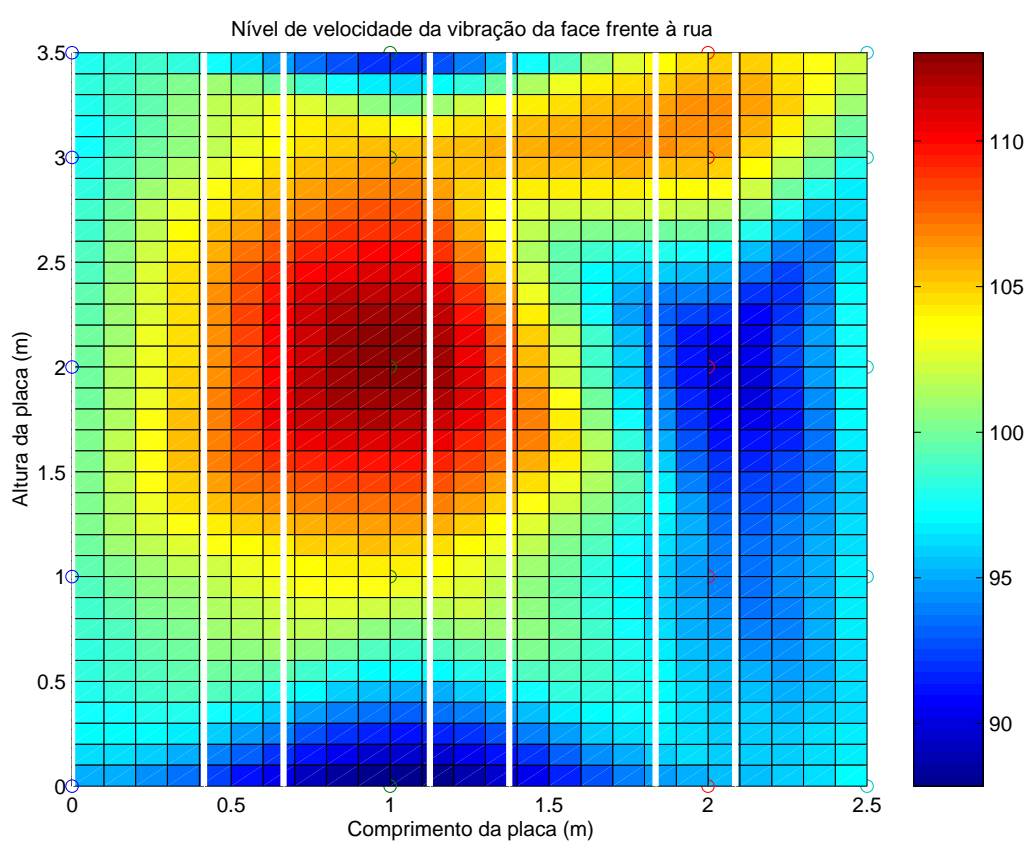

Figura 4.11: Níveis de velocidade e dimensões geométricas da face frente à rua.

A figura 4.12 mostra dois instantes de maiores deslocamentos opostos. As figuras 4.13 e 4.14 mostram os deslocamentos nestes dois instantes separadamente, incluindo um gráfico com a intensidade de cor representando o deslocamento no plano.

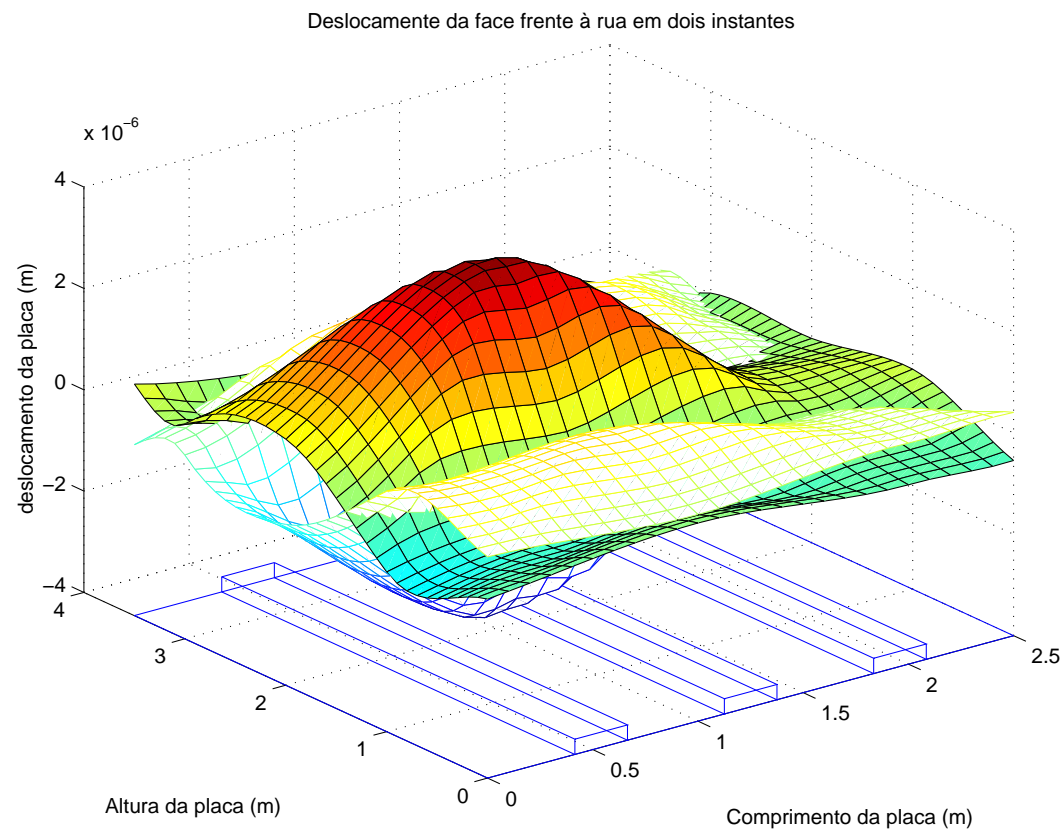

Figura 4.12: Deslocamento da face frente à rua para dois instantes com defasagem de 180 graus. 


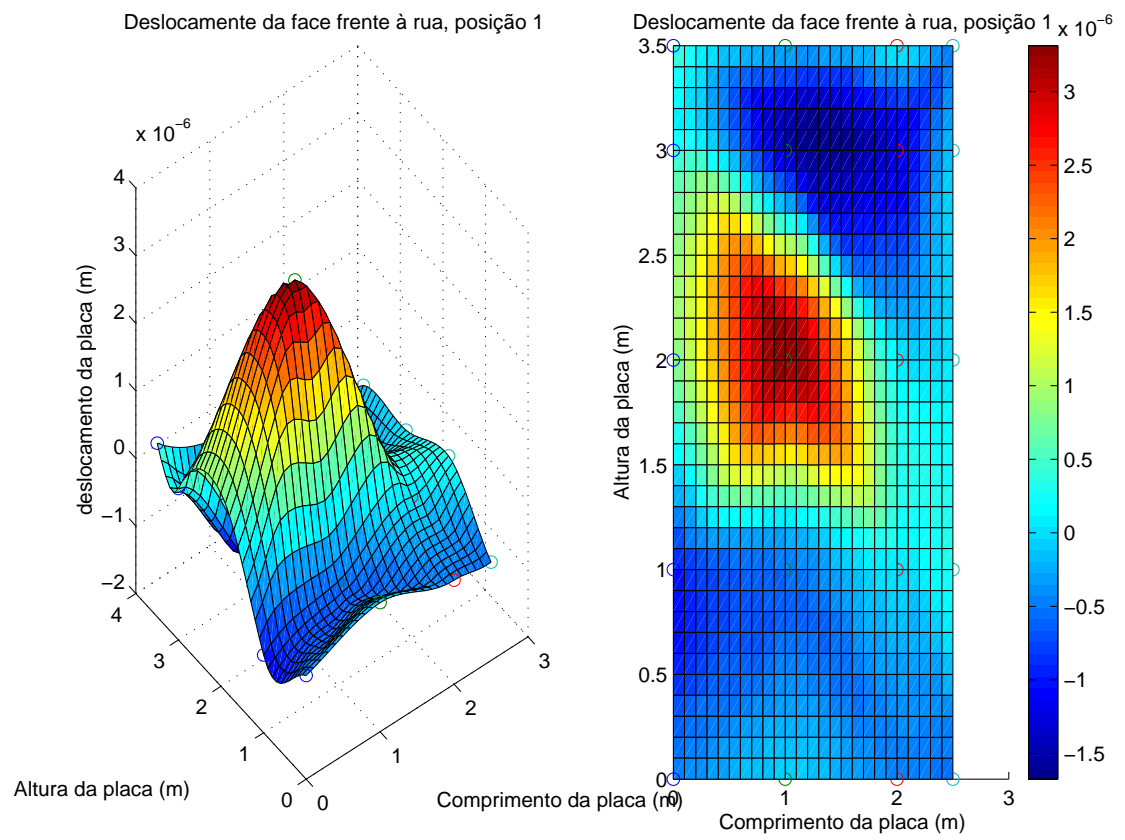

Figura 4.13: Gráfico de cores do deslocamento máximo na face frente à rua.

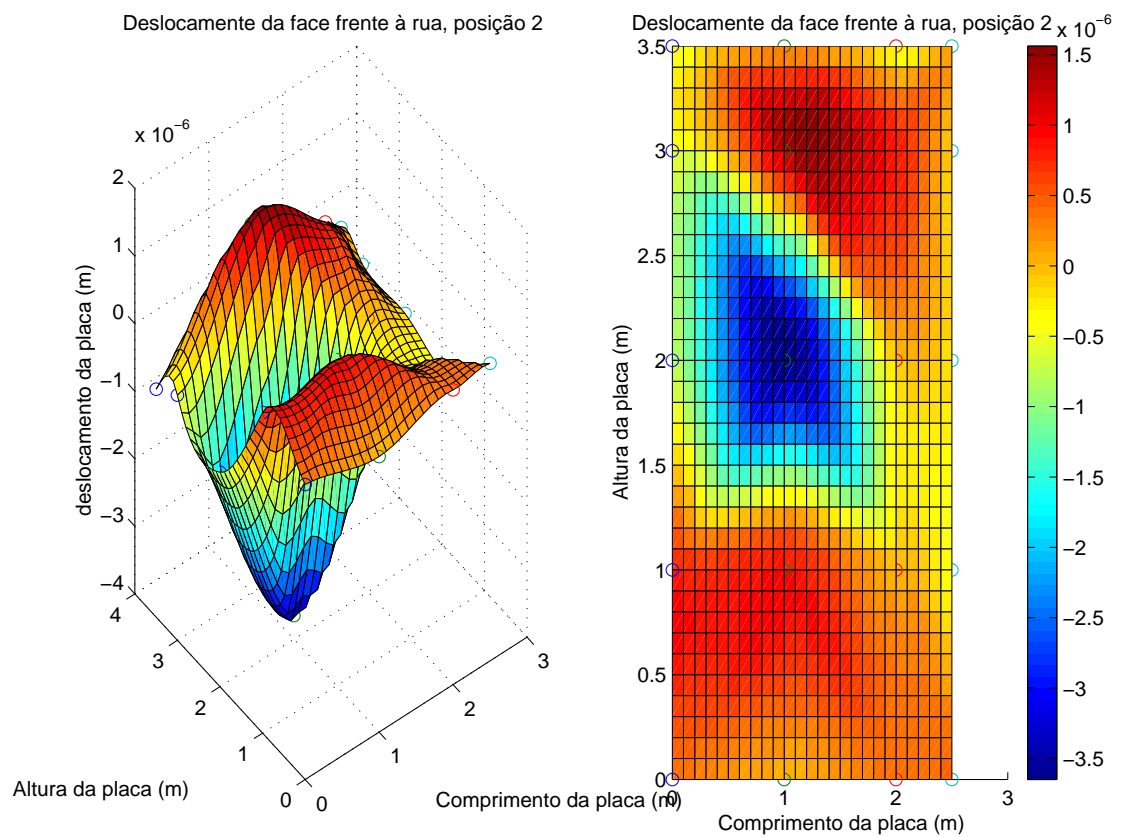

Figura 4.14: Gráfico de cores do deslocamento máximo da face frente à rua em outro instante

O deslocamento da superfície da face, mostrado nas figuras 4.12, 4.13 e 4.14, evidenciam três regiões: duas estão deslocando em fase e uma em oposição de fase; sendo a região que esta em oposição a de maior deslocamento. Observando uma linha horizontal da face nota-se um pico ao longo da largura. Considerando uma linha vertical mais à esquerda, observam-se dois picos. Em uma linha vertical 
no centro da face, notam-se três picos. Na linha vertical, no extremo direito da face, o deslocamento é muito pequeno. Os pontos sem deslocamento formam uma linha diagonal.

Da observação das figuras de 4.10 até 4.14 observa-se que as regiões que mostram maior emissão de som (considerando a intensidade do som correlacionada com a velocidade) coincidem com as regiões de maior deslocamento, e isso justifica a estratégia de se posicionar os absorvedores dinâmicos nestas regiões.

A figura 4.15 mostra os absorvedores dinâmicos posicionados nas regiões críticas, (regiões vermelhas das figuras 4.10 e 4.11). No desenho os absorvedores dinâmicos são representados por retângulos azuis.

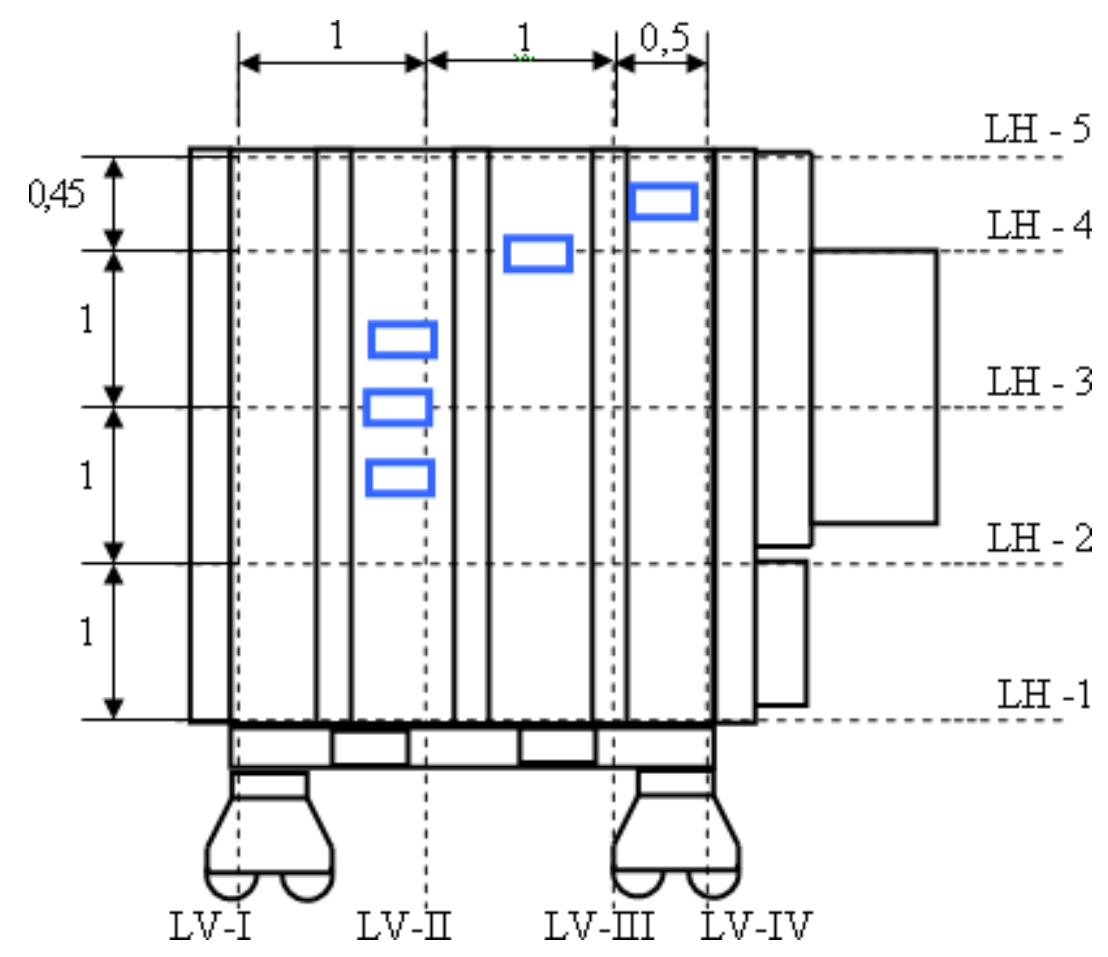

Figura 4.15: Desenho da face frente à rua, indicando o posicionamento dos absorvedores dinâmicos.

\subsubsection{Análise da face oposta à rua}

A placa da face oposta à rua tem a mesma forma geométrica que a face frente à rua, e foi seguido o mesmo procedimento. A figura 4.16 mostra o desenho da face oposta à rua.

A figura 4.17 mostra o PSD da velocidade da face oposta à rua. Da observação dos sinais na primeira e na segunda linha vertical, no lado esquerdo da face, percebe-se que o deslocamento é maior na parte superior, ver linha verde e 


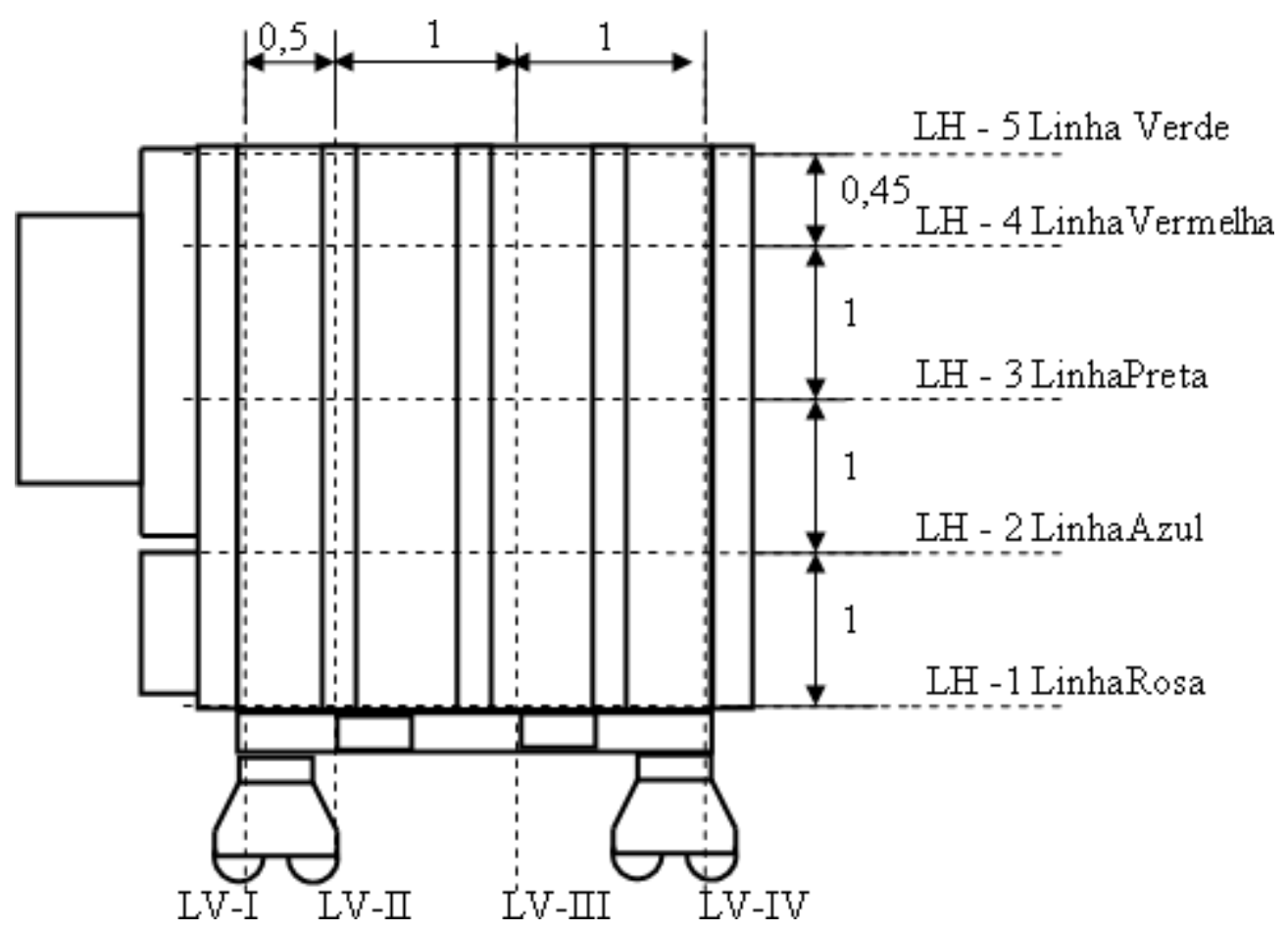

Figura 4.16: Desenho da face oposta à rua.

vermelha, em $120 \mathrm{~Hz}$. A escala de 0 a 40 é indicativa, e não representa distância em metros.

PSD da velocidade da face oposto à rua

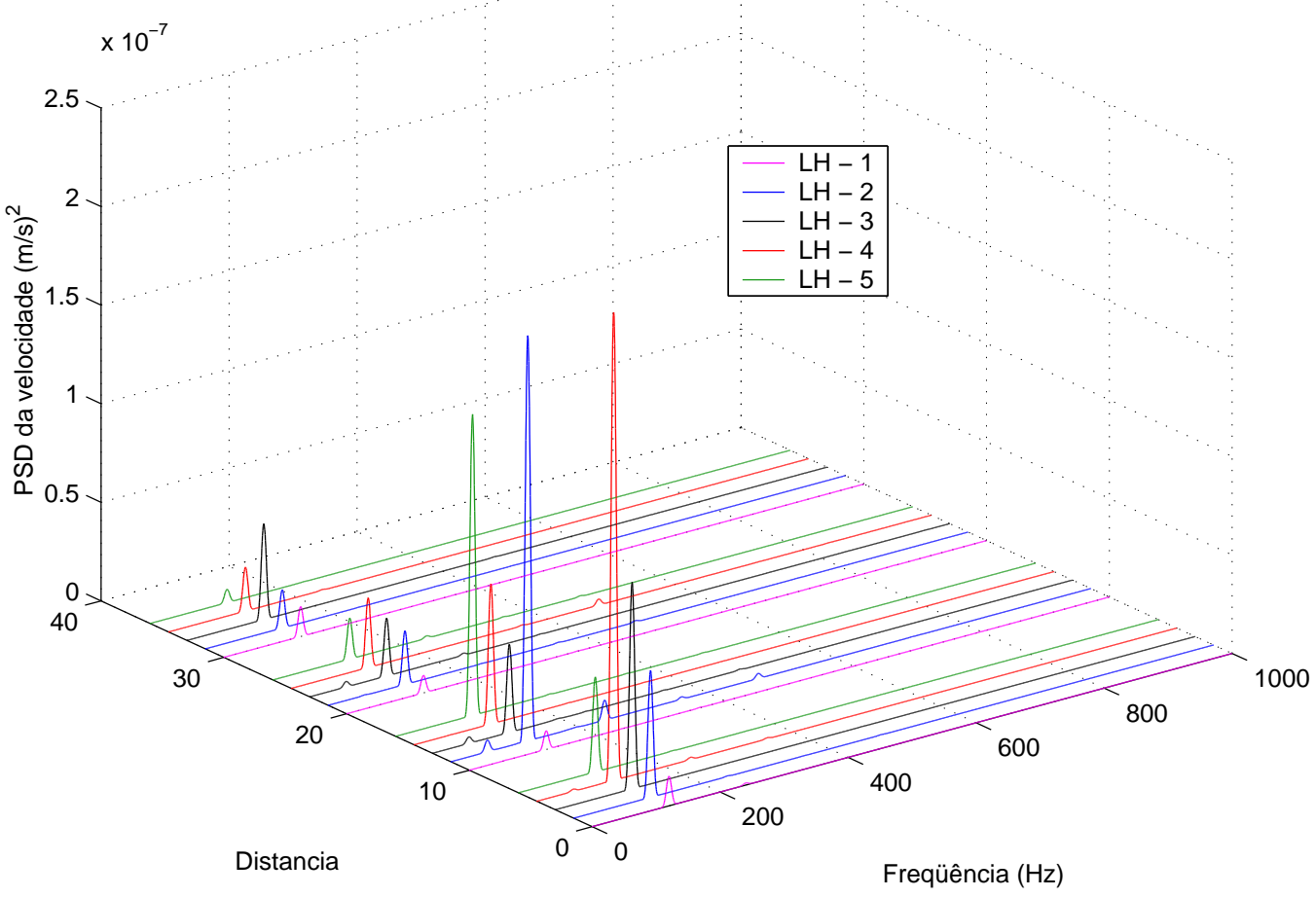

Figura 4.17: Densidade Espectral de Potência da velocidade dos sinais coletados na face oposta à rua. 
Os níveis de velocidade, da face oposta à rua são mostrados nas figura 4.18, e 4.19, a intensidade dos níveis de velocidade $L v$ ( $\left.r e, v_{r e f}\right)$, estão diferenciadas por uma escala de cores. As linhas brancas na figura 4.19 mostram as dimensões da face e a posição dos reforços da estrutura.

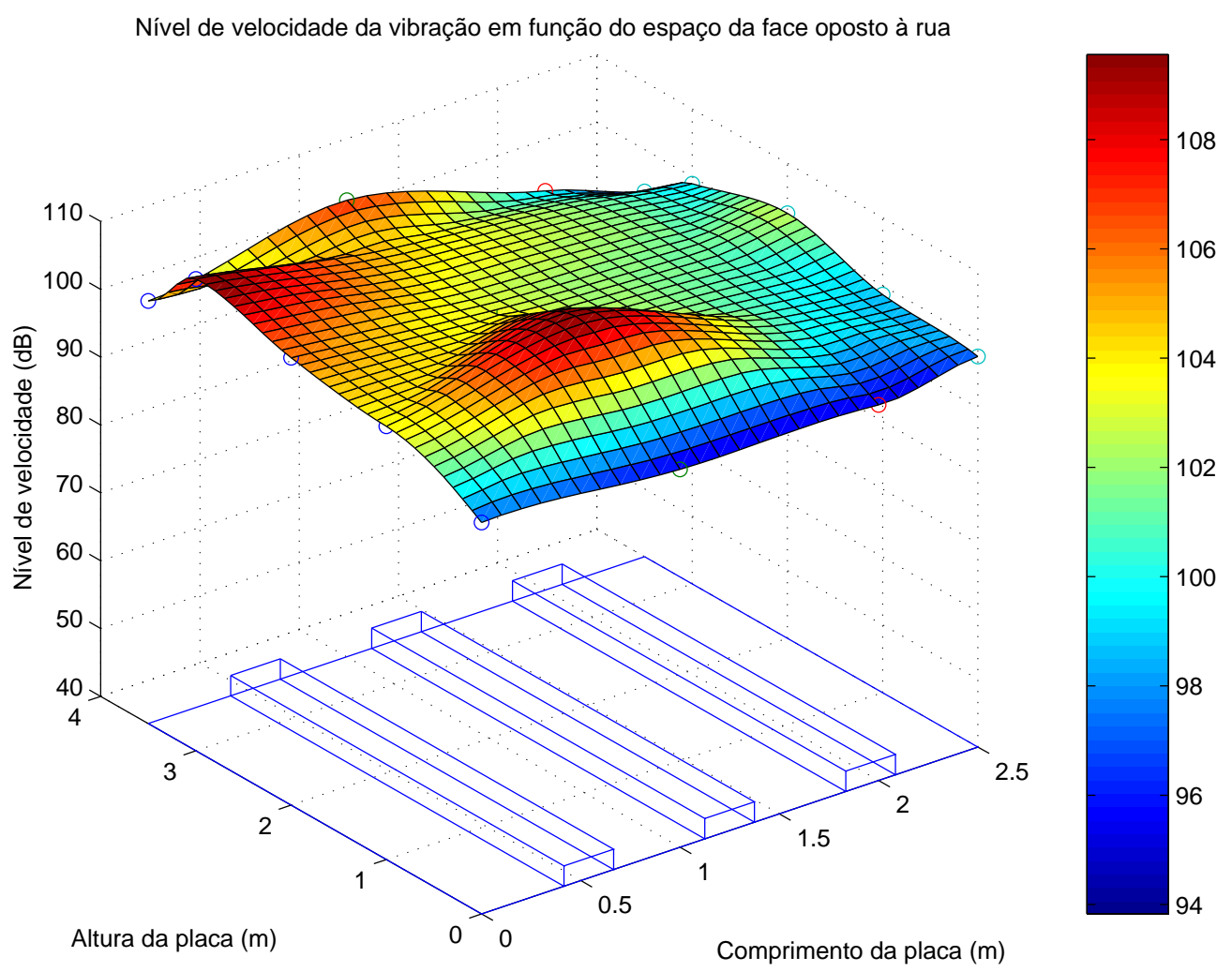

Figura 4.18: Níveis de velocidade função da posição na face oposta à rua

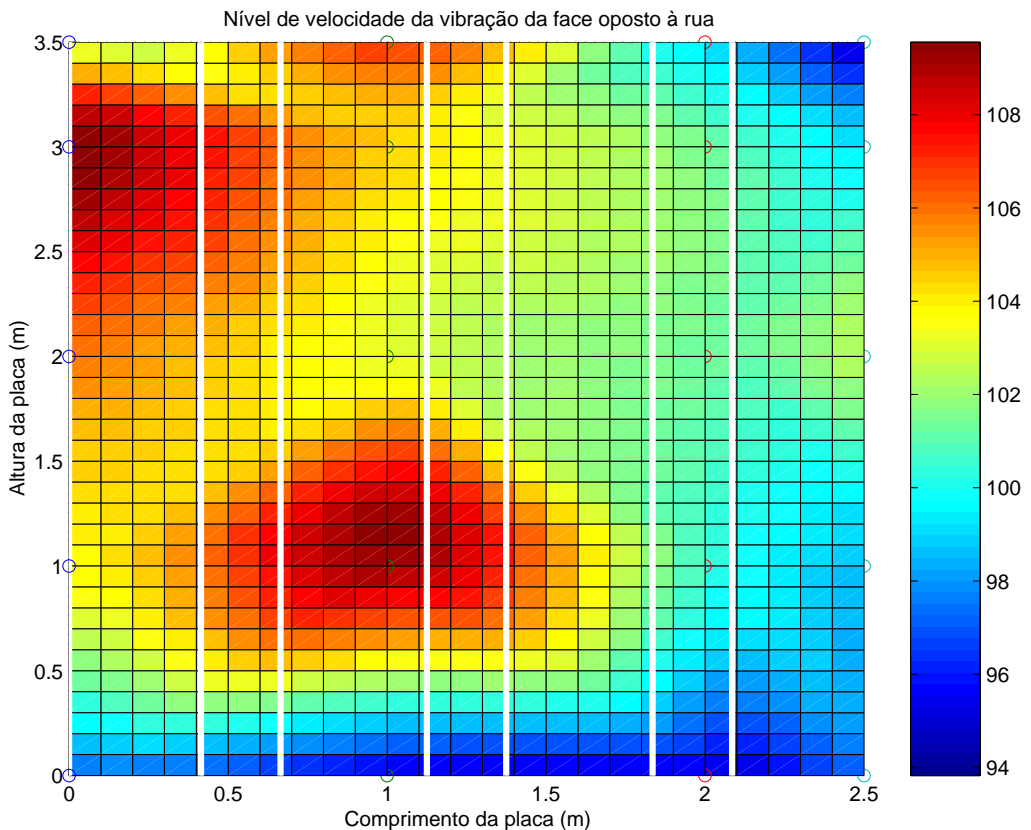

Figura 4.19: Gráfico de cores dos níveis de velocidade na face oposta à rua 
A figura 4.20 mostra o deslocamento em dois instantes. Estes mesmos deslocamentos, de maneira mais detalhada e separada, são mostrados nas figuras 4.21 e 4.22. A aresta superior apresenta elevados deslocamentos.

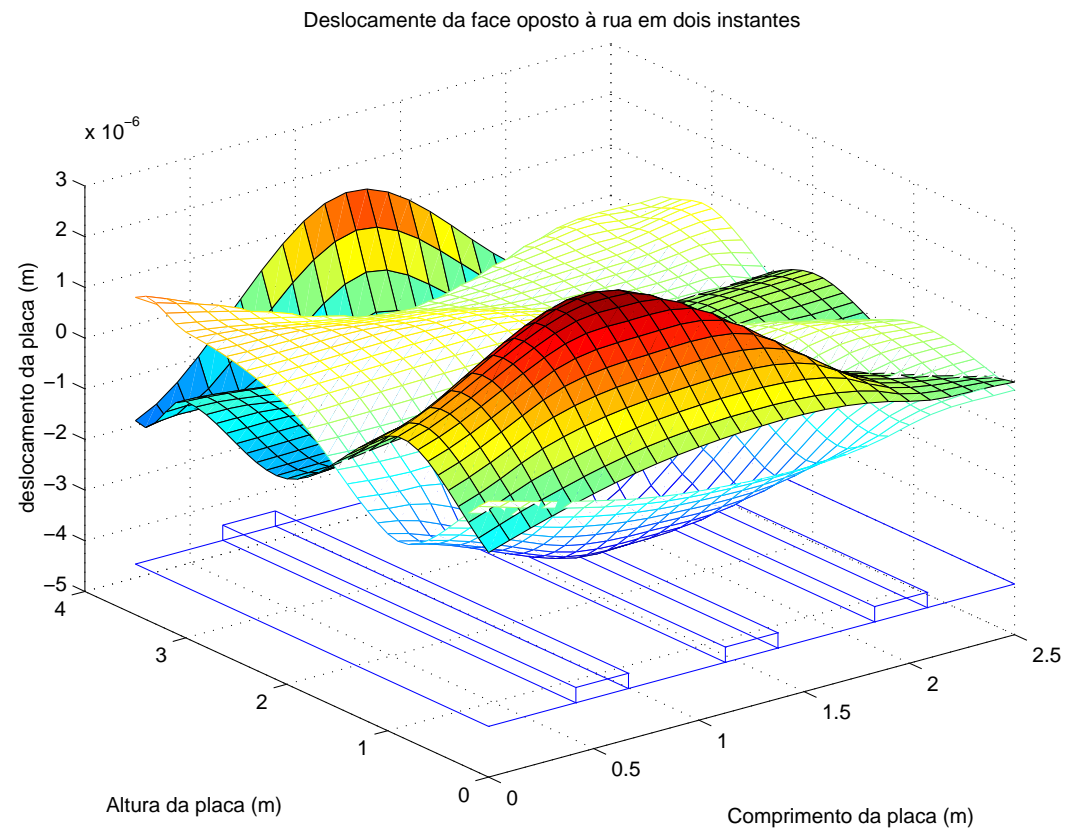

Figura 4.20: Gráfico de cores do deslocamento da face oposta à rua em dois instantes defasados de 180 graus.

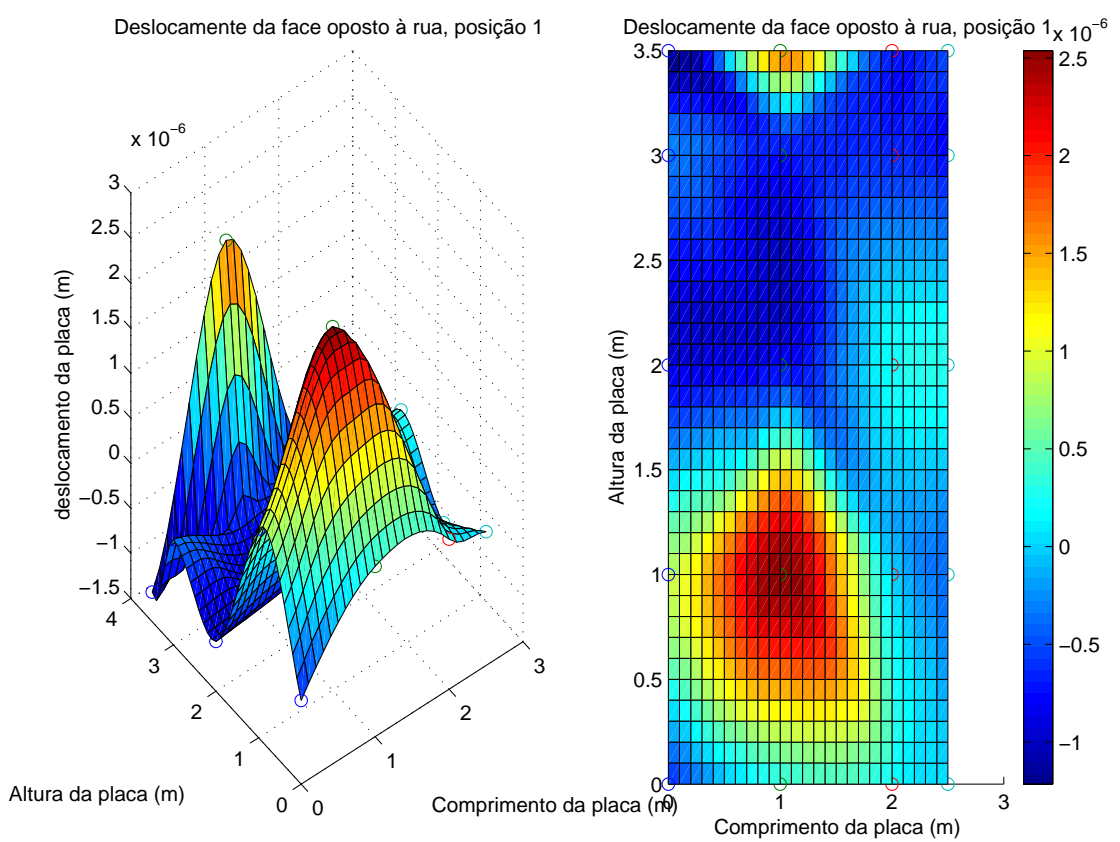

Figura 4.21: Gráfico de cores do deslocamento máximo da face oposta à rua. 


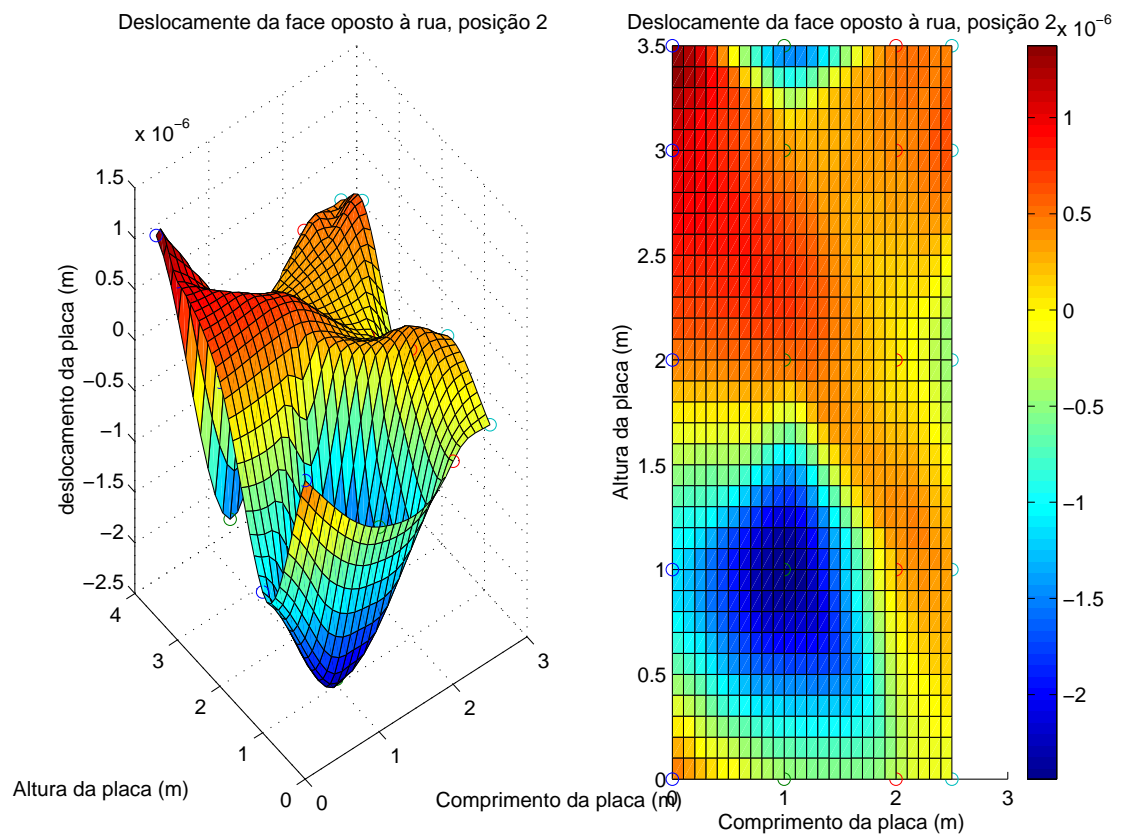

Figura 4.22: Gráfico de cores do deslocamento máximo da face oposta à rua em outro instante

Considerando os resultados das figuras 4.18 até 4.22, é proposta uma disposição dos absorvedores dinâmicos, nas regiões onde é detecta maior manifestação de energia (parte vermelha das figuras 4.18 e 4.18) conforme mostrado na figura 4.23 , onde cada retângulo azul representa um absorvedor dinâmico.

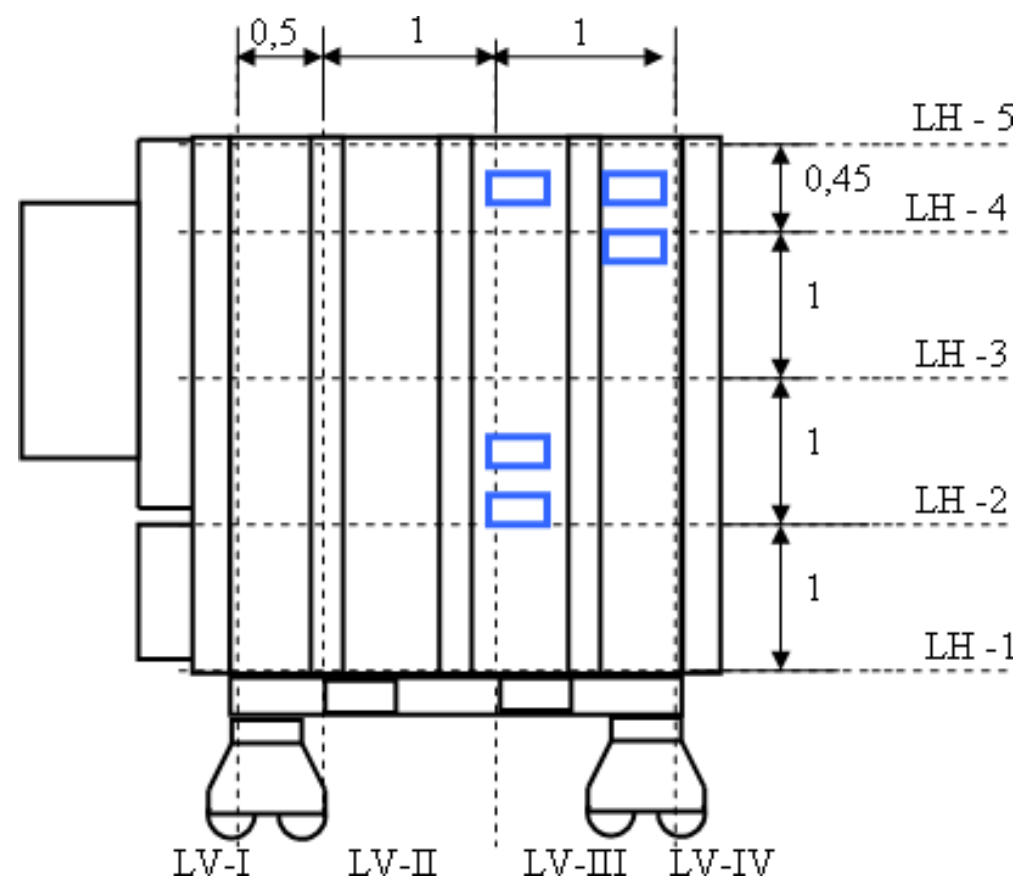

Figura 4.23: Desenho da face oposta à rua, indicando o posicionamento dos absorvedores dinâmicos 


\subsubsection{Análise da face oposta ao edifício}

A análise nesta face segue o procedimento das anteriores. A figura 4.24 mostra um desenho da face oposta ao edifício, onde se observam oito painéis com 7 reforços. Nesta figura estão identificados os pontos onde foram coletadas as acelerações através das intersecções das linhas tracejadas.

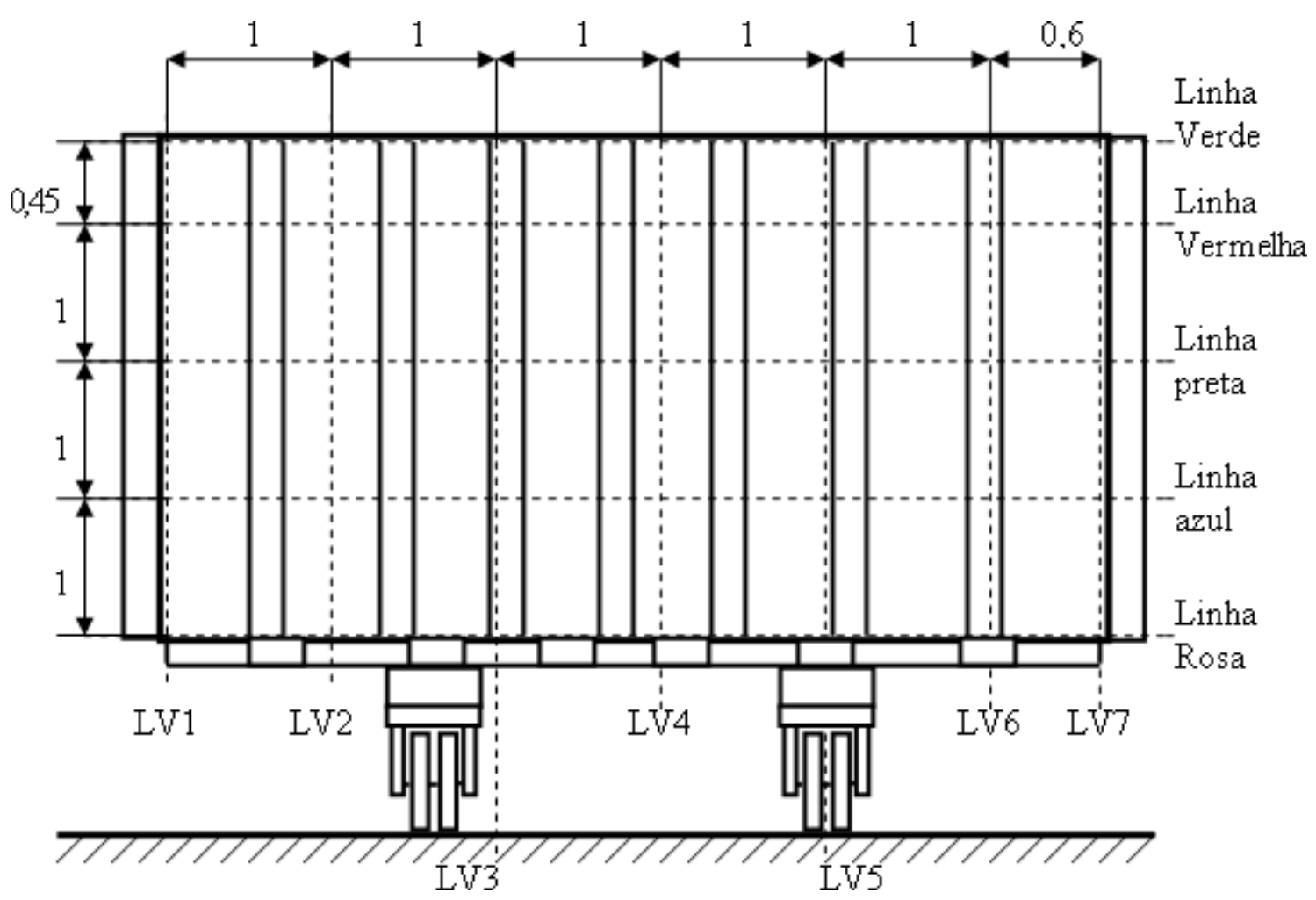

Figura 4.24: Desenho da face oposta ao edifício.

A PSD de velocidade de face oposta ao edifício é apresentado na figura 4.25, nela observam-se vários picos com amplitudes relativamente altas, estes estariam localizados na altura média e na parte inferior da face.

Os níveis de velocidade da face oposta ao edifício, estão mostrados na figura 4.26 em um gráfico de cores em 3 dimensões. Podem-se observar três picos com valores distintos. Na parte inferior da figura encontra-se um diagrama que mostra a forma e as proporções da face oposta ao edifício, construído com linhas azuis. 
PSD da velocidade da face oposto ao edifício

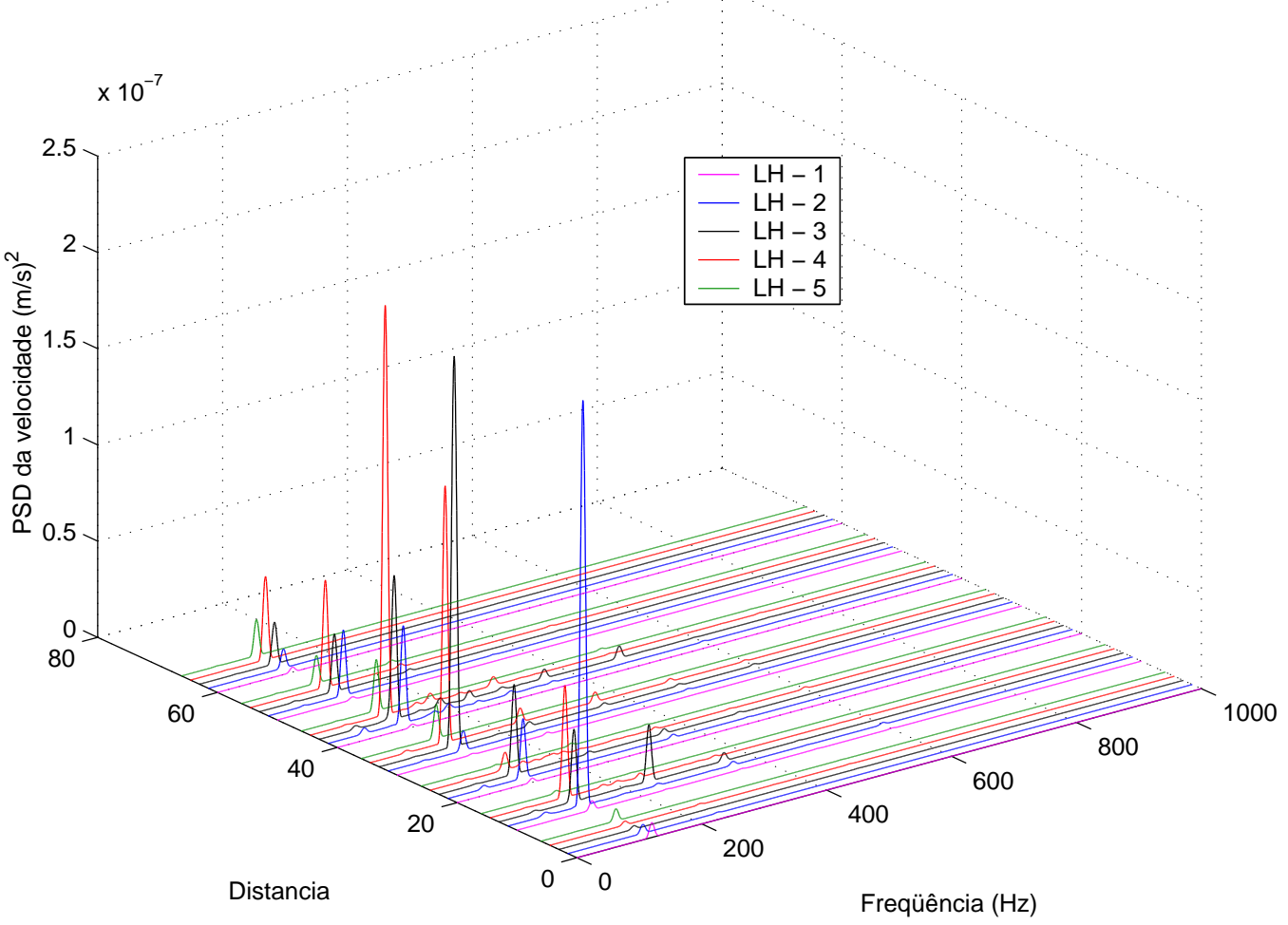

Figura 4.25: Densidade Espectral de Potência da velocidade dos sinais coletados na face oposta ao edifício

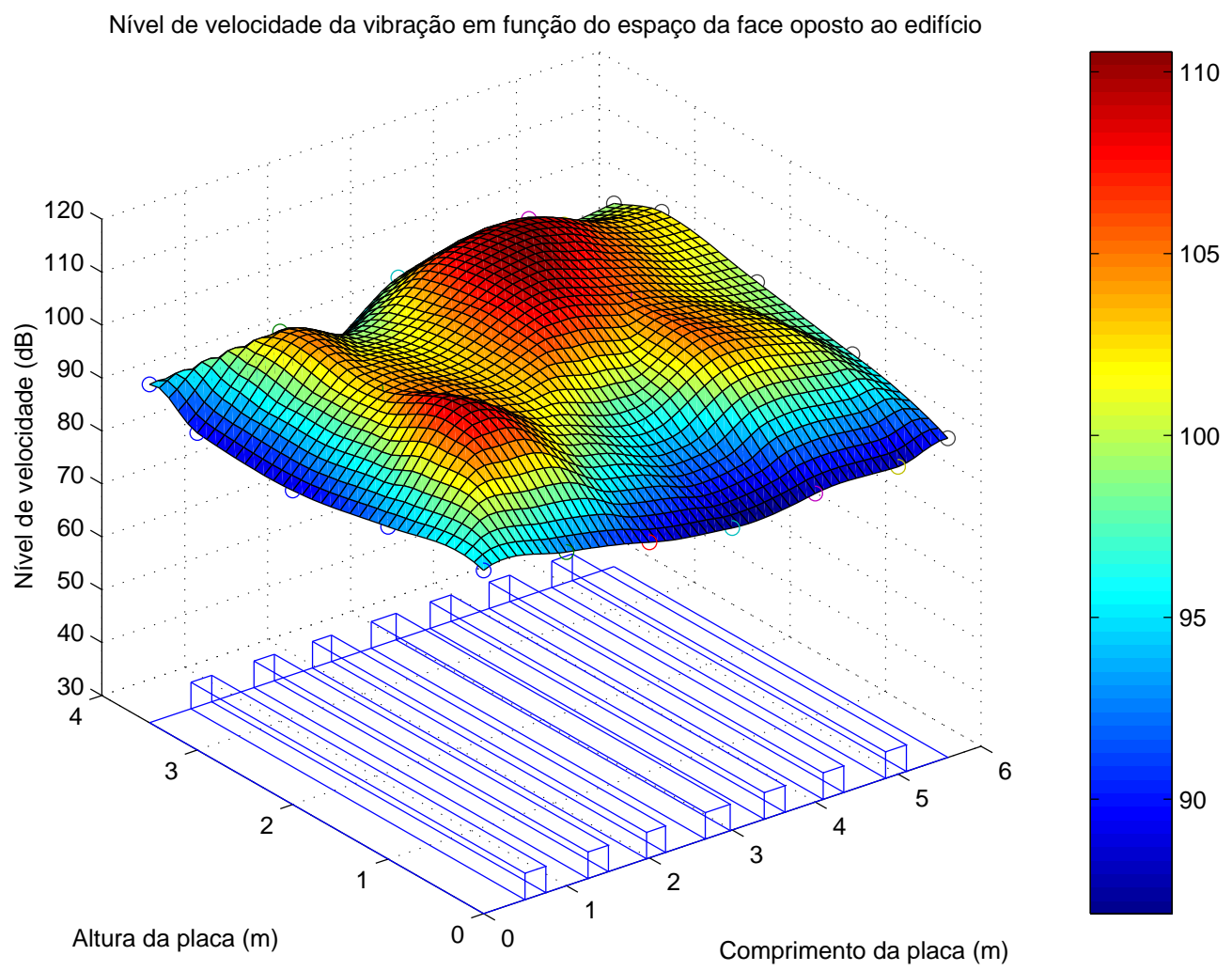

Figura 4.26: Níveis de velocidade da vibração da face oposta ao edifício. 
A figura 4.27 mostra uma vista superior da figura 4.26, este gráfico é superposto com o desenho da face, e projetado no plano.

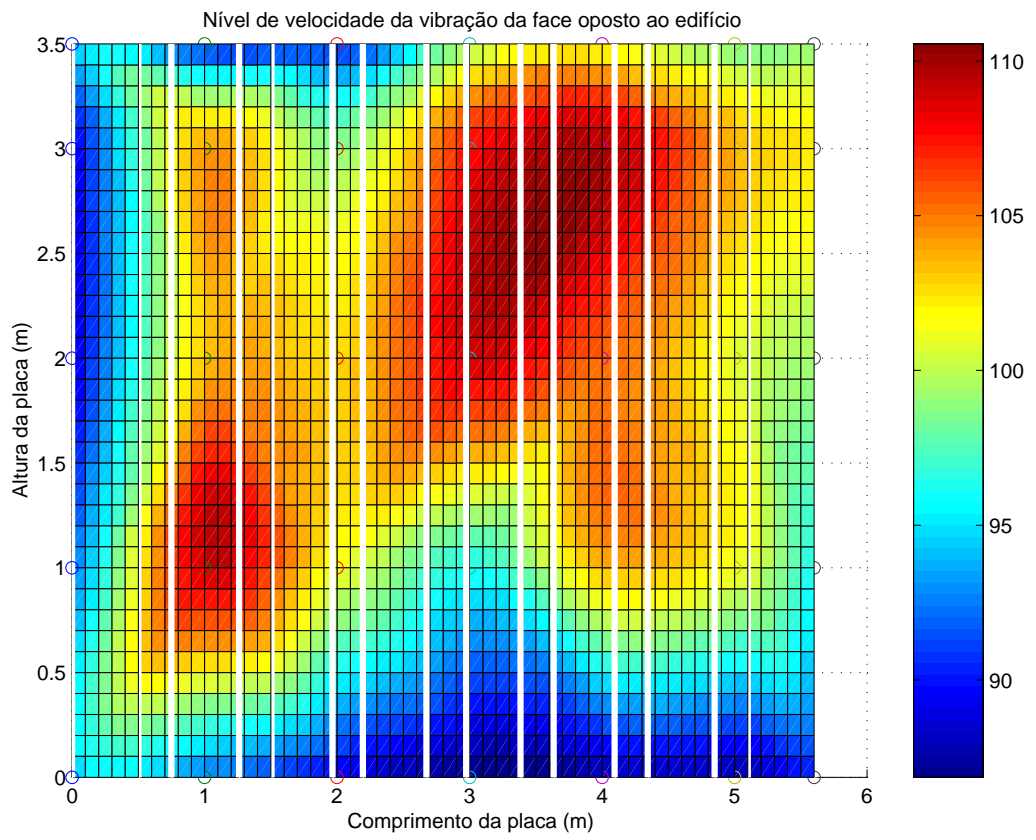

Figura 4.27: Níveis de velocidade sobrepostos com as medidas geométricas da face oposta ao edifício.

O gráfico do deslocamento é mostrado na fig. 4.28, na fig. 4.29 e na fig. 4.30, mostrando dois instantes de maior deslocamento, defasados de 180 graus.

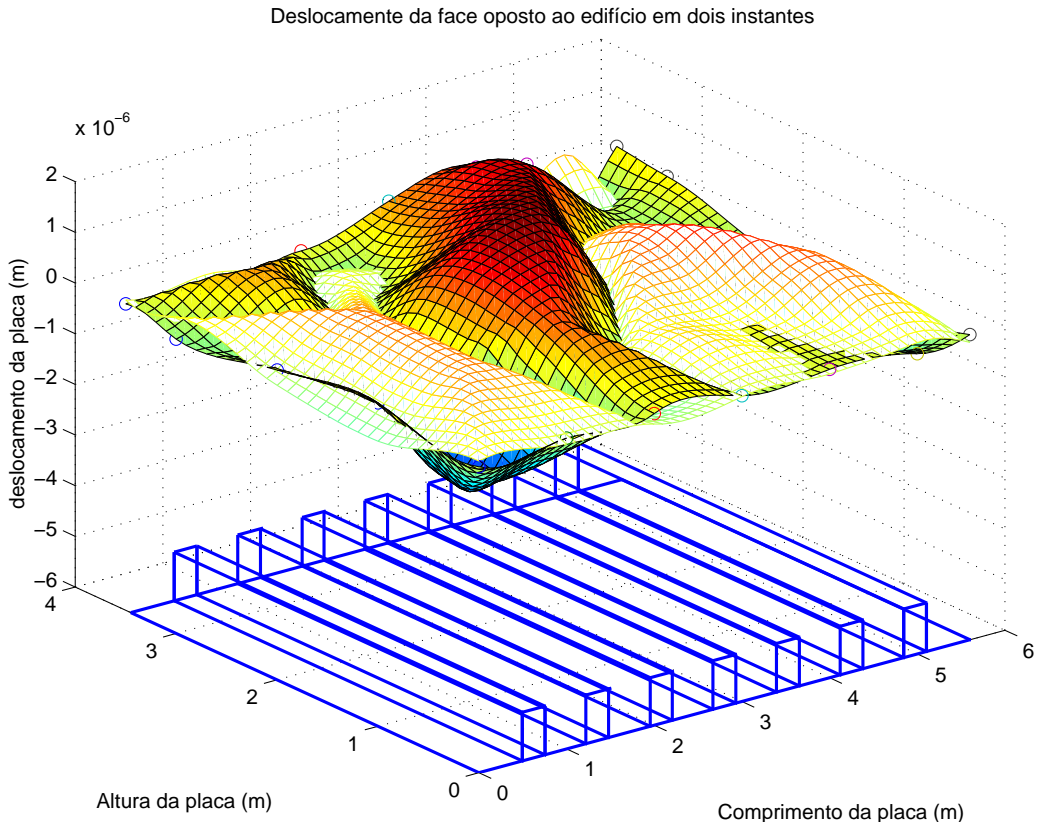

Figura 4.28: Gráfico de cores do deslocamento da face oposta ao edifício em dois instantes defasados de 180 graus. 


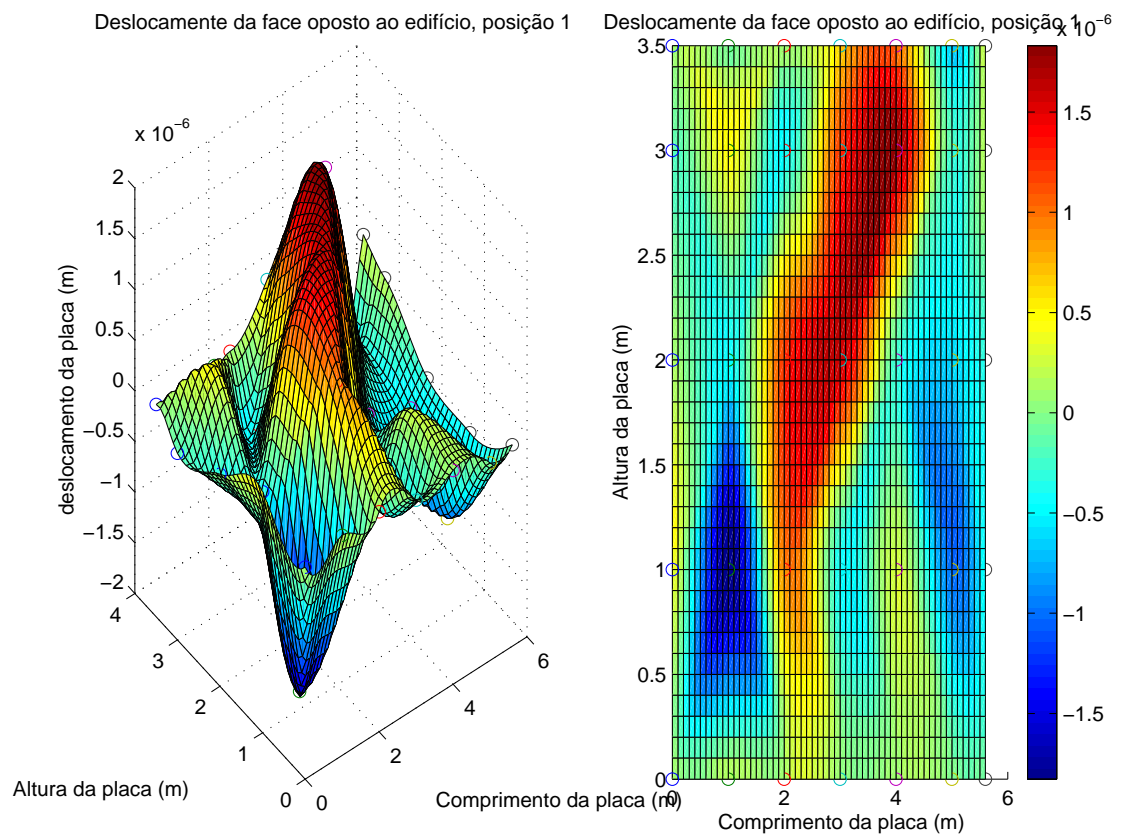

Figura 4.29: Gráfico de cores do deslocamento máximo da face atrás dos edifícios.

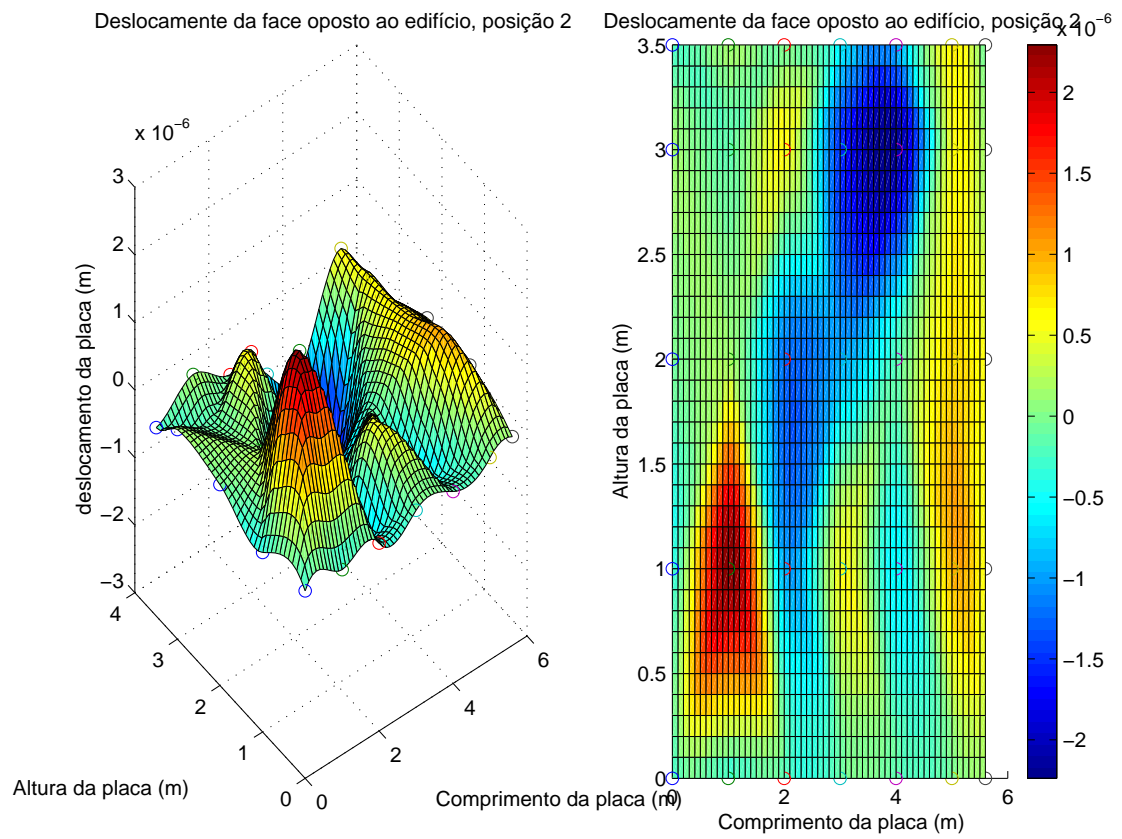

Figura 4.30: Gráfico de cores do deslocamento máximo da face atrás dos edifícios com defasagem de 180 graus.

As áreas vermelhas da fig. 4.26 e da fig. 4.27 ou vermelhas e muito azuis da fig. 4.28 até a fig. 4.30 representam áreas com maior vibração. Entretanto, o ruído total não é maior em comparação com as outras faces. Por outro lado, da fig. 4.28, fig. 4.29 e da fig. 4.30 nota-se que o formato do deslocamento forma um padrão 
complexo, aparecendo curvas que invadem vários painéis. A localização proposta para os absorvedores dinâmicos está mostrada na figura 4.31. Os retângulos em branco são os espaços dos absorvedores dinâmicos. A posição dos absorvedores coincide com as regiões vermelhas.

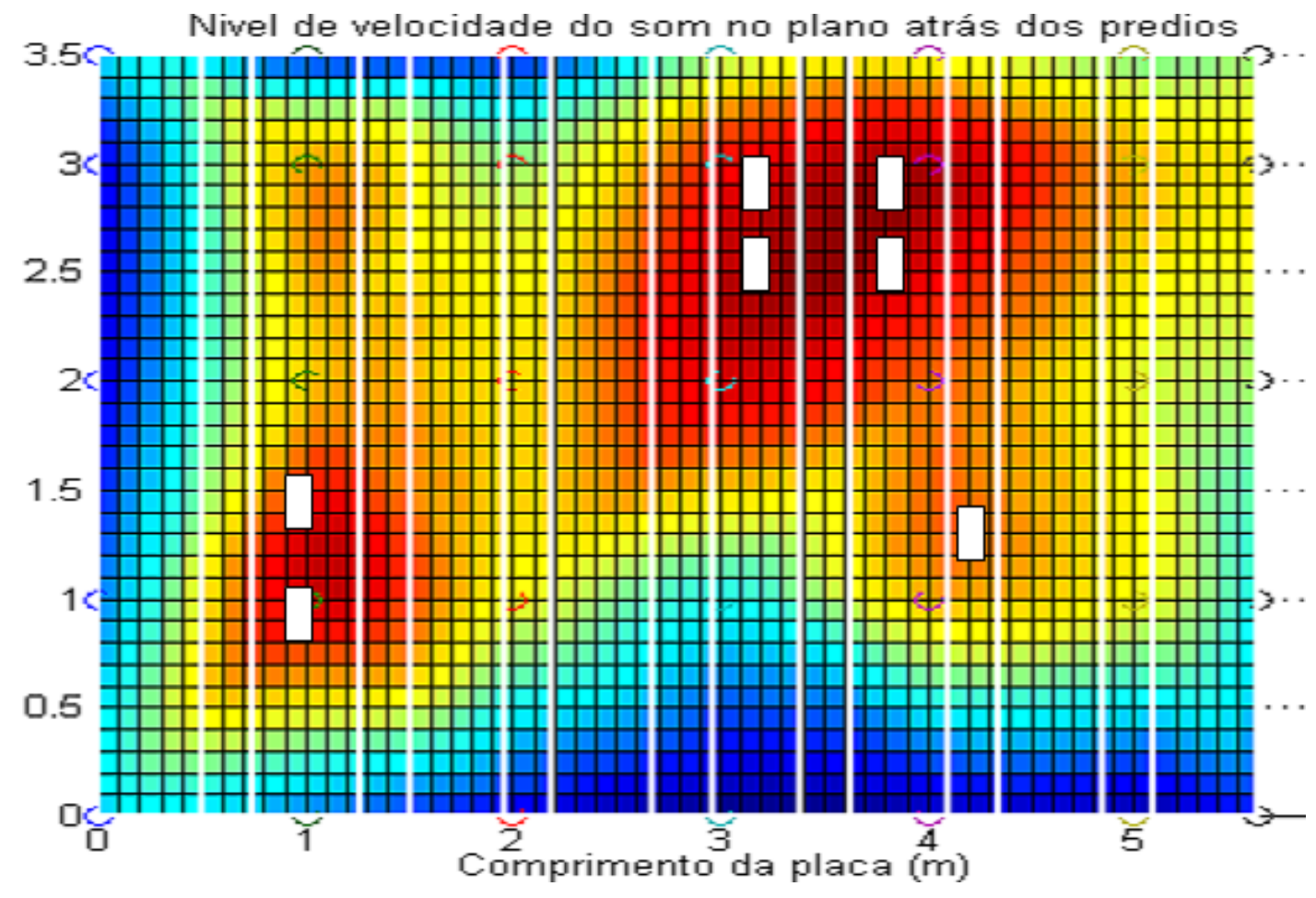

Figura 4.31: Posicionamento dos absorvedores dinâmicos na face oposta ao edifício.

\subsubsection{Análise da face frente ao edifício}

A face frente ao edifício é diferente a todas as faces anteriores, devido à existência de dobras e outras estruturas fixadas a ela, como a caixa do comutador e a caixa de medições. A figura 4.32 mostra o desenho de uma seção da face frente ao edifício.

A PSD da velocidade da face é mostrada na fig. 4.33, onde se observa que existem só 2 picos notórios que estão na ante-penúltima linha vertical. 


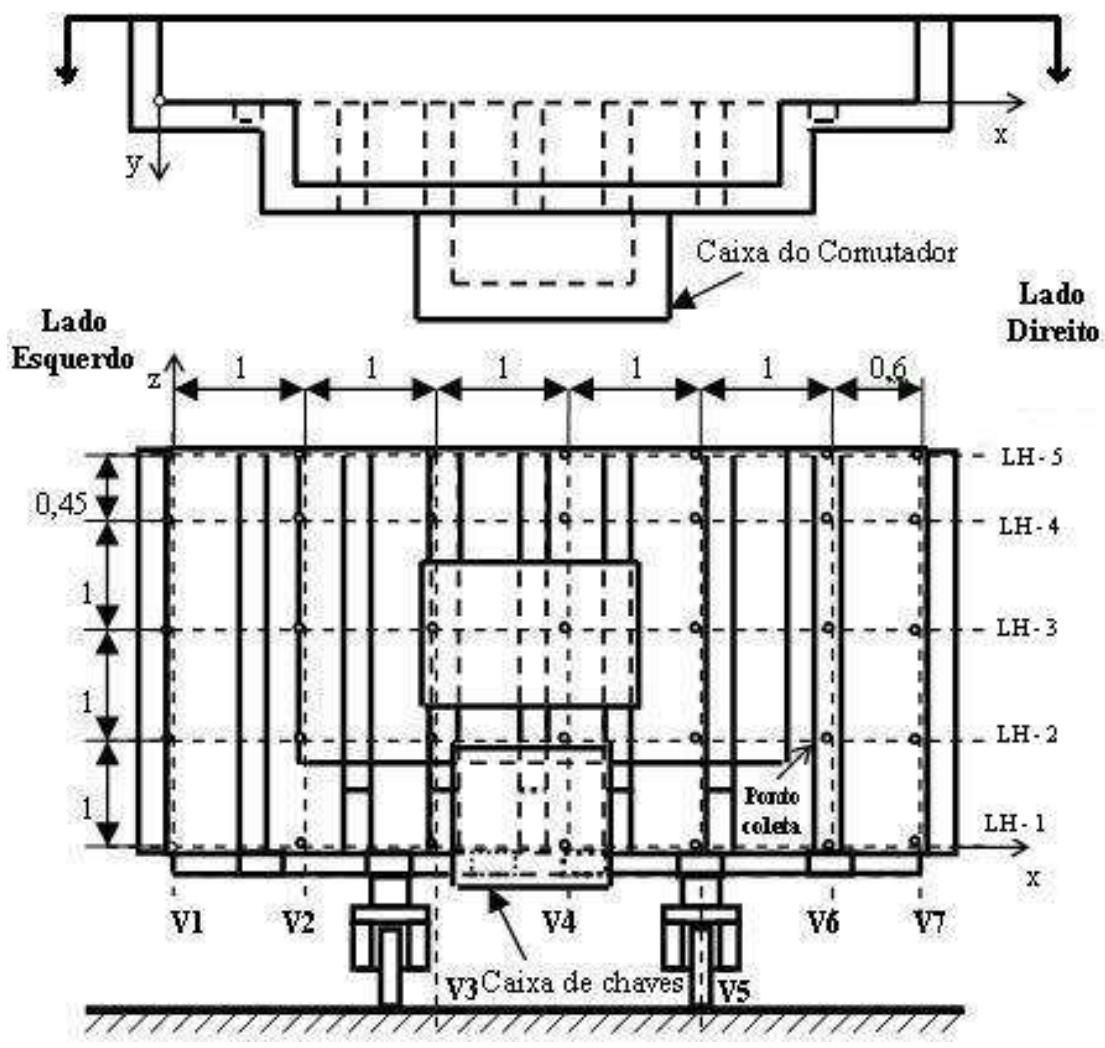

Figura 4.32: Desenho de uma seção da face frente aos edifícios.

PSD da velocidade da face frente aos edifícios

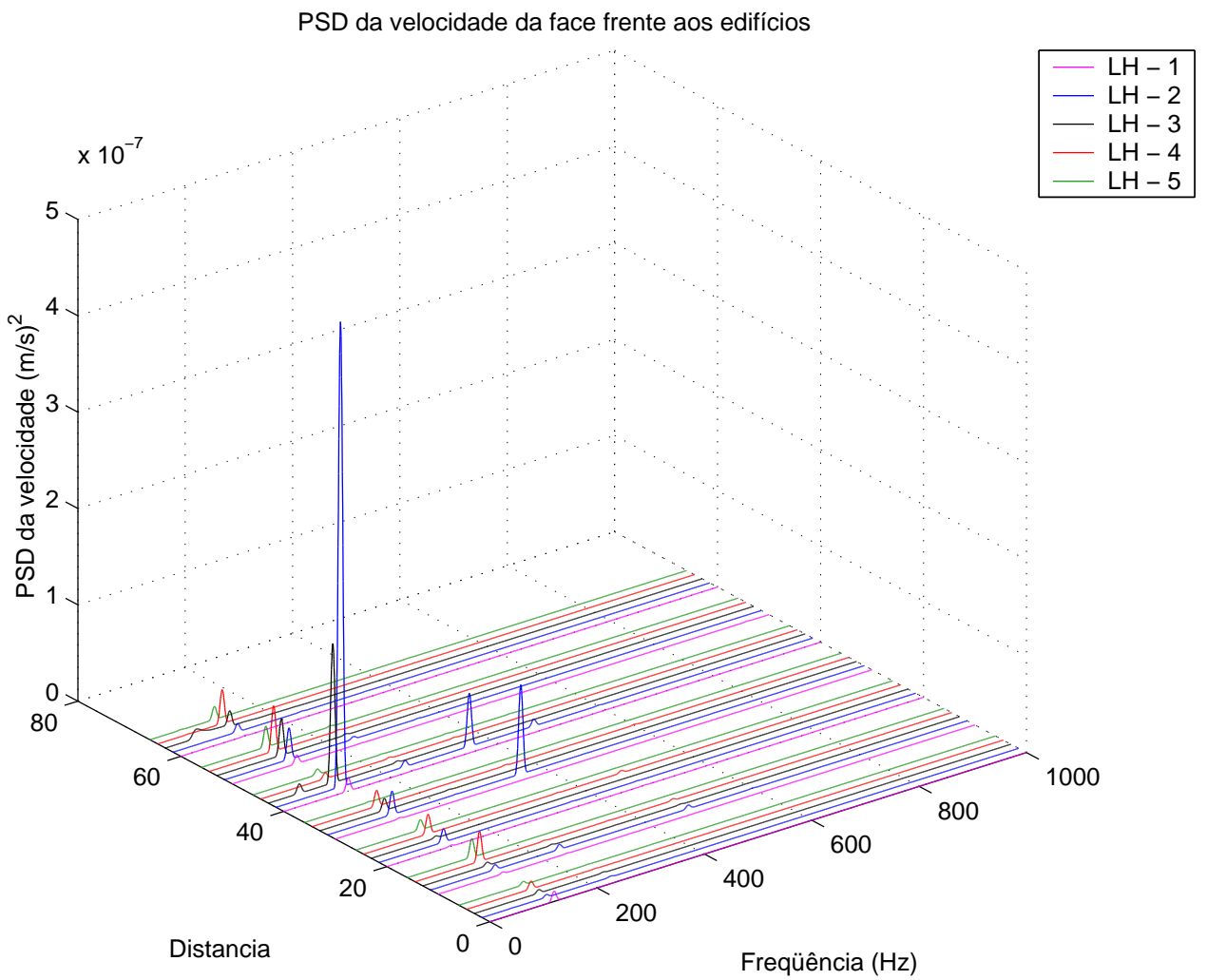

Figura 4.33: Densidade Espectral de Potência da velocidade dos sinais coletados na face frente aos edifícios. 
Os níveis de velocidade são mostrados nas figuras $4.34 \mathrm{com}$ cores em 3D e na fig. 4.35 com cores em 2D, sobreposto ao desenho geométrico da face. A concentração de maior nível de velocidade em uma única região é uma particularidade desta face.

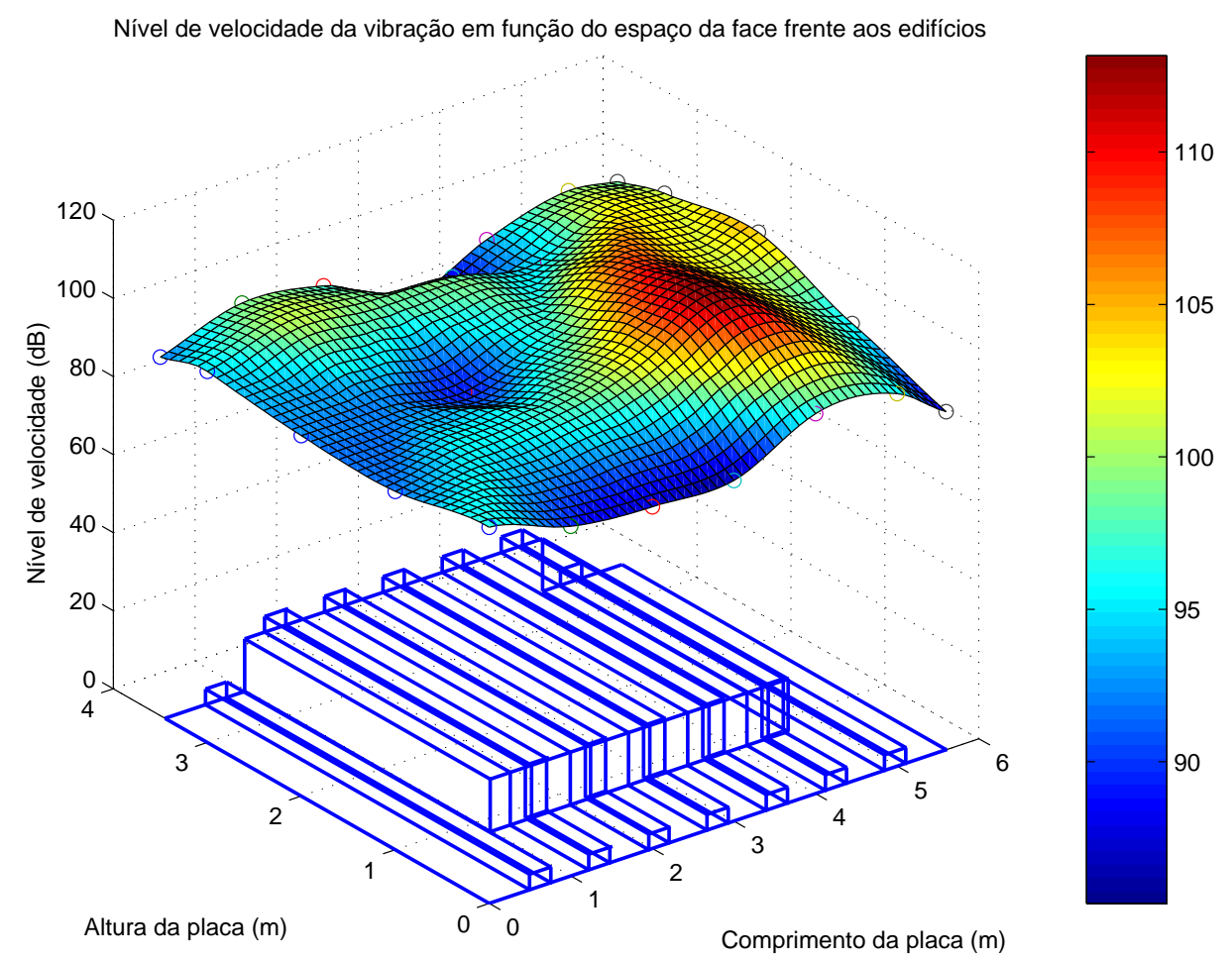

Figura 4.34: Níveis de velocidade da vibração da face frente aos edifícios.

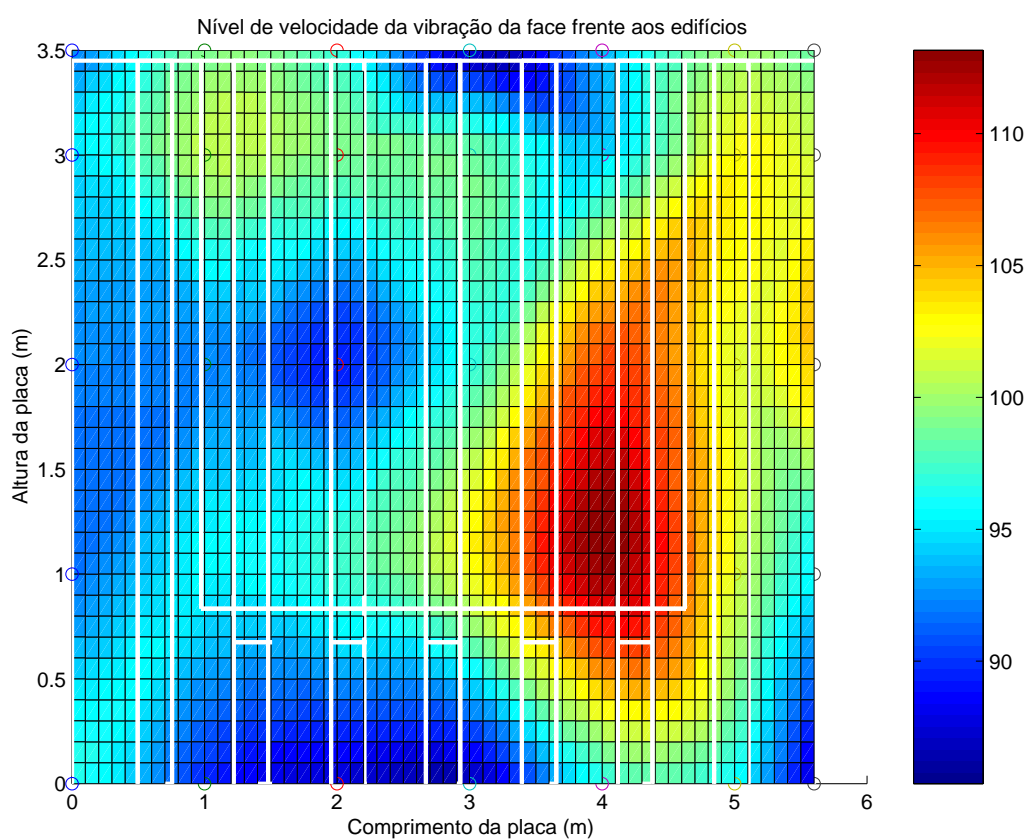

Figura 4.35: Níveis de velocidade sobrepostos com o desenho da face frente ao edifício. 
Os deslocamentos são mostrados na fig. 4.36, nela estão representados dois instantes defasados de 180 graus. A fig. 4.37 e a fig. 4.38 mostram o deslocamento nos mesmos instantes que a fig. 4.36, porém em gráficos separados, e ajudam a confirmar que o maior nível de velocidade está próximo ao lado direito da caixa do comutador, sendo os demais deslocamentos pequenos.

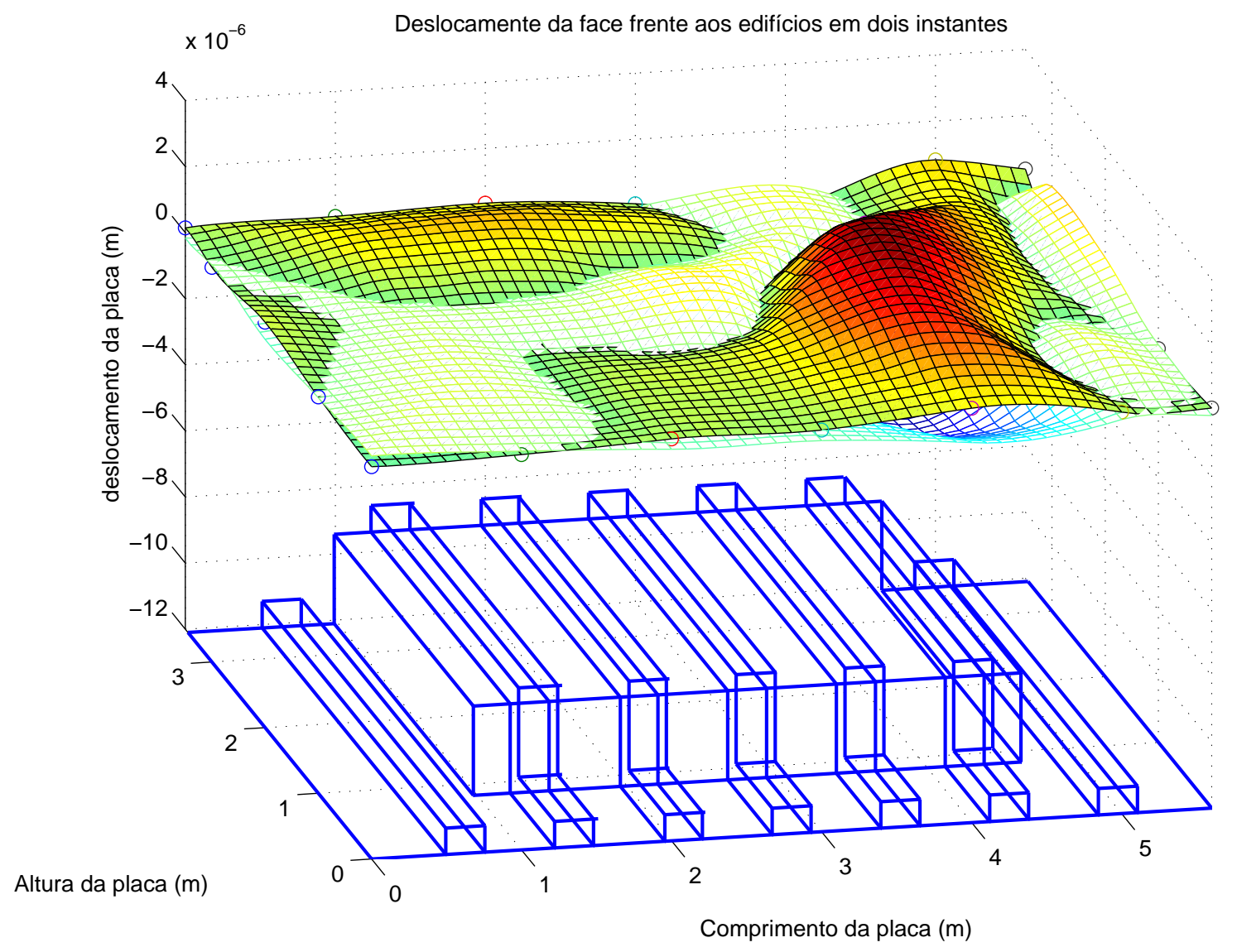

Figura 4.36: Gráfico de cores do deslocamento da face frente ao edifício em dois instantes defasados de 180 graus 


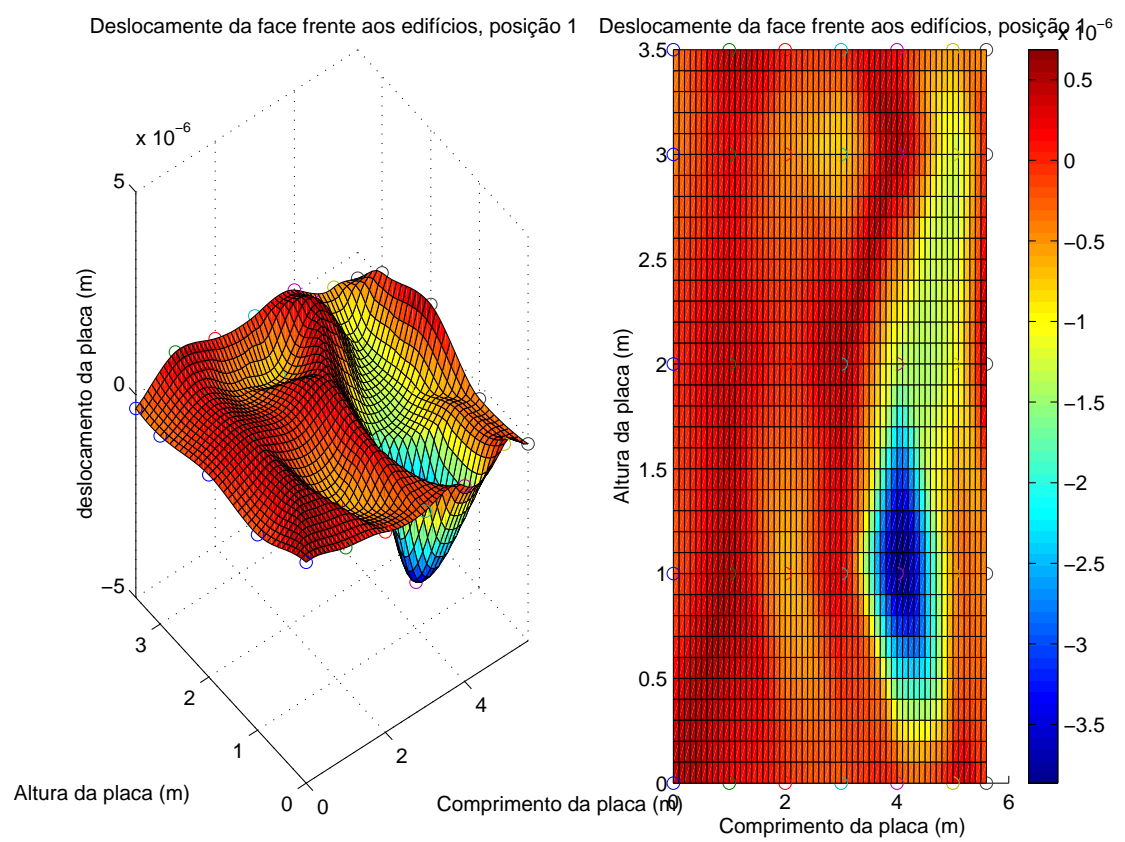

Figura 4.37: Gráfico de cores do deslocamento máximo da face frente ao edifício em um instante.

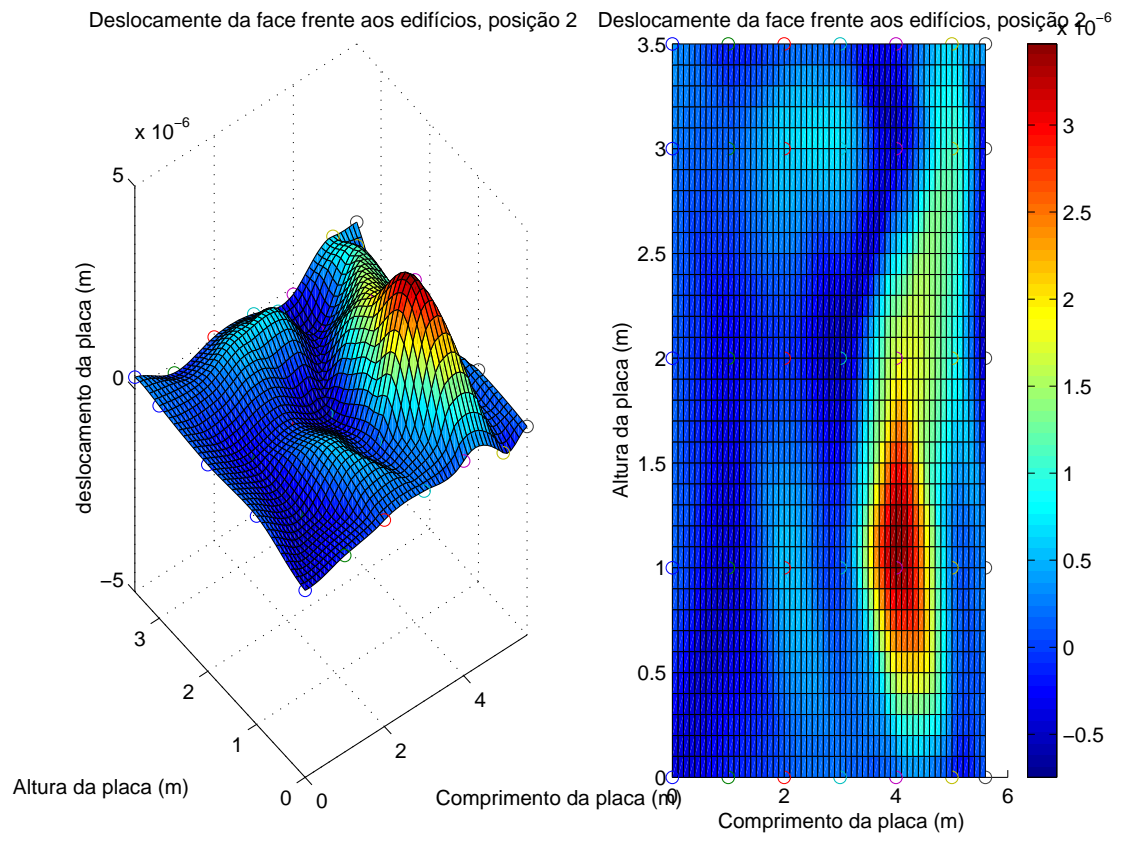

Figura 4.38: Gráfico de cores do deslocamento máximo da face frente ao edifício em outro instante .

A proposta de posicionamento dos absorvedores dinâmicos é mostrada na fig. 4.39. Os retângulos verdes com fundo claro representam a localização dos absorvedores dinâmicos nas regiões de maiores níveis de velocidade. Observa-se dificuldade de espaço para posicionar os absorvedores dinâmicos. 


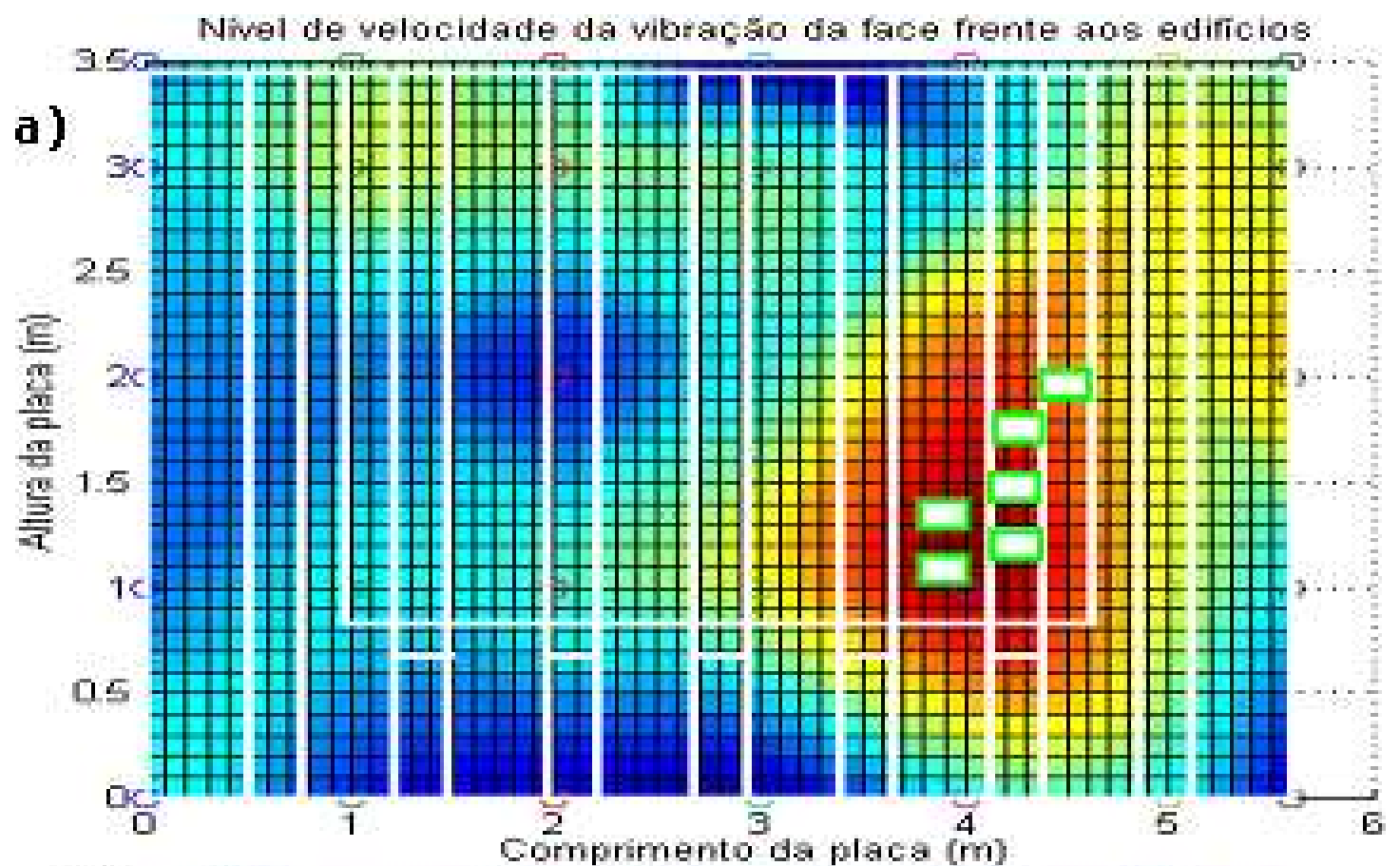

b)

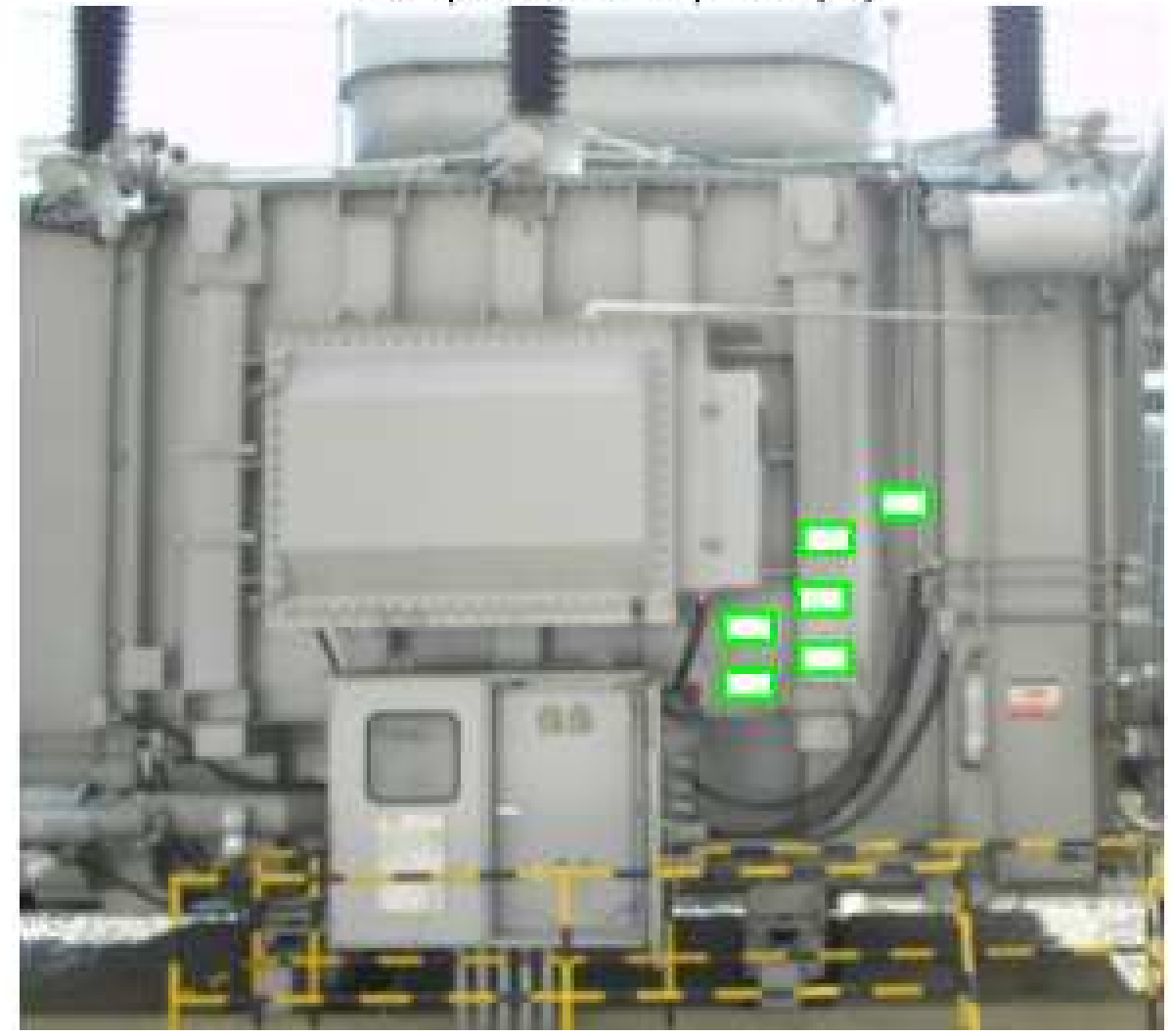

Figura 4.39: Posicionamento dos absorvedores dinâmicos na face frente ao edifício: a) usando o resultados dos níveis de velocidade, b) usando uma foto que ilustra os espaços livres. 


\subsubsection{Análise da base do transformador}

A base tem a forma geométrica mostrada na figura 4.40, a diferença das demais faces são os reforços cruzados, ao longo do comprimento e da largura. O peso do transformador encontra-se distribuído nesta face, sendo o tanque apoiado por 4 suportes. Cada suporte tem instalado dois pares de rodas de aço. O tanque só pode ser deslocado sobre umas guias de aço. As rodas estão travadas com cunhas de aço. Tais condições tem efeito sobre a vibração.

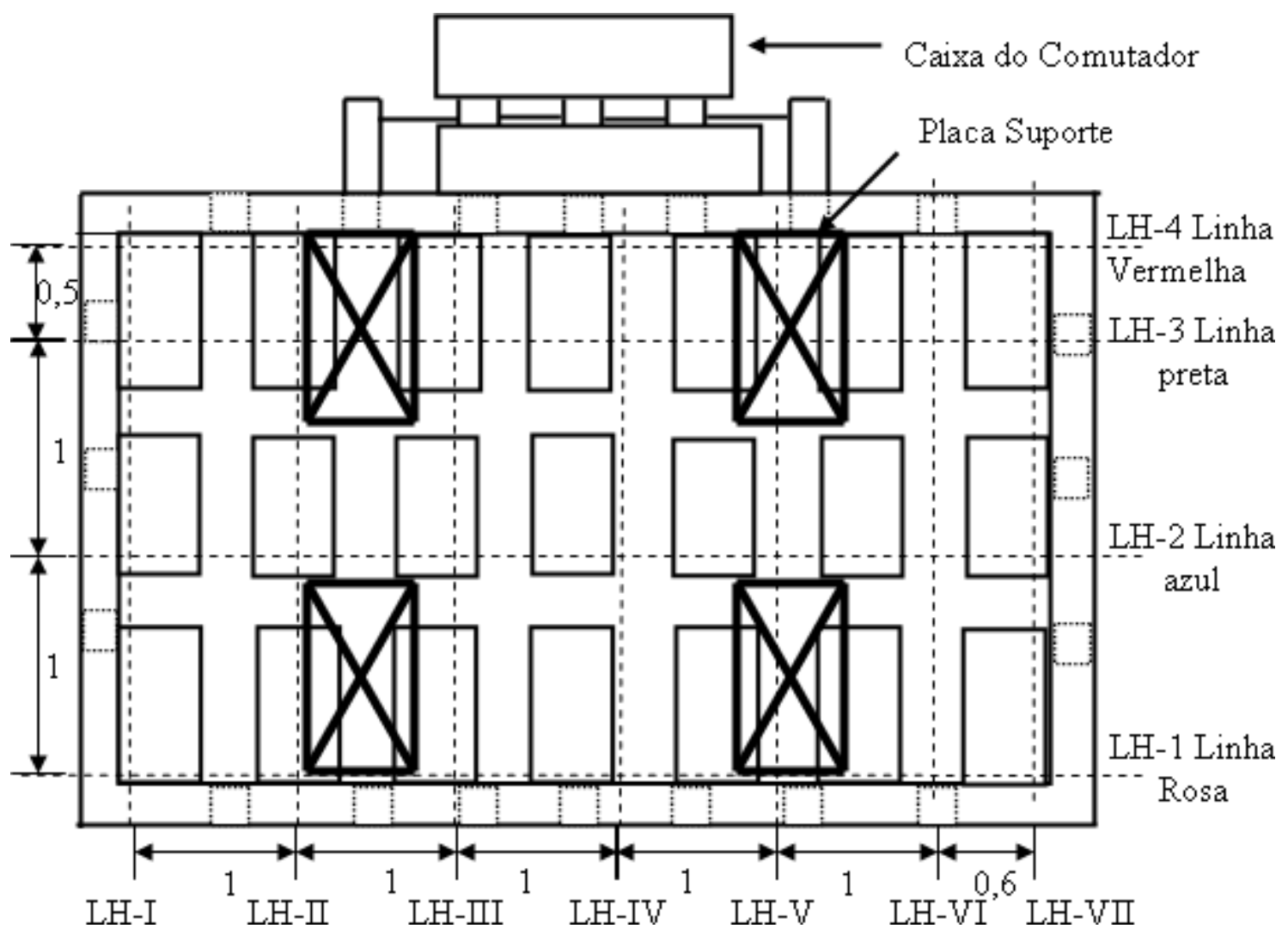

Figura 4.40: Desenho da superfície base do tanque, indicando a posição dos acelerômetros na intersecção das linhas tracejadas.

A PSD da velocidade da base é mostrada na figura 4.41. Em alguns sinais observam-se picos pequenos quase imperceptíveis, indicando que em algumas regiões há pouca vibração, estas partes estão próximas às estruturas suporte do transformador. Também se observa que as amplitudes são bastante irregulares por grupos ou por cores. 


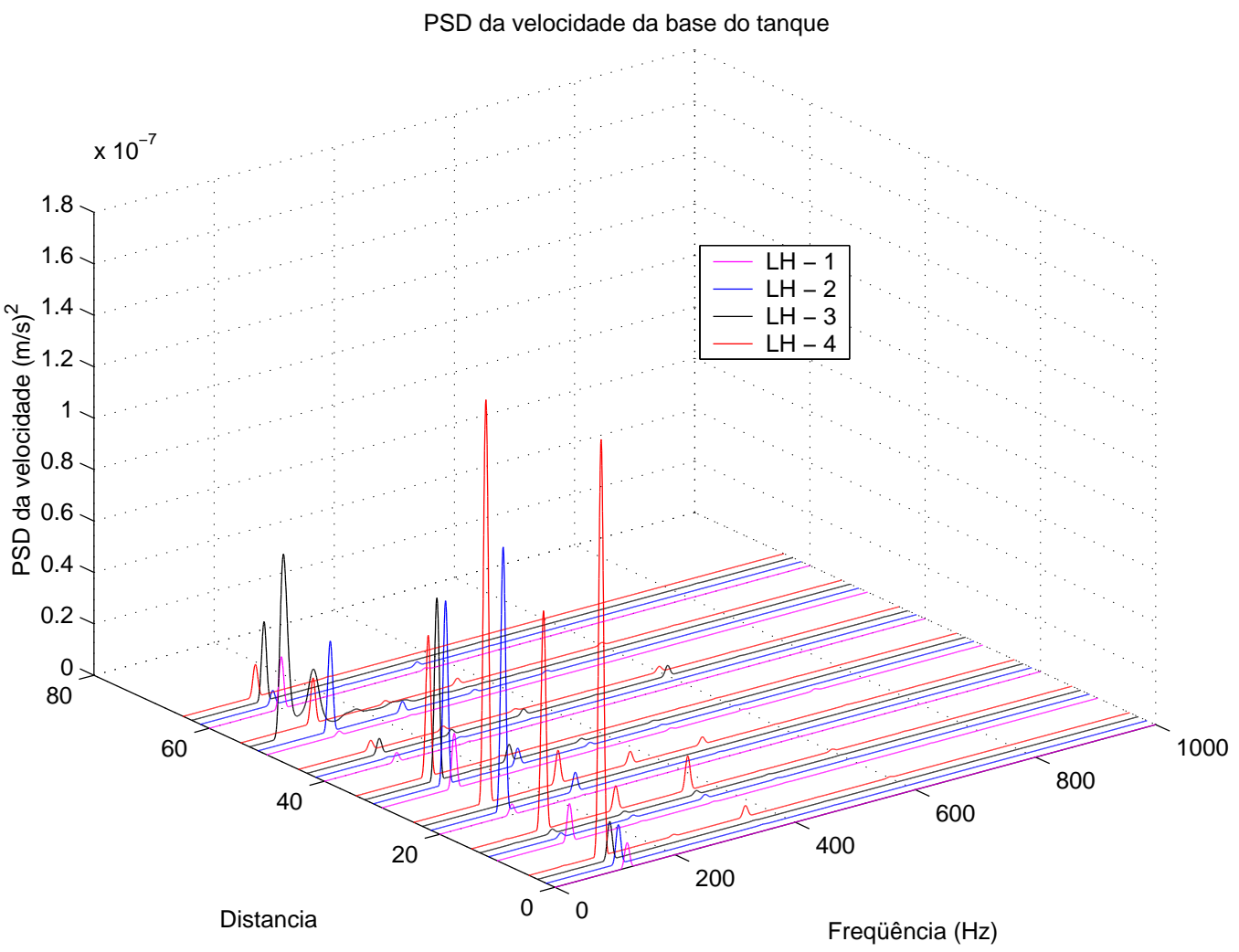

Figura 4.41: Densidade Espectral de Potência da velocidade da base do tanque.

A figura 4.42 mostra um gráfico de cores 3D mostrando os níveis de velocidade da base. Já a figura 4.43 mostra a mesma informação em um gráfico de cores 2D sobreposto ao diagrama da base. 


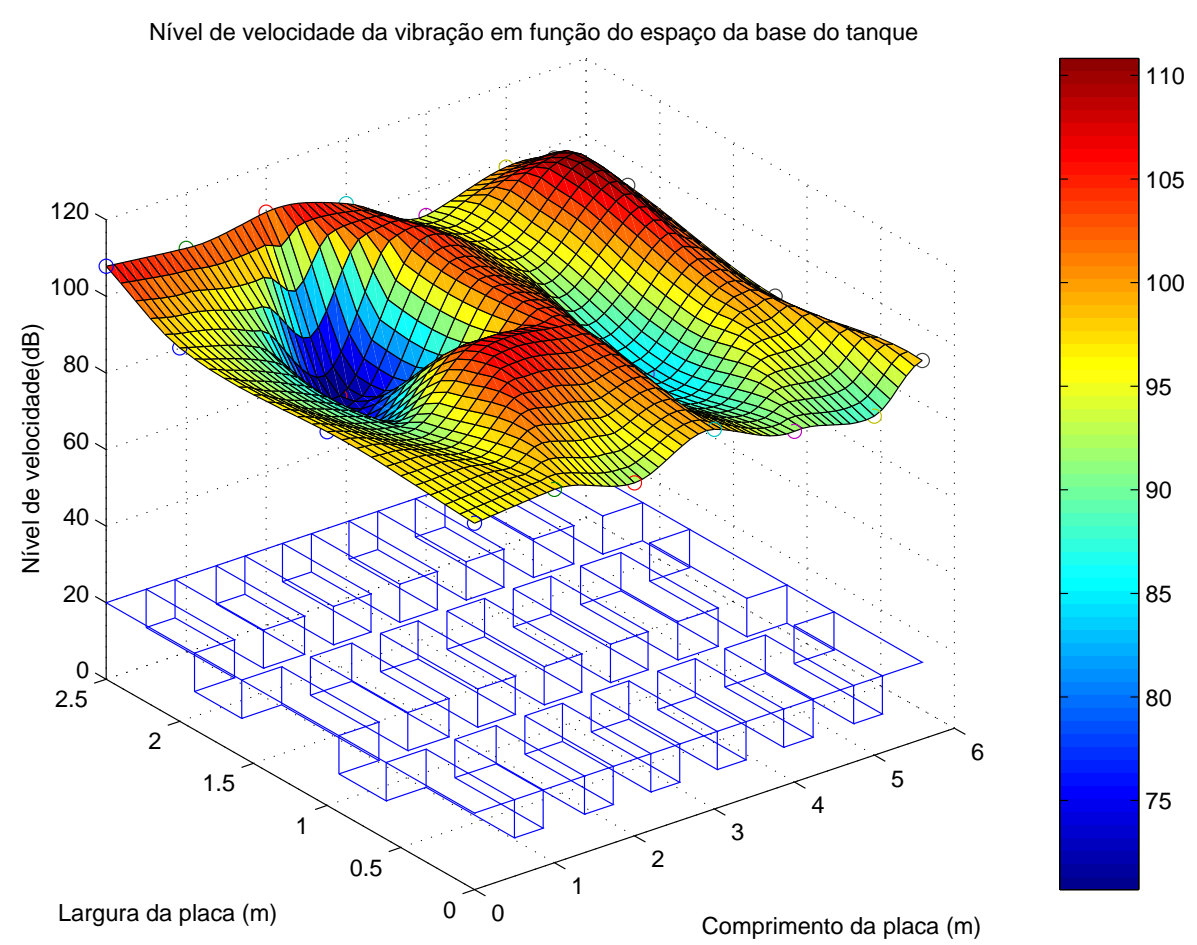

Figura 4.42: Níveis de velocidade da vibração da base do tanque

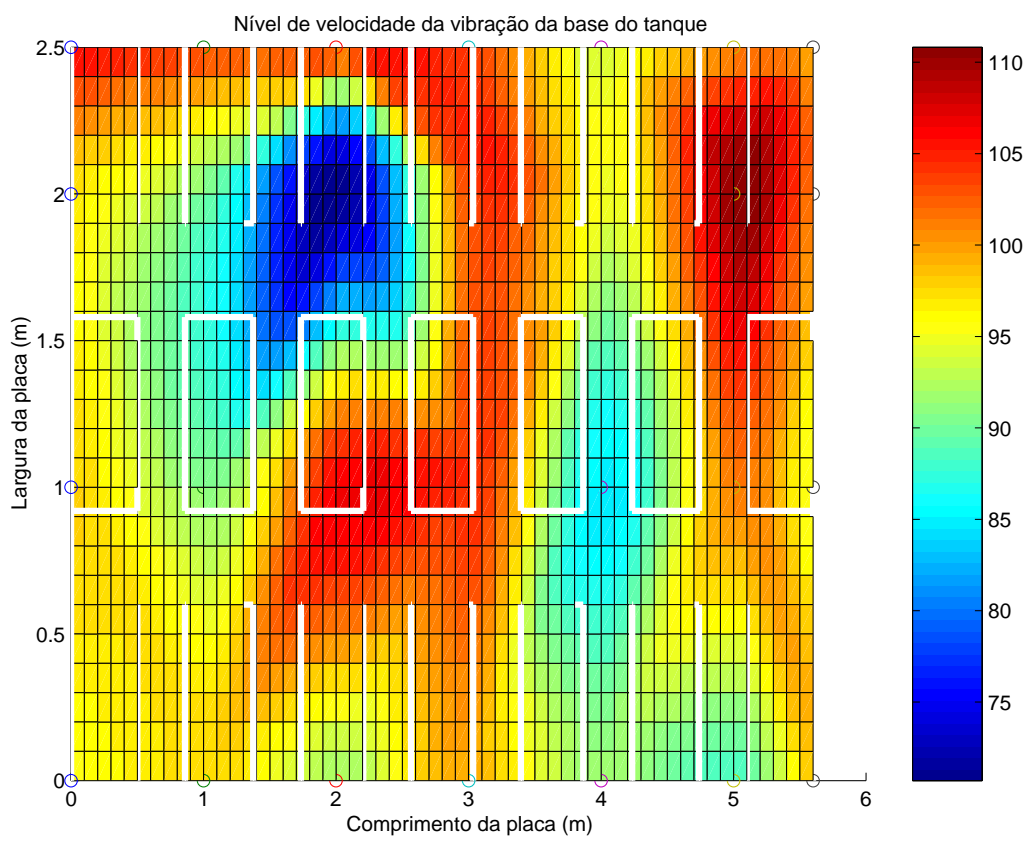

Figura 4.43: Níveis de velocidade em 2 dimensões sobreposto ao diagrama da base do tanque

O deslocamento da base é mostrado nas figuras 4.44, 4.45 e 4.46. Nesta placa os deslocamentos formam um padrão mais complexo. Como há espaço para montar amortecedores viscosos entre a base e a fundação de concreto, este tipo de dispositivo de redução de vibração foi explorado. 


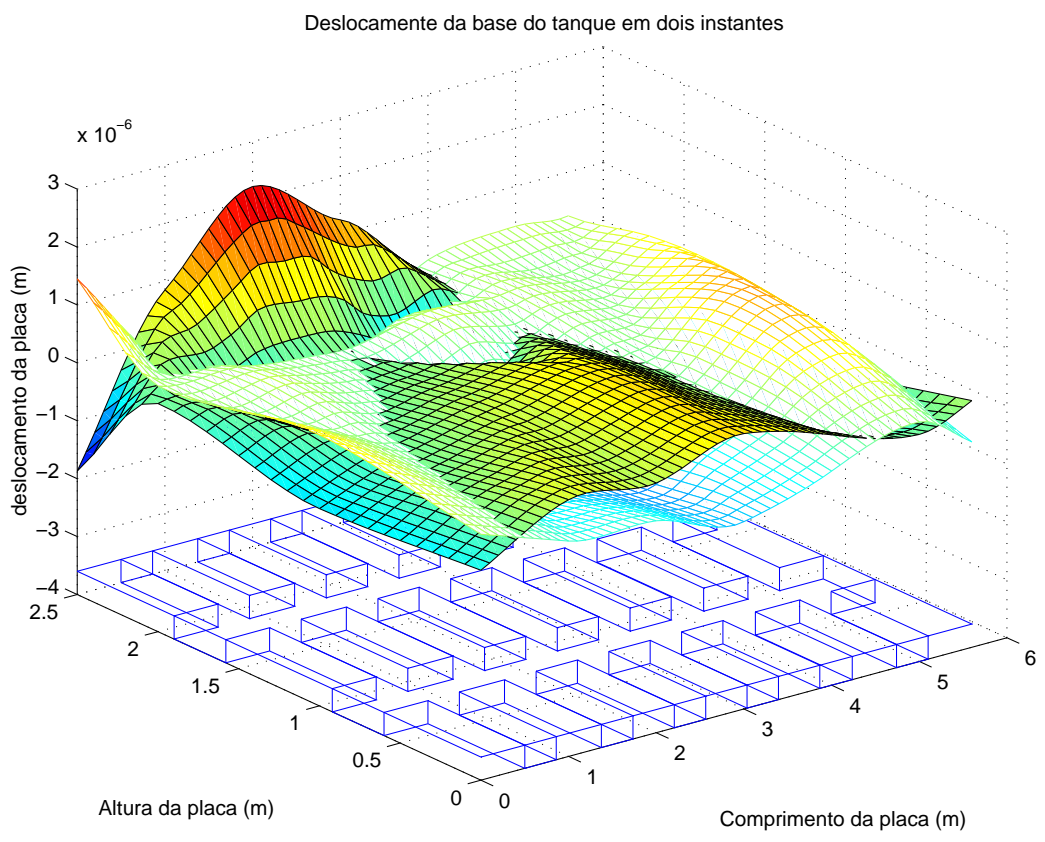

Figura 4.44: Gráfico de cores do deslocamento da base para dois instantes defasados em 180 graus.

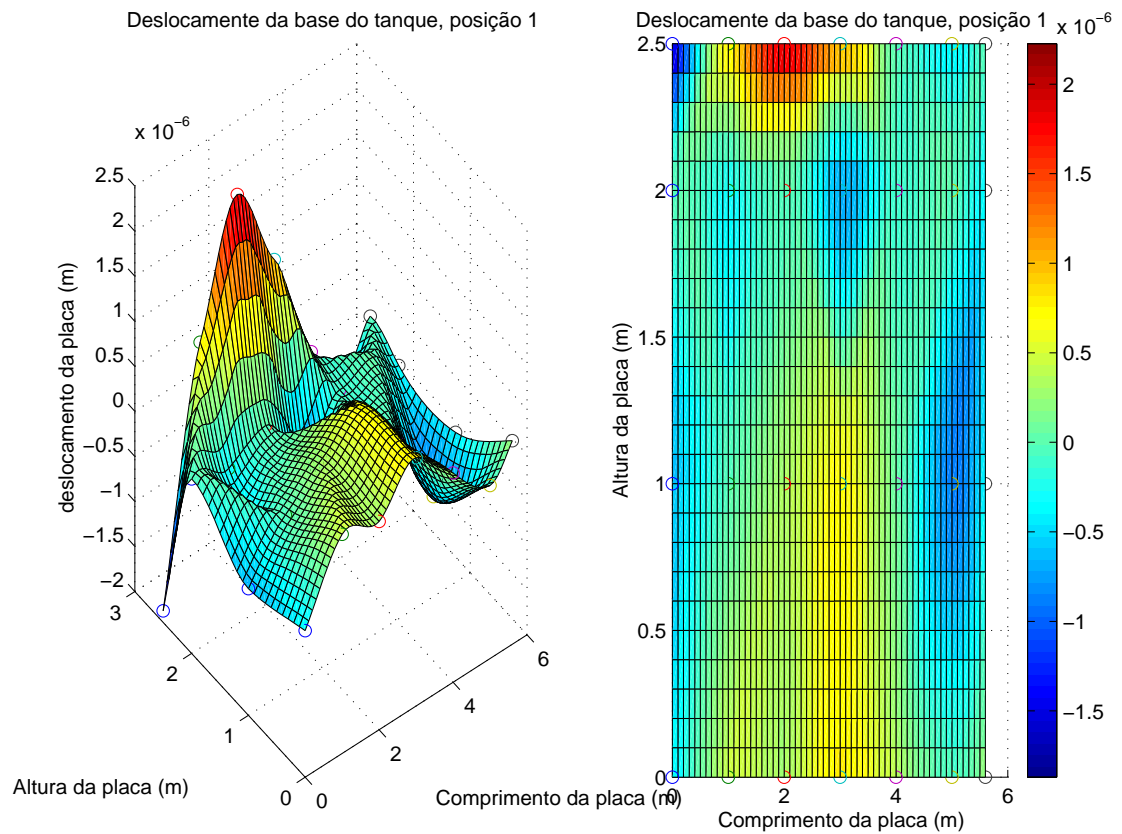

Figura 4.45: Gráfico de cores do deslocamento máximo da base em um instante de maior deslocamento. 


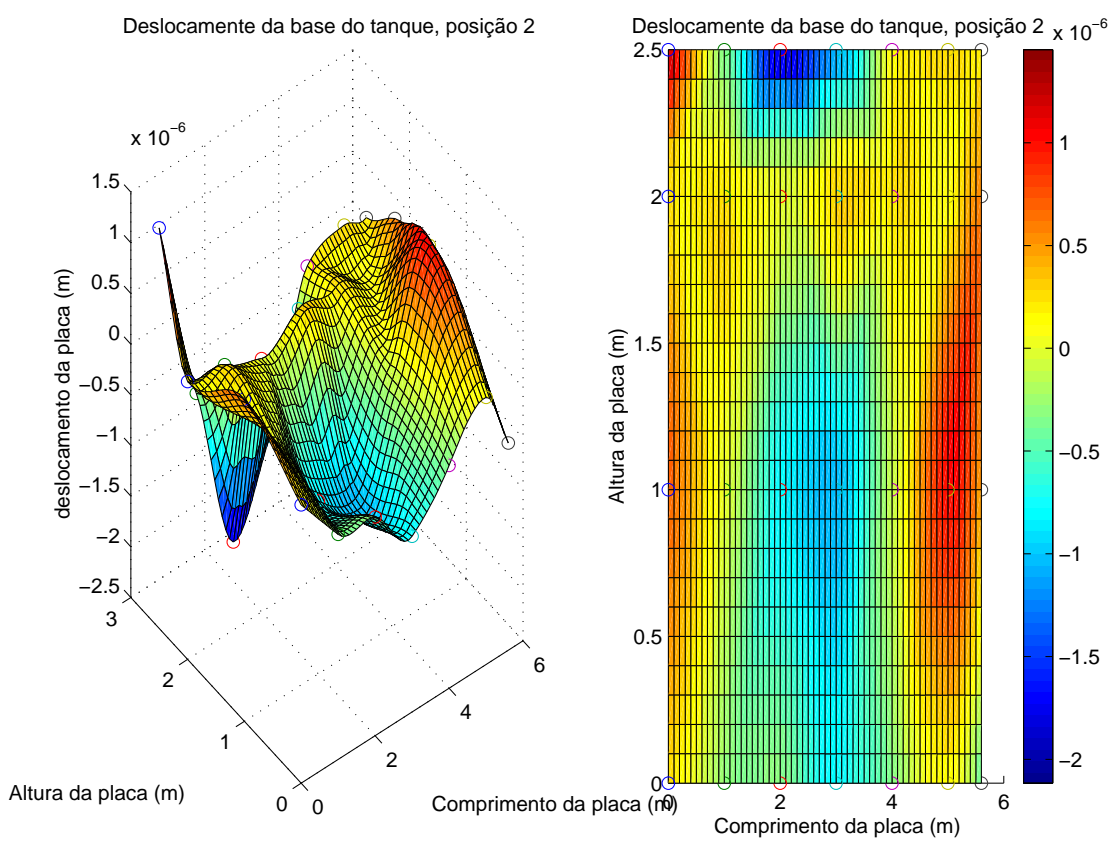

Figura 4.46: Gráfico de cores do deslocamento máximo da base em outro instante.

\subsubsection{Avaliação dos níveis de velocidade na superfície do tanque}

Os resultados de níveis de velocidade, e os de deslocamentos das superfícies do tanque, mostraram correspondência, como esperado, já que partem da mesma informação original, os sinais de aceleração. Os resultados mostram que as regiões de maiores deslocamentos coincidem com as regiões de maiores níveis de velocidade. Por acoplamento entre ar e vibração estrutural, as regiões de maiores níveis de velocidade são as regiões de maior emissão de ruído, quando a estrutura é plana, de dimensões grandes e sem obstáculos próximos para as ondas sonoras. Estes fatos permitem a seleção das regiões onde os absorvedores dinâmicos e/ou amortecedores devem ser instalados.

Outra comparação entre os níveis de velocidade e de emissão de ruído é realizado com os resultados da análise de holografia acústica da empresa $01 \mathrm{~dB}$, que são mostrados nas figuras 4.47-a e 4.47-c, nelas observa-se que a maior emissão de som na face do edifício encontra-se na proximidade da caixa do comutador, no lado direito. As figuras 4.47-b e 4.47-d são fotos com detalhes da face frente ao edifício. As figuras de holografia acústica são comparáveis com as figuras 4.47-e e 4.47-e que indicam o nível de velocidade da face frente ao edifício. As regiões vermelhas estão próximas da caixa do comutador, no lado direito. 


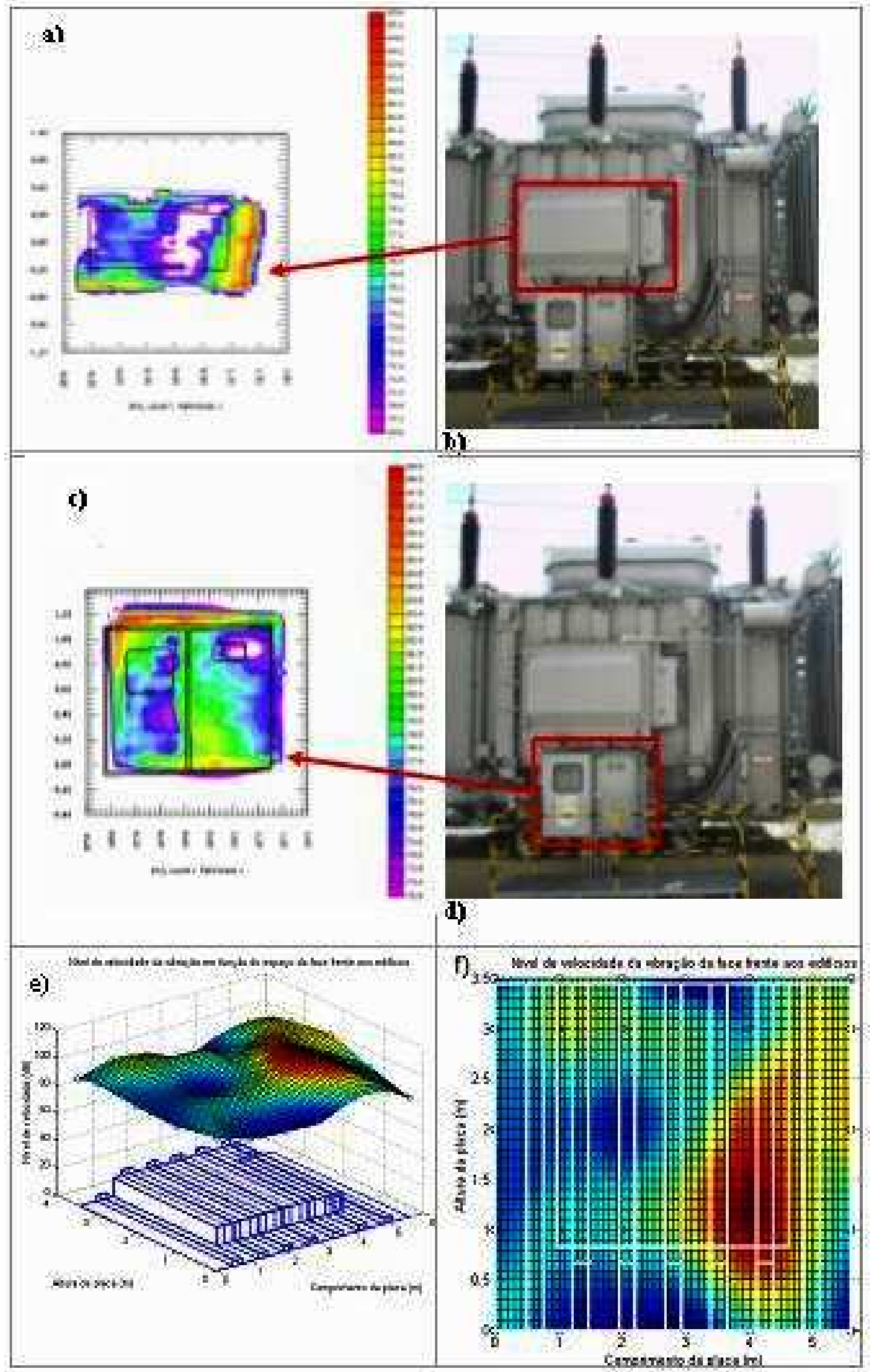

Figura 4.47: Comparação dos resultados de holografia acústica com os obtidos pelo método de nível de velocidade da superfície na face frente aos edifícios. 
Os níveis de velocidade global foram calculados por face, os valores são apresentados na tabela 4.2. Observa-se que os valores estão entre 107, $25 d B$ (re, $v_{\text {ref }}$ ) e 109, $59 d B\left(r e, v_{r e f}\right)$ o nível de velocidade médio do global é $L_{v t-\text { medio }}=108,49$ $d B\left(r e, v_{r e f}\right)$ e o desvio padrão é $0,89 d B\left(r e, v_{r e f}\right)$. Os dados sugerem que a emissão do som é quase homogênea em cada face.

Tabela 4.2: Níveis de velocidade do tanque

\begin{tabular}{|l|l|l|l|l|l|}
\hline tanque & Face rua & Face oposta & Face abaixo & Face edifício & Face atrás \\
\hline$L_{v t-\text { medio }}$ & $109,06 d B$ & $109,59 d B$ & $108,41 d B$ & $107,25 d B$ & $108,15 d B$ \\
\hline
\end{tabular}

\subsection{Projeto da montagem de amortecedores vis- $\operatorname{cosos}$}

A base suporta o peso e as forças verticais do núcleo e das bobinas do transformador. A base encontra-se apoiada sobre quatro suportes com rodas, que recebem o peso. A particularidade de que a base se encontra a $0,475 m$ de uma superfície de concreto se torna vantajosa, pois possibilita a montagem de amortecedores viscosos da base à fundação de concreto. Os amortecedores devem funcionar com deslocamentos menores do que 0,01 $\mathrm{mm}$, e portanto, as exigências de precisão dos componentes de montagem é da ordem de milésimos de $m m$. Estes dispositivos serão abordados em outra seção.

Devido à existência de forças na direção horizontal, produz-se uma rotação do tanque, fato que foi observado na análise de ODS. Três dos quatro suportes se movimentam. Foram colocados os amortecedores em posição inclinada formando um ângulo de 45 graus com o chão, como se mostra na fig. 4.48. Na base foram colocados 8 amortecedores distribuídos conforme mostra a fig. 4.49. Os quadrados verdes com fundo branco representam a posição da montagem dos amortecedores. 


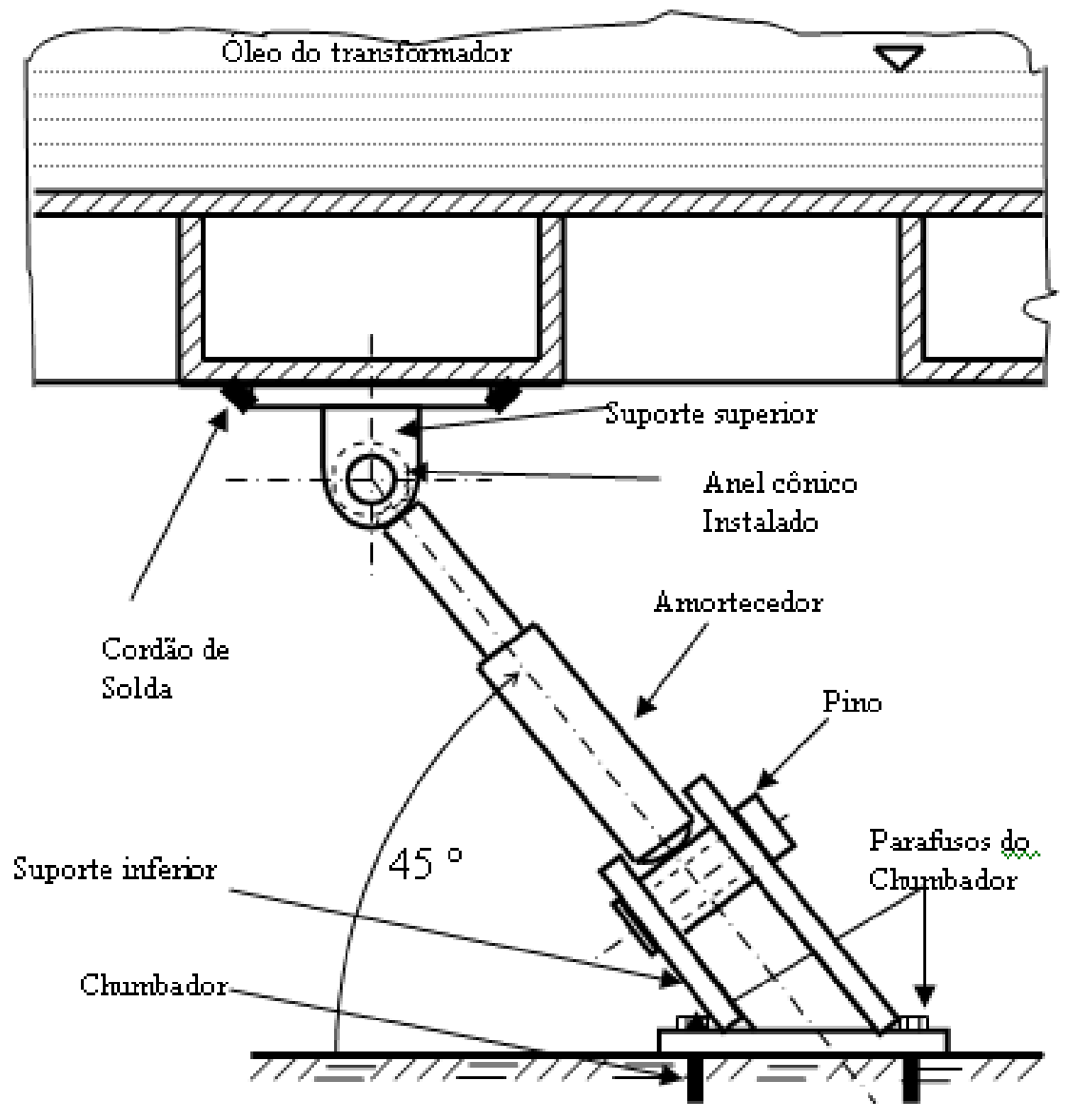

Figura 4.48: Desenho do amortecedor montado entre a base e a fundação de concreto.

Face frente aos prédios

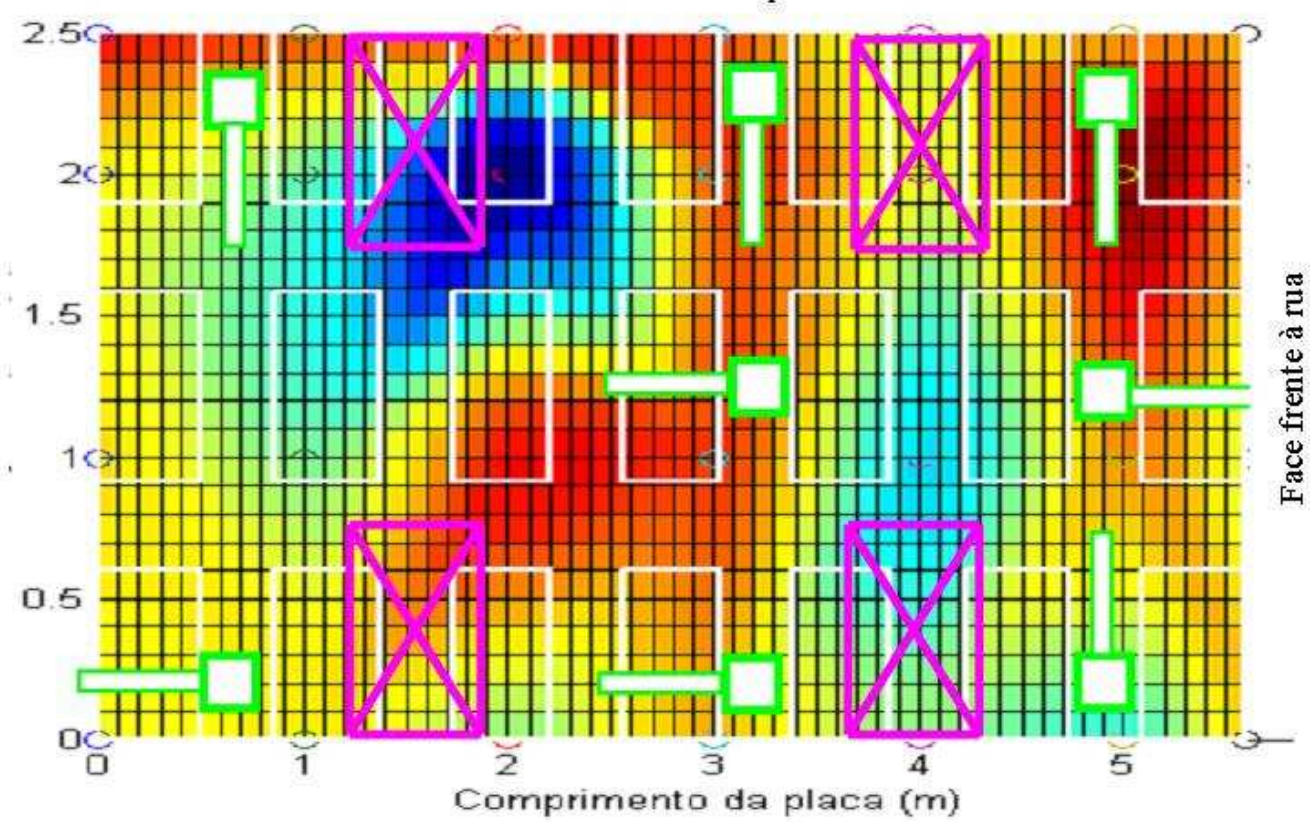

Figura 4.49: Distribuição dos amortecedores na base do tanque. 


\subsection{Projeto do Absorvedor Dinâmico}

Para diminuir a vibração e o ruído do transformador, foram instalados absorvedores dinâmicos nas paredes do tanque. Quando a freqüência natural dos absorvedores dinâmicos é sintonizada um pouco acima da freqüência de excitação do transformador, os absorvedores dinâmicos reduzem a oscilação de sua base e apresentam significativa amplitude de oscilação em sua massa sísmica. A energia cinética da base é dirigida para a massa sísmica. Neste sentido eles absorvem a energia cinética da base. Se a massa sísmica se acopla fracamente com o ar, o absorvedor dinâmico irá reduzir a emissão de ruído acústico.

\subsubsection{Equação do movimento do Absorvedor Dinâmico}

Para modelar o funcionamento do absorvedor dinâmico, utiliza-se um sistema de 2 massas com 2 molas, ambas amortecidas. Uma primeira análise usa este modelo bastante simples com dois graus de liberdade, conforme apresentado no esquema da figura 4.50 .

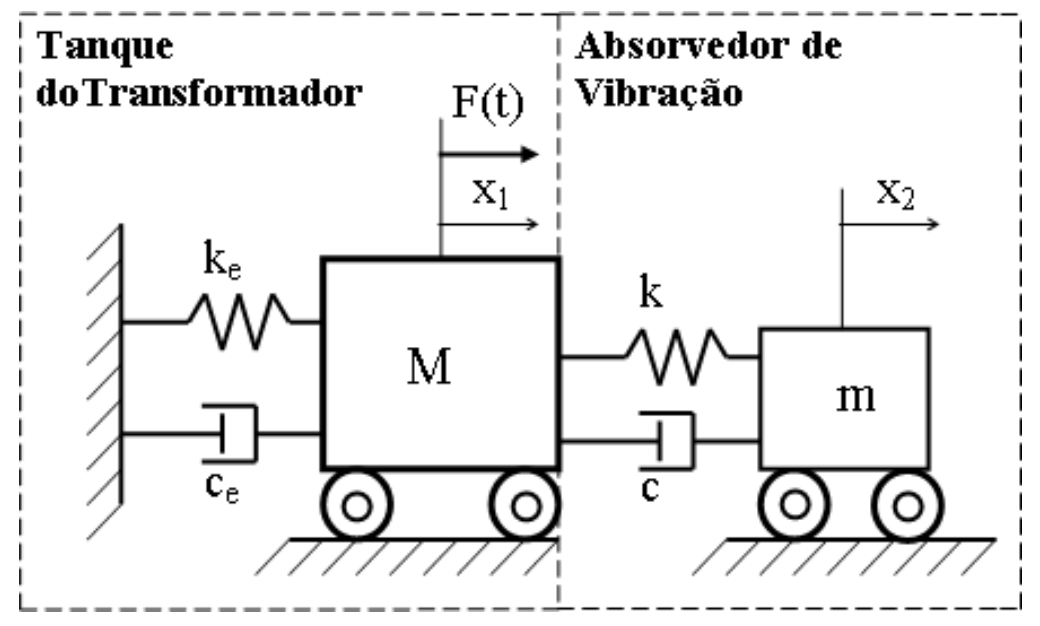

Figura 4.50: Diagrama de um sistema duas massas e duas molas amortecido

A equação do movimento do modelo físico da figura 4.50 é:

$$
\begin{gathered}
M \ddot{x}_{1}+\left(c_{e}+c\right) \dot{x}_{1}-c_{a} \dot{x}_{2}+\left(k_{e}+k\right) x_{1}-k x_{2}=f(t) \\
m \ddot{x}_{2}+c \dot{x}_{2}-c_{a} \dot{x}_{1}+k x_{2}-k x_{1}=0
\end{gathered}
$$




\subsubsection{Características fundamentais do absorvedor dinâmico}

Para projetar o absorvedor dinâmico usando a eq. 4.1 e a eq. 4.2, primeiro calculam-se os coeficientes dinâmicos do tanque, massa e rigidez equivalente, e depois do Absorvedor, Mercado E. Gonzalez (2007). A parede do tanque é modelada como um simples sistema de massa-mola-amortecedor. Os coeficientes de massa e de rigidez foram estimados por simulação numérica, usando-se o Método dos Elementos Finitos (MEF).

Nesta trabalho empregou-se um processador de elementos finitos, o software aberto CalculiX. com o qual, modelou-se uma face do tanque do transformador e calculou-se o coeficiente dinâmico de rigidez e a massa efetiva. Na modelagem da face consideram-se a geometria, as dimensões e o material que compõe a face do tanque.

A geometria do tanque do transformador foi extraída do desenho denominado Dimensões externas fornecido pela Siemens Ltda. à Eletropaulo. São desenhos de um transformador regulador de potência trifásico 30/40 MVA 138-13,8/11,95 $k V A$. Uma face tem 3,06 $m$ de altura, 5,306 $m$ de comprimento e 0,01 $m$ de espessura. Os reforços estruturais tem 0,012 $m$ de espessura, 0,2 $m$ de largura e $3,06 m$ de altura.

Para calcular o coeficiente de rigidez do tanque com o modelo geométrico da face, aplica-se uma força de forma pulso retangular, $F$ de $1 \mathrm{~N}$, durante um intervalo de tempo curto, $\Delta t=0.0001$ comparado ao período da menor da freqüência natural do sistema. A figura 4.51 ilustra a simulação MEF da carcaça submetida a uma força no ponto médio da face. A resposta em deslocamento do ponto central é gravada em um arquivo. O sinal no tempo esta representado na figura 4.52-a. 


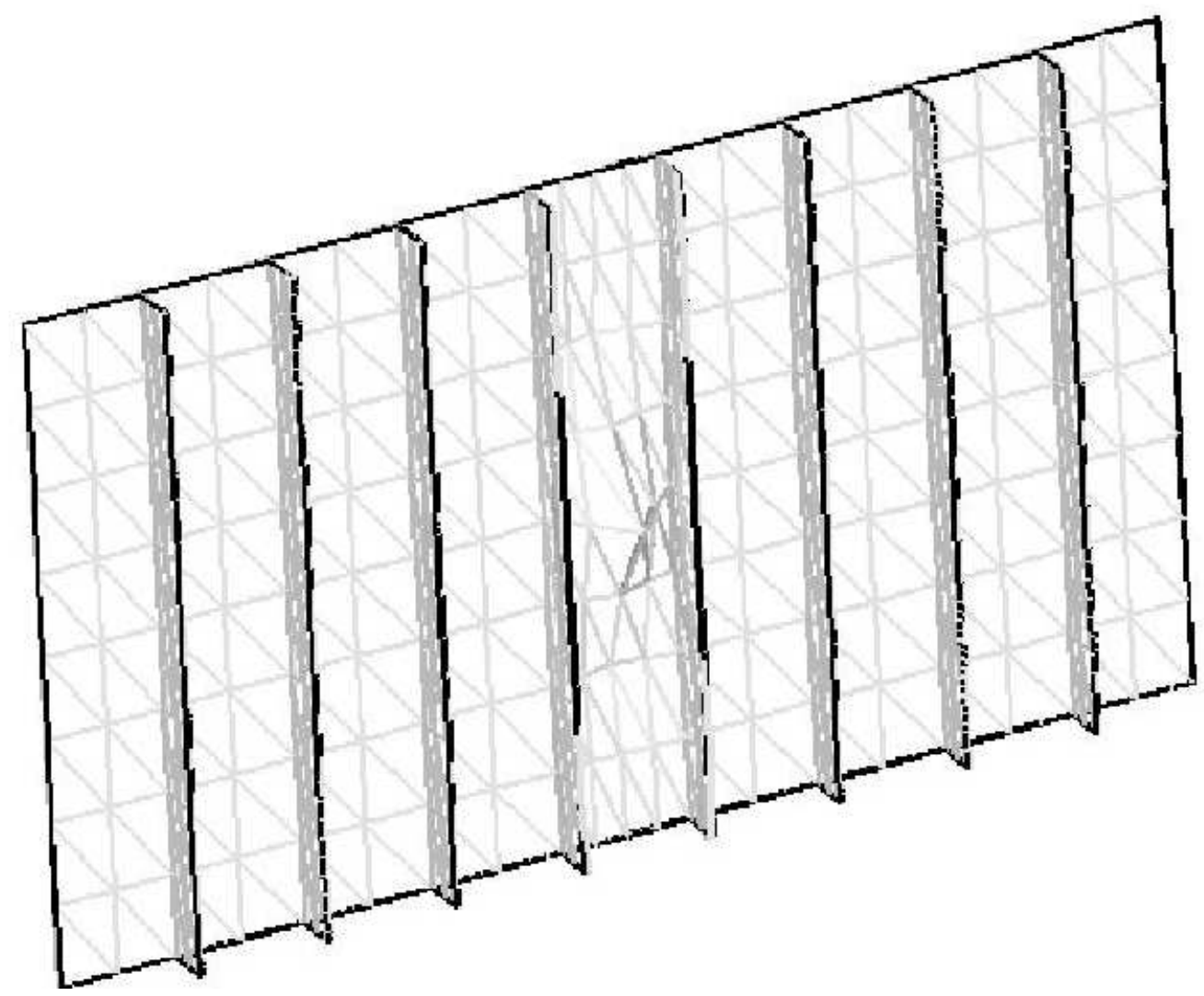

Figura 4.51: Simulação por EF da força em um ponto da face do tanque

O gráfico da resposta em FFT (Transformada rápida de Fourier) está mostrado na fig. 4.52-b. O primeiro pico do deslocamento no tempo decorrente de uma força tipo degrau é o dobro do deslocamento estático e permite avaliar a rigidez equivalente da face. O primeiro pico na FFT do sinal de deslocamento, decorrente de um pulso retangular estreito, permite estimar a freqüência natural do sistema. A massa efetiva decorre da rigidez e da freqüência natural.

O coeficiente de rigidez da parede do tanque é

$$
k_{e}=\frac{F}{X \max / 2} .
$$

Conhecida a primeira freqüência natural e o coeficiente de rigidez determinase a massa aparente $M$ da parede do tanque:

$$
M=\frac{k_{e}}{\omega_{n}^{2}} .
$$

onde a freqüência natural em $r d / s$ é dada por

$$
\omega_{n}=2 . \pi . f_{n} .
$$



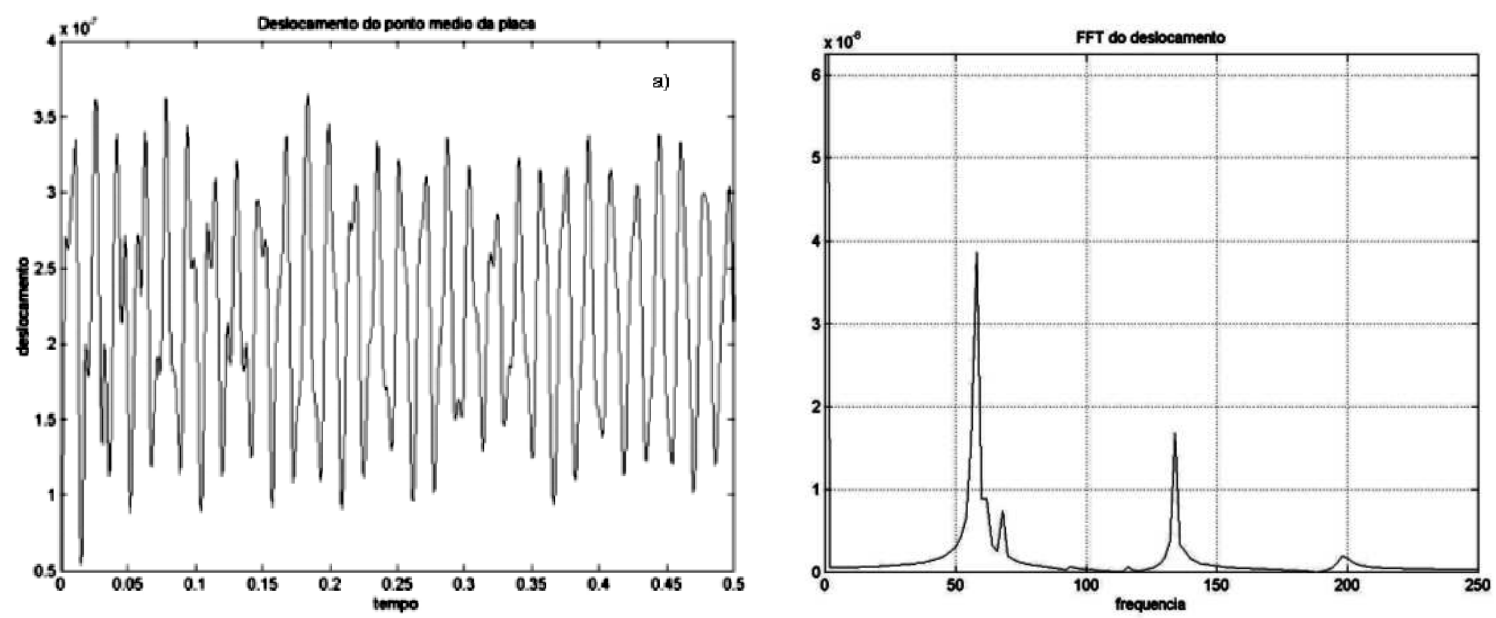

Figura 4.52: Sinal do deslocamento do ponto central da parede do tanque: a) No domínio do tempo, b) No domínio da freqüência

O primeiro pico ocorre na freqüência de $58 \mathrm{~Hz}$ e seu valor é $3,9 x 10^{-8} \mathrm{~m}$. O valor da rigidez resulta $5,1282 \times 10^{7} \mathrm{~N} / \mathrm{m}$ e o valor da massa aparente no ponto médio da face resulta $386 \mathrm{~kg}$. Adotou-se o coeficiente de amortecimento $c_{e}=$ 10000, $0 \mathrm{Ns} / \mathrm{m}$.

Den Hartog recomenda que a freqüência natural do absorvedor dinâmico sem amortecimento $f_{a}$ seja quase igual à freqüência de excitação $f_{e}$ da superfície base. A fig. 4.53 mostra o comportamento de um absorvedor dinâmico sem amortecimento, curva com linhas interrompidas, e com um amortecimento pequeno, linha continua.

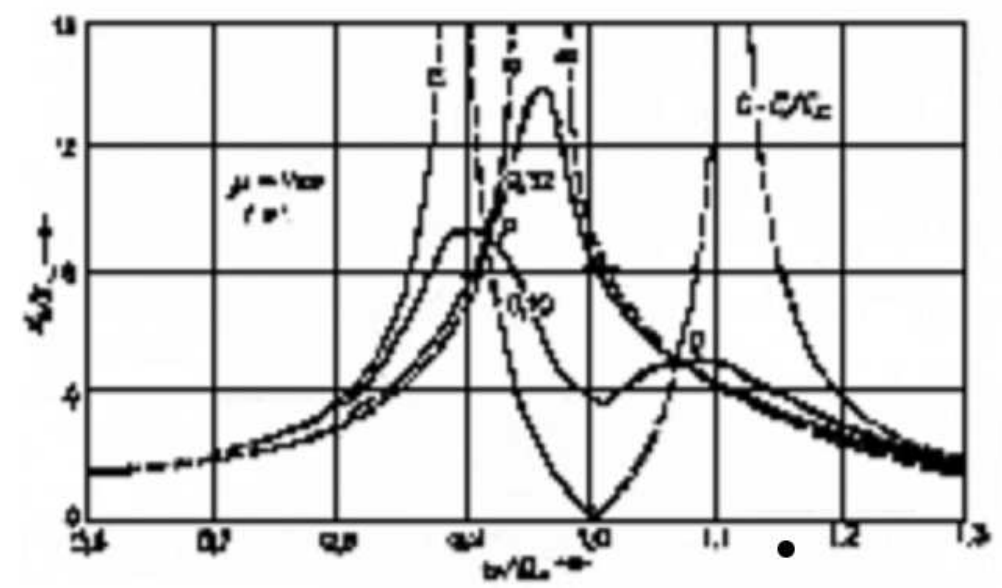

Figura 4.53: Curva que mostra o comportamento do absorvedor dinâmico com e sem amortecimento, extraído de Hartog (1972)

Para projetar o absorvedor dinâmico, a freqüência natural do absorvedor é selecionada um pouco acima da freqüência de excitação da base, $f_{a}=123 \mathrm{~Hz}$. O 
coeficiente de rigidez $k$ do absorvedor dinâmico, é calculado pela equação 4.6.

$$
k=\left(2 \pi \cdot f_{a}\right)^{2} m
$$

Assumindo vários valores de $c_{a}$, resolvem-se a eq. 4.1 e a eq. 4.2 , simultaneamente, tendo como variável a massa do absorvedor dinâmico para várias condições de amortecimento. $\mathrm{O}$ fator de amortecimento relaciona o valor do coeficiente de amortecimento com a massa e a freqüência natural e é definido por

$$
\xi=\frac{c_{a}}{2 \cdot m \cdot \omega_{n}}
$$

A equação 4.7 faz-se necessária por que a massa não é um valor constante. Ao resolver a eq. 4.1 e a eq. 4.2 obtém-se o deslocamento máximo da parede do tanque e do absorvedor dinâmico para cada massa $m$. O deslocamento máximo da parede do tanque é um índice de desempenho do absorvedor dinâmico. A figura 4.54 mostra as curvas que representam o máximo deslocamento do ponto médio da parede do tanque em função da massa do absorvedor dinâmico $m$.

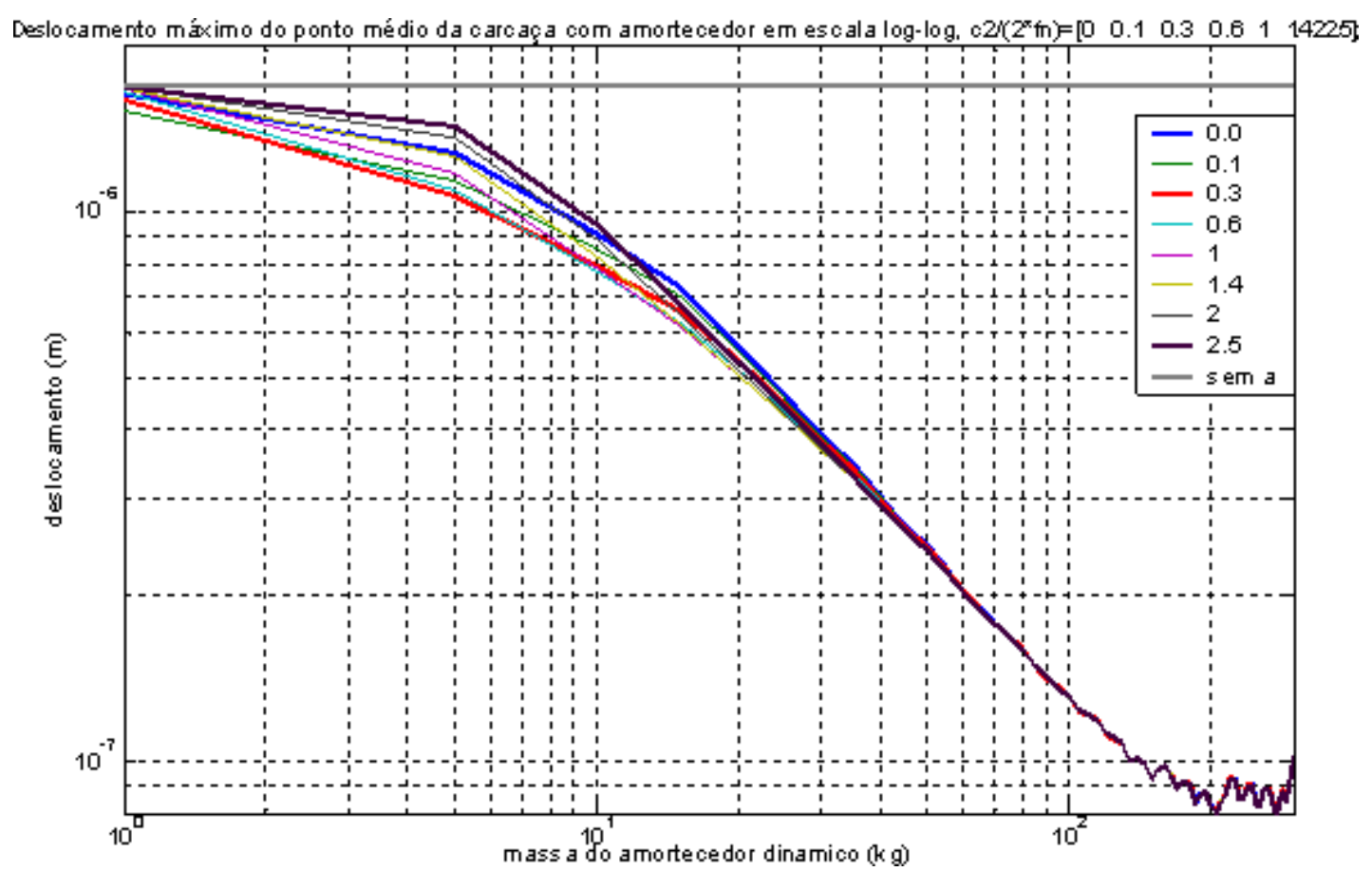

Figura 4.54: Amplitude em função da massa do absorvedor dinâmico e do coeficiente de amortecimento.

A fig. 4.55 mostra dois grupos de curvas que representam o máximo deslocamento do ponto médio da parede do tanque, é o grupo de curvas na parte inferior do gráfico. O deslocamento do absorvedor dinâmico, representado pelo grupo de 
curvas da parte superior do gráfico. As curvas resultam de diferentes valores de massa e de coeficiente de amortecimento do absorvedor dinâmico.

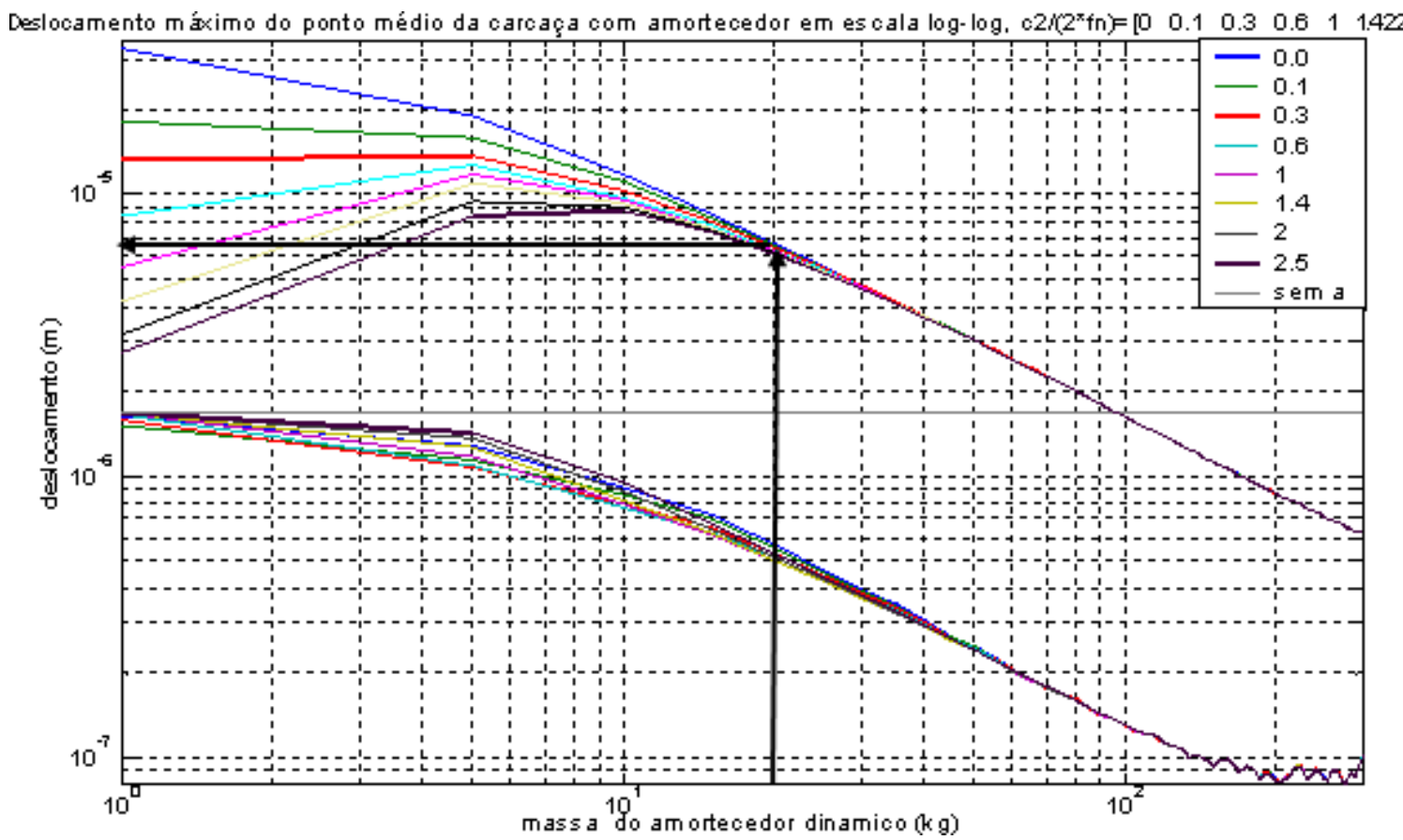

Figura 4.55: Comparação do deslocamento da carcaça e do absorvedor dinâmico.

Da fig. 4.55, observa-se que o fator $\frac{c_{a}}{2 . f_{a}}$ é relevante quando as massas são pequenas. Com massas maiores que $20 \mathrm{~kg}$ o fator $\frac{c_{a}}{2 \cdot \omega_{n}}$ não apresenta vantagem em relação a um absorvedor dinâmico sem amortecimento (curva azul). A fim de verificar estes resultados preliminares foi construído um primeiro protótipo, escolhendo-se uma massa de $20 \mathrm{~kg}$. O absorvedor dinâmico deve possibilitar acrescentar ou diminuir a massa durante os testes.

A fig. 4.56, ilustra que com a escolha de $20 \mathrm{~kg}$ e sem ter amortecimento, $\frac{c_{a}}{2 . \omega_{n}}=0$, é possível reduzir $70 \%$ do deslocamento da parede do tanque. 


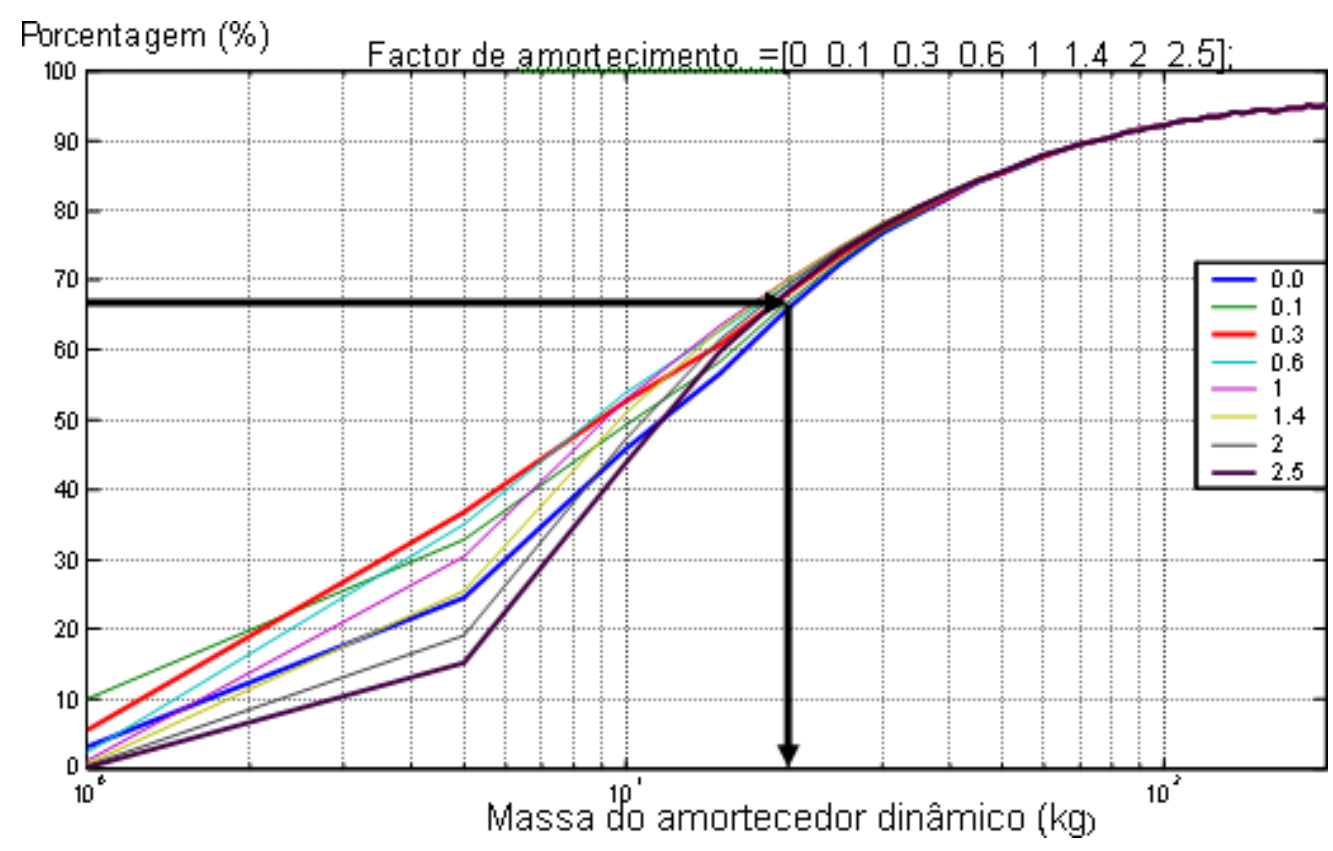

Figura 4.56: Comparação do deslocamento da parede do tanque e do absorvedor dinâmico.

\subsubsection{Simulação numérica do primeiro absorvedor dinâmico}

Para avaliar o desempenho de um absorvedor dinâmico AD1, simulou-se o comportamento do AD1 colocando-se uma mola e uma massa no ponto médio da face, e aplicando 3 forças senoidais na linha de simetria vertical de cada painel, a distância vertical entre as forças é de $0,75 \mathrm{~m}$, sendo 9 painéis, aplicaram-se 27 forças ao todo. A fig. 4.57 mostra a simulação do AD1.

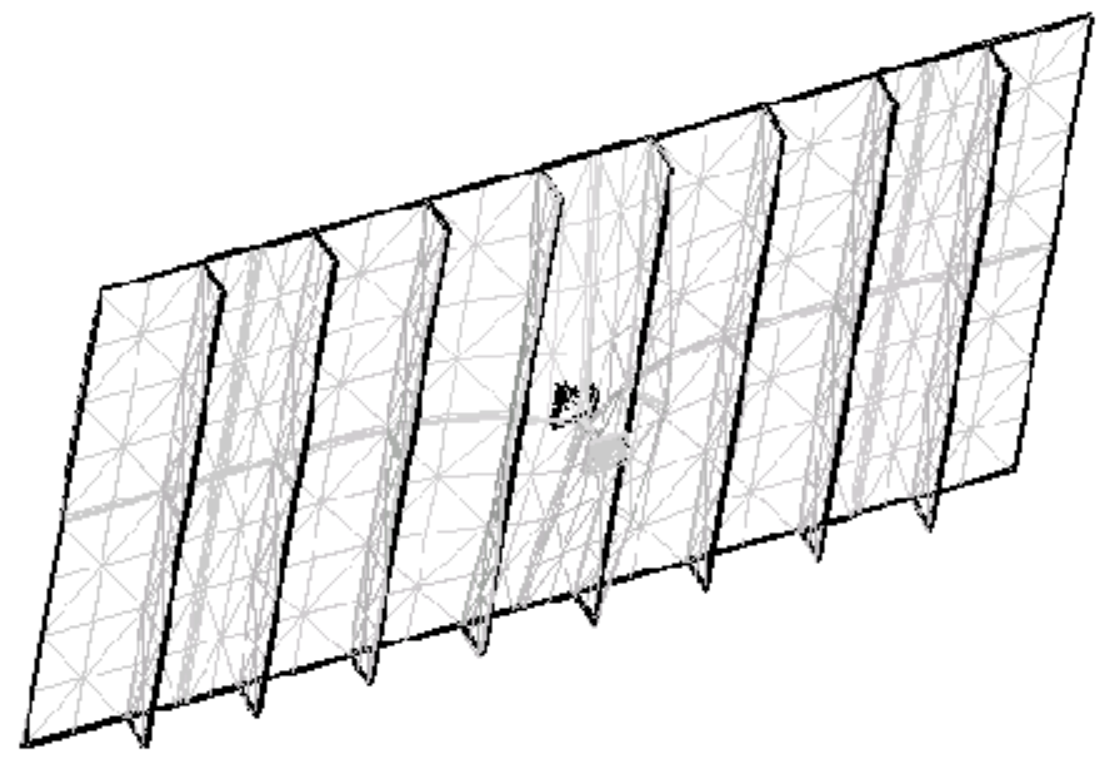

Figura 4.57: Simulação do funcionamento do AD1 no ponto médio do tanque 
Observa-se que com um absorvedor dinâmico de $20 \mathrm{~kg}$ no centro da parede do tanque obtém-se reduções dos deslocamentos. Nos pontos que estão a 0,75 $m$ acima ou abaixo do AD1 (linha vertical) a redução é de 50\%, mas na direção horizontal (a dois metros do AD1) obteve-se redução de apenas $25 \%$. No ponto médio obteve-se quase $70 \%$ de redução do deslocamento. Avalia-se que será necessário colocar mais de um absorvedor dinâmico para se garantir uma queda significativa da vibração.

\subsubsection{Cálculo das dimensões do primeiro absorvedor dinâ- mico}

Definida a massa e a freqüência, têm-se todos os dados necessários para projetar o AD1. Se requer que o AD1 tenha um modo de vibrar, na direção perpendicular à superfície do tanque, por isso a proposta é usar uma mola de chapa de aço conformada, apoiada em uma barra chata, no outro extremo, de modo que só tenha deslocamento na direção horizontal em sua instalação. A massa do AD1 é construído de várias barras chatas, unidas com parafusos, de maneira que se possa modificar a massa. A figura 4.61 ilustra a forma geométrica proposta e o modelo físico usado para os respectivos cálculos.

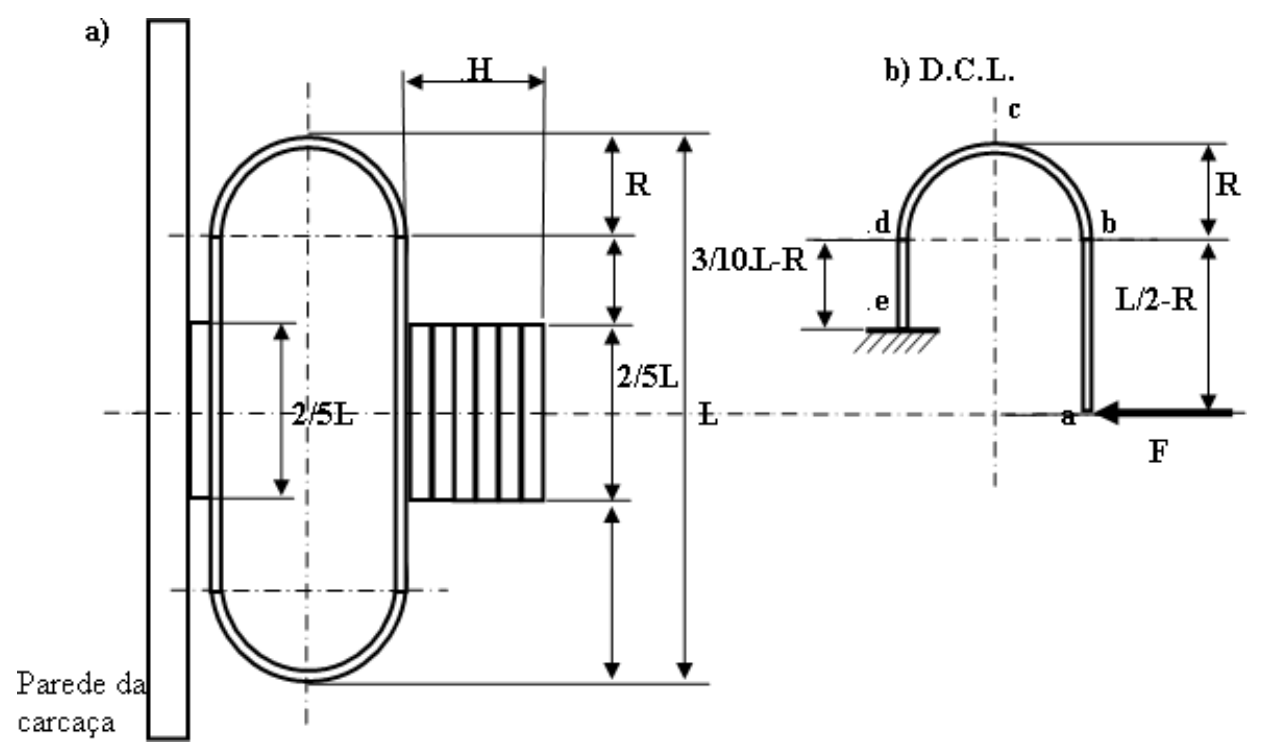

Figura 4.58: Desenho do AD1: a) Esquema com as proporções b) Diagrama de corpo livre da mola.

Dada uma uma força $F$ arbitrária, calcula-se o deslocamento total, usando o diagrama da figura 4.61-b. Para calcular o deslocamento total, somam-se os deslocamentos parciais nos pontos $a, b, c, d$, e por último em $e$ na viga engastada. Para os cálculos dos deslocamentos parciais e seus respectivos coeficientes de 
rigidez, usam-se as fórmulas recomendadas por Juvinall (1991).

O deslocamento produzido por uma força em uma viga engastada é dado por

$$
\delta_{a}=\frac{F L^{3}}{3 E I_{n}}
$$

e o coeficiente de rigidez é a razão

$$
k_{a}=\frac{F}{\delta_{a}} .
$$

O deslocamento produzido por um momento fletor em uma viga engastada é calculado por

$$
\delta_{a M}=\frac{M_{a} \cdot L^{2}}{2 E \cdot I_{n}}
$$

e o coeficiente de rigidez resultante é

$$
k_{a M}=\frac{M_{a}}{\delta_{a M}}
$$

onde $F$ é uma força aplicada, $k_{a}$ é o coeficiente de rigidez no ponto de aplicação da força, $M_{a}$ é o momento fletor aplicado, $k_{a M}$ é o coeficiente de rigidez associado ao momento fletor, $L_{a}$ é o comprimento da viga, $E$ é o módulo de Young e $I_{n}$ é o momento de inércia da seção transversal da viga.

O momento de inércia da seção transversal da placa é:

$$
I_{n}=\frac{b h^{3}}{12}
$$

Somam-se os deslocamentos parciais, obtendo-se o deslocamento total, equação 4.13).

$$
\delta_{t}=\delta_{a}+\delta_{b}+\delta_{c}+\delta_{d}
$$

O material selecionado é aço 1020, por resistir o esforço de escoamento de 290 MPa. Seu módulo de Young é $E=210$ GPa. Para determinar o coeficiente de rigidez do conjunto que forma a mola, pode-se interpretar a estrutura como conjunto de molas em série e paralelo, conforme a figura 4.59.

Pode-se escrever uma função que relaciona $k$ em termos de $R, L$ e $I_{n}$, onde $R$ denota o raio de curvatura, $L$ denota o comprimento total e $I_{n}$ denota o momento de inércia da seção transversal da chapa. Lembrando que $k$ decorre da freqüência do absorvedor dinâmico e da massa escolhida da equação (4.6).

$$
\frac{24 E I_{n}}{k}=\frac{151 \cdot L^{3}}{1000}-\frac{87 \cdot R \cdot L^{2}}{100}+\frac{2 \cdot R^{2} \cdot L}{3}
$$




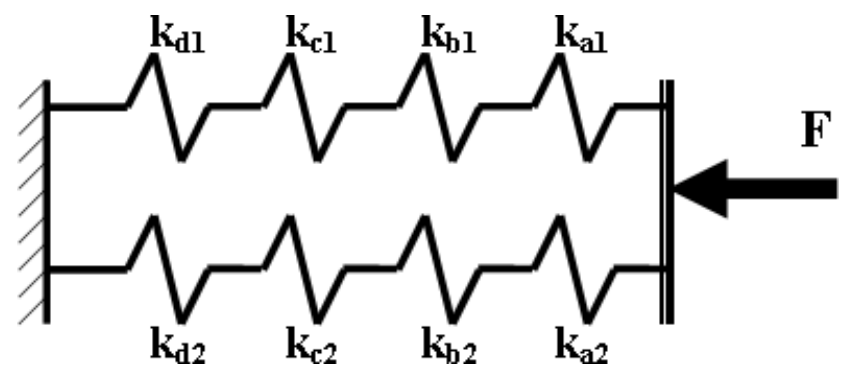

Figura 4.59: Esquema do funcionamento da mola

\subsection{Ensaios Experimentais do Primeiro Absorve- dor Dinâmico}

O absorvedor dinâmico foi fixado por solda no centro da parede do tanque como se ilustra na figura 4.60. Nesta figura mostra-se também a localização de três pontos onde se analisará a vibração.

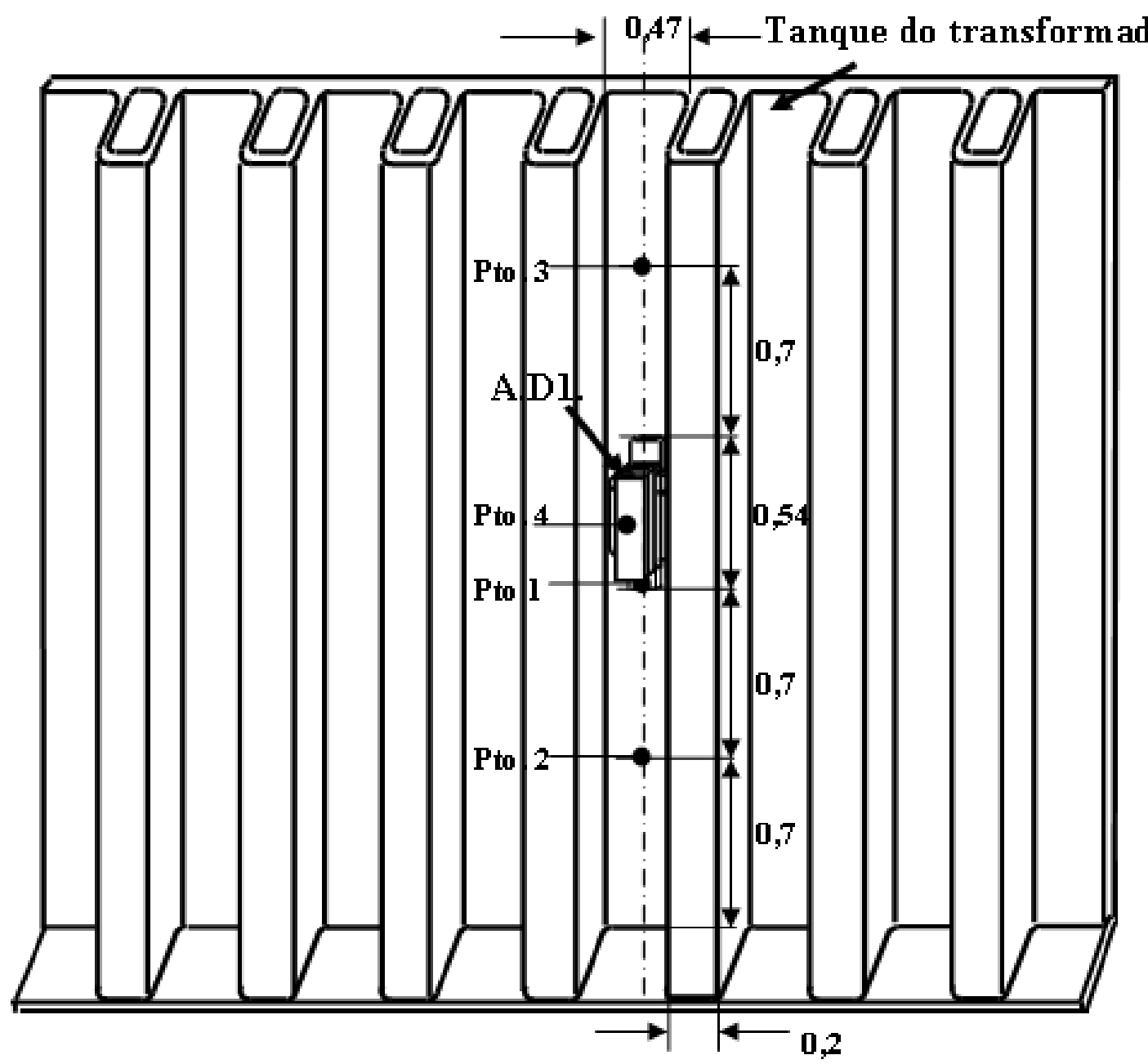

Figura 4.60: Desenho do AD1 montado no ponto central de uma face oposta ao edifício. 
formador da Subestação de Bela Aliança, da AES Eletropaulo, de 30/40 kVA. A figura 4.61-a e 4.61-b mostra uma foto do protótipo inicial do absorvedor dinâmico.
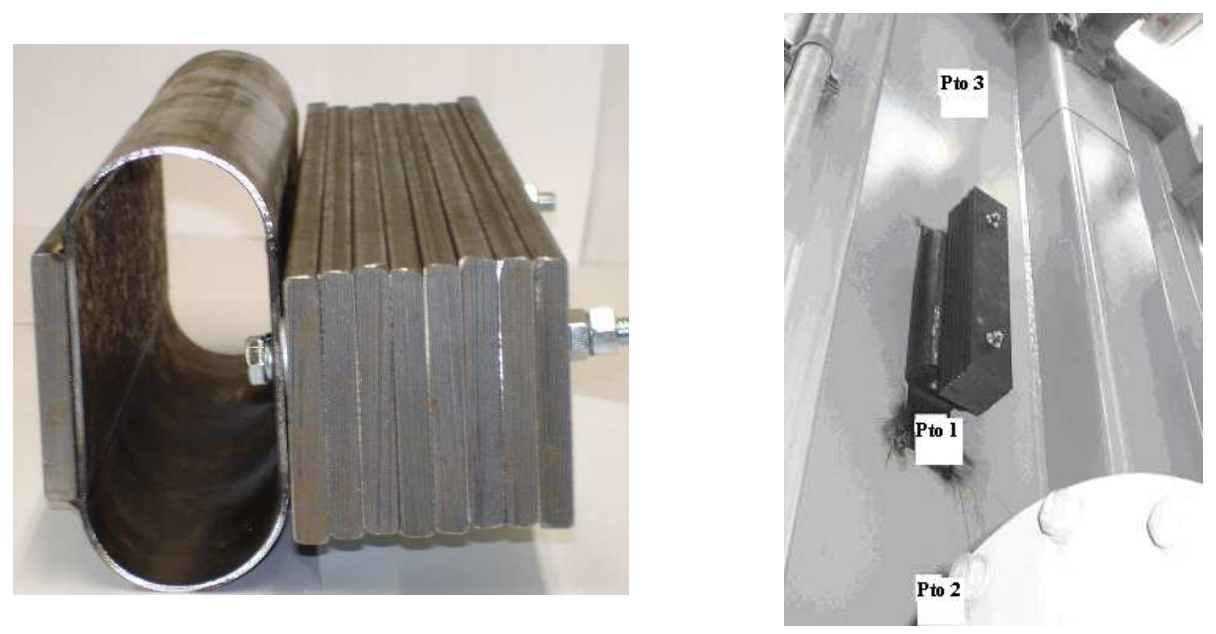

Figura 4.61: Fotos do primeiro protótipo do absorvedor dinâmico: a) mostrando suas partes b) fixado no transformador.

\subsubsection{Avaliação do desempenho do absorvedor dinâmico na redução da vibração}

Foram coletados sinais de aceleração da vibração do ponto central da face oposta ao edifício do tanque. No teste foram efetuados experimentos com diferentes valores de massa: $18,50 \mathrm{~kg}, 20,00 \mathrm{~kg}$ e 21,00 $\mathrm{kg}$. Para avaliar o aumento ou a diminuição da vibração, calculou-se a potência do sinal nos três pontos em estudo. A potência do sinal discreto da vibração é:

$$
P_{s}=\frac{\sum_{i=1}^{n}\left(\ddot{x}_{i}-\bar{x}\right)^{2}}{t_{n}-t_{1}}
$$

O melhor desempenho foi obtido com a massa de $20 \mathrm{~kg}$ como pode ser observado na fig. 4.62 que mostra a potência da vibração em função das massas em três pontos do painel do transformador. 

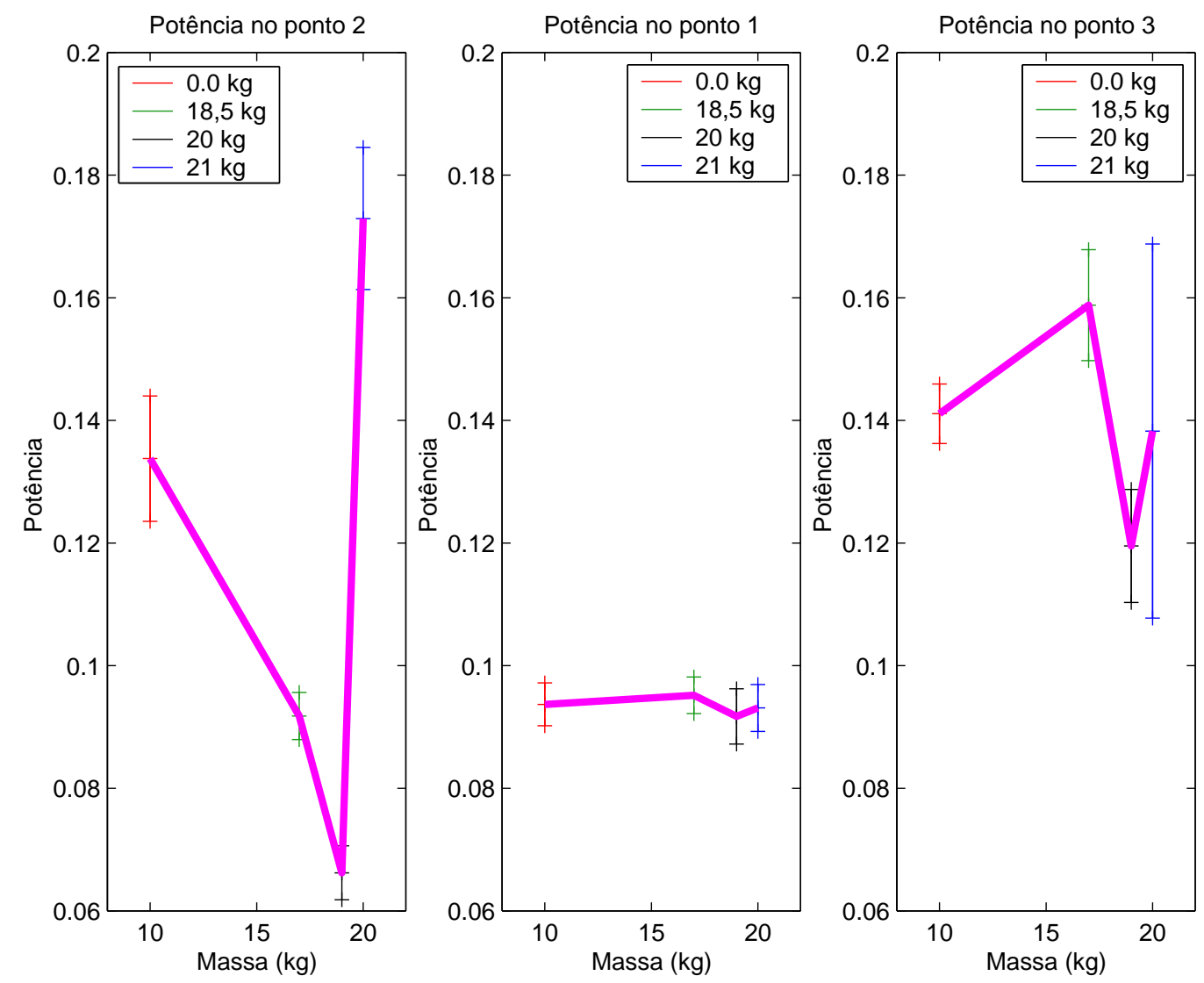

Figura 4.62: Comparação da potência de vibração sem e com AD1 de $18,5 \mathrm{~kg}$, $20 \mathrm{~kg}$ e $21 \mathrm{~kg}$ de massa: a) no ponto 2 , b) no ponto 1 , c) no ponto 3 .

A fig. 4.62 mostra três figuras na mesma escala: nelas estão os cálculos da potência dos sinais por ponto, com valores da média e o desvio padrão. As linhas verticais representam desvios padrão e a linha rosa une a média da potência do sinal. A primeira figura refere-se ao ponto 2, nela se observa que não há intersecção entre as barras de desvio padrão, evidenciando níveis distintos de vibração em função da massa do absorvedor dinâmico. No ponto 1 observa-se que as médias e desvios padrão de potência estão quase na mesma faixa, portanto o efeito da variação da massa da absorvedor dinâmico não é significativo neste ponto. O ponto 1 é o ponto que irradia menos potência quando esta sem absorvedor dinâmico e se mostrou pouco sensível com absorvedor dinâmico. Este ponto está próximo a um nó. Os resultado do ponto 3 mostra que um absorvedor dinâmico, com uma massa de 20,0 kg, diminui significativamente a vibração nesse ponto.

A fig. 4.63 compara a potência do sinal de aceleração coletado no tanque e a porcentagem de variação da potência para as três massas testadas. A barra vermelha representa o sistema sem absorvedor, a barra verde representa o sistema com absorvedor e massa de $18,5 \mathrm{~kg}$, a barra preta representa o sistema com absorvedor e massa de $20 \mathrm{~kg}$ e a barra azul representa o sistema com absorvedor 
e massa de $21 \mathrm{~kg}$.
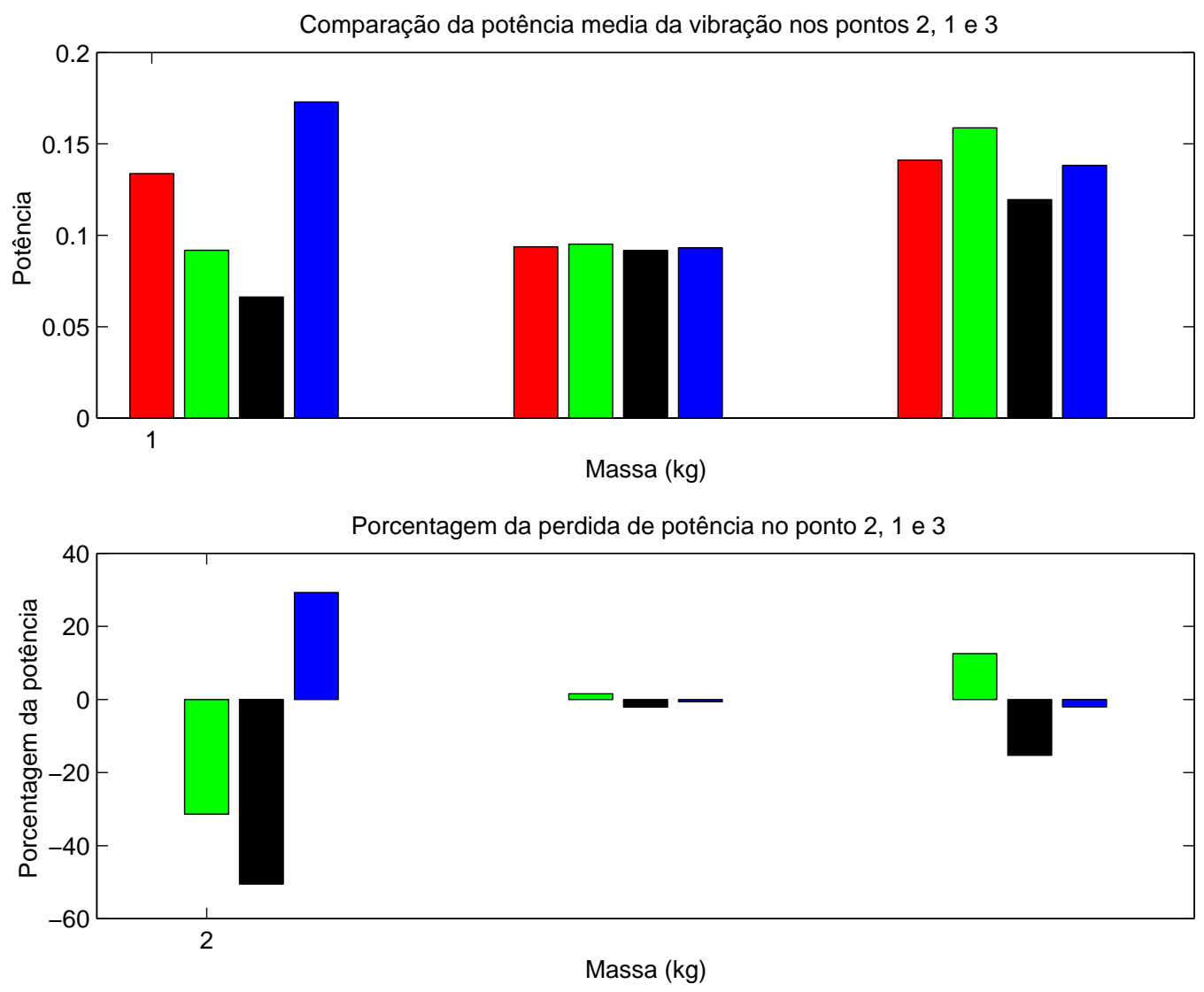

Figura 4.63: Comparação da potência: a) Potência em pontos b) Porcentagem da redução da potência.

\subsubsection{Avaliação do desempenho do absorvedor dinâmico na atenuação do ruído}

O sinal de aceleração é integrado para obter a velocidade. A velocidade é relacionada com o ruído através da equação 2.23. A velocidade da vibração e a velocidade do ar na superfície são iguais. Os sinais de velocidade ao quadrado são representados pela densidade espectral de potência (PSD Power Spectral Density) da velocidade. A diminuição da velocidade da vibração em função da freqüência é mostrada na fig. 4.64, que mostra o PSD da velocidade, nela observa-se a diminuição das amplitudes e notam-se duas amplitude notáveis na faixa de 100 até $250 \mathrm{~Hz}$. 


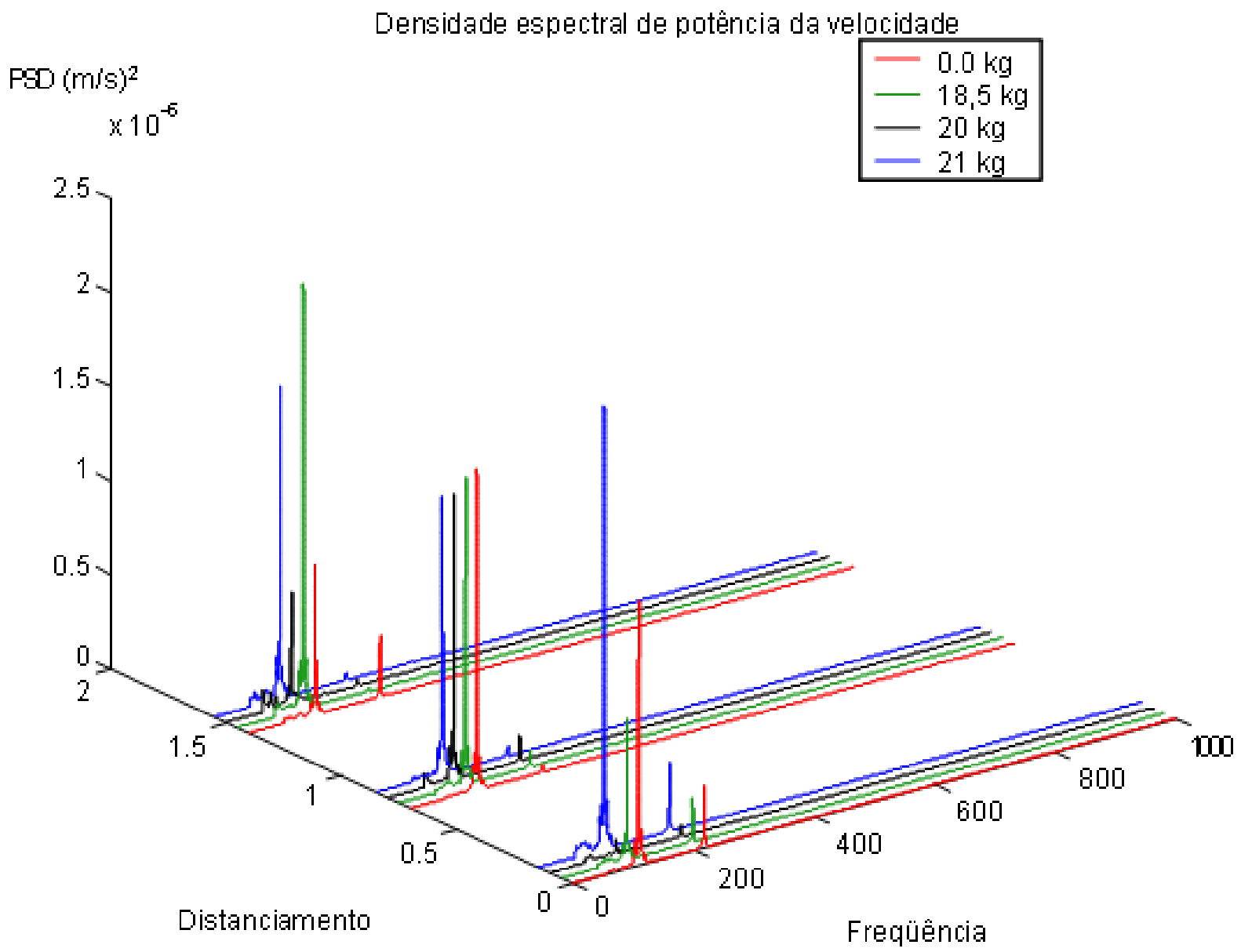

Figura 4.64: Comparação do sinal de aceleração, com e sem absorvedor dinâmico nos pontos 1, 2 e 3

O procedimento para avaliar a energia sonora, consiste em calcular $L_{v}$ em faixas de freqüências; estas faixas estão padronizadas em: 8 faixas, denominadas faixas de oitavas, ou 24 faixas, agrupadas de $3 \mathrm{em} \mathrm{3}$, denominadas faixas de terças de oitavas; ambas começam na freqüência zero e alcançam freqüência 10 kHz.

Após do cálculo de $L_{v}$ por faixa, determina-se o valor total, para isso consideramse todas as faixas como se fossem várias fontes de som simultâneas, determinando a soma de acordo com a eq. 4.16

$$
L_{v t}=10 . \log _{10}\left(10^{\frac{L_{v 31,5}}{10}}+10^{\frac{L_{v 63}}{10}}+10^{\frac{L_{v 125}}{10}}+10^{\frac{L_{v 250}}{10}} 10^{\frac{L_{v 500}}{10}}+10^{\frac{L_{v 1000}}{10}}\right)
$$

Nota-se que $L_{v}$ é relevante até a freqüência de $1000 \mathrm{~Hz}$ e compreende as 6 primeiras faixas de oitava, eles estão na média do intervalos da faixa. O nível de velocidade, $L_{v}$, por faixas e o nível de velocidade total $L_{v t}$ são mostrados na tabela 4.3. 
Tabela 4.3: Valores do PSD de velocidade de cada faixa de oitava para os pontos 2,1 e 4 e o nível de velocidade total $L_{v t}$

\begin{tabular}{|c|c|c|c|c|c|c|c|}
\hline faixas de Oitavas & 31,5 & 63 & 125 & 250 & 500 & 1000 & $L_{v} t$ \\
\hline Ponto 2 sem AD1 & 0,0 & 90,4 & 108,4 & 99,1 & 88,9 & 78,2 & 108,99 \\
\hline Ponto 2 com AD1 de $18,5 \mathrm{~kg}$ & 0,0 & 93,1 & 106,9 & 97,8 & 87,9 & 77,7 & 107,61 \\
\hline Ponto 2 com AD1 de $20,0 \mathrm{~kg}$ & 0,0 & 94,7 & 102,0 & 96,0 & 88,1 & 78,3 & 103,70 \\
\hline Ponto 2 com AD1 de $21,0 \mathrm{~kg}$ & 0,0 & 96,5 & 111,3 & 100,1 & 89,2 & 78,9 & 111,77 \\
\hline Ponto 1 sem AD1 & 0,0 & 89,6 & 109,3 & 92,8 & 84,9 & 78,9 & 109,46 \\
\hline Ponto 1 com AD1 de $18,5 \mathrm{~kg}$ & 0,0 & 92,3 & 109,4 & 95,2 & 87,3 & 77,3 & 109,67 \\
\hline Ponto 1 com AD1 de 20,0 $\mathrm{kg}$ & 0,0 & 99,3 & 108,8 & 96,0 & 86,8 & 76,7 & 109,48 \\
\hline Ponto 1 com AD1 de 21,0 $\mathrm{kg}$ & 0,0 & 94,2 & 109,2 & 94,8 & 87,4 & 77,6 & 109,51 \\
\hline Ponto 3 sem AD1 & 0,0 & 94,6 & 106,8 & 99,3 & 88,3 & 81,5 & 107,78 \\
\hline Ponto 3 com AD1 de $18,5 \mathrm{~kg}$ & 0,0 & 98,2 & 111,2 & 96,3 & 90,5 & 80,9 & 111,58 \\
\hline Ponto 3 com AD1 de $20,0 \mathrm{~kg}$ & 0,0 & 100,4 & 107,4 & 96,7 & 90,3 & 80,9 & 108,56 \\
\hline Ponto $3 \mathrm{com}$ AD1 de $21,0 \mathrm{~kg}$ & 0,0 & 97,7 & 110,1 & 96,1 & 90,1 & 80,32 & 110,54 \\
\hline
\end{tabular}

Na análise da tabela 4.3 observa-se que na faixa compreendida de 63 até $125 \mathrm{~Hz}$ encontra-se a maior concentração de energia, nessa faixa a potência é reduzida de 108,4 para 102,0 no ponto 2 , de 109,3 para 108,8 no ponto 1 , mas há um aumento de 106,8 para 107,4 no ponto 3 .

Com o objetivo de comparar a energia de vibração, com e sem AD1, em três pontos da parede do tanque, a fig. 4.65, mostra a velocidade média ao quadrado $\left(v_{m}^{2}\right)$ para 4 condições: sem AD1; com AD1 e 18,5 kg; com AD1 e $20 \mathrm{~kg}$; e com AD1 e $21 \mathrm{~kg}$; em três pontos indicados na fig. 4.61-b. As faixas assumidas pertencem a terças de oitava e são: $25-31,5-40-50-63-80-100-125$ $-160-200-250-315-400-500$.

Calculou-se a média de nível de velocidade (Lv) dos pontos 1, 2 e 3, para cada condição que foi testada. A tabela 4.4 mostra os valores calculados de nível de velocidade total. Na última fila da tabela 4.4 estão a diminuição (negativo) ou aumento (positivo) em $d B$ do nível de velocidade por ponto comparando o resultado com AD1 e o resultado sem AD1. 
Tabela 4.4: Diminuição de nível de velocidade segundo a massa do absorvedor dinâmico

\begin{tabular}{|l|r|r|r|r|}
\hline Descrição & Sem AD1 & AD1=18,5 kg & AD1=20 kg & AD1=21 kg \\
\hline$L_{\text {vmedia ptos. } 1,2 \text { e } 3(d B)}$ & 109,07 & 109,625 & 107,24 & 110,60 \\
\hline Diminuição de Lv em $d B$ & - & 0,55 & $-1,83$ & 1,53 \\
\hline
\end{tabular}

Da fig. 4.65 nota-se que o AD1 com a massa de $20 \mathrm{~kg}$ tem melhor desempenho.

A redução de $-1,83 d B$ de velocidade foi possível com a massa de $20 \mathrm{~kg}$. A fig. 4.66 mostra a comparação do PSD por faixas da velocidade das condições sem AD1 e com AD1 de $20 \mathrm{~kg}$.
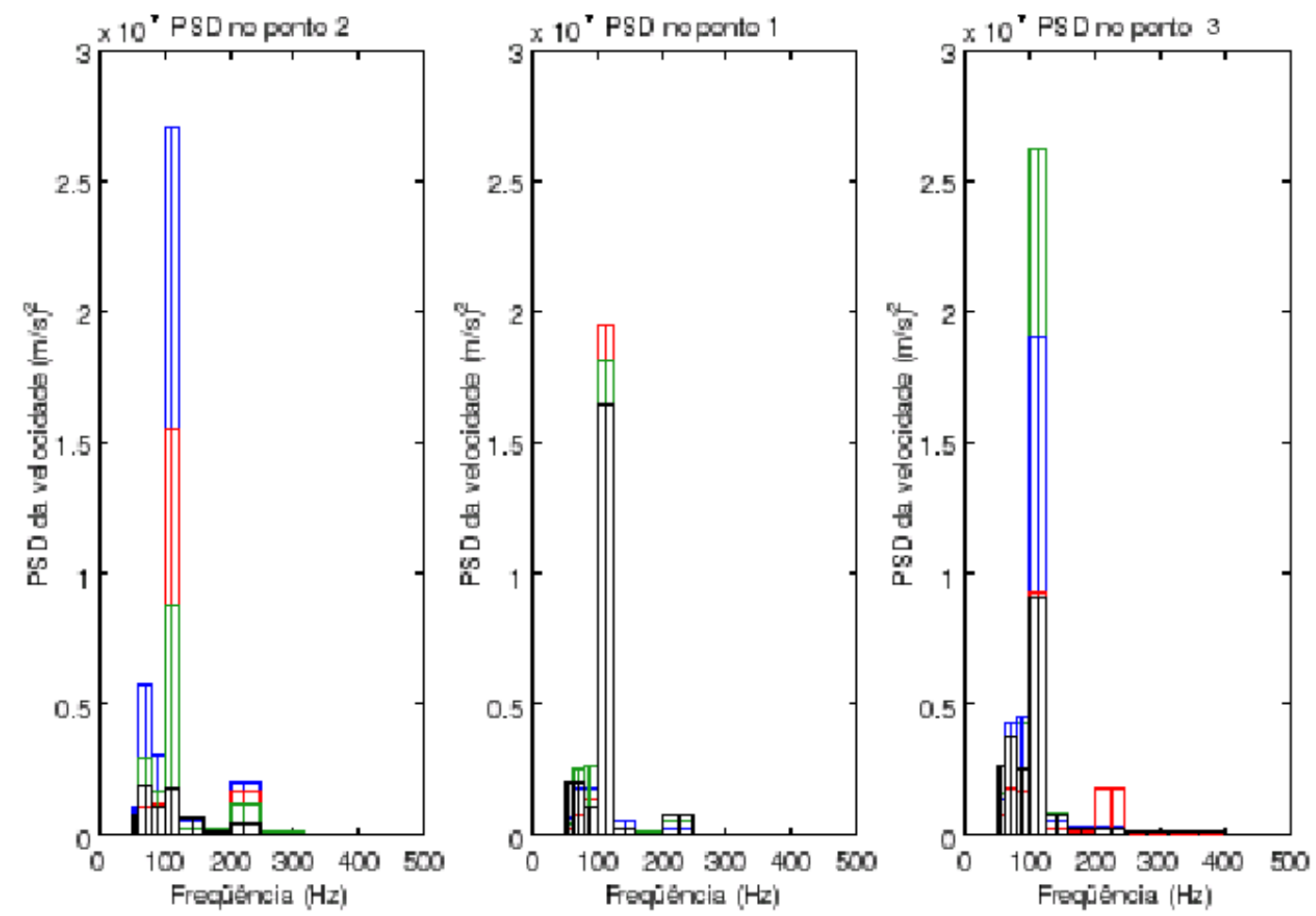

Figura 4.65: Comparação do $L_{v}$ por faixa de terça de oitava para os pontos 2 , 1 e 3 (vermelho, massa de $0,0 \mathrm{~kg}$, verde, massa de 18,5 $\mathrm{kg}$, preto, massa de 20 $\mathrm{kg}$ e azul, massa de $21 \mathrm{~kg}$ ).

Os ensaios mostram que diminuindo a vibração é possível diminuir o nível de intensidade sonora e por conseqüência o ruído. A diminuição da vibração em $50 \%$ resultou numa diminuição de $6,4 \mathrm{~dB}$ na faixa de oitavas de 63 até 125, sendo esta a faixa de maior densidade espectral de potência. 


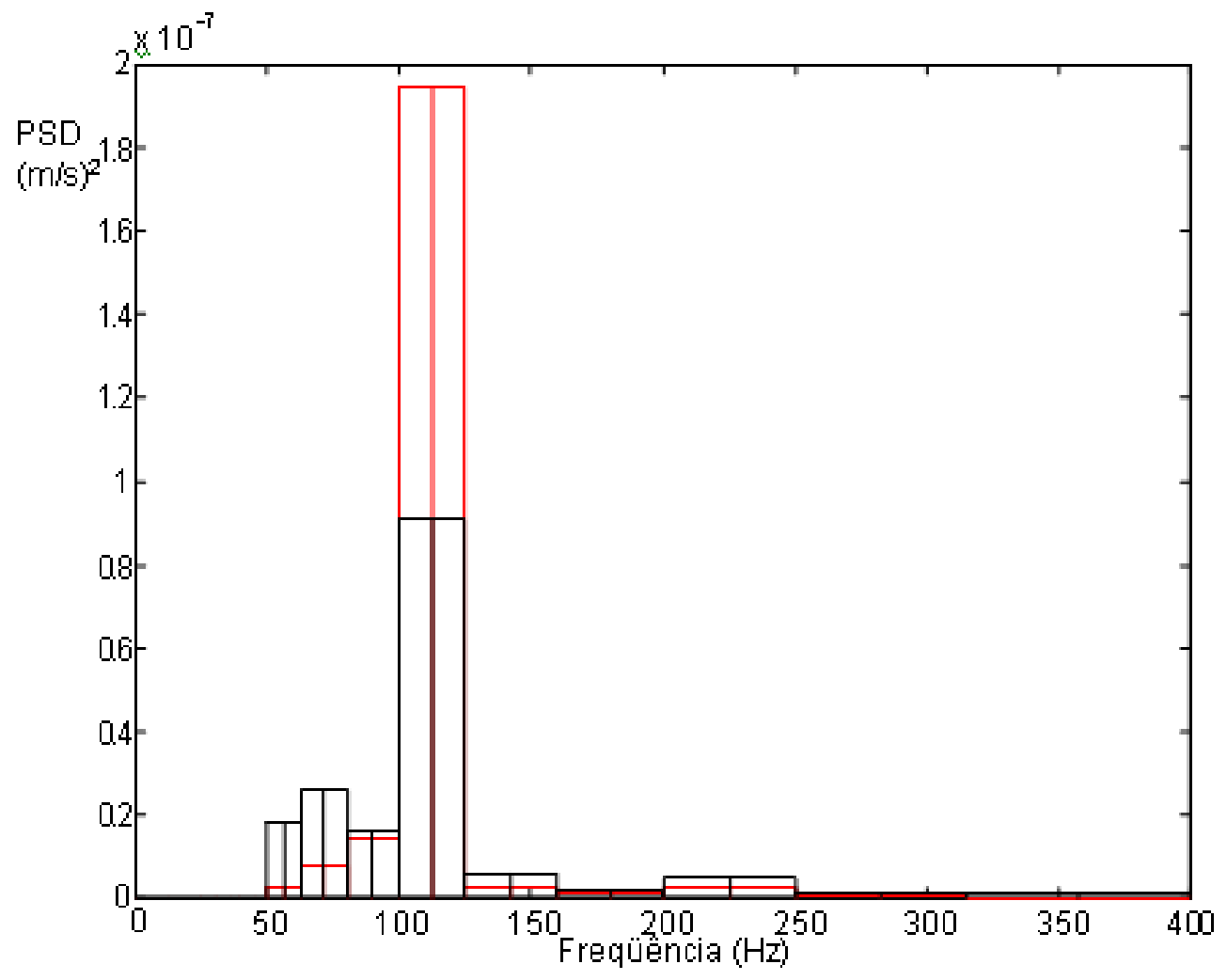

Figura 4.66: Comparação da diminuição do PSD da velocidade para o caso sem $\mathrm{AD}$ (vermelho) e com absorvedor dinâmico (preto)

\subsection{Projeto do Segundo Absorvedor Dinâmico}

O segundo protótipo de Absorvedor dinâmico (AD2) tem a particularidade de que o coeficiente de rigidez se modifica com a mudança da posição da massa. Os cálculos são semelhantes ao do primeiro protótipo e o desenho de montagem se mostra na fig. 4.67, a lista de materiais esta na tabela 4.5 .

A forma circular da massa dificulta a formação de ondas sonoras, a superfície plana impulsa o ar na mesma direção em quanto que com a forma circular o ar não e impulsado na mesma direcção. A borracha na superfície amortece o contato entre o ar e a superfície plana em movimento. 


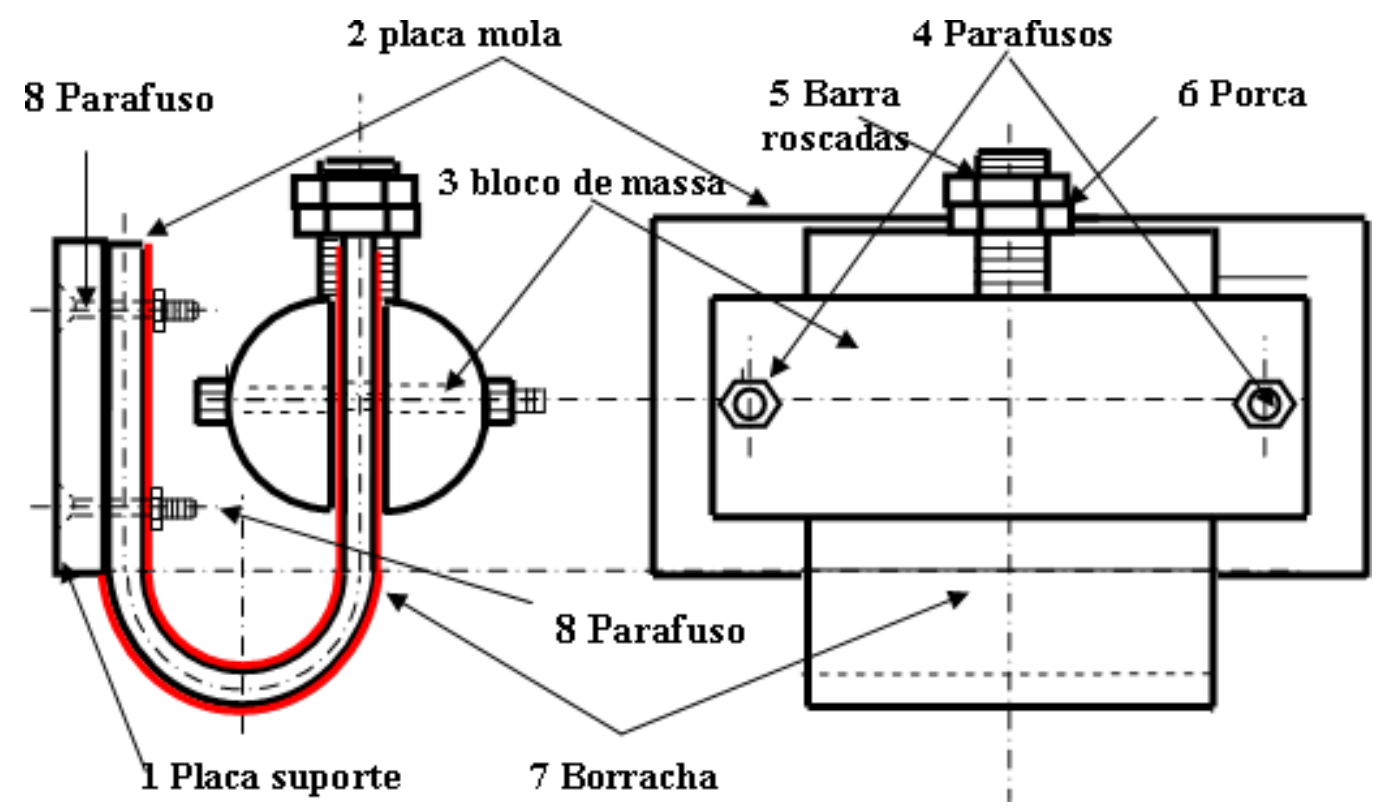

Figura 4.67: Esquema do AD2 montado indicando seus componentes.

Tabela 4.5: Lista dos componentes do segundo absorvedor dinâmico

\begin{tabular}{|c|l|c|l|l|}
\hline Ítem & Descrição & Quant. & Material & Dimensões \\
\hline 1 & Suporte de fixação & 1 & Celerom & $10 x 150 \times 200 \mathrm{~mm}$ \\
\hline 2 & Placa encurvada & 1 & Aço 1020 & $3 \times 95 x 250 \mathrm{~mm}$ \\
\hline 3 & Bloco de barra redonda & 1 & Aço comum $(036)$ & D51x170 $\mathrm{mm}$ \\
\hline 4 & Parafuso & 2 & Aço galvanizado & D38x80 $\mathrm{mm}$ \\
\hline 5 & Porca com trava & 1 & Aço galvanizado & D19x08 $\mathrm{mm}$ \\
\hline 6 & Borracha de recobrimento & 2 & Borracha & $1 \times 96 x 96 \mathrm{~mm}$ \\
\hline 7 & Parafuso & 2 & Aço galvanizado & D14x20 $\mathrm{mm}$ \\
\hline
\end{tabular}

\subsection{Simulação da Vibração do Tanque Usando o MEF}

Com o objetivo de simular no computador as vibrações da superfície de uma face desenvolveu-se um modelo numérico de elementos finitos contendo as dimensões, as características geométricas e estruturais do transformador. Posteriormente, construíram-se as malhas contendo nós nos pontos onde foram feitas as medições de aceleração. A fig. 4.68 apresenta o modelo usado para as simulações numéricas. 


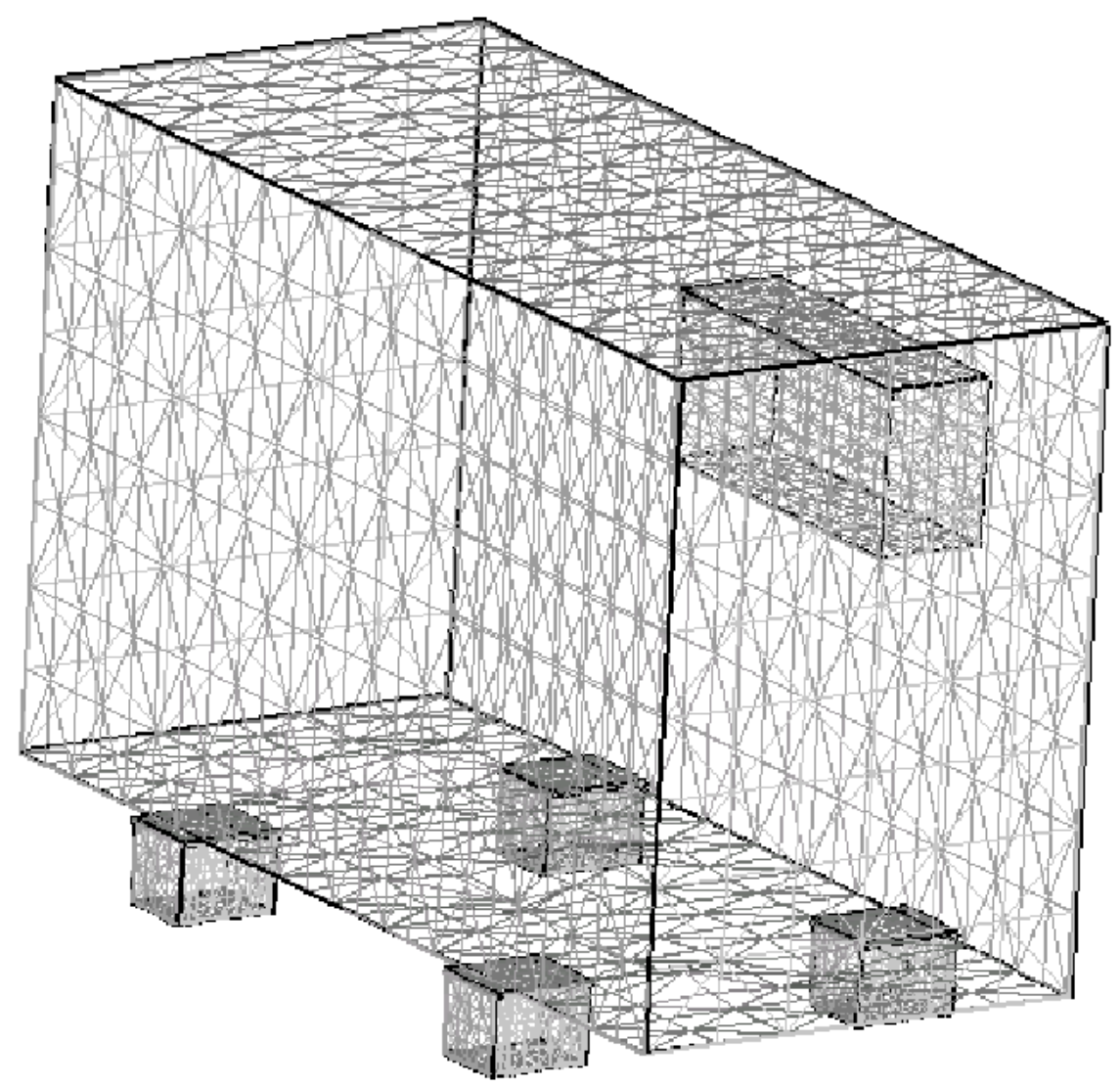

Figura 4.68: Modelo geométrico do tanque do transformador em EF.

Para efetuar as simulações no modelo de elementos finitos impuseram-se carregamentos proporcionais aos deslocamentos provenientes dos sinais de aceleração como se fossem sinais de forcas. Foram utilizados 132 sinais de deslocamento a partir dos sinais de aceleração medidos pela empresa $01 \mathrm{~dB}$. O tempo de aplicação da força sinoidal é um período ou $1 / f_{p}$ da freqüência selecionada $(120 \mathrm{~Hz})$, para efeito do cálculo da potência a chapa das paredes são consideradas planas, o cálculo da massa é realizado considerando a massa específica $\left(\delta_{p}\right)$, a espessura da chapa $\left(e_{p}\right)$ e a área da superfície da face $\left(S_{p}\right)$. O deslocamento médio ao quadrado $d_{m}{ }^{2}$, de todos os pontos em observação são calculados com a equação 4.17 usando os dados fornecidos pela simulação.

$$
d_{m}{ }^{2}=\frac{\frac{1}{n} \sum_{i=1}^{n} x_{i}^{2}}{N_{p}}
$$

O cálculo da potência de cada face é realizado com a seguinte equação: 


$$
P_{s}=\frac{0,707 \delta_{p} e_{p} S_{p}\left(2 \pi f_{p}\right)^{2} d_{m}^{2}}{\left(\frac{1}{f_{p}}\right)}
$$

A hipótese de que a vibração das faces provém da vibração da base não se sustenta. Quando foram utilizados apenas os deslocamento da base para excitar o transformador, a somatório da potência dos sinais de deslocamento de cada face num intervalo de tempo de $1 / 120 \mathrm{~s}$, torna-se muito pequena, conforme a tabela 4.6. Os deslocamentos medidos nas faces das paredes devem apresentar potência da ordem de $10^{-} 10$ ou $10^{-} 9$ como é mostrado na tabela 4.7 , onde está a potência dos sinais de cada face obtida por simulação numérica, sem uso de absorvedores dinâmicos.

Tabela 4.6: Somatório da potência dos sinais de cada face, excitação apenas na base do transformador

\begin{tabular}{|c|c|c|}
\hline Face & deslocamento ao quadrado $\left(\mathrm{mm}^{2}\right)$ & Potência $(N . m / s)$ \\
\hline base & $3.6481 \mathrm{e}-11$ & 1.9362 \\
\hline frente ao edifício & $2.1565 \mathrm{e}-12$ & 0.15794 \\
\hline oposto ao edifício & $3.1207 \mathrm{e}-12$ & 0.22856 \\
\hline frente à rua & $8.7349 \mathrm{e}-13$ & 0.024302 \\
\hline oposto à rua & $1.1412 \mathrm{e}-12$ & 0.037314 \\
\hline
\end{tabular}

Tabela 4.7: Somatório da potência dos sinais de cada face, sem uso de absorvedores dinâmicos

\begin{tabular}{|c|c|c|}
\hline Face & Deslocamento ao quadrado $\left(\mathrm{mm}^{2}\right)$ & Potência $(N . m / s)$ \\
\hline base & $8.9032 \mathrm{e}-11$ & 4.7252 \\
\hline frente ao edifício & $4.7580 \mathrm{e}-10$ & 34.848 \\
\hline oposto ao edifício & $1.9174 \mathrm{e}-08$ & 1404.3 \\
\hline frente à rua & $2.3719 \mathrm{e}-10$ & 7.7553 \\
\hline oposto à rua & $8.1881 \mathrm{e}-10$ & 26.772 \\
\hline
\end{tabular}

A constante de proporcionalidade utilizada na obtenção da força foi 1,4137e10 $N / m$. Depois de ter uma aproximação entre a vibração medida e a obtida por simulação numérica, foi gerada uma malha de elementos finitos com 12 absorvedores dinâmicos, conforme a fig. 4.69. Os absorvedores dinâmicos possuem $5 \mathrm{~kg}$ de massa sísmica e freqüência natural $123 \mathrm{~Hz}$.

Para efetuar a alocação dos absorvedores dinâmicos no modelo de elementos finitos procedeu-se da seguinte maneira, primeiro localizou-se o ponto de maior deslocamento em uma face e colocou-se nesse ponto um absorvedor dinâmico. Depois determinou-se por cálculo o ponto de maior deslocamento com um absorve- 
dor dinâmico instalado. Neste ponto foi instalado o segundo absorvedor dinâmico e assim por sucessivamente. Depois de instalado cada absorvedor, calculou-se a potência média de deslocamento que se produz na superfície, avalia-se a diferença com a condição anterior, em porcentagem. A quantidade apropriada de absorvedores é obtida pela avaliação da diminuição da potência média de deslocamento na superfície. Nestas simulações obtiveram-se reduções significativas da potência média de deslocamento utilizando até 6 absorvedores.

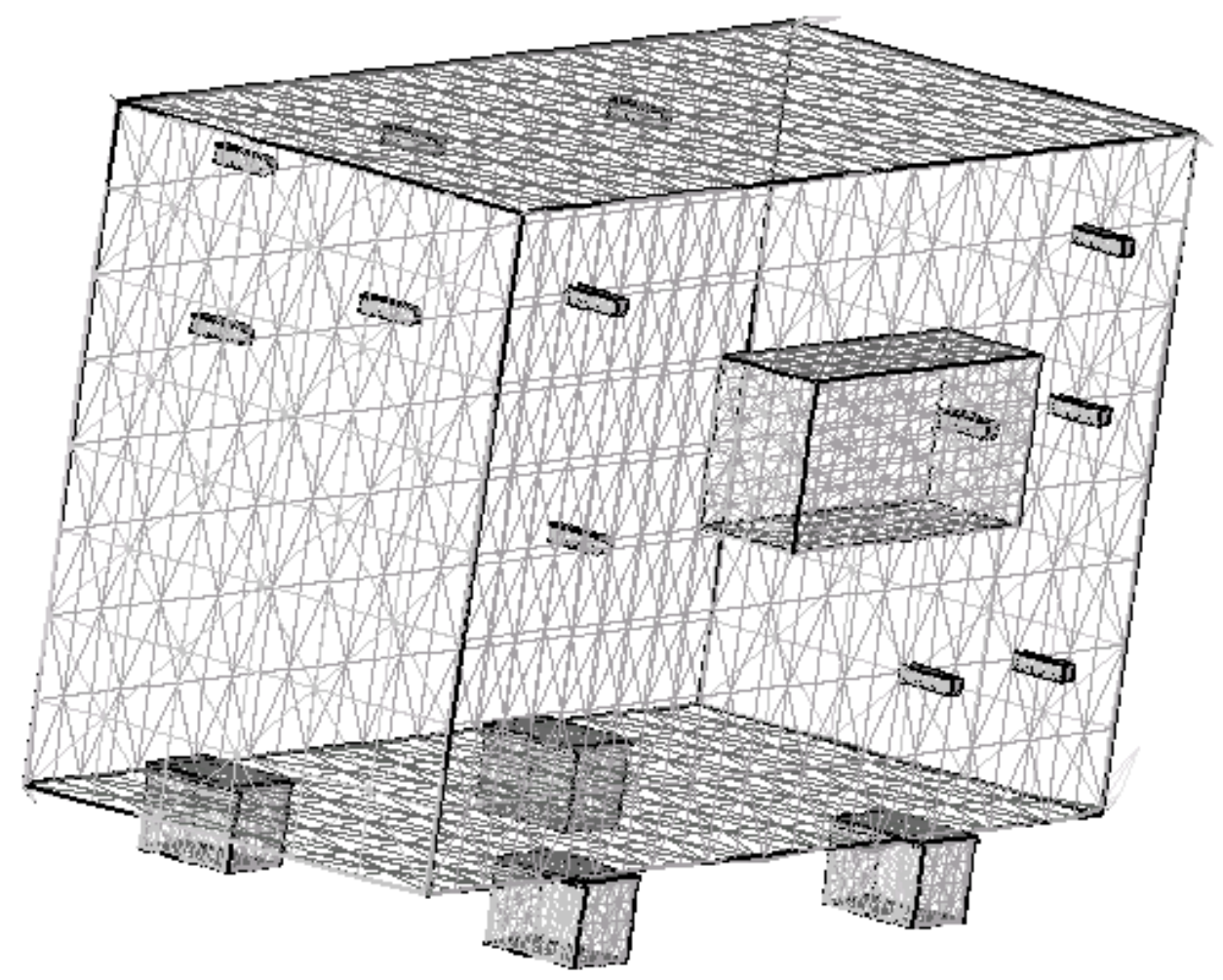

Figura 4.69: Malha de elementos finitos do tanque do transformador com doze absorvedores dinâmicos de $5 \mathrm{~kg}$ cada um.

A potência média de deslocamento de cada face obtido por simulação numérica com uso de 12 absorvedores dinâmicos de $5 \mathrm{~kg}$ de massa estão apresentadas na tabela 4.7

Da tabela 4.9 calcula-se a diminuição da potência e de níveis de potência em $d B$ com a eq. 2.16. Dos resultados pode-se observar que a diminuição da potência de irradiação se efetua em todas as faces. Os resultados de diminuição de potência irradiada pode ser melhorado colocando absorvedores com maiores massas. Esta simulação foi realizada com uma massa de $5 \mathrm{~kg}$. Trata-se da maior massa que pode ser colada ao tanque. Não é possível instalar com soldagem os absorvedores dinâmicos por que o calor danificaria a pintura isolante e contaminaría o óleo do 
Tabela 4.8: A potência média de deslocamento de cada face, com 12 absorvedores dinâmicos

\begin{tabular}{|c|c|c|}
\hline Face & Deslocamento ao quadrado $\left(\mathrm{mm}^{2}\right)$ & Potência $(N . \mathrm{m} / \mathrm{s})$ \\
\hline base & $6.9863 \mathrm{e}-11$ & 3.7078 \\
\hline frente ao edifício & $4.2627 \mathrm{e}-10$ & 31.220 \\
\hline oposto ao edifício & $1.5051 \mathrm{e}-08$ & 1102.3 \\
\hline frente à rua & $2.2764 \mathrm{e}-10$ & 7.4431 \\
\hline oposto à rua & $7.8228 \mathrm{e}-10$ & 25.578 \\
\hline
\end{tabular}

Tabela 4.9: Redução do nível de potência segundo as simulações

\begin{tabular}{|c|c|c|}
\hline Face & Porcentagem da potência reduzida & Atenuação $L_{W}$ \\
\hline base & $21.530 \%$ & $1.0530 \mathrm{~dB}$ \\
\hline frente ao edifício & $10.410 \%$ & $0.47740 \mathrm{~dB}$ \\
\hline oposto ao edifício & $21.503 \%$ & $1.0515 \mathrm{~dB}$ \\
\hline frente à rua & $4.0263 \%$ & $0.17848 \mathrm{~dB}$ \\
\hline oposto à rua & $4.4614 \%$ & $0.19821 \mathrm{~dB}$ \\
\hline
\end{tabular}

transformador.

Dimensões Nas simulações não foram consideradas as modificações que produzem os amortecedores viscosos. Experimentalmente observou-se que a instalação destes diminui a vibração das paredes do tanque. O modelo de carregamento imposto ao modelo de elementos finitos pode não refletir o carregamento real. O carregamento que o óleo transmite ao tanque parece ter uma componente parecida com uma pressão hidrostática, que ao ser restringido em um ponto da superfície do tanque, os deslocamentos aumentam em outras regiões, conforme constatou-se nos testes experimentais descritos na seção seguinte.

Sugere-se investigar um modelo de carregamento que imite um carregamento hidrostático. Uma maneira simples de reproduzir este efeito consiste em reproduzir em 3D o mecanismo que transmite forças nos limpadores de para-brisa atuais.

Outro critério para melhorar o desempenho dos absorvedores dinâmicos é considerar na simulação como a instalação de um absorvedor dinâmico influencia todo o tanque. A procura do ponto com maior deslocamento ocorrer no tanque e não apenas numa face.

\section{A metodologia proposta é}

1. avaliar os níveis de velocidade de todo o tanque, localizando as regiões de maior vibração;

2. instalar os amortecedores viscosos para reduzir a vibração na base do tan- 
que;

3. reavaliar o nível de velocidade e o ponto de maior deslocamento do tanque com a técnica de ODS;

4. instalar o primeiro absorvedor no ponto de maior deslocamento;

5. reavaliar o ponto de maior deslocamento e colocar o segundo absorvedor dinâmico;

6. calcular a redução da potência irradiada;

7. repetir o procedimento a partir do penúltimo ítem;

A massa apropriada é um pouco maior de $20 \mathrm{~kg}$, como foi calculado no primeiro absorvedor dinâmico chamada de protótipo 1, mas as condições de aderesão do absorvedor dinâmico na superfície do tanque limitaram do tamanho da massa. Jasinski R. Calomeno e Fillippin (2005) comenta que a massa recomendada é um terço da massa efetiva, o cálculo feito no centro da face oposto aos edifícios foi $396 \mathrm{~kg}$, no trabalho experimental e na simulações foram colocados $30 \mathrm{~kg}$ ao todo e obteve-se $21 \%$ de redução da vibração. Porém, se for possível utilizar $30 \mathrm{~kg}$ ou mais em cada ponto, o desempenho poderá ser maior. Cálculos do efeito da massa e do posicionamento são realizados em um trabalho complementar a este, Chávez (2008).

\subsection{Verificação Experimental no Transformador}

A análise da vibração do tanque permitiu a definição do posicionamento dos absorvedores dinâmicos e dos amortecedores, e procedeu-se à verificação experimental da solução proposta no transformador localizado na subestação de Bela Aliança, no transformador mais próximo dos edifícios. Um desenho que ilustra as condições das instalações dos transformadores na subestação Bela aliança é mostrado na fig. 4.70. Observa-se que o ruído produzido pelos transformadores afeta os moradores do edifício que existe ao lado da subestação. 


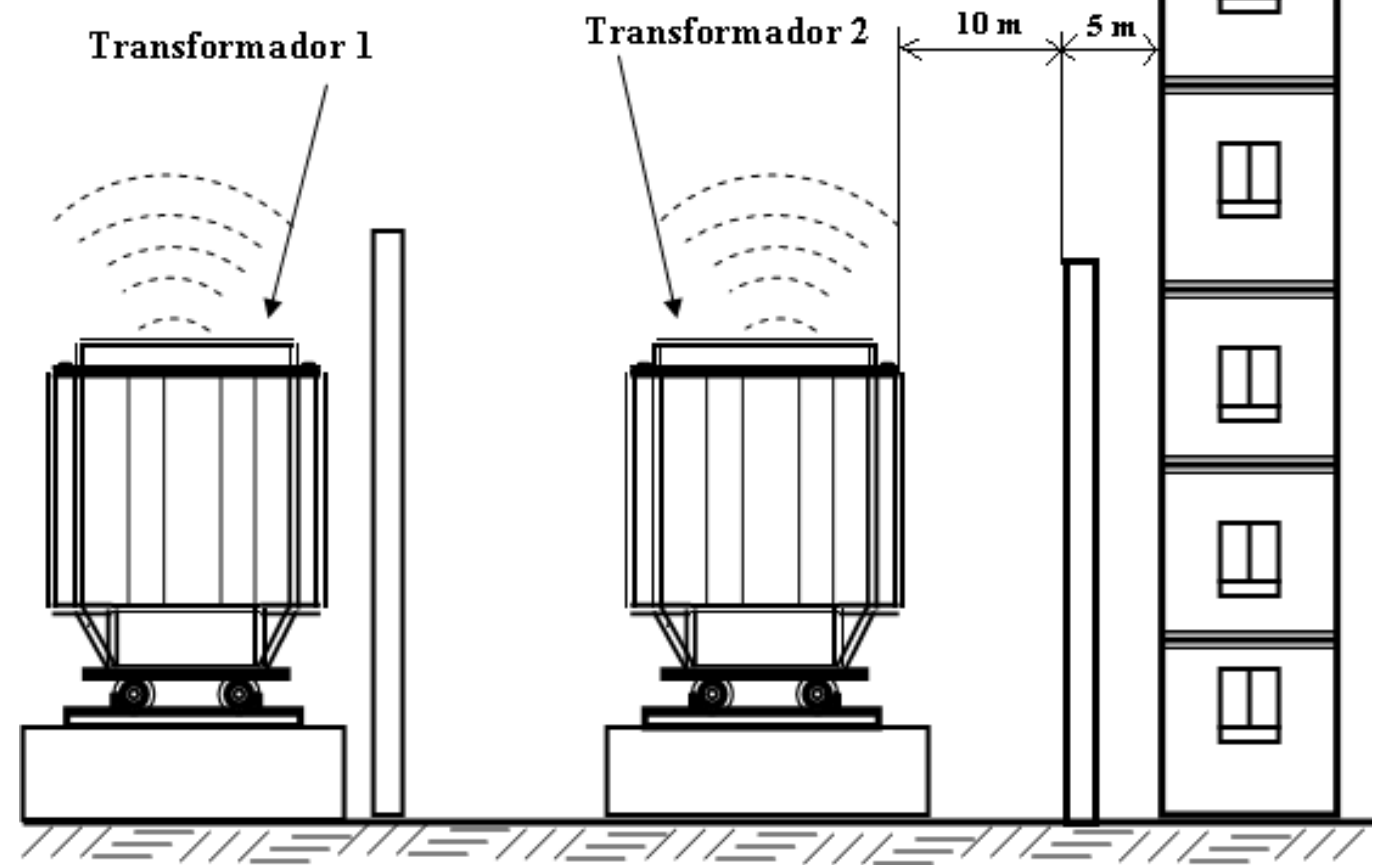

Figura 4.70: Desenho da distribuição dos transformadores da subestação Bela aliança

A seqüência de medidas foram as seguintes

1. medição do som e da vibração antes da implementação dos dispositivos, realizado no dia 14 de março entre as 9:00 e as 11:00 h. Após este ensaio colaram-se as bases dos absorvedores dinâmicos;

2. medição do som e da vibração depois da instalação dos amortecedores, no dia 23 de Março, após as 14:00 horas;

3. medição do som e da vibração após a instalação dos absorvedores dinâmicos, em 24 de março entre as 15:00 até 17:00 horas, com os amortecedores já montados;

4. medição do som e da vibração considerando apenas os absorvedores dinâmicos, foram desmontados os amortecedores. O teste foi realizado entre 17:30 até 18:30 horas.

A medição do Campo Acústico foi realizado usando o método Ponto por Ponto e avaliou-se o comportamento do Campo Acústico antes e depois da aplicação dos dispositivos. Para a construção do plano imaginário de medição foi definida uma área distante $7,4 \mathrm{~m}$ da face frente ao edifício, encontrando-se o muro de $5 \mathrm{~m}$ de 
altura, que separa a subestação dos edifícios, a 9,0 $m$ de distância do tanque. A área de medição de som selecionada tem de 10,00 $m$ de largura e 6,0 $m$ de altura. A fig. 4.71 mostra a grade definida para a medição do som.

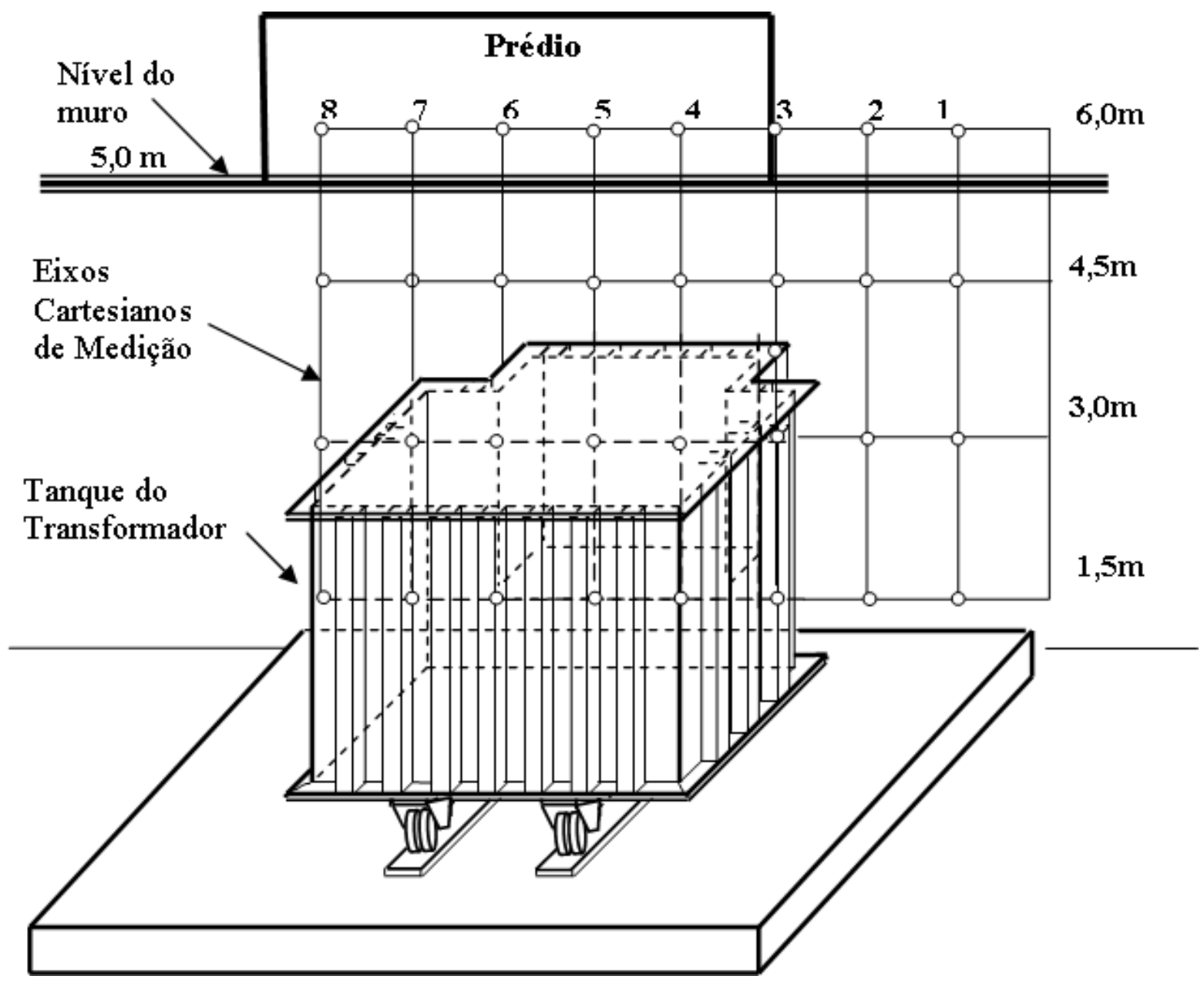

Figura 4.71: Desenho do tanque mostrando os pontos de medição de som

Para a medição das vibrações selecionaram-se 6 pontos por face da parede do tanque, e seis pontos da base do tanque, conforme mostra a fig. 4.72. Os pontos selecionados estão compreendidos dentro da região que foram detectados maior vibração e maior nível de velocidade de vibração.

A instalação dos amortecedores foi realizada com uma inclinação de $45^{\circ} \mathrm{com}$ respeito ao chão para que atuassem nas direções vertical e horizontal. A fig. 4.73 mostra uma foto onde se mostram os amortecedores instalados em seus suportes. E a fig. 4.74 mostra seu posicionamento. 


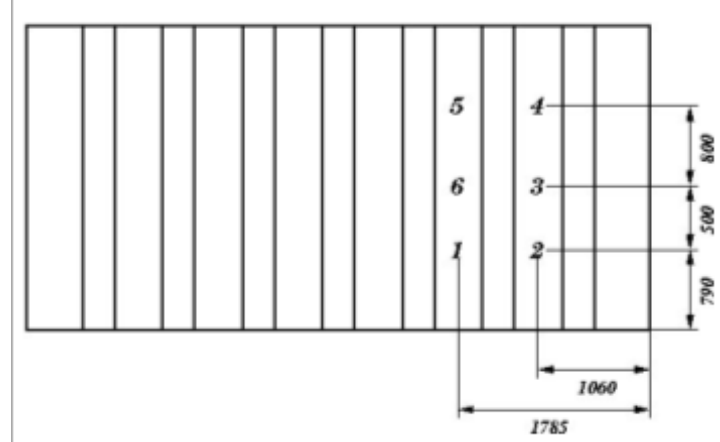

a)

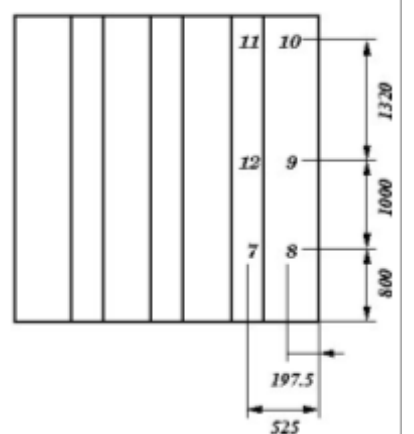

b)
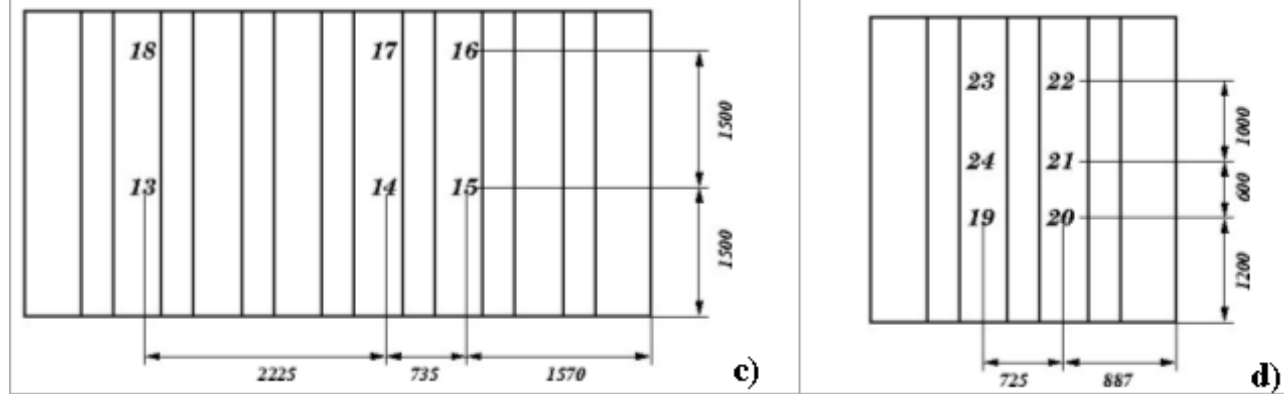

Figura 4.72: Localização dos pontos onde foram coletados os sinais de vibração a) face frente ao edifício, b) face oposta à rua, c) face oposta ao edifício d) face frente à rua

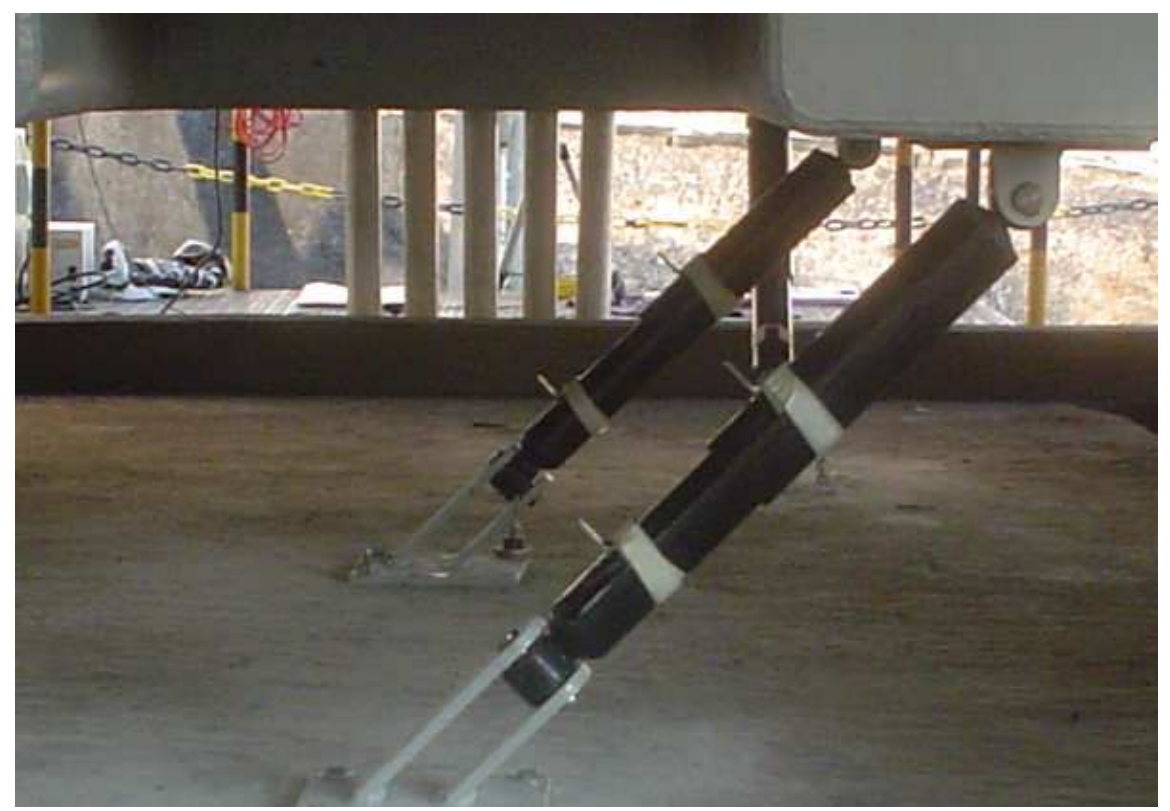

Figura 4.73: Foto do amortecedor montado na base do tanque 


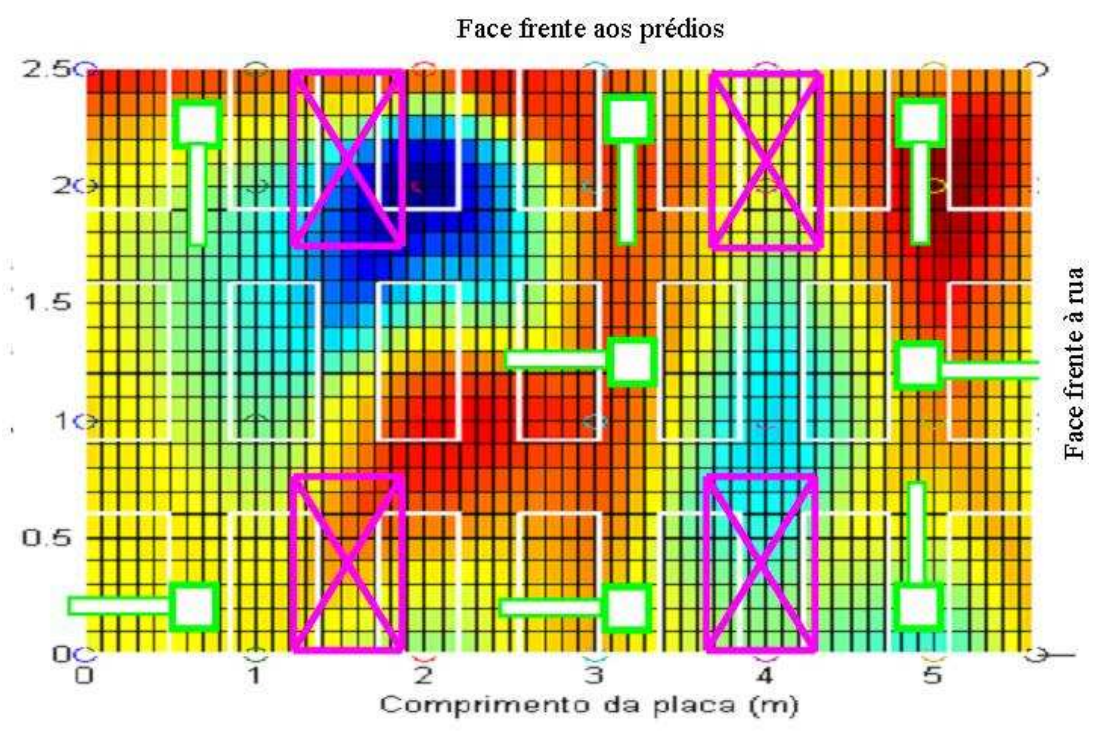

Figura 4.74: Posicionamento dos amortecedores na base do tanque. O quadrado de aresta verde representa a posição do suporte superior, e o retângulo de aresta verde representa o amortecedor

A base para suporte dos absorvedores dinâmicos foi colada com resina, já que não é possível usar solda para evitar danos na pintura isolante e para evitar eventual formação de bolhas no óleo isolante dentro do tanque. Após a cura da cola, os absorvedores dinâmicos já sintonizados para uma freqüência natural entre 122 e $125 \mathrm{~Hz}$ foram montados nas regiões críticas. A fig. 4.75 mostra os espaços onde foram colocados os absorvedores dinâmicos, e a fig. 4.76 mostra uma foto dos absorvedores dinâmicos na face frente ao edifício. 


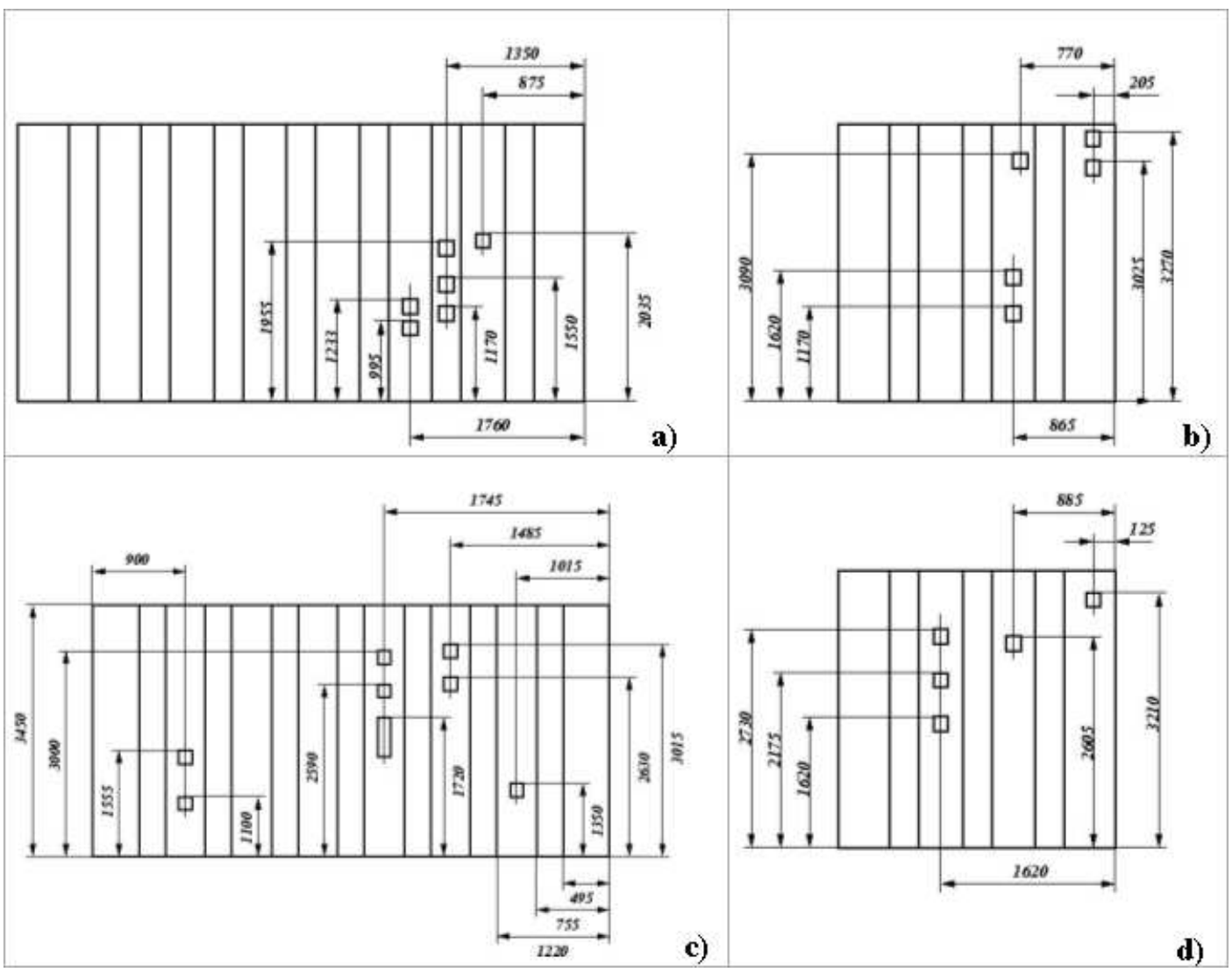

Figura 4.75: Localização dos absorvedores dinâmicos a) face frente ao edifício, b) face oposta à rua, c) face oposta ao edifício d) face frente à rua.

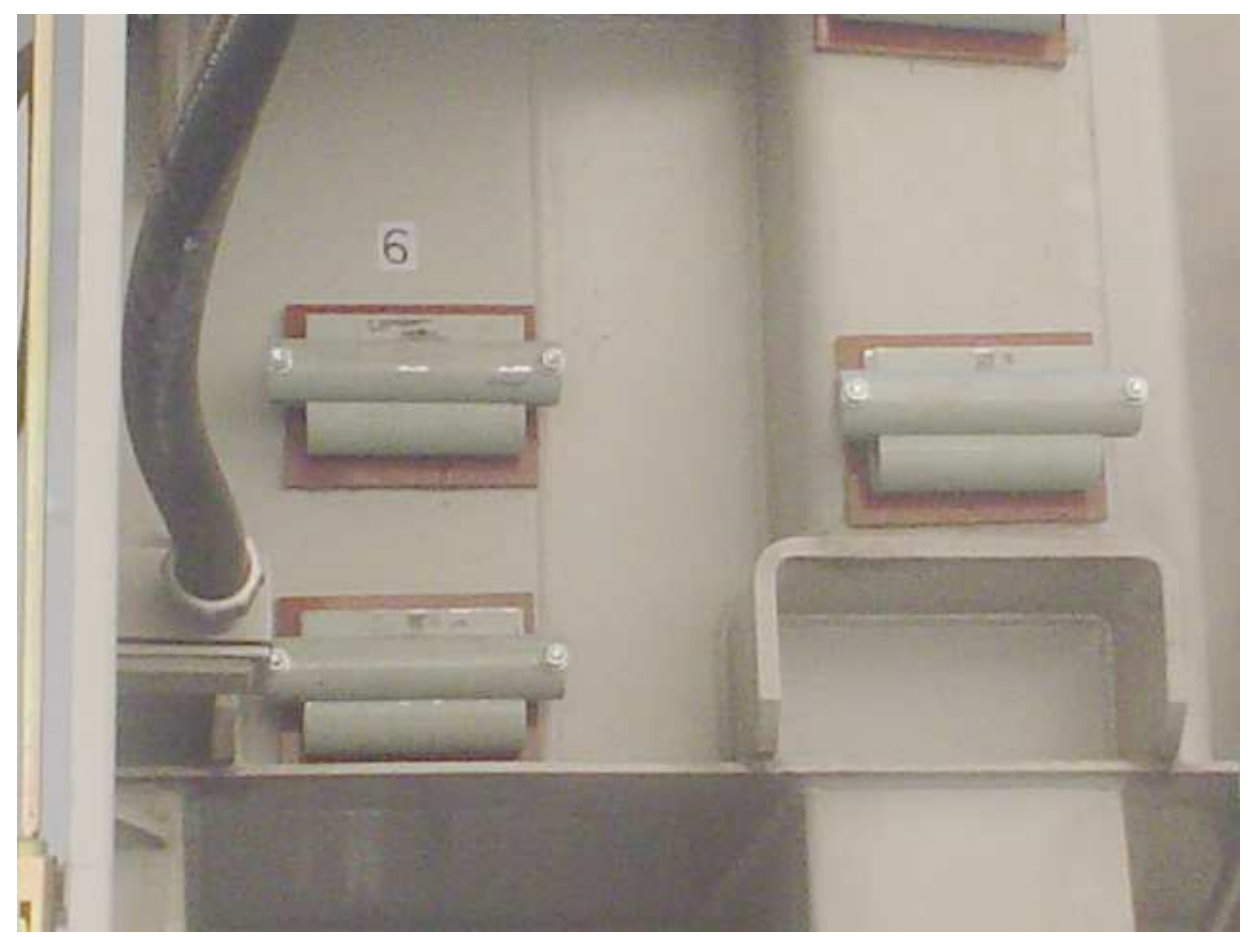

Figura 4.76: Foto dos absorvedores dinâmicos montados na face frente ao edifício 
Em cada etapa foram coletadas 32 medições tendo os quatro casos: normal (sem os dispositivos para redução de ruído acústico), só com amortecedores, só com absorvedores dinâmicos, e com amortecedores e absorvedores dinâmicos. $\mathrm{Na}$ tabela 4.10 mostram-se os resultados da medição de pressão sonora na freqüência de $120 \mathrm{~Hz}$.

Tabela 4.10: Medidas da pressão sonora na freqüência de $120 \mathrm{~Hz}(\mathrm{em} d B$ )

\begin{tabular}{|l|l|l|l|l|l|l|l|l|}
\hline MEDIÇÃO 120 & Pt. 1 & Pt. 2 & Pt. 3 & Pt. 4 & Pt. 5 & Pt. 6 & Pt. 7 & Pt. 8 \\
\hline \hline 1,5m normal & 61,4 & 65,7 & 63,9 & 64,8 & 66,6 & 69,3 & 63,5 & 63,1 \\
\hline 1,5m c. amort. & 67,4 & 61,5 & 65,1 & 65,1 & 65,9 & 69,4 & 66,1 & 59,3 \\
\hline 1,5m c. amort.+AD & 64,5 & 61,7 & 62,4 & 67,9 & 70,2 & 69,5 & 65,3 & 59,8 \\
\hline 1,5m c. AD & 65,5 & 64,5 & 57,6 & 65,6 & 67,8 & 71,0 & 64,9 & 64,5 \\
\hline \hline 3,0m normal & 64,8 & 65,7 & 63,6 & 66,3 & 63,3 & 68,1 & 62,7 & 54,6 \\
\hline 3,0m c. amort. & 63,6 & 65,8 & 66,0 & 67,3 & 62,3 & 67,9 & 63,3 & 52,0 \\
\hline 3,0m c. amort.+AD & 65,4 & 63,8 & 64,8 & 68,8 & 70,0 & 70,0 & 64,8 & 62,9 \\
\hline 3,0m c. AD & 63,0 & 65,1 & 62,9 & 66,9 & 60,0 & 71,5 & 64,0 & 58,6 \\
\hline \hline 4,5m normal & 64,0 & 64,5 & 60,2 & 67,1 & 63,3 & 70,6 & 67,3 & 54,5 \\
\hline 4,5m com amort. & 63,5 & 65,6 & 63,3 & 69,7 & 61,7 & 61,7 & 67,7 & 52,7 \\
\hline 4,5m c. amort.+AD & 64,9 & 63,9 & 62,6 & 65,8 & 65,2 & 72,4 & 69,6 & 56,5 \\
\hline 4,5m c. AD & 64,9 & 64,5 & 62,8 & 64,5 & 64,0 & 72,2 & 69,2 & 49,1 \\
\hline \hline 6,0m normal & 61,8 & 67,0 & 64,0 & 72,0 & 63,6 & 60,5 & 49,8 & 56,4 \\
\hline 6,0m c. amort. & 66,3 & 66,8 & 72,8 & 70,3 & 64,8 & 59,8 & 59,7 & 65,8 \\
\hline 6,0m c. amort.+AD & 54,3 & 62,2 & 61,8 & 67,3 & 70,5 & 69,6 & 70,2 & 64,4 \\
\hline 6,0m c. AD & 66,8 & 67,8 & 65,6 & 71,7 & 65,0 & 72,9 & 72,3 & 66,2 \\
\hline
\end{tabular}

A comparação entre as condições sem ou com dispositivos é resumida na tabela 4.11 nela mostram-se os valores da diminuição (negativo) ou incremento (positivo) para as condições com amortecedor viscoso (com amort.) com amortecedor viscoso e absorvedor dinâmico juntos (com amort. com AD) e com absorvedor dinâmico (com AD).

O Campo Acústico é afetado pela reflexão do som com o muro até a altura de $5 \mathrm{~m}$. A faixa de incremento ou diminuição é a maior e varia de -8 e $25 d B$. As medições na altura de $6 m$ ocorrem na direção das janelas dos edifícios é não são afetadas pela reflexão do ruído. Por isso, as medições na altura de $6 m$ são as mais significativas para verificar a atenuação do ruído. O melhor desempenho ocorreu na altura de $6 m$, onde houve diminuição de até $8 \mathrm{~dB}$ com amortecedores e absorvedores dinâmicos.

O cálculo do Nível de Pressão Global é realizado com a equação 4.19, os resultados são mostrados na tabela 4.12 dos pontos medidos. 
Tabela 4.11: Avaliação da redução de som por ponto e total em $120 \mathrm{~Hz}$

\begin{tabular}{|l|l|l|l|l|l|l|l|l|}
\hline MEDIÇÃO 120 & Pt. 1 & Pt. 2 & Pt. 3 & Pt. 4 & Pt. 5 & Pt. 6 & Pt. 7 & Pt. 8 \\
\hline \hline 1,5m com amort. & 6,0 & $-1,8$ & 4,9 & 0,3 & $-0,7$ & 0,1 & 2,6 & $-3,8$ \\
\hline 3,0m com amort. & 3,1 & $-4,0$ & 5,8 & 3,1 & 3,6 & 0,2 & 1,8 & $-3,3$ \\
\hline 4,5m com amort. & 4,1 & $-1,2$ & 1,0 & 0,8 & 1,2 & 1,7 & 1,4 & 1,4 \\
\hline 6,0m com amort. & $-1,2$ & 0,1 & 2,4 & 1,0 & $-1,0$ & $-0,2$ & 0,6 & $-2,6$ \\
\hline \hline 1,5m com amort.+AD & 0,9 & 0,0 & 2,6 & $-2,6$ & 0,7 & 1,6 & 1,9 & $-5,4$ \\
\hline 3,0m com amort.+AD & 4,5 & $-0,2$ & 8,8 & $-1,7$ & 1,2 & $-0,7$ & 9,9 & 9,4 \\
\hline 4,5m com amort.+AD & $-7,5$ & $-4,8$ & $-2,2$ & $-4,7$ & 6,9 & 8,0 & 20,4 & 9,1 \\
\hline 6,0m com amort.+AD & 5,0 & 0,8 & 1,6 & $-0,3$ & 1,4 & 12,4 & 22,5 & 9,8 \\
\hline \hline 1,5m com AD & 0,6 & $-1,9$ & 1,2 & 2,5 & 6,7 & 1,9 & 2,1 & 8,3 \\
\hline 3,0m com AD & $-1,8$ & $-0,6$ & $-0,7$ & 0,6 & $-3,3$ & 3,4 & 1,3 & 4,0 \\
\hline 4,5m com AD & $-0,5$ & 1,1 & 3,1 & 2,6 & $-1,6$ & $-8,9$ & $-0,5$ & $-0,5$ \\
\hline 6,0m com AD & 0,9 & $-0,6$ & 2,4 & $-1,3$ & 1,9 & 1,8 & 2,3 & 2,0 \\
\hline
\end{tabular}

$$
L_{p t}=10 \cdot \log _{10}\left(\frac{\sum p_{i}^{2}}{p_{r e f}^{2}}\right)
$$

Onde: $p_{i}$ é a pressão em toda a faixa de freqüência.

Tabela 4.12: Valores do nível de pressão global do som (em $d B$ ).

\begin{tabular}{|l|l|l|l|l|l|l|l|l|}
\hline MEDIÇÃO GLOBAL & Pt. 1 & Pt. 2 & Pt. 3 & Pt. 4 & Pt. 5 & Pt. 6 & Pt. 7 & Pt. 8 \\
\hline \hline 1,5m normal & 67,19 & 71,73 & 67,66 & 69,26 & 70,97 & 73,19 & 67,91 & 68,09 \\
\hline 3,0m normal & 69,61 & 69,55 & 68,68 & 70,64 & 72,39 & 71,72 & 68,24 & 67,24 \\
\hline 4,5m normal & 68,94 & 69,02 & 66,47 & 73,20 & 69,25 & 73,67 & 70,62 & 65,54 \\
\hline 6,0m normal & 67,66 & 72,00 & 72,00 & 75,03 & 68,48 & 69,58 & 66,45 & 65,41 \\
\hline \hline 1,5m c. amort. & 72,00 & 70,60 & 70,42 & 70,33 & 72,54 & 74,27 & 72,32 & 69,29 \\
\hline 3,0m c. amort. & 72,85 & 70,87 & 70,98 & 71,63 & 69,42 & 73,36 & 69,72 & 68,12 \\
\hline 4,5m c. amort. & 68,97 & 71,61 & 69,88 & 73,32 & 72,56 & 72,56 & 71,48 & 67,38 \\
\hline 6,0m c. amort. & 71,01 & 71,32 & 76,07 & 73,91 & 70,30 & 68,06 & 66,89 & 71,08 \\
\hline \hline 1,5m c. amort.+AD & 71,07 & 69,61 & 69,52 & 71,67 & 74,99 & 72,99 & 70,01 & 68,88 \\
\hline 3,0m c. amort.+AD & 70,37 & 69,02 & 69,39 & 72,47 & 73,93 & 73,58 & 69,77 & 70,92 \\
\hline 4,5m c. amort.+AD & 70,44 & 69,27 & 67,89 & 70,21 & 69,86 & 75,34 & 73,14 & 66,70 \\
\hline 6,0m c. amort.+AD & 72,98 & 71,62 & 70,02 & 72,85 & 74,09 & 73,11 & 73,70 & 70,24 \\
\hline 1,5m c. AD & 72,09 & 71,05 & 69,74 & 71,58 & 73,22 & 74,74 & 70,79 & 70,23 \\
\hline 3,0m c. AD & 70,42 & 71,43 & 69,44 & 72,09 & 71,09 & 74,99 & 70,41 & 69,07 \\
\hline 4,5m c. AD & 70,69 & 70,67 & 69,63 & 70,94 & 70,00 & 75,54 & 73,26 & 66,16 \\
\hline 6,0m c. AD & 72,00 & 72,61 & 70,92 & 75,43 & 70,94 & 76,04 & 77,01 & 71,23 \\
\hline
\end{tabular}

Com os dados da tabela 4.10 e da tabela 4.12 e com interpolação cúbica, construiram-se as curvas de pressão sonora e de nível de pressão, $L p$. Primeiro mostra-se na fig. 4.77 a curva de níveis de pressão normal na freqüência de 120 $H z$ e níveis de pressão global. Na fig. 4.78 mostra-se a comparação do campo 
acústico na condição normal, e com amortecedores na base do transformador. Na fig. 4.79 mostra-se a comparação do campo acústico entre a condição normal (sem dispositivos de redução de ruído acústico) e a condição com amortecedores e absorvedores dinâmicos instalados nas paredes do tanque. Na fig. 4.80 mostra-se a comparação do campo acústico entre a condição normal e com absorvedores dinâmicos instalados nas paredes do tanque.

Normal freq $=120$

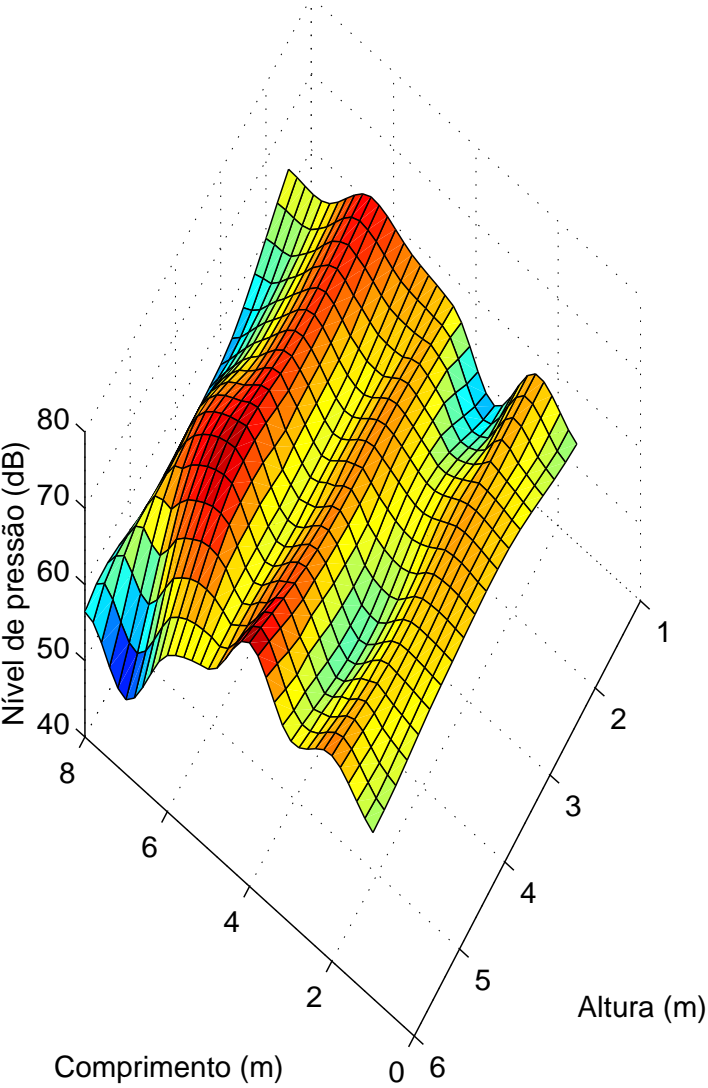

Normal global

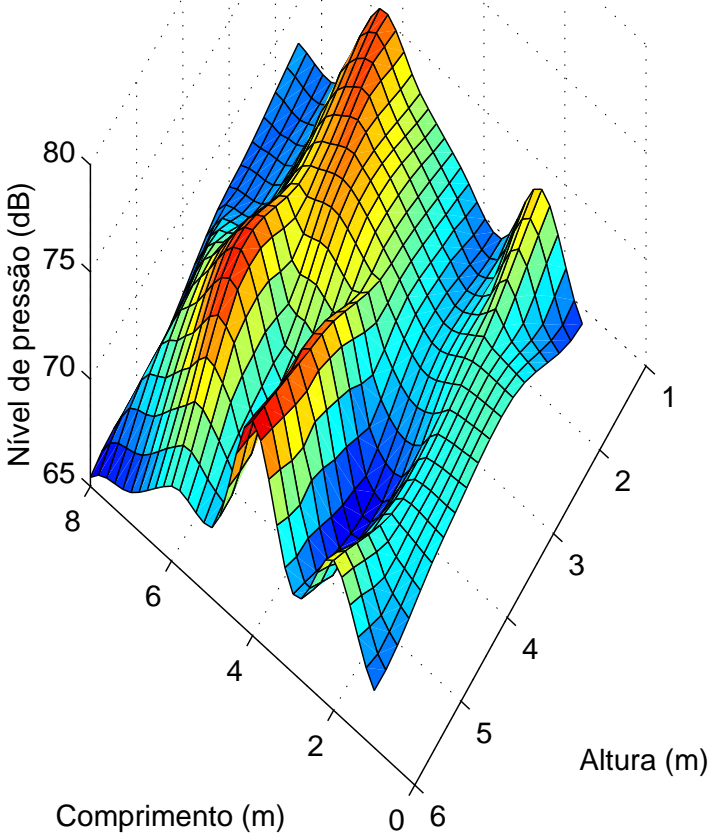

Figura 4.77: Superfície curva que mostra valores das medições no caso normal a) medição do $L p$ na freqüência de $120 \mathrm{~Hz}$, b) medição do $L p$ global sonora 

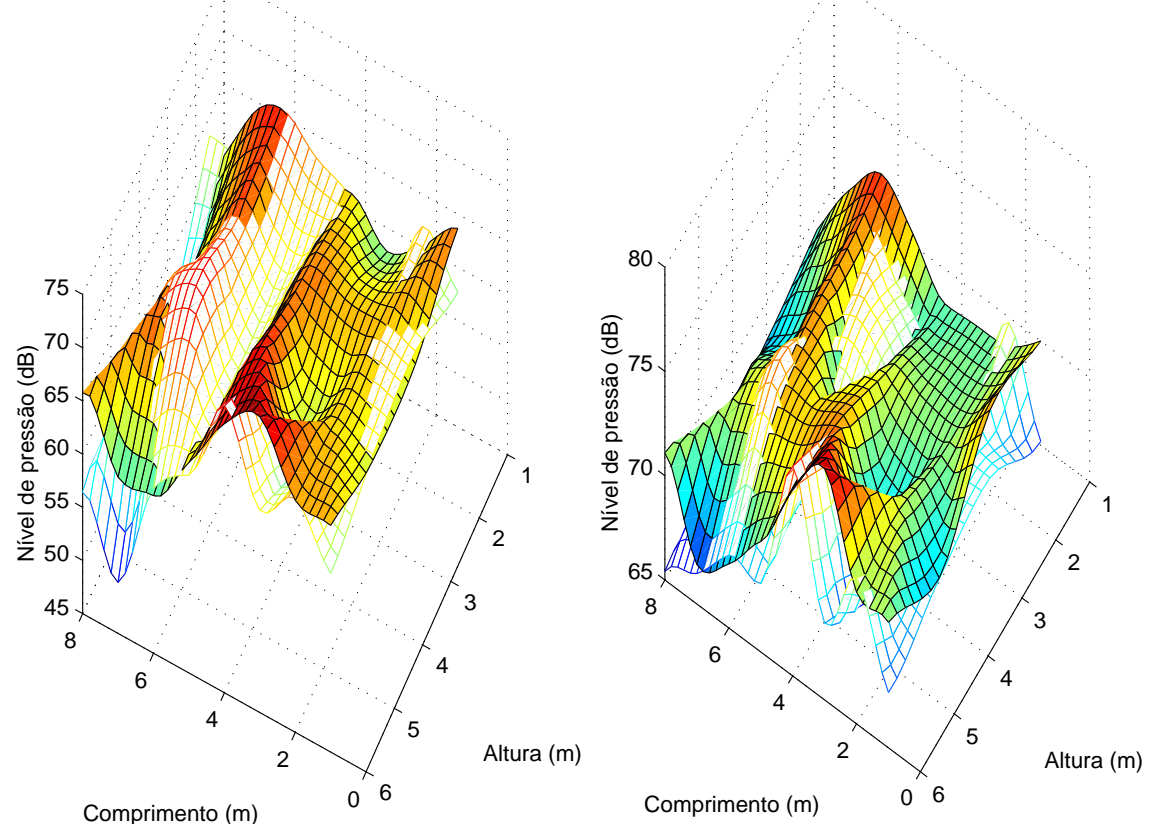

Figura 4.78: Comparação entre os valores da medição normal (malha de linhas) e os valores da medição só com amortecedor (superfície colorida) a) comparação em $120 \mathrm{~Hz}$, b) comparação no nível global de pressão sonora
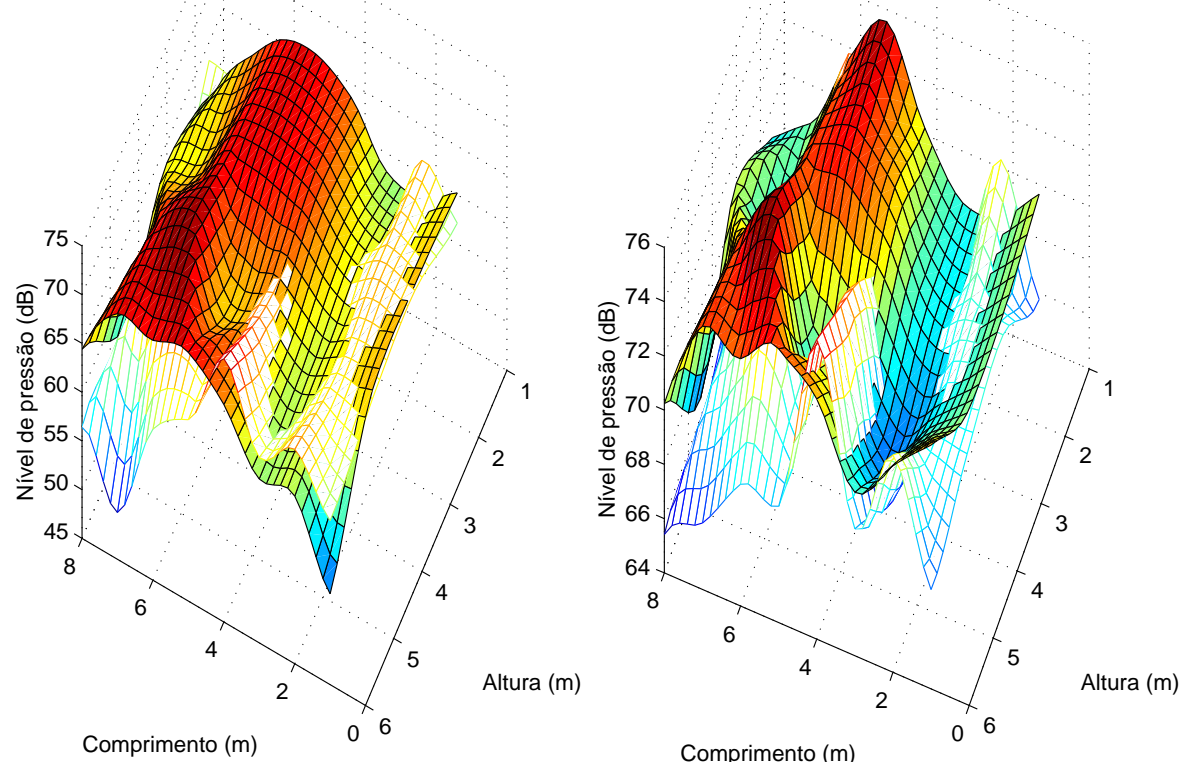

Figura 4.79: Comparação entre os valores da medição normal (malha de linhas) e e os valores da medição com amortecedor e ADs (superfície colorida) a) comparação em $120 \mathrm{~Hz}$, b) comparação no nível global de pressão sonora 

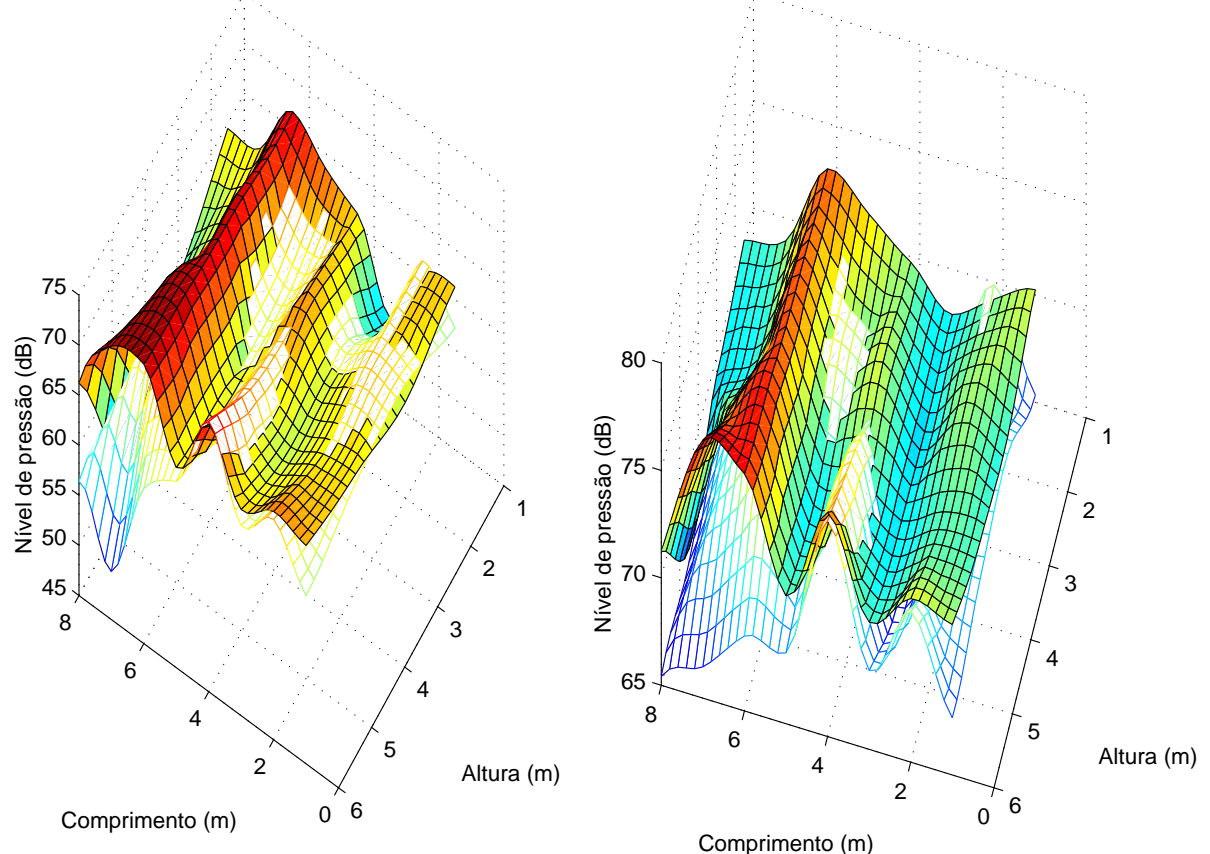

Figura 4.80: Comparação entre os valores da medição normal (malha de linhas) e os valores da medição com ADs (superfície colorida) a) comparação em $120 \mathrm{~Hz}, \mathrm{~b})$ comparação no nível global de pressão sonora

Da observação da fig. 4.78, da fig. 4.79 e da fig. 4.80 observa-se que o campo acústico foi modificado, em alguns pontos de maneira favorável com a diminuição do som e em outros pontos de maneira desfavorável pelo aumento do nível de pressão.

As coletas de dados não ocorreram nas mesmas condições, ocorreram em horários distintos. O som se modifica por influência da carga. Como foi explicado anteriormente o som muda no transcurso do dia. Na fig. 4.2 observa-se que entre as 9 horas e as 15 horas há uma diferença de aproximadamente 3,5 dB, nas medidas de um transformador de Furnas, que fornece energia para a cidade de São Paulo. Como os horários de medição de pressão sonora no caso dos ensaios em Bela Aliança foram diferentes, foi realizada uma correção, em função dos dados de Furnas.

A fig. 4.81, a fig. 4.82 e a fig. 4.82 apresentam uma estimativa dos resultados que seriam obtidos, em condições normais e com a implementação de absorvedores e amortecedores no mesmo horário. 


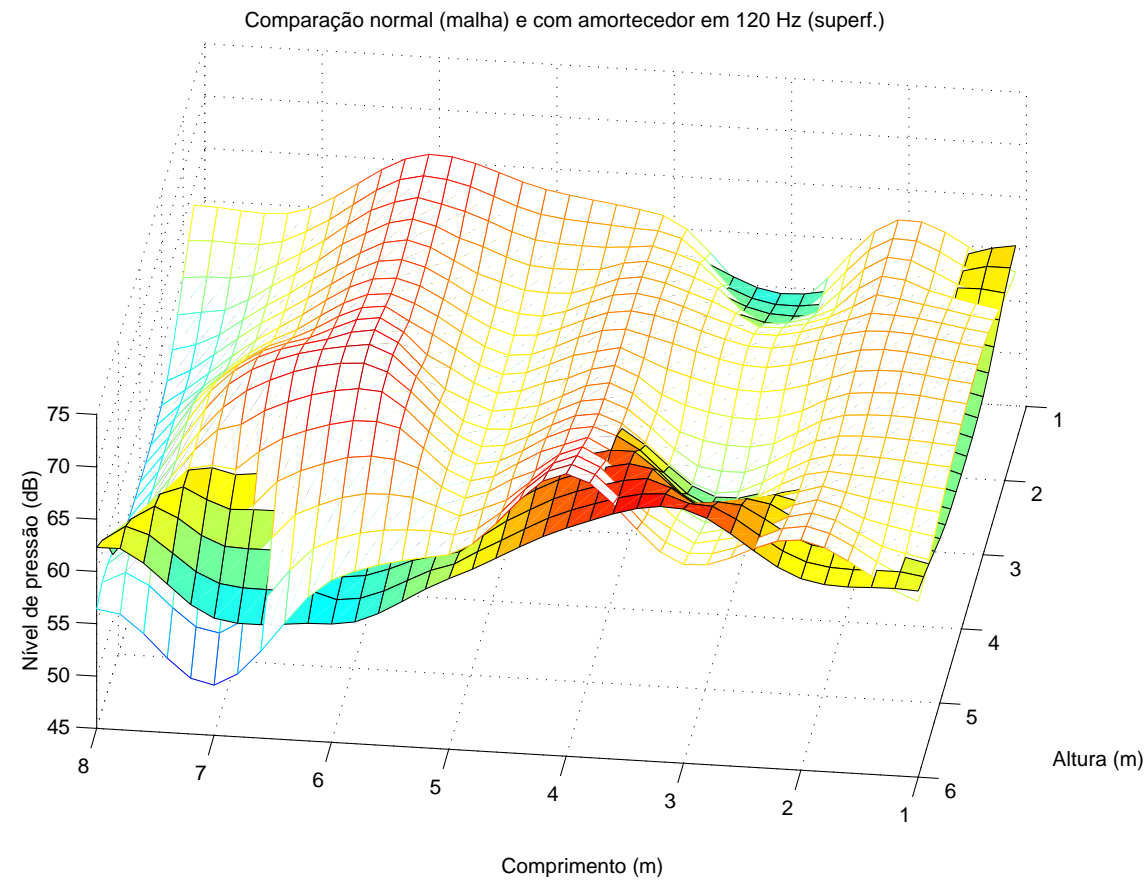

Figura 4.81: Comparação entre os valores da medição normal (malha de linhas) e os valores da medição só com amortecedor (superfície colorida) considerando uma correção $(-3,5 d B)$ devido ao horário, comparação na freqüência de $120 \mathrm{~Hz}$

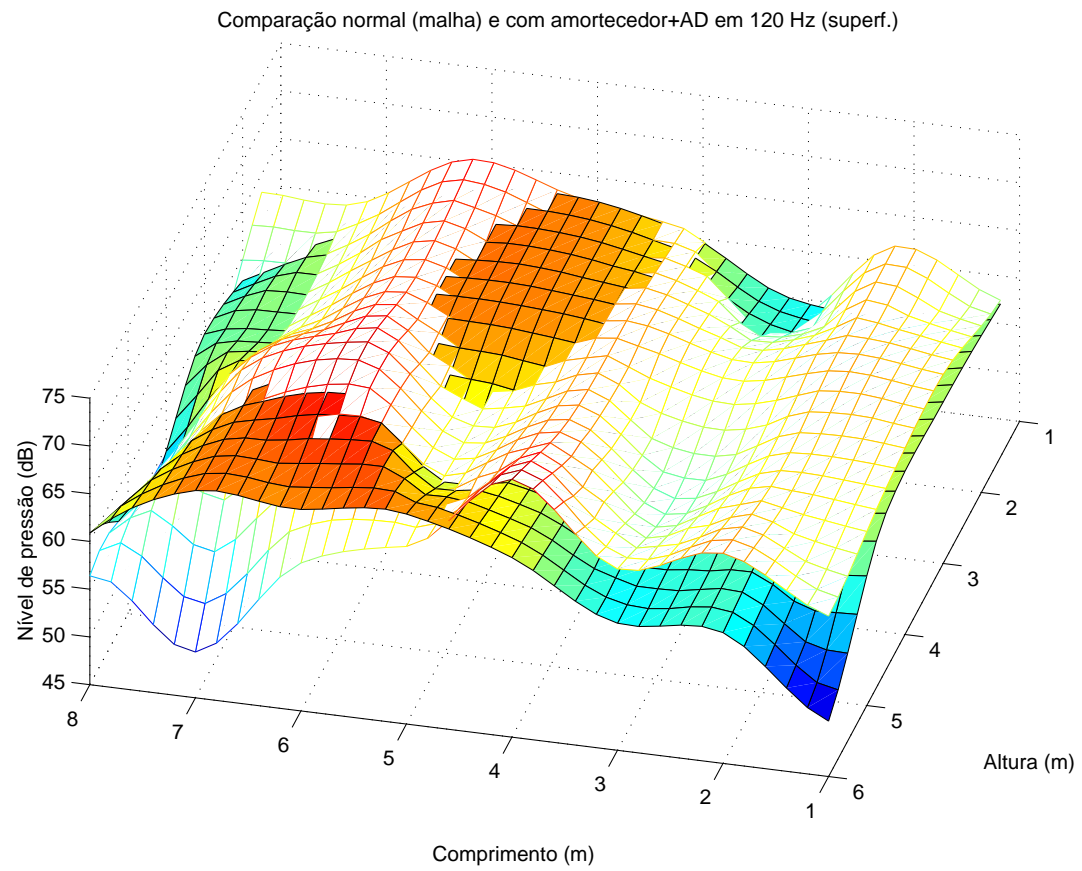

Figura 4.82: Comparação entre os valores da medição normal (malha de linhas) e os valores da medição com amortecedor e absorvedores dinâmicos (superfície colorida) considerando uma correção $(-3,5 \mathrm{~dB})$ devido ao horário, comparação na freqüência de $120 \mathrm{~Hz}$ 


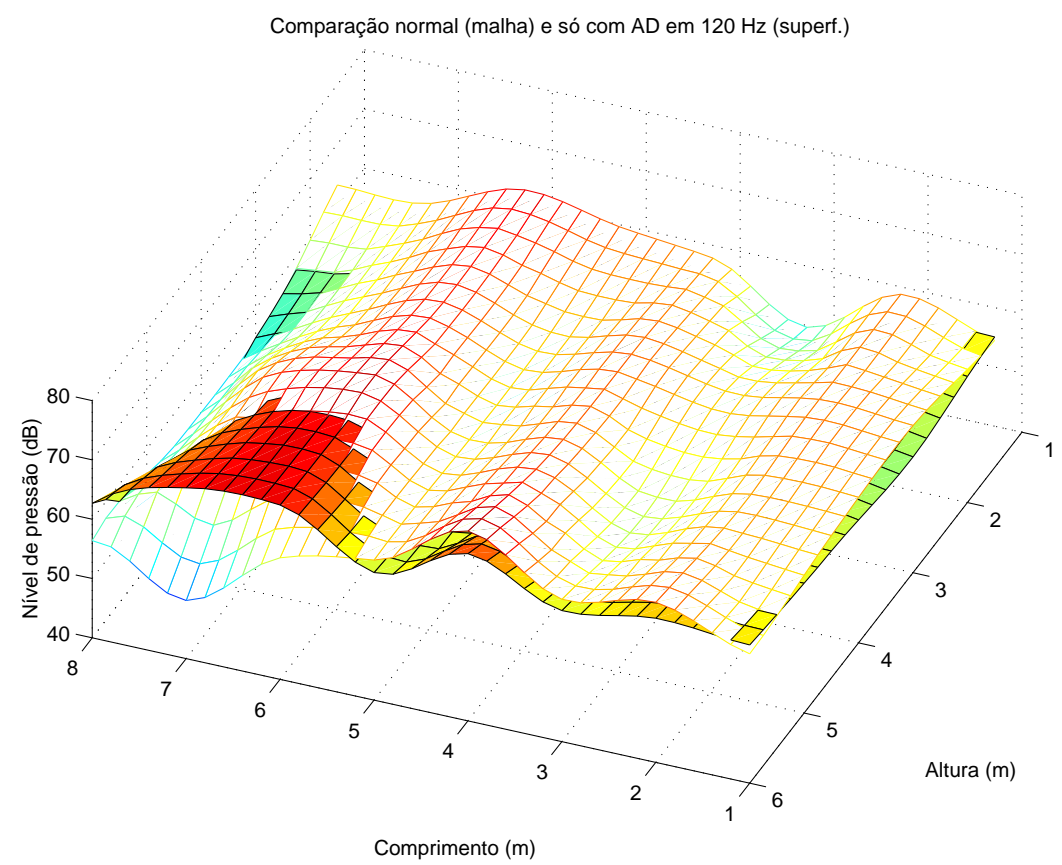

Figura 4.83: Comparação entre os valores da medição normal (malha de linhas) e os valores da medição só com absorvedores dinâmicos (superfície colorida) considerando uma correção $(-3,5 d B)$ devido ao horário, comparação na freqüência de $120 \mathrm{~Hz}$

A predominância da malha de linhas sobre a superfície colorida nas figuras indica a redução de ruído acústico, lembrando que nestas figuras (4.81 a 4.83) há uma correção estimada devido aos horários diferentes das medições.

Projetando os resultados obtidos da medição do som em um plano de 2 dimensões, considerando a posição da face frente ao edifício e os radiadores de calor e posição dos absorvedores dinâmicos em escala elaboram-se a fig. 4.84, a fig. 4.85, a fig. 4.86 e a fig. 4.87. Os valores de atenuação do som estão incorporados nas figuras, encontram-se nos pontos que foram coletados os dados. 


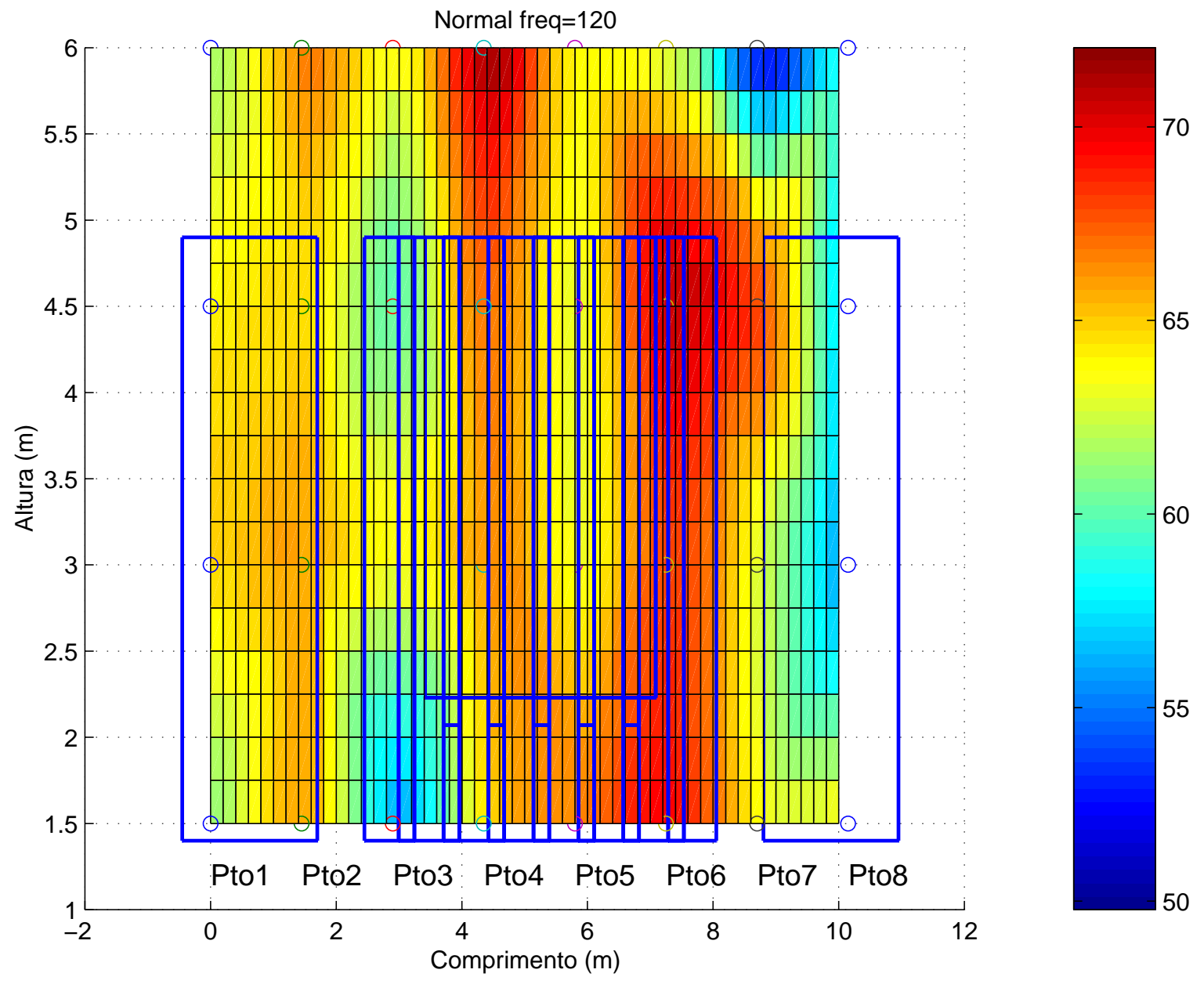

Figura 4.84: Sinais do $L p$ na freqüência de $120 \mathrm{~Hz}$ na condição normal em duas dimensões projetado diante da face frente ao edifício, incluindo os radiadores em proporção a suas dimensões 


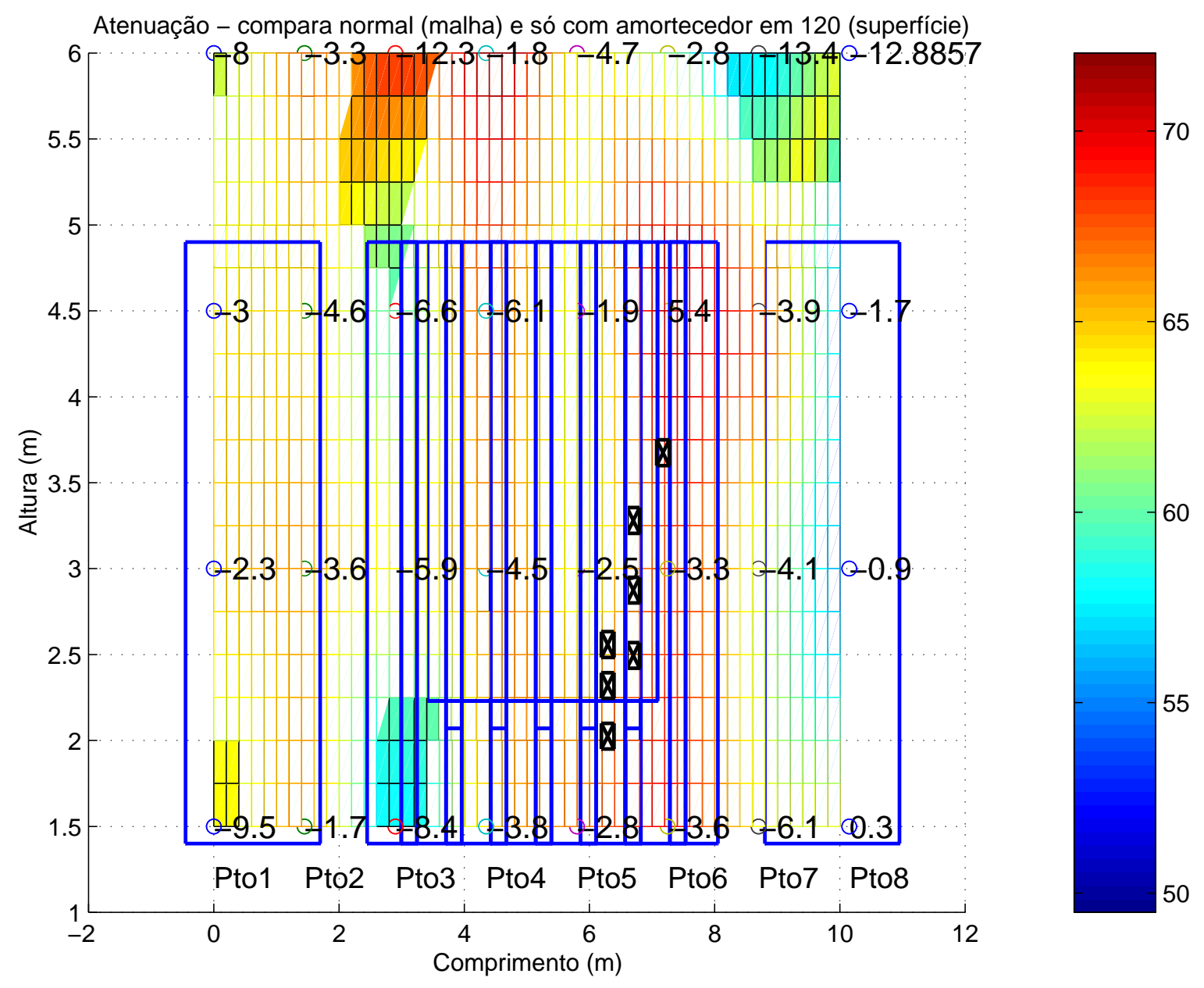

Figura 4.85: Comparação dos sinais do $L p$, na freqüência de $120 \mathrm{~Hz}$, na condição normal e com amortecedor em duas dimensões projetado na face frente ao edifício, incluindo os radiadores e absorvedores dinâmicos (retângulo pequeno preto) em escala 


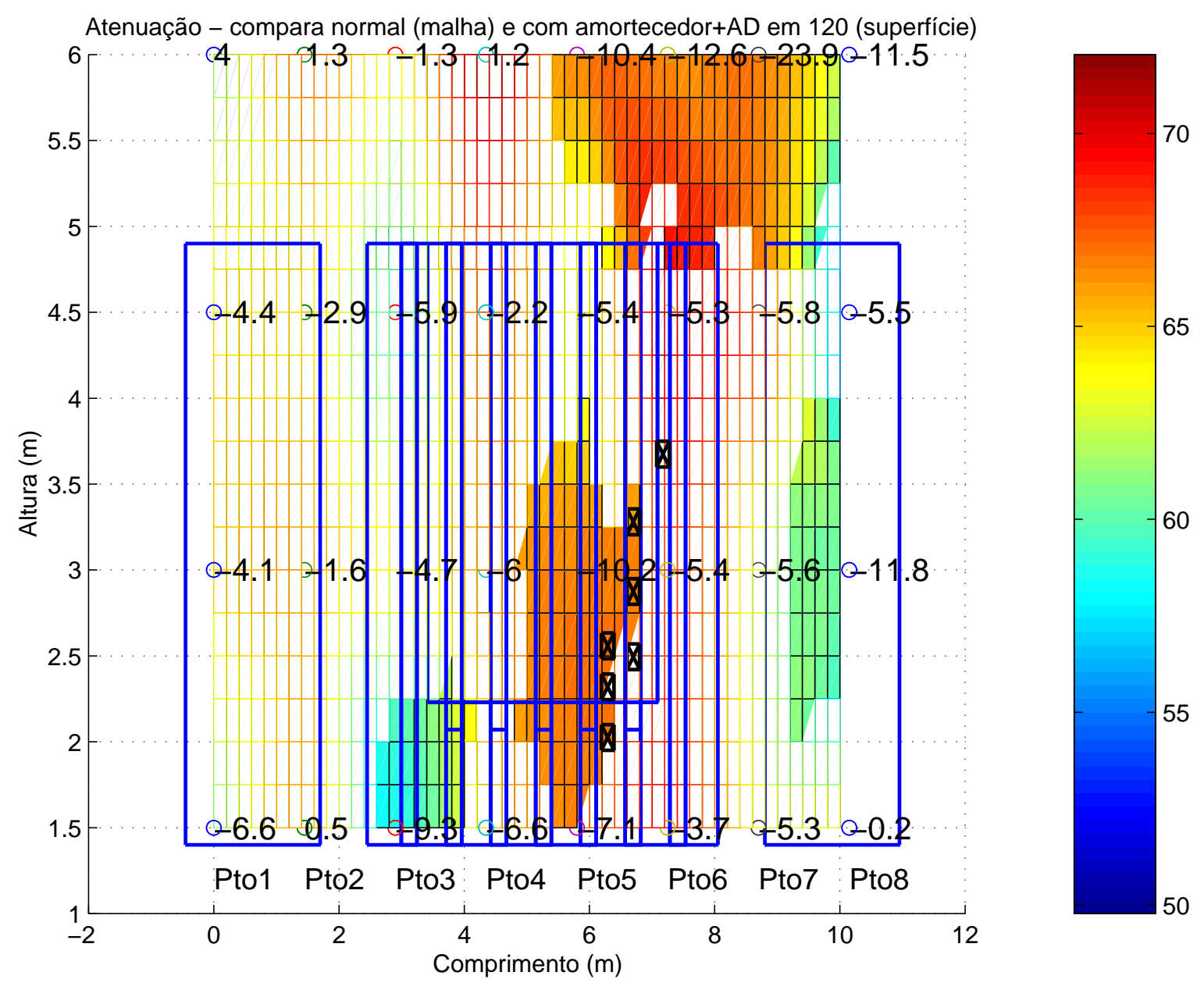

Figura 4.86: Comparação dos sinais do $L p$, na frequência de $120 \mathrm{~Hz}$, na condição normal e com amortecedor e absorvedor dinâmico, em duas dimensões, projetado na face frente ao edifício, incluindo os radiadores e absorvedor dinâmico (retângulo pequeno preto) em escala 


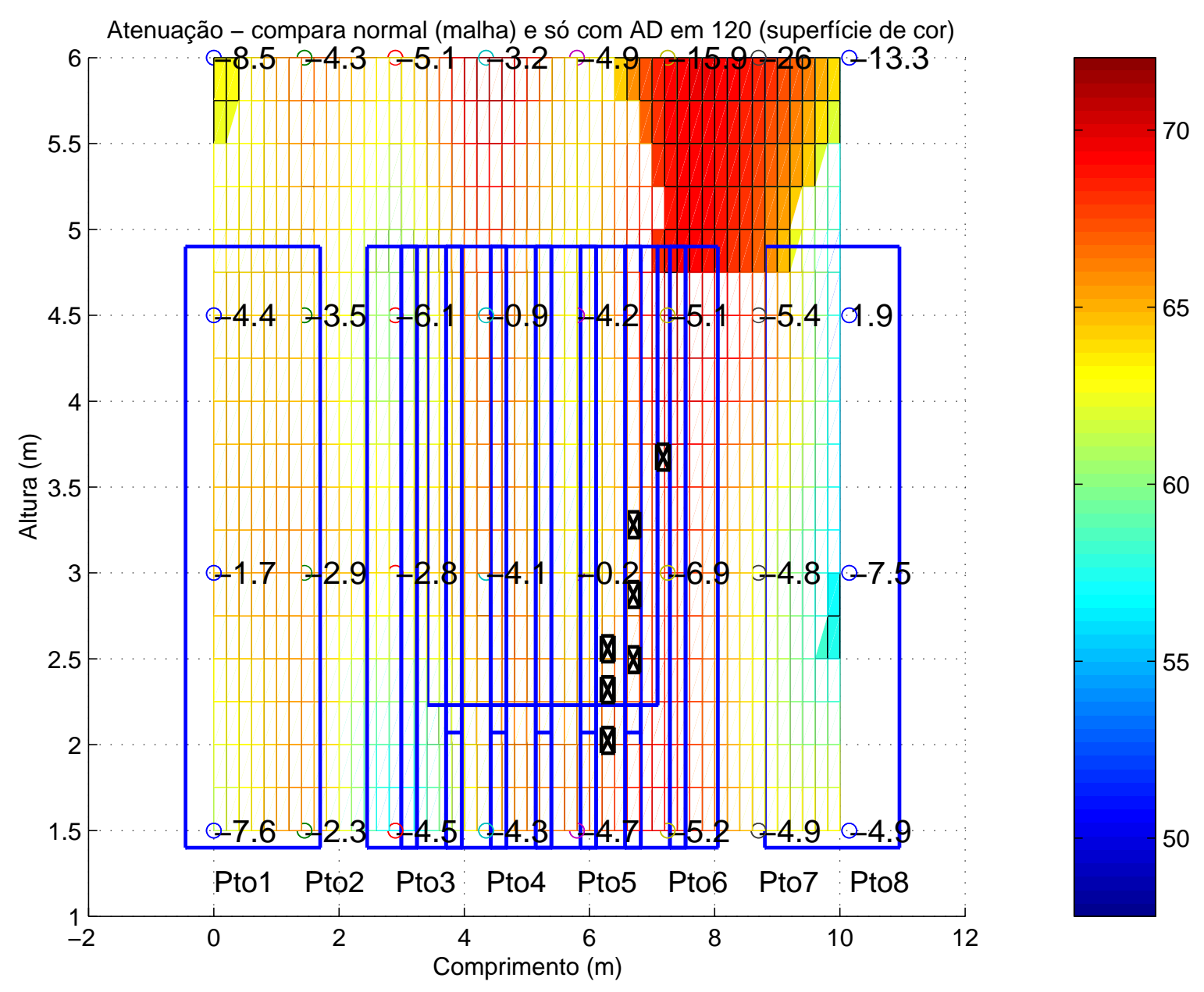

Figura 4.87: Comparação dos sinais do Lp a $120 \mathrm{~Hz}$ normal e com absorvedor dinâmico em duas dimensões projetado diante a face frente aos prédios incluindo os radiadores e absorvedor dinâmico (retângulo pequeno preto) em escala

Observando as figuras constata-se que existem regiões onde o ruído não diminui, mas os valores máximos não são maiores que a condição normal. As regiões que apresentaram maior emissão de som diminuiram nas condições só com amortecedores e só com absorvedores dinâmicos. Na condição com amortecedores e absorvedores dinâmicos, o resultado não foi favorável. Provavelmente ao instalar os amortecedores ao tanque seu comportamento de rigidez é modificada, a vibração na superfície do tanque é modificado. Ao instalar absorvedores dinâmicos, as regiões de maior vibração são modificadas.

\subsubsection{Avaliação dos resultados de vibração}

Os pontos onde se mediu a aceleração e os espaços ocupados pelos absorvedores dinâmicos são mostrados na fig. 4.88 e na fig. 4.89, onde são apresentadas as faces do transformador e os absorvedores dinâmicos em escala. As acelerações foram medidas nas condições normal, com amortecedor, com amortecedor e absorvedor 
dinâmico e com absorvedor dinâmico.

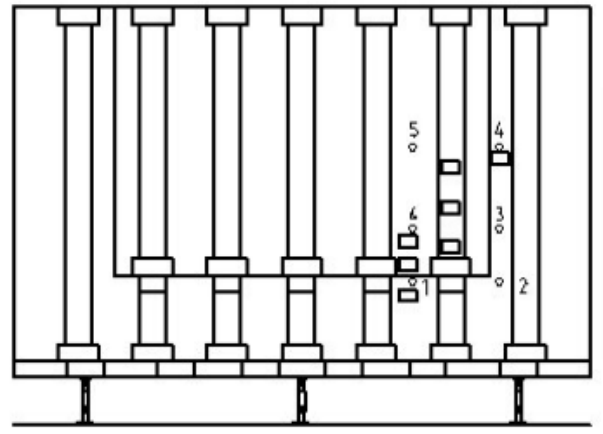

a)

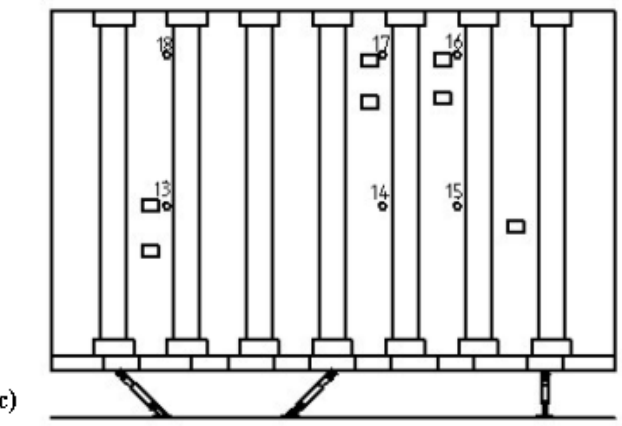

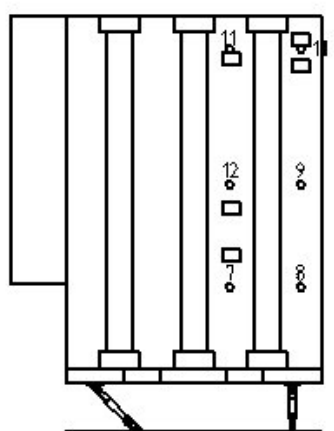

b)

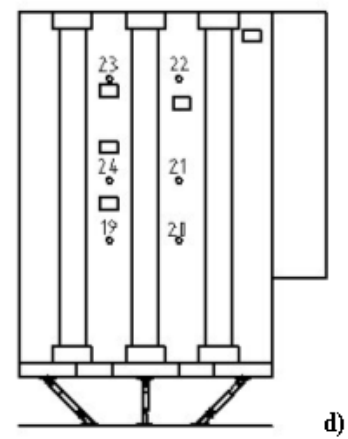

Figura 4.88: Localização dos suportes dos amortecedores e pontos de medição (desenho em escala)

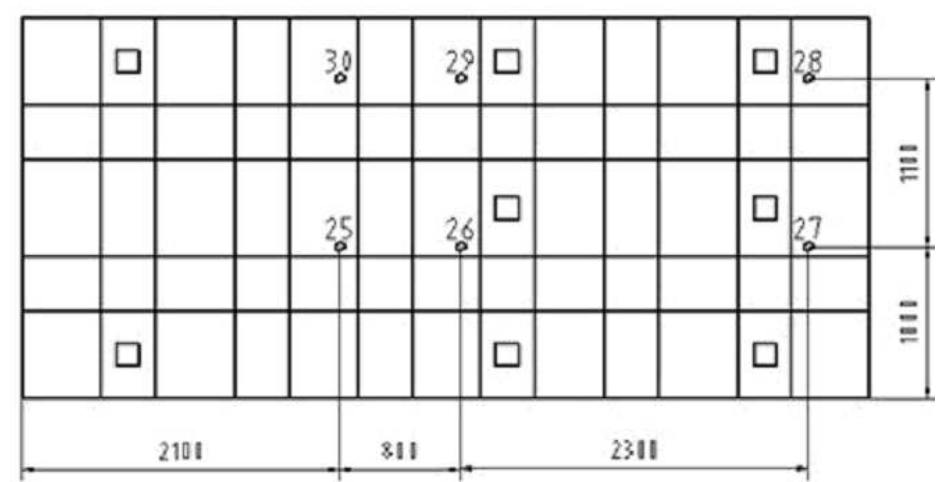

Figura 4.89: Localização dos pontos de medição e dos absorvedores dinâmicos (desenho em escala) (a) face frente ao edifício, b) face oposta à rua, c) face oposta ao edifício d) face frente à rua e) base

Os resultados das medições de vibração são mostrados na fig. 4.90, na fig. 4.91 e na fig. 4.92. Na fig. 4.90 mostram-se os sinais no domínio da freqüência nas quatro faces e na base, na faixa de zero até 900 Hz. Na fig. 4.91 e na fig. 4.92 mostra-se o comportamento na faixa de 100 até $270 \mathrm{~Hz}$. 

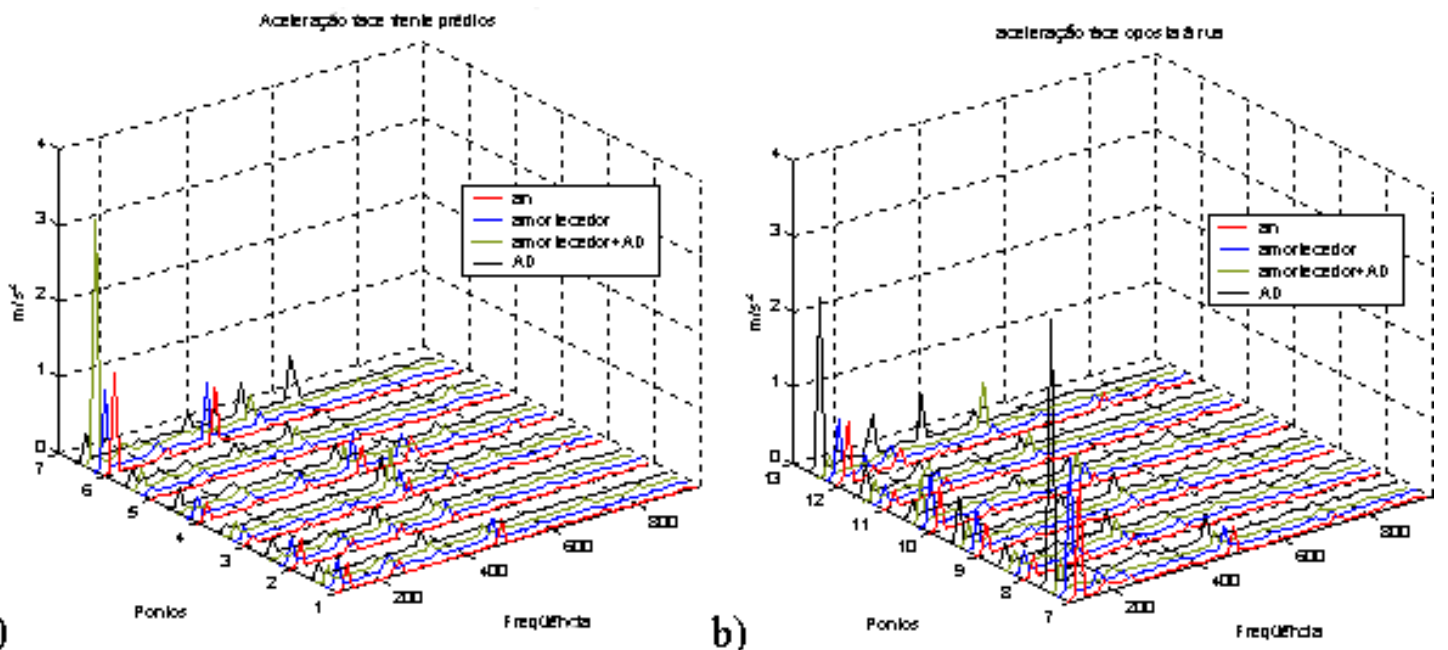

a)

b)
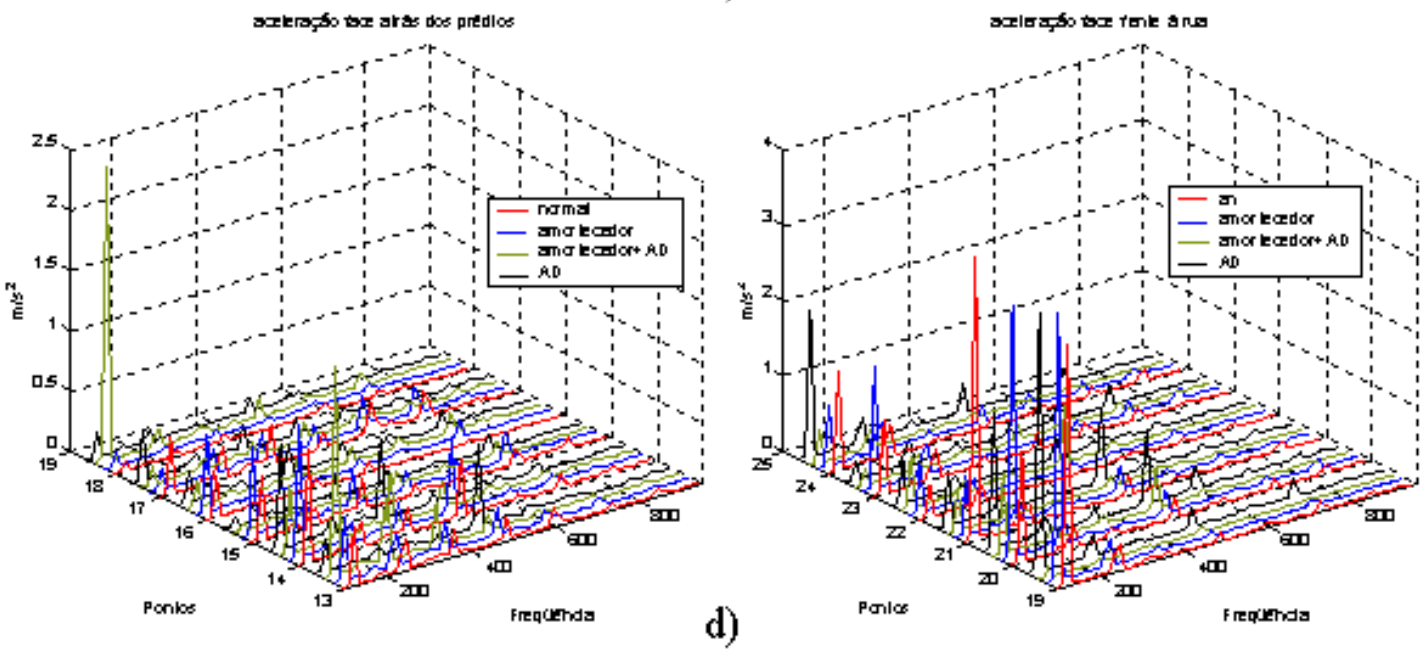

c)

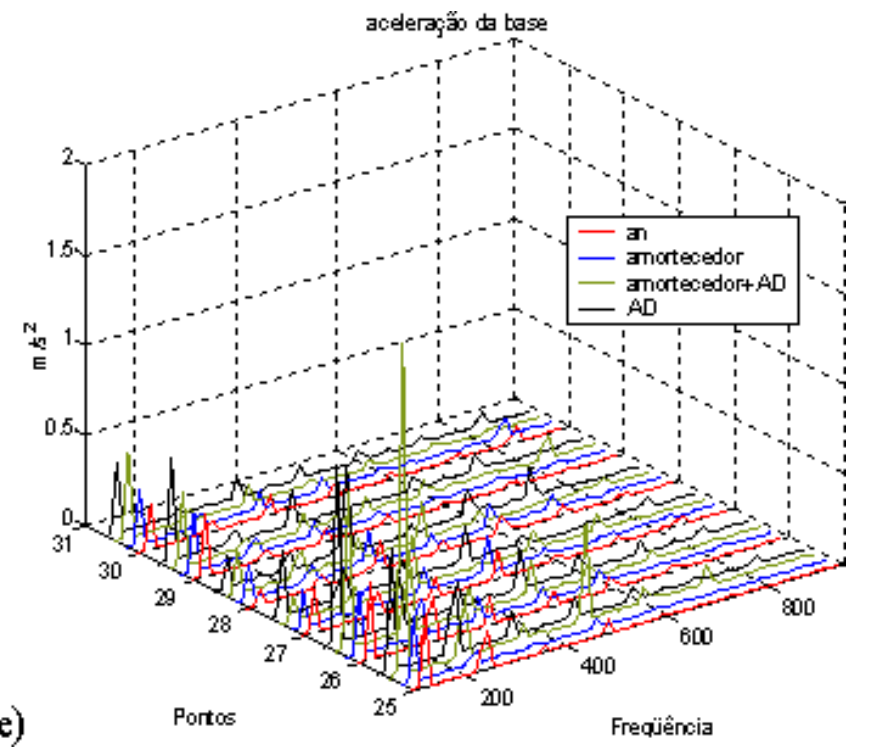

Figura 4.90: Sinais de aceleração no domínio da freqüência, na faixa de 0 até $900 \mathrm{~Hz}$ : a) face frente ao edifício b) face oposta à rua c) face oposta ao edifício d) face frente á rua e) base do transformador.

Os resultados dos sinais de aceleração estão relacionados com a proximidade com os absorvedores dinâmicos, em quase todos os casos que se mediu próximo 
aos absorvedores dinâmicos as amplitudes da aceleração foram reduzidas, mas em pontos distantes a amplitude de aceleração eventualmente aumentou na freqüência de $120 \mathrm{~Hz}$.
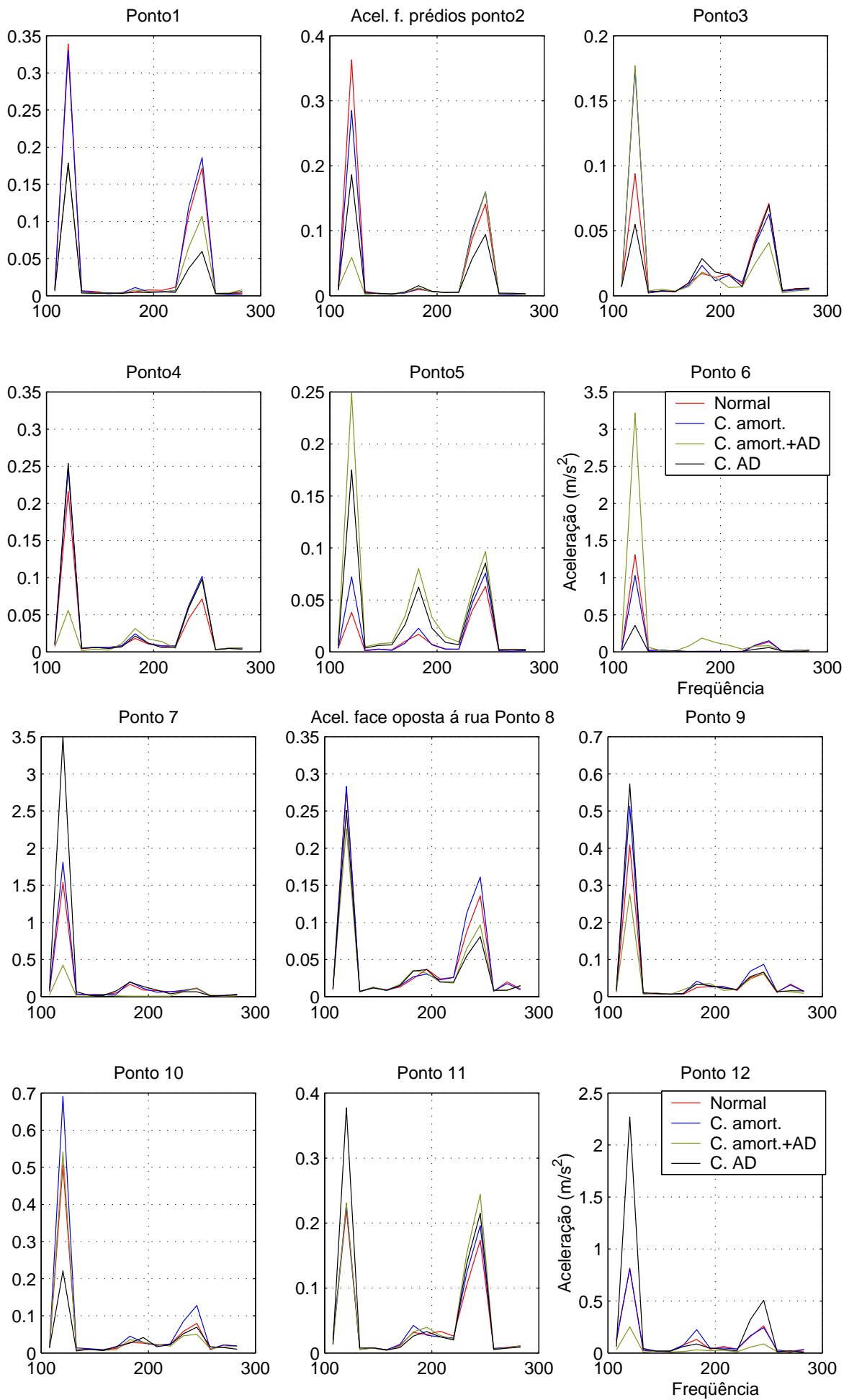

Figura 4.91: Sinais de aceleração no domínio da freqüência, na faixa de 100 até $275 \mathrm{~Hz}$ : a) face frente ao edifício b) face oposta á rua. 

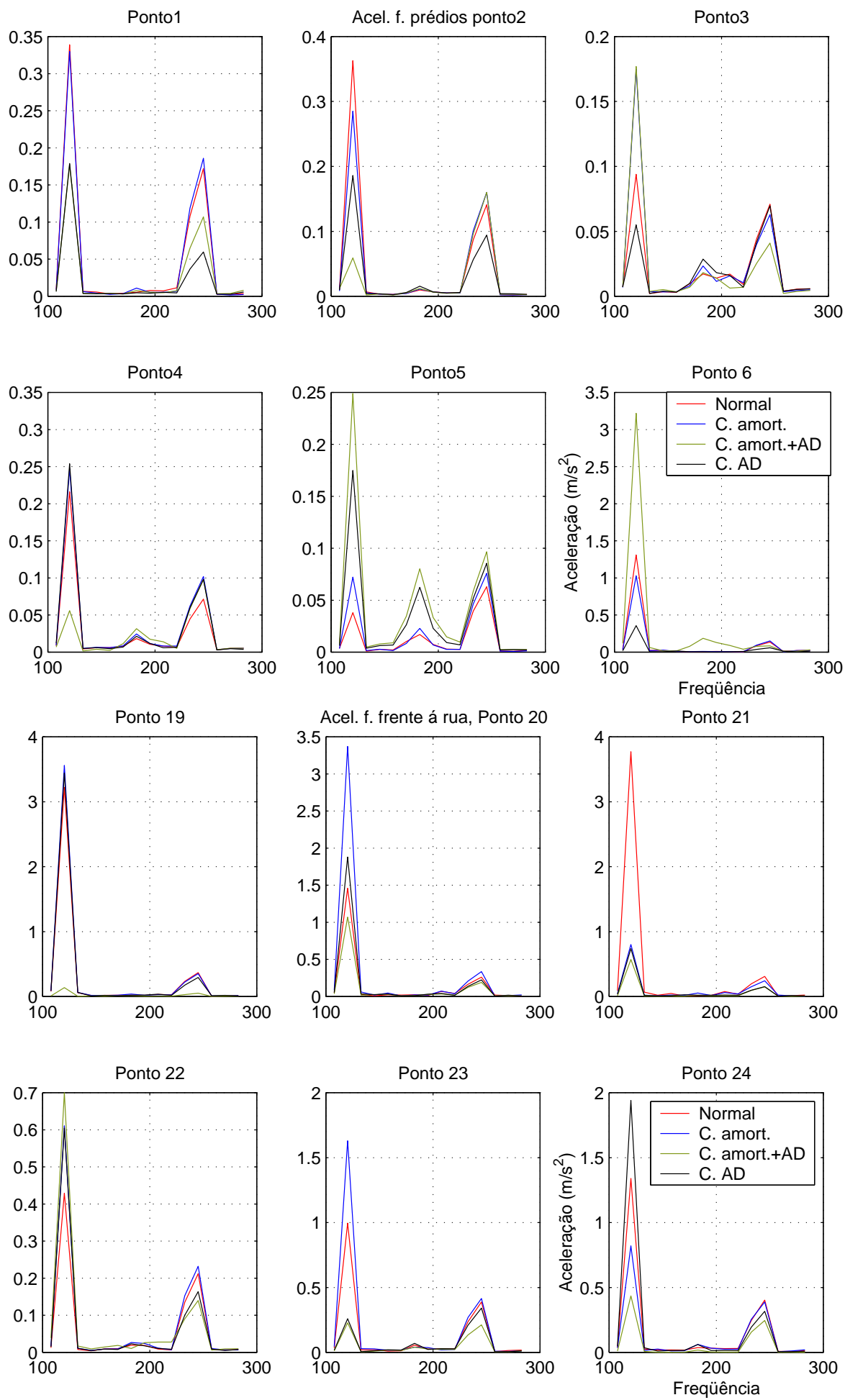

Figura 4.92: Sinais de aceleração no domínio da freqüência,na faixa de 100 até $275 \mathrm{~Hz}:$ c) face oposta ao edifício d) face frente á rua

Avaliando o nível de velocidade da vibração em cada ponto, na freqüência de $120 \mathrm{~Hz}$ obtém-se a atenuação em cada ponto. O cálculo do Nível de Velocidade da vibração $L v$ é realizado com a equação 2.25 e os resultados são mostrados na tabela 4.13 
Tabela 4.13: Valores calculados da atenuação

\begin{tabular}{|l|l|l|l|l|l|l|}
\hline F. Frente ao edifício & Pt. 1 & Pt. 2 & Pt. 3 & Pt. 4 & Pt. 5 & Pt. 6 \\
\hline \hline Com amortecedor & $-0,23$ & $-2,09$ & 5,37 & 1,19 & 5,56 & $-2,14$ \\
\hline Com amort.+AD & $-5,64$ & $-15,80$ & 5,45 & $-11,70$ & 16,30 & 7,80 \\
\hline Com AD & $-5,53$ & $-5,78$ & $-4,67$ & 1,39 & 13,24 & $-11,27$ \\
\hline F. oposta aos edifícios & 7 & 8 & 9 & 10 & 11 & 12 \\
\hline Com amortecedor & 1,44 & 0,04 & 1,96 & 2,71 & 0,32 & $-0,08$ \\
\hline Com amort.+AD & $-11,10$ & $-1,92$ & $-3,40$ & 0,58 & 0,40 & $-10,19$ \\
\hline Com AD & 7,13 & $-1,03$ & 2,92 & $-7,16$ & 4,67 & 8,9 \\
\hline \hline F. Atrás do edifício & 13 & 14 & 15 & 16 & 17 & 18 \\
\hline Com amortecedor & 0,56 & 1,41 & 2,98 & 5,56 & $-8,31$ & 2,07 \\
\hline Com amort.+AD & 11,00 & $-4,50$ & $-21,10$ & $-3,93$ & $-9,70$ & 28,50 \\
\hline Com AD & $-5,00$ & $-0,65$ & $-16,57$ & $-1,64$ & $-0,66$ & 7,24 \\
\hline \hline F. Frente á rua & 19 & 20 & 21 & 22 & 23 & 24 \\
\hline Com amortecedor & 0,87 & 7,27 & $-13,49$ & 3,06 & 4,31 & $-4,25$ \\
\hline Com amort.+AD & $-27,40$ & $-2,66$ & $-16,41$ & 4,25 & $-12,81$ & $-9,75$ \\
\hline Com AD & 0,57 & 2,24 & $-14,16$ & 2,99 & $-11,70$ & 3,19 \\
\hline \hline Base & 25 & 26 & 27 & 28 & 29 & 30 \\
\hline Com amortecedor & $-1,91$ & $-1,93$ & $-1,18$ & 7,29 & $-0,54$ & 1,43 \\
\hline Com amort.+AD & 13,21 & 6,06 & $-4,90$ & 9,01 & 1,45 & 5,56 \\
\hline Com AD & 4,54 & 7,18 & 3,53 & 6,6 & 4,22 & 3,67 \\
\hline
\end{tabular}

A atenuação difere em cada face. Na maioria das medições na condição com amortecedores e absorvedores dinâmicos obtiveram-se melhores resultados que nos outros casos. Na base a atuação conjunta de amortecedores e absorvedores dinâmicos não foi superior à atuação isolada dos amortecedores. Enfatiza-se que essa atenuação é local, reflete os dados obtidos nos poucos pontos onde se fez a medição da aceleração. 


\section{COMENTÁRIOS FINAIS}

Este trabalho propõe uma metodologia de projeto de dispositivos para reduzir o ruído irradiado por transformadores elétricos de potência. Com algum processamento de sinais de aceleração, é possível determinar regiões de maiores níveis de velocidade de vibração.

O primeiro critério para posicionamento de absorvedores dinâmicos é posicionálos nestas regiões de maiores níveis de velocidade de vibração. Entretanto, estas regiões de maiores níveis de velocidade parecem se deslocar quando um absorvedor dinâmico é instalado no tanque do transformador, tornando o problema de buscar posições para os absorvedores dinâmicos mais complexo.

Reproduzindo em modelo numérico os deslocamentos da base do tanque do transformador, não se reproduzem as amplitudes dos deslocamentos medidos nas faces do tanque. Isto revela que o óleo tem um papel proeminente na transmissão de forças para as faces do tanque. A forma de carregamento do modelo numérico deveria levar em conta este aspecto da transmissão de forcas do núcleo para o tanque. Sugere-se para trabalhos futuros um refinamento do carregamento do modelo numérico. Neste trabalho o carregamento do modelo numérico foi proporcional ao deslocamento medido, de forma a reproduzir os deslocamentos máximos medidos em cada face e respeitando a fase de cada sinal de deslocamento.

Os absorvedores dinâmicos, de fato, reduzem a amplitude das oscilações em sua vizinhança e desviam as oscilações para a massa do absorvedor dinâmico que se acopla com o ar de forma menos eficiente que as superfícies planas do tanque.

Os amortecedores viscosos reduzem a amplitude das oscilações em média no espaço. Uma de suas vantagens reside na ampla faixa de freqüências que eles operam.

A metodologia de projeto de dispositivos para reduzir o ruído irradiado por transformadores de potência requer simulações numéricas que antecipem o efeito de cada dispositivo. Estas simulações numéricas, por sua vez, requerem detalhado conhecimento do campo de deslocamentos na superfície em condições operacio- 
nais e seu comportamento na freqüência. Trata-se de controlar os deslocamentos de uma estrutura em regime forçado. Este trabalho propõe determinar o posicionamento dos absorvedores dinâmicos e/ou dos amortecedores viscosos através de simulações numéricas.

Como trabalhos futuros sugere-se testar a metodologia proposta em outros transformadores e desenvolver amortecedores adequados para pequenos deslocamentos, elevadas cargas e elevada durabilidade. 


\section{Anexo A}

\subsection{Holografia Acústica - Resultados}

As figuras que seguem fazem parte do relatório de teste de holografia acústica realizada pela empresa $01 \mathrm{~dB}$.

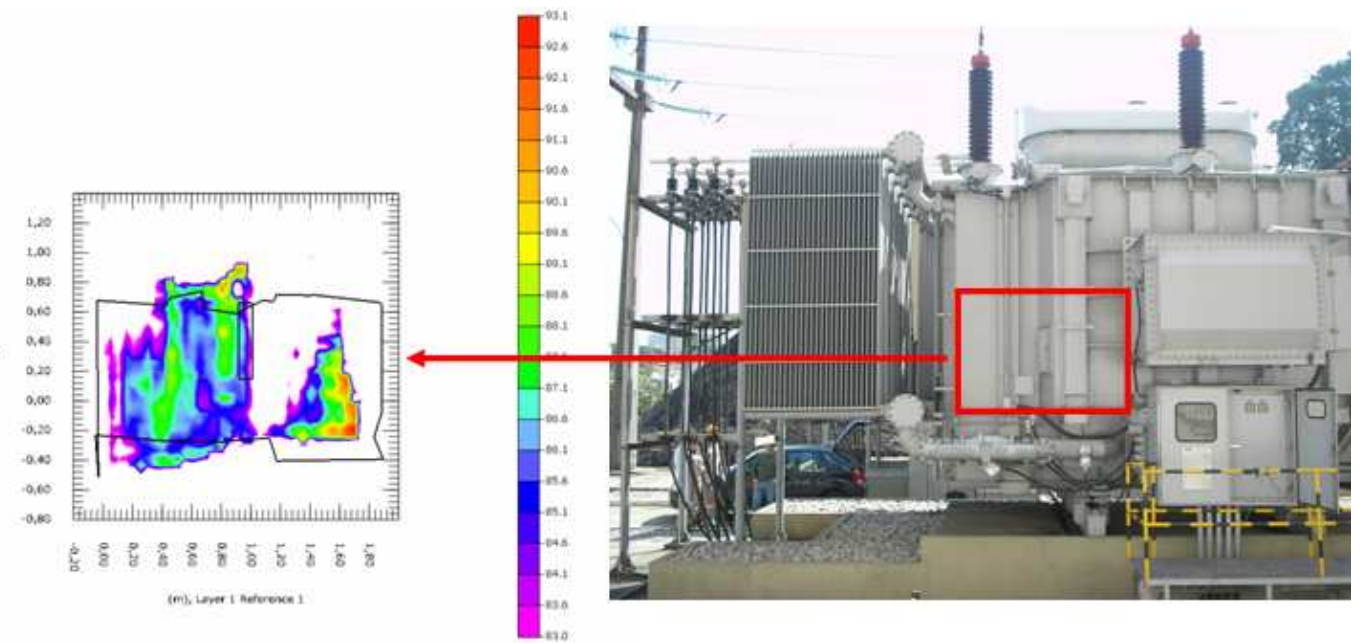

Figura 6.1: Intensidade acústica face frente ao predio, detalhe lado esquerdo do comutador

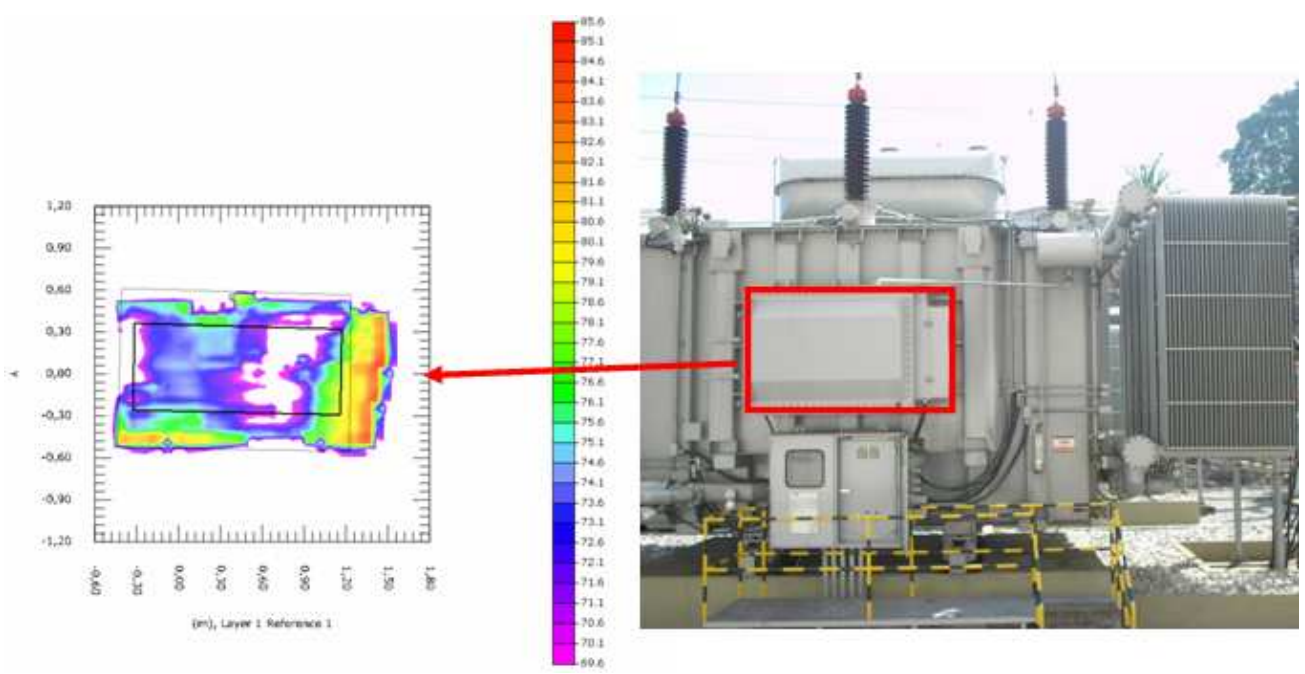

Figura 6.3: Intensidade acústica face frente ao predio, detalhe no comutador. 


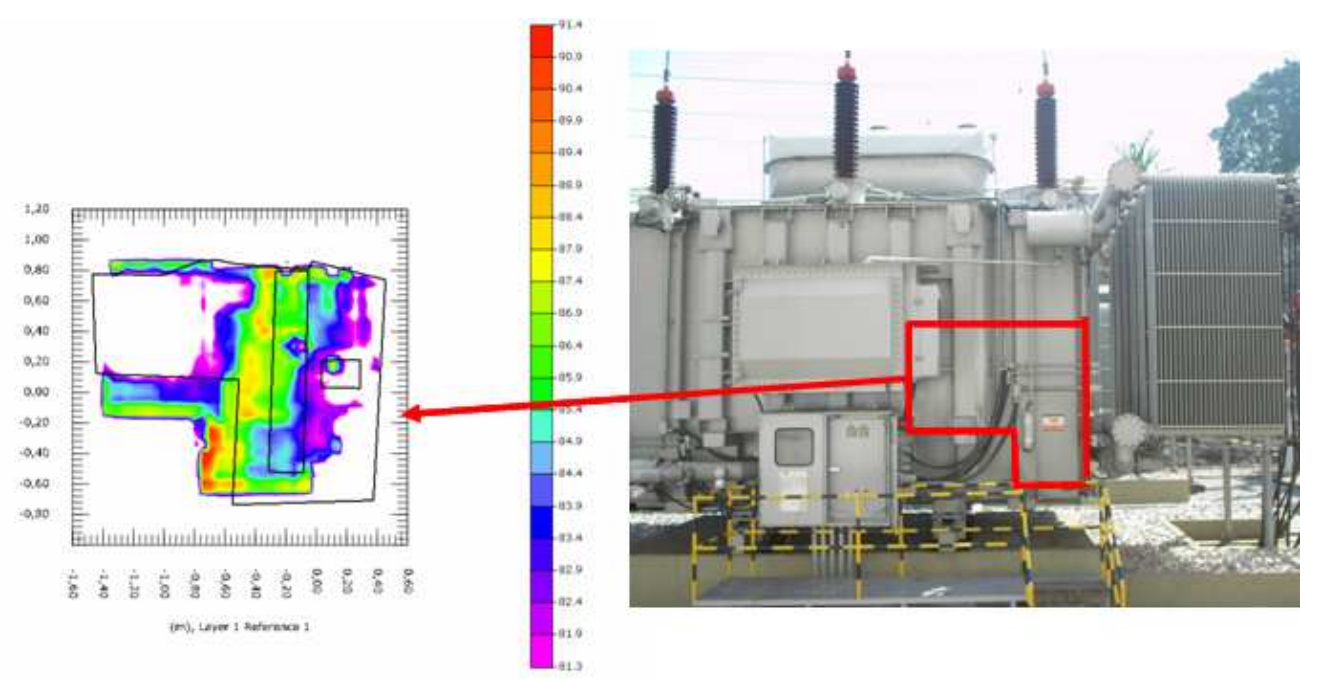

Figura 6.2: Intensidade acústica face frente ao predio, detalhe lado dereito do comutador.

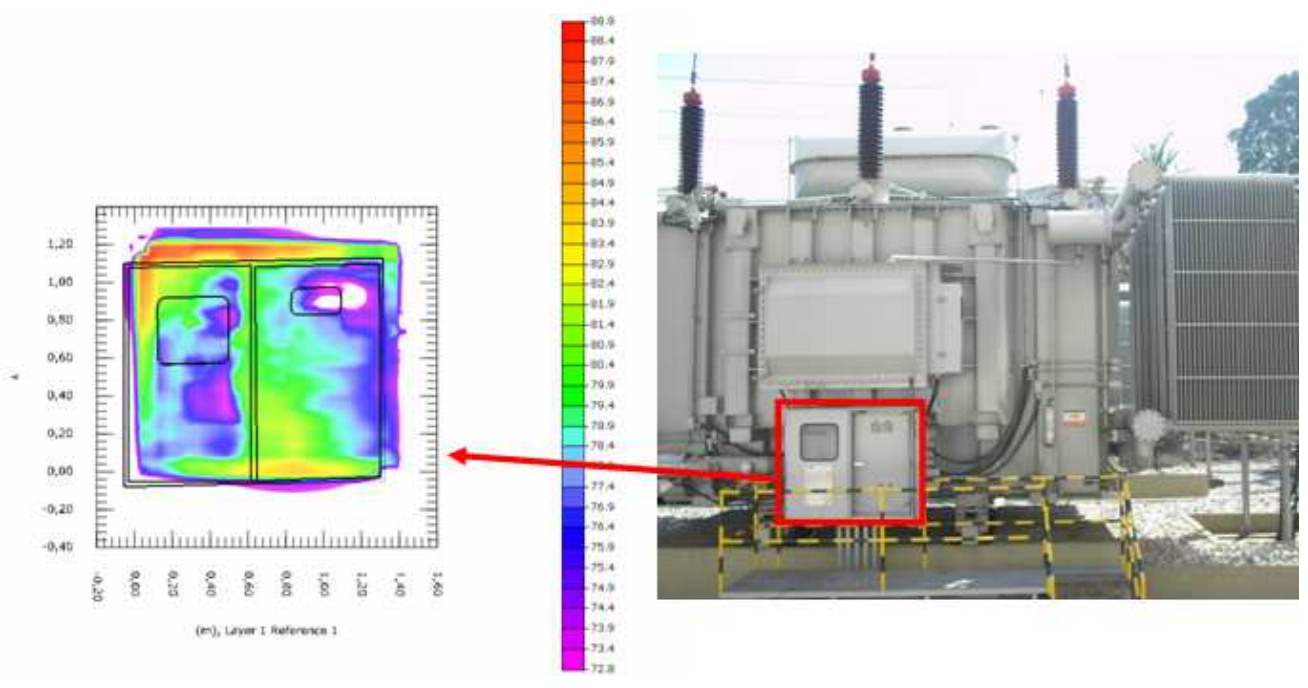

Figura 6.4: Intensidade acústica face frente ao predio, detalhe abaixo do comutador. 


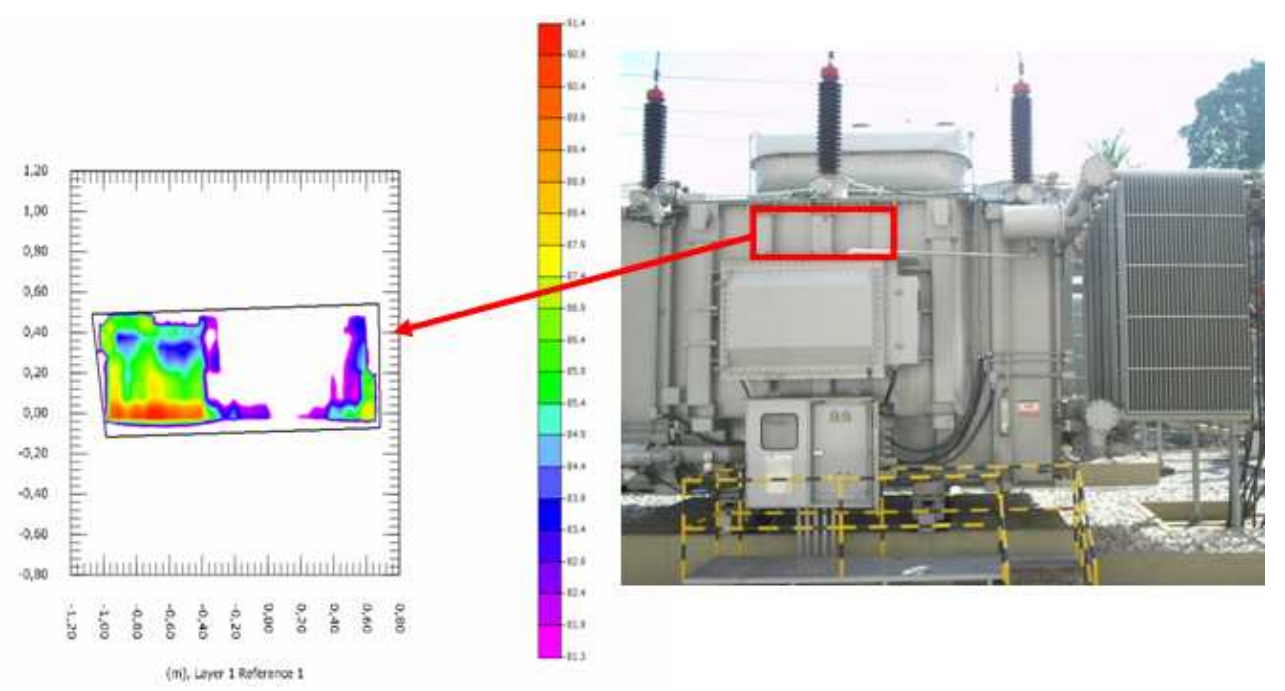

Figura 6.5: Intensidade acústica face frente ao predio, detalhe acima do comutador.

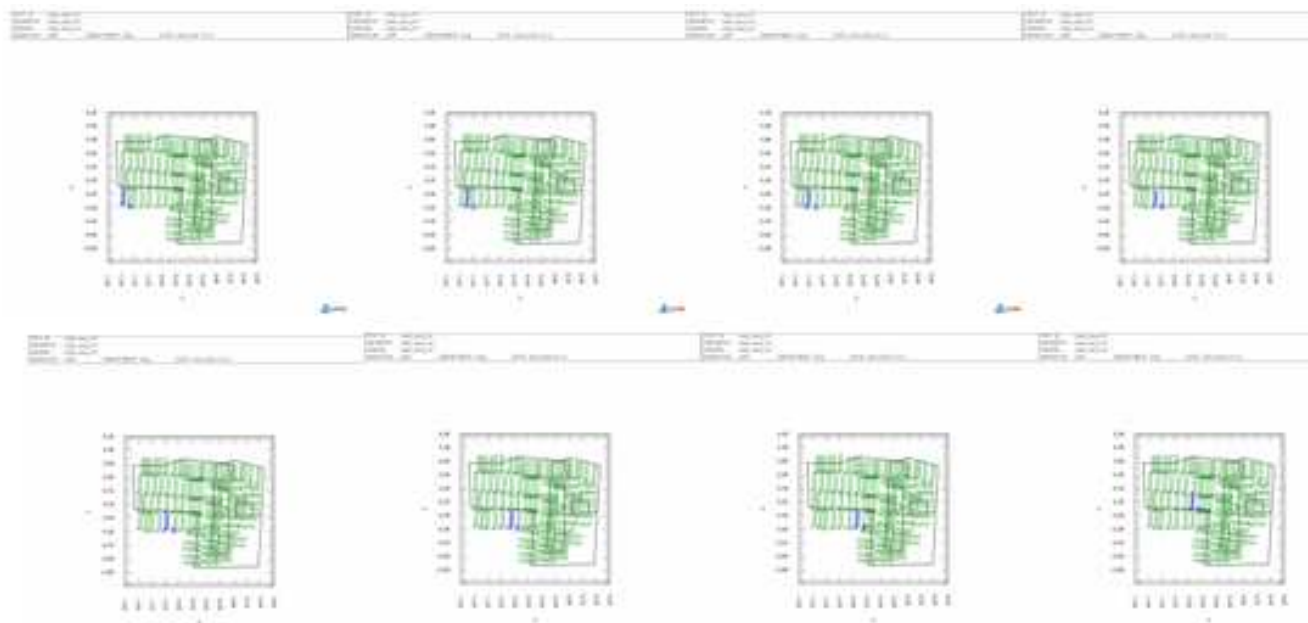

Figura 6.6: Intensidade acústica face frente ao predio, sinais em proceso. 


\section{Referências}

ABBOTT, J. Acoustical design criteria for active noise-control systems. p. 630-633, 1993.

BIES, D. A.; HANSEN, C. H. Engineering Noise Control: Theory and Practice. EPMN 534.83-B478e2: 2nd Edition, London, New York, E \& Fn Spon, 1996. 417 p. ISBN 0-419-20430- X.

BISTAFA, R. S. Acústica aplicada ao controle do ruído. EPMN 534-B545a: Editora Edgar Blücher, 2006. 54 p. ISBN 85-212-0376-4.

BRAUN, E. Electromagnetismo : de la ciencia a la tecnologia. Internet: Editorial la ciencia - México, 1992. 112 p.

CHAMPOUX Y. GOSSELIN, B.; NICOLAS, J. Application of the intensity technique to the characterization of transformation noise. IEEE Transactions On Power Delivery; Vol. 3 No 4, p. 1802-1808, October 1988.

CHáVEZ, L. Modelo estructural numérico que simula a alocação de absorvedores dinãmicos para a redução de ruído acústico emitido por un transformador de potência. [S.l.]: Disertação de mestrado, Escola politecnica USP, 2008. 59 p.

DENENBERG, J. Anti-noise: quieting the enviroment with active noise cancellation technology. IEEE Potentials,, p. 36-40, April 1992.

DOSSING, O. Structural stroboscopy - measurement of operational deflection shapes. edit BEK, p. 18-26, 1988.

ELLIOTT, S.; NELSON, P. The active control of sound. Electronics $\&$ Communication Engineering Journal, August 1990.

ELLIOTT, S.; NELSON, P. Active noise control. IEEE Signal Processing Magazine, p. 12-35, October 1993.

FILHO, X. V.; SOBRINHO, E. S.; GARCIA, L. A.; DRUMMOND, A. G.; GUEDES, M. A.; ROITMAN, M. Aspectos empresariais aplicados a p\&d "o diferencial tecnológico da inversão em p\&d". 17 ao 22 de otubro 1999.

FULLER, C. R.; FLOTOW, A. H. V. Active control of sound and vibration. IEEE Control Systems, p. 9-19, December 1995.

FUlleR, C. R.; MAIllaRD, J. P.; MERCADAL, M.; FLOTOW, A. H. V. Control of aircraf interior noise using globally detuned vibration absorvers. Journal of Sound and Vibration, Vo. 203, No. 5, p. 745-761, 1997.

GARCIA B. BURGOS, J. C.; ALONSO, A. M. Transformer tank vibration modeling as a method of detecting winding deformation - part i theoretical foundation. IEEE Transaction on Power Delivery, Vol. 21, No. 1, p. 157-163, 2006 . 
GORDEN, C. G. A method for predicting the audible noise emission from large outdoors power transformers. IEEE Transactions on Power Apparatus and Systems (PAS) 98, p. 1109 - 1112, 1979.

GRISSON, M. D.; BELEGUNDU A. D.; KOOPMANN, G. H. A reduced eingvalue method for broadband analysis of a structure with vibration absorbers possessing rotatory inertia. Journal of Sound and Vibration, Vol. 281, p. 869-886, 2005.

HARTOG, J. P. D. Vibrações nos Sistemas Mecânicos. EPMN 534.01-D41np-e6: Editora Edgard Blücher Ltda, 1972.

JASINSKI R. CALOMENO, R.; FILLIPPIN, C. Seminário nacional de produção e transmissão de energia elétrica. SNPTEE, (Grupo de Estudo de Subestações e Equipamentos Elétricos-GSE), Curitiba (PR), 16-21 Outubro 2005.

JUVINALL, R. C. Fundamentos de Diseño para Ingeniería Mecánica. [S.1.]: Editorial Limusa, 1991. 156 p. ISBN 0-471-06485-8.

KARSAI K. KERENYI, D.; KISS, L. Large Power Transformer. EPIEE 621-314-K148nI: Studies in Electrical and Eletronic Enginering 25 Elsevier Science Publishing Company, Inc, 1987. 15 p. ISBN 0-444-99511-0.

KELLEY, A. Mesurement of spacecraft power transformer acoustic noise. IEEE Transaction on Magnetics, Vol. 26, No. 1, p. 281-289, 1990.

KENDIG, R. P.; WRIGHT, S. E. Validation of acoustic intensity measurements for power transformers jeee. Transactions on Power Delivery, Vol. 6, No. 4, p. 1524 - 1530, October 1991.

KOSTENKO, M.; PIOTROSVSKY, L. Electrical Machines. EPMN 621-313K848e-1: printend in URSS, 1950. 12 p.

KUO, S.; MORGAN, D. R. Active noise control: a tutorial review. proceedings of the ieee. p. 943-973, June 1999.

LIU, Z. S.; LEE, H. P. Passive and active interior noise control of box structures using the structural intensity method. Applied Acoustics, Vol. 67, p. 112-134, 2006 .

MASON P. BERRY, A.; NICOLAS, J. Active structural acoustic control using strain sensing. Journal of the Acoustic Society of America, v. 102, n. 3, p. 1588-1599, September 1997.

MAYNARD J. D. WILLIAMS, E. G.; LEE, Y. Near-field acoustic holography: I. theory of generalized holography and the development of nah. The Journal of the Acoustical Society of America, Vol. 78, No. 4, p. 1395-1413, October 1985.

MERCADO E. GONZALEZ, R. T. E. B. S. F. F. B. Metodologia para projetar absorvedores dinâmicos usando o metodo de elementos finitos. Oitavo Congresso Iberoamericano de Engenharia Mecânica, Cuzco 23 - 25 de Outubro 2007, p. 8, Otubro 2007.

MING, R. S. e. a. Sound field characterisation of a power transformer. Applied Acoustics, Vol. 56, p. 257-272, 1999. 
MING, R. S. e. a. Sound field characterisation of a power transformer. Applied Acoustics, Vol. 56, p. 257-272, 2000.

NAGAYA, K.; LI, L. Control of sound noise radiated from a plate using dynamic absorvers under the optimization by neural network. Journal of Sound and Vibration, Vol. 208, No. 2, p. 289-298, 1997.

OLKIN J. A. HECK, L.; NAGHSHINEH, K. Automated placement of transducers for active noise control: Performance measures in. IEEE International Conference on Acoustics, Speech, and Signal Processingv, Atlanta, Proceedings. 2, p. 969-972, 1996.

RAUSCH M. KALTENBACHER, M. L. H.; LERCH, R. Numerical computation of the emitted noise of power transformers. COMPEL: The International Journal for Computation and Mathematics in Electrical and Electronic Engineering, Vol 20, No 2, p. 636-649, 2001.

RAUSCH M. KALTENBACHER, M. L. H.; LERCH, R. Combination of finite and boundary element methods in investigation and prediction of load-controlled noise of power transformers. Journal of Sound and Vibration Vol. 250, No. 2, p. 323-338, 2002.

SOCIETY, T. C. of the I. P. E. Ieee guide for sound level abatement and determination for liquid-immersed power transformers and shunt reactors rated over 500 kva. p. 630-633, September 2000.

USRY, G.; SAHA, P.; HADDEN, J.; PIERCE, A. Prediction of far field sound radiation from transformers. IEEE Transactions on Power Apparatus and Systems Vol. PAS-99; No 1, p. 358-364, 1980.

VIPPERMAN, J. S.; CLARK, R. L. Multivariable feedback active structural acoustic control using adaptive piezoelectric sensoriactuators. Journal of the Acoustic Society of America, v. 105, n. 1, p., p. 219-225, January 1999.

WEISER V. PFüTZNER, R.; ANGER, J. Relevance of magnetostriction and forces for the generation of audible noise of transformer cores. IEEE TRANSACTIONS ON MAGNETICS, Vol. 36, No. 5, p. 3759-3777, September 2000.

WILLIAMS, E. G. Fourier acoustics: Uncovering the origins of sound. Eleventh International Congress on Sound and Vibration? St. Petesburg, Russia, p. 37593777, July 2004.

WILLIAMS, E. G.; MAYNARD, J. D. Holographic imaging without the wavelength resolution limit. Physics Review Letters, Vol. 45, p. 554-557, 1980. 